\title{
Aplicação da Inferência Bayesiana para a Simulação da Dinâmica de Produção de Sementes de Plantas Daninhas
}

\author{
LILIAN DE SOUZA VismaRA
}

Dissertação apresentada à Escola de Engenharia de São Carlos da Universidade de São Paulo, como parte dos requisitos para obtenção do título de Mestre em Engenharia Elétrica

Orientadora: Profa. Dra. Vilma Alves de Oliveira 
Ao meu grande amor Edgar, pelos momentos em que estive ausente ...

Aos meus pais Luiz \& Maria, pelo modo singular de amar e partilhar a vida ...

Às minhas irmãs Roberta e Taís e ao meu 'irmão por parte de vô' Antoniel, pela admiração insana que só os irmãos mais novos admitem possuir pelos mais velhos ...

À Luiz de Souza, 'finado meu pai', por nos fazer sorrir sempre!

Eu amo tudo o que foi,

Tudo o que já não é, A dor que já me não dói, A antiga e errônea fé, $O$ ontem que dor deixou,

O que deixou alegria Só porque foi, e voou E hoje é já outro dia. (Fernando Pessoa) 
Todo trabalho científico é resultante de um trabalho em equipe. Assim, algum mérito que este trabalho possa apresentar é dedicado àqueles que direta e indiretamente colaboraram em sua realização, em especial:

À minha FAMÍLIA, pelo amor, dedicação, apoio, compreensão e, principalmente, pela vida maravilhosa que me proporcionam.

À minha orientadora e amiga Professora Vilma Alves de Oliveira e amigos do Laboratório de Controle (LAC), pela agradável convivência e frutíferas conversas.

Aos meus amigos, em especial às amigas Lia Hanna, Roberta, Anay e Adriana, pela atenção, alegria e inestimável apoio nas fases de condução deste trabalho.

Aos professores e funcionários do Departamento de Engenharia Elétrica da EESC/USP, pela amizade, disposição e atenção no atendimento.

À Escola de Engenharia de São Carlos, especialmente ao Departamento de Engenharia Elétrica, pela oportunidade concedida para a realização deste curso.

Aos pesquisadores e funcionários ligados à Empresa Brasileira de Pesquisa Agropecuária Embrapa Milho e Sorgo, em especial ao Professor Décio Karam, pela colaboração e auxílio dispensados no desenvolvimento deste trabalho.

Aos órgãos públicos de fomento, FAPESP e CNPq, pelas bolsas de estudo concedidas desde minha iniciação científica.

Ao saudoso Departamento de Matemática da UFSCar, em especial aos Professores José Ruidival Soares dos Santos Filho e João Sampaio, pela preocupação e dedicação em formar recursos humanos.

Às minhas queridas 'tias-madrinhas' Valdice e Terezinha e à minha 'sogra-mãe' Doris, pelo orgulho inocente de me ver 'mestre'.

Às sábias e carinhosas vovós Isabel Vieira de Menezes (in memoriam), Maria Moura (in memoriam) e Saturnina Dlouhy, pelos pais excepcionais que me deram.

Ao pequenino e 'finado' Gilbert, pela alegria, fidelidade e sabedoria canina.

Enfim, à todos aqueles que simplesmente fazem parte da minha estória ... 


\section{Conteúdo}

Lista de Figuras vii

Lista de Tabelas $\quad$ xxii

Resumo $\quad$ xxv

Abstract $\quad$ xxvi

1 Introdução 1

1.1 Objetivos e importância do trabalho . . . . . . . . . . . . . . 1

1.2 Organização do trabalho . . . . . . . . . . . . . . . . . 2

1.3 Síntese bibliográfica do tema . . . . . . . . . . . . . . 3

1.4 Modelagem matemática: conceitos básicos . . . . . . . . . . 7

1.4.1 Razões para a construção de modelos . . . . . . . . . . . . . 8

1.4.2 Tipos de modelos . . . . . . . . . . . . . . . . . . 8

1.4.3 Regras gerais para a construção de um modelo dinâmico . . . . 10

$1.5 \mathrm{O}$ conceito de estado . . . . . . . . . . . . . . . . . . . . . 10

1.6 Equações a diferenças não lineares . . . . . . . . . . . . . . . . . . . 11

1.6.1 Reconhecendo equações a diferenças não lineares . . . . . . . . . 11

1.6.2 Estado de equilíbrio e estabilidade . . . . . . . . . . . . . . 12

1.6.3 Sistema de equações a diferenças não lineares . . . . . . . . . . . 16

1.6.4 Método gráfico recursivo para visualizar soluções de equações a diferença de primeira ordem . . . . . . . . . . . . . . 18

2 A dinâmica populacional de plantas daninhas e sua interferência $\begin{array}{ll}\text { em culturas agrícolas } & 21\end{array}$

2.1 Práticas de controle de plantas daninhas em culturas agrícolas . . . . . 23

2.2 Fases das plantas daninhas envolvidas na regulação populacional . 24

2.2 .1 Semente . . . . . . . . . . . . . . . . . . . . 25

$2.2 .2 \quad$ Planta . . . . . . . . . . . . . . . . . . . . . . . . . . 29 
2.2 .3 Reprodução vegetativa . . . . . . . . . . . . . . . . . . . . 32

2.3 Disseminação de espécies daninhas e sua interferência em culturas agrícolas 32

2.4 Representação matemática da relação plantas daninhas versus cultivadas 34

2.4.1 Modelos de perda de rendimento da cultura . . . . . . . . . . . 35

2.4.2 Produção de sementes de plantas daninhas a partir de dados de perda de rendimento da cultura . . . . . . . . . . . . 38

2.5 Discussão . . . . . . . . . . . . . . . . . . . . . . . . . 40

3 Representação matemática da dinâmica populacional de plantas daninhas

3.1 Modelos de único estádio para a dinâmica populacional intrínseca . . . 43

3.1.1 Modelos de único estádio para uma única espécie daninha . . . . 43

3.1.2 Análise da trajetória populacional via alteração de parâmetros do modelo de único estádio para a produção de sementes . . . . . 46

3.1.3 Modelos de único estádio para mais de uma espécie daninha . . 50

3.2 Fatores extrínsecos que alteram a dinâmica populacional . . . . . . 51

3.2.1 O efeito do uso de herbicidas em modelos de único estádio . . . 52

3.2.2 Simulação da dinâmica populacional de uma única espécie daninha via modelo de único estádio sem e com a introdução de um parâmetro de controle . . . . . . . . . . . . . 55

3.2.3 Função resposta exponencial para aplicação de herbicidas . . . . 59

3.3 Modelos de múltiplos estádios para a dinâmica populacional . . . . . . 60

3.3.1 Modelos modulares de múltiplos estádios . . . . . . . . . . . . . 61

3.3.2 Modelos matriciais de múltiplos estádios . . . . . . . . . . . . . 63

3.4 Modelos que descrevem o movimento vertical das sementes no solo . . . 66

3.4.1 Processo aleatório e cadeia de Markov . . . . . . . . . . . . . 66

3.4.2 Modelos matriciais da distribuição vertical do banco de sementes 67

3.4.3 A inserção dos efeitos dependentes da densidade em modelos que descrevem a posição vertical de sementes no solo . . . . . . . . 70

3.5 Discussão . . . . . . . . . . . . . . . . . . . . . . . . . . 71

4 A inferência estatística e o método de Monte Carlo 74

4.1 A estatística clássica versus a bayesiana . . . . . . . . . . . . . 75

4.2 A inferência clássica . . . . . . . . . . . . . . . . . . 76

4.2 .1 Regressão linear . . . . . . . . . . . . . . . . . . . 76

4.2 .2 Regressão não linear . . . . . . . . . . . . . . . . . . . . . . . . . 79

4.2.3 Testes de hipóteses sobre os parâmetros do modelo de regressão 80

4.2 .4 Intervalos de confiança . . . . . . . . . . . . . . . . 80 
4.3 Princípio da verossimilhança . . . . . . . . . . . . . . . . . . 81

4.4 Introdução à inferência bayesiana . . . . . . . . . . . . . . . . . . 82

4.4.1 Fórmula de Bayes . . . . . . . . . . . . . . . . . . . . . . . 83

4.4.2 Distribuição ou função de densidade a priori . . . . . . . . . . . 84

4.4.3 Distribuição ou função de densidade a posteriori . . . . . . . . . 85

4.4.4 Estimadores de Bayes . . . . . . . . . . . . . . . . . . 86

4.4.5 Intervalos de confiança bayesianos . . . . . . . . . . . . . 87

4.5 O método de Monte Carlo . . . . . . . . . . . . . . . . . . . 87

4.5.1 Método de Monte Carlo simples . . . . . . . . . . . . . . . . 87

4.5.2 Método de Monte Carlo via cadeias de Markov . . . . . . . . . . 89

4.6 Discussão . . . . . . . . . . . . . . . . . . . . . . . . . . . . . . . . . . . . . . 94

5 Experimento de campo $\quad 96$

5.1 Dados obtidos . . . . . . . . . . . . . . . . . . . . . . . . 97

5.1 .1 Coleta dos dados . . . . . . . . . . . . . . . . . . . . . 98

5.1.2 Espécies daninhas encontradas na área experimental . . . . . . . 99

5.2 Aspectos botânicos das espécies daninhas encontradas em campo . . . . 102

5.2 .1 Espécies de "folha larga" . . . . . . . . . . . . . . . . . . . 103

5.2 .2 Espécies de "folha estreita" . . . . . . . . . . . . . . . . . 106

5.3 Seleção de espécies daninhas para análise do comportamento populacional107

5.3.1 Tabelas dos dados utilizados para análise do comportamento populacional . . . . . . . . . . . . . . . . 108

6 Formulação do problema de inferência estatística 112

6.1 Inferência clássica do modelo de produção de sementes . . . . . . 113

6.1.1 Função de verossimilhança . . . . . . . . . . . . . . . . . . . . 113

6.1.2 Inferência sobre os parâmetros do modelo . . . . . . . . . . . . . 114

6.1.3 Problema de inferência clássica . . . . . . . . . . . . . . . . . 115

6.2 Inferência bayesiana do modelo de produção de sementes . . . . 115

6.2.1 Densidade a priori para os parâmetros . . . . . . . . . . . 116

6.2.2 Densidade a posteriori para os parâmetros . . . . . . . . . . . 117

6.2.3 Programas para a inferência bayesiana . . . . . . . . . . . . . 118

$\begin{array}{llr}7 & \text { Resultados e discussão } & 121\end{array}$

7.1 Digitaria ciliaris (capim colchão) ․ . . . . . . . . . . . . . . . . 123

7.1.1 Diagnósticos envolvendo a variável dependente . . . . . . . . . . 123

7.1.2 Abordagem clássica do modelo de produção de sementes . . . . 124 
7.1.3 Abordagem bayesiana do modelo de produção de sementes . . . 127

7.2 Panicum maximum (capim guiné) . . . . . . . . . . . . . . . . . . . 140

7.2.1 Diagnósticos envolvendo a variável dependente . . . . . . . . . . 140

7.2.2 Abordagem clássica do modelo de produção de sementes . . . . 141

7.2.3 Abordagem bayesiana do modelo de produção de sementes . . . 144

7.3 Euphorbia heterophylla (leiteiro) _. . . . . . . . . . . . . . . 157

7.3.1 Diagnósticos envolvendo a variável dependente . . . . . . . . . 157

7.3.2 Abordagem clássica do modelo de produção de sementes . . . 158

7.3.3 Abordagem bayesiana do modelo de produção de sementes . . . 161

7.4 Simulação da dinâmica de produção de sementes usando inferência bayesiana . . . . . . . . . . . . . . . . . . . . . . 174

7.5 Curvas das densidades de gerações sucessivas da produção de sementes 182

7.6 Discussão . . . . . . . . . . . . . . . . . . . . . . . . . . . . . . . . . . . . 184

8 Conclusões e proposições para futuros trabalhos 188

8.1 Conclusões . . . . . . . . . . . . . . . . . . . . . . . . . 188

8.2 Proposições para trabalhos futuros . . . . . . . . . . . . . . . . . . 190

$\begin{array}{lr}\text { Bibliografia } & 192\end{array}$

$\begin{array}{ll}\text { A Alguns conceitos de probabilidade e estatística } & 200\end{array}$

A.1 Definições e conceitos de probabilidade e estatística . . . . . . . . . . 200

A.2 Distribuições Normal e Gama . . . . . . . . . . . . . . . . . . . . . . . 203

A.2.1 Distribuição Normal . . . . . . . . . . . . . . . . . . . . . . . . 203

A.2.2 Distribuição Gama . . . . . . . . . . . . . . . . . . . . . 203

B Tabelas das observações realizadas em campo 205 


\section{Lista de Figuras}

Figura 1.1 Plantação de soja infestada com plantas daninhas (São Gabriel

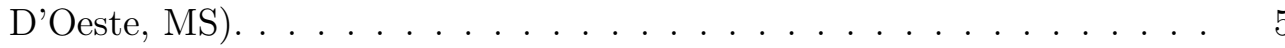

Figura 1.2 Exemplo de equilíbrio estável (bola 1), equilíbrio instável (bola 3) e ausência de equilíbrio (bola 2). As bolas 1 e 3 estão em repouso e representam situações de equilíbrio. A bola 1 é estável, sob uma perturbação suficientemente pequena a bola irá retornar a sua posição anterior. A bola 3 é instável, qualquer perturbação suficientemente pequena causará a queda para um dos vales. A bola 2 não está em equilíbrio desde que sua posição e velocidade estão variando continuamente. . . . . . . .

Figura 1.3 Método gráfico recursivo ('cobwebbing') para determinar o nível populacional no decorrer do tempo (Edelstein-Keshet, 1988). A parábola $x_{t+1}=f\left(x_{t}\right)$ e a linha $x_{t+1}=x_{t}$ são usadas para obter os valores sucessivos de $x_{t}, t=0,1,2, \cdots$. Abaixo mostra-se o mapa de gerações obtido, onde o eixo vertical representa o tempo $t$.

Figura 2.1 Dinâmica de uma população de sementes no solo como resultado do balanço entre entrada de novas sementes por emigração e reprodução e perdas por germinação, deterioração, predação, agentes patogênicos e imigração. . . . . . . . . . . . . . . . . . . . .

Figura 2.2 Resposta $R_{e}$ do modelo hiperbólico (2.4) com a variação do parâmetro de forma $Y 50_{R_{e}}$ (coeficiente de declividade) da expressão. Ambas as curvas possuem o mesmo valor $U_{R_{e}}=200$, mas, valores distintos de $Y 50_{R_{e}}$. A variação em $Y 50_{R_{e}}$ altera a forma das curvas para o mesmo valor de $U_{R_{e}} \cdot 50 \%=100$ (sem alterar a escala vertical). . . . . . . 
Figura 2.3 Resposta $R_{e}$ do modelo hiperbólico (2.4) com a variação do parâmetro $U_{R_{e}}$ (assíntota máxima) da expressão (2.4). Ambas as curvas têm o mesmo valor $Y 50_{R_{e}}=2$, mas, valores distintos de $U_{R_{e}}$. Há alteração para os valores de $U_{R_{e}} \cdot 50 \%$, logo, as curvas possuem a mesma forma

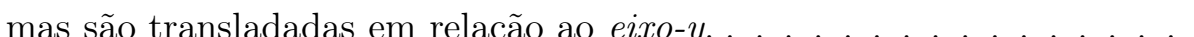

Figura 3.1 Representação da dinâmica do banco de sementes de espécies daninhas anuais. As letras nos triângulos indicam as taxas de germinação $(g)$, floração ou estabelecimento e sobrevivência à maturidade $(o)$, sementes viáveis no solo no ciclo seguinte $(v)$ e produtividade $(s)$. As principais causas de perdas de plantas e de redução de produção de sementes são indicadas ao lado dos triângulos.

Figura 3.2 Trajetória simulada da dinâmica populacional do modelo (3.7) com $\phi$ dado por (3.8) para $R=1,4, b=0,8, d=0,004, X_{0}=1 \mathrm{e}$ densidade limiar de 4000 plântulas $/ m^{2}$ quando a taxa de produtividade de sementes é nula.

Figura 3.3 Trajetória simulada da dinâmica populacional do modelo (3.7) com $\phi$ dado por (3.8) para $R=1, b=1, d=0,0004, X_{0}=1$ e densidade limiar de 4000 plântulas $/ \mathrm{m}^{2}$ quando a taxa de produtividade de sementes é nula.

Figura 3.4 Trajetória simulada da dinâmica populacional do modelo (3.7) com $\phi$ dado por (3.8) para $R=6,8, b=1,5, d=0,0004, X_{0}=1 \mathrm{e}$ densidade limiar de 4000 plântulas $/ m^{2}$ quando a taxa de produtividade de sementes é nula.

Figura 3.5 Trajetória simulada da dinâmica populacional do modelo (3.7) com $\phi$ dado por (3.8) para $R=100, b=3, d=0,0004, X_{0}=1 \mathrm{e}$ densidade limiar de 4000 plântulas $/ m^{2}$ quando a taxa de produtividade de sementes é nula.

Figura 3.6 Trajetória simulada da dinâmica populacional do modelo (3.7) com $\phi$ dado por (3.8) para $R=100, b=5, d=0,0004, X_{0}=1 \mathrm{e}$ densidade limiar de 4000 plântulas $/ m^{2}$ quando a taxa de produtividade de sementes é nula. 
Figura 3.7 Comportamento populacional descrito por (3.7) com taxa de crescimento dada por (3.8) (Cousens e Mortimer, 1995). As trajetórias definem quatro zonas no gráfico: (I) a população aproxima-se assintoticamente do equilíbrio, (II) a população oscila e converge assintoticamente para o equilíbrio, (III) a população oscila e diverge e (IV) a população oscila e converge para zero. . . . . . . . . . . . . . . . . 50

Figura 3.8 Diagrama de representação da interação entre os processos intrínsecos da população e os fatores extrínsecos. . . . . . . . . . . . . . . 52

Figura 3.9 Trajetórias descritas pelo modelo (3.7) com $\phi$ dado por (3.20) para diferentes níveis de controle com herbicida, supondo que este reduz a densidade de plântulas sob uma taxa proporcional fixada (Cousens e Mortimer, 1995). A seta vertical indica o nível de aumento de controle de plantas daninhas. A linha tracejada indica $X_{t+1}=X_{t} \ldots \ldots \ldots$.

Figura 3.10 Dinâmica simulada de (3.7) com $\phi$ dado por (3.24), $s=248$, $a=0,004, b=2,77, g=0,1, X_{0}=1$ e e densidade limiar de 4000 plântulas $/ m^{2}$ quando a taxa de produtividade $s$ é nula. Tem-se $R=$ $s g=24,8, d=a g=0,0004$ e a população de sementes converge para uma densidade estável por oscilações amortecidas. . . . . . . . . . . . . .

Figura 3.11 Dinâmica simulada de (3.7) com $\phi$ dado por (3.24), $s=248$, $a=0,004, b=2,77, g=0,2, X_{0}=1$ e e densidade limiar de 4000 plântulas $/ m^{2}$ quando a taxa de produtividade $s$ é nula. Tem-se $R=$ $s g=49,2, d=a g=0,008$ e a população apresenta comportamento periódico.

Figura 3.12 Dinâmica simulada de (3.7) com $\phi$ dado por (3.24), $s=248$, $a=0,004, b=2,77, g=0,5, X_{0}=1$ e densidade limiar de 4000 plântulas $/ m^{2}$ quando a taxa de produtividade $s$ é nula. Tem-se $R=$ $s g=124, d=a g=0,002$ e a população é extinta. 
Figura 3.13 Dinâmica simulada de (3.7) com $\phi$ dado por (3.25), $s=248$, $a=0,004, b=2,77, g=0,5, h=0,9, X_{0}=1$ e densidade limiar de 4000 plântulas $/ m^{2}$ quando a taxa de produtividade $s$ é nula. Tem-se $R=(1-h) s g=12,4, d=a g=0,002$ e, apesar do alto nível de controle efetuado e $g \in[0,4 ; 1,0]$, a população de sementes é reduzida sem ser

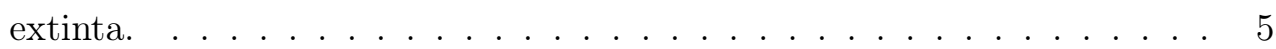

Figura 3.14 Ilustração do ciclo de vida de uma planta daninha anual. As probabilidades (fluxos) de uma fase à seguinte são mostradas nos parênteses. As letras referem-se a germinação $(g)$, mortalidade induzida por herbicida $(h)$, mortalidade natural da planta $\left(m_{p}\right)$, produção de semente $(s)$, remoção provocada pela maquinaria da colheita $(r)$, predação $(p)$, queima da cobertura vegetal dessecada $(q)$ e mortalidade da semente $\left(m_{s}\right) .62$

Figura 4.1 Exemplos de distribuições de probabilidade: normal, triangular, uniforme e lognormal. . . . . . . . . . . . . . . . . . . . . 84

Figura 5.1 Foto aérea do pivô experimental - Sete Lagoas, MG. . . . . . . . 96

Figura 5.2 Cobertura de uma parcela para que esta não sofra a ação do herbicida aplicado. . . . . . . . . . . . . . . . . . 97

Figura 5.3 Distribuição das 41 parcelas experimentais pelo pivô. . . . . . 98

Figura 5.4 Quadro utilizado em campo para coletar amostras de plantas daninhas. . . . . . . . . . . . . . . . . . . . . . . 99

Figura 5.5 Instrumento para realizar a coleta de solo: trado. . . . . . . . . 99

Figura 5.6 Plantas daninhas: mentrasto (esquerda) e capim colchão (direita).100

Figura 5.7 Contagem de espécies de plantas daninhas nas parcelas. . . . . . 101

Figura 5.8 Número de plantas daninhas por parcela. . . . . . . . . . . . . 102

Figura 5.9 Espécies daninhas selecionadas para análise do comportamento populacional: capim colchão (esquerda) e capim guiné (direita) espécies de "folha estreita" e leiteiro (centro) de "folha larga". . . . . . . . . . . . 108 
Figura 7.1 Gráfico de caixa segundo Batista (2004): a caixa é delimitada pelo primeiro e terceiro quartil, tendo a mediana como uma linha interior. As linhas que saem da caixa se expandem até 1,5 vezes a distância interquartil ou até a observação mais extrema. A partir da distância interquantil, as observações são marcadas individualmente como observações discrepantes.

Figura 7.2 Gráfico de caixa: densidade de sementes produzidas de capim colchão com (esquerda) e sem (direita) observações discrepantes. . . . . .

Figura 7.3 Gráfico de dispersão da variável independente versus variável dependente (esquerda) e histograma (direita) para as observações de capim colchão.

Figura 7.4 Gráficos de dispersão da variável independente versus variável dependente com a reta da regressão linear do modelo (4.8) (esquerda) e de normalidade dos resíduos (direita) para as observações de capim colchão.125

Figura 7.5 Gráficos de dispersão da variável independente versus variável dependente com a curva da regressão não linear do modelo (6.9) (esquerda) e dos resíduos versus valores ajustados (direita) para as observações de capim colchão. . . . . . . . . . . . . . . . . . . . . 126

Figura 7.6 Histograma (esquerda) e gráfico de normalidade dos resíduos (direita) para as observações de capim colchão. . . . . . . . . . . . . 126

Figura 7.7 Traços a posteriori das três cadeias geradas de $s, a$ e $\tau$ considerando a população de capim colchão e as prioris: $s \sim N(209,6 ; 1)$, $a \sim N\left(5,9.10^{-2} ; 1\right)$ e $\tau \sim G a(1 ; 1)$. Nota-se uniformidade nos traços $a$ posteriori de $s, a$ e $\tau$ o que indica a convergência do algoritmo. . . . . .

Figura 7.8 Teste gráfico de Gelman e Rubin: verifica-se que houve convergência do algoritmo de Metropolis-Hastings na geração de amostras das três cadeias para os parâmetros $s$ e $\tau$ considerando a população de capim colchão e as prioris: $s \sim N(209,6 ; 1), a \sim N\left(5,9.10^{-2} ; 1\right)$ e $\tau \sim G a(1 ; 1)$.

Figura 7.9 Densidades a posteriori de $s, a$ e $\tau$ obtidas a partir das 27000 amostras geradas pelas três cadeias considerando a população de capim colchão e as prioris: $s \sim N(209,6 ; 1), a \sim N\left(5,9.10^{-2} ; 1\right)$ e $\tau \sim G a(1 ; 1)$. 
Figura 7.10 Traços a posteriori das duas cadeias geradas de $s, a$ e $\tau$ considerando a população de capim colchão e as prioris: $s \sim N(209,6 ; 1)$, $a \sim N\left(5,9.10^{-2} ; 1\right)$ e $\tau \sim G a(0,001 ; 0,001)$. Nota-se uniformidade nos traços a posteriori de $s$ e $\tau$, mas alguns pontos discrepantes nos traços de $a$.

Figura 7.11 Teste gráfico de Gelman e Rubin: verifica-se um nível aceitável de convergência do algoritmo de Metropolis-Hastings na geração de amostras das duas cadeias para os parâmetros $s$ e $\tau$ considerando a população de capim colchão e as prioris: $s \sim N(209,6 ; 1), a \sim N\left(5,9.10^{-2} ; 1\right)$ e $\tau \sim G a(0,001 ; 0,001)$

Figura 7.12 Densidades a posteriori de $s, a$ e $\tau$ obtidas a partir das 18000 amostras geradas pelas duas cadeias considerando a população de capim colchão e as prioris: $s \sim N(209,6 ; 1), a \sim N\left(5,9.10^{-2} ; 1\right)$ e $\tau \sim$ $G a(0,001 ; 0,001) \ldots \ldots \ldots \ldots \ldots \ldots \ldots$

Figura 7.13 Traços a posteriori das três cadeias geradas de $s, a$ e $\tau$ considerando a população de capim colchão e as prioris: $s \sim N\left(209,6 ; 1.10^{6}\right)$, $a \sim N\left(5,9.10^{-2} ; 1.10^{6}\right)$ e $\tau \sim G a(0,1 ; 0,1)$. Nota-se razoável uniformidade nos traços a posteriori de $s, a$ e $\tau$ o que indica a convergência do algoritmo

Figura 7.14 Teste gráfico de Gelman e Rubin: verifica-se que houve convergência do algoritmo de Metropolis-Hastings na geração de amostras das três cadeias para os parâmetros $s$ e $a$ considerando a população de capim colchão e as prioris: $s \sim N\left(209,6 ; 1.10^{6}\right), a \sim N\left(5,9.10^{-2} ; 1.10^{6}\right) \mathrm{e}$ $\tau \sim G a(0,1 ; 0,1)$.

Figura 7.15 Densidades a posteriori de $s, a$ e $\tau$ obtidas a partir das 9600 amostras geradas pelas três cadeias considerando a população de capim colchão e as prioris: $s \sim N\left(209,6 ; 1.10^{6}\right), a \sim N\left(5,9.10^{-2} ; 1.10^{6}\right)$ e $\tau \sim$ $G a(0,1 ; 0,1)$. 
Figura 7.16 Traços a posteriori das três cadeias geradas de $s, a$ e $\tau$ considerando a população de capim colchão e as prioris: $s \sim N(209,6 ; 1)$, $a \sim U(0 ; 1)$ e $\tau \sim G a(1 ; 1)$. Nota-se uniformidade nos traços a posteriori de $s$ e $\tau$, mas alguns pontos discrepantes nos traços de $a \ldots \ldots . \ldots 135$

Figura 7.17 Teste gráfico de Gelman e Rubin: verifica-se que houve convergência do algoritmo "Slice-sampling" na geração de amostras das três cadeias para o parâmetro $\tau$ considerando a população de capim colchão e as prioris: $s \sim N(209,6 ; 1), a \sim U(0 ; 1)$ e $\tau \sim G a(1 ; 1) \ldots \ldots \ldots$

Figura 7.18 Densidades a posteriori de $s, a$ e $\tau$ obtidas a partir das 27000 amostras geradas pelas três cadeias considerando a população de capim colchão e as prioris: $s \sim N(209,6 ; 1), a \sim U(0 ; 1)$ e $\tau \sim G a(1 ; 1) . \ldots$.

Figura 7.19 Traços a posteriori das duas cadeias geradas de $s, a$ e $\tau$ considerando a população de capim colchão e as prioris: $s \sim N(209,6 ; 1)$, $a \sim U(0 ; 1)$ e $\tau \sim G a(0,001 ; 0,001)$. Nota-se poucos pontos discrepantes e uniformidade nos traços a posteriori de $s, a \tau \ldots \ldots \ldots \ldots$

Figura 7.20 Teste gráfico de Gelman e Rubin: verifica-se que houve convergência do algoritmo "Slice-sampling" na geração de amostras das duas cadeias para os parâmetros $a$ e $\tau$ considerando a população de capim colchão e as prioris: $s \sim N(209,6 ; 1), a \sim U(0 ; 1)$ e $\tau \sim G a(0,001 ; 0,001) .137$

Figura 7.21 Densidades a posteriori de $s, a$ e $\tau$ obtidas a partir das 18000 amostras geradas pelas duas cadeias considerando a população de capim colchão e as prioris: $s \sim N(209,6 ; 1), a \sim U(0 ; 1)$ e $\tau \sim G a(0,001 ; 0,001)$. 137

Figura 7.22 Traços a posteriori das três cadeias geradas de $s$, a e $\tau$ considerando a população de capim colchão e as prioris: $s \sim N\left(209,6 ; 1.10^{6}\right)$, $a \sim U(0 ; 1)$ e $\tau \sim G a(0,1 ; 0,1)$. Nota-se uniformidade nos traços a posteriori de $s$ e $a$, e apenas alguns pontos discrepantes nos traços de $\tau$. . .

Figura 7.23 Teste gráfico de Gelman e Rubin: verifica-se que houve convergência do algoritmo "Slice-sampling" na geração de amostras das três cadeias para os parâmetros $s$ e $a$ considerando a população de capim colchão e as prioris: $s \sim N\left(209,6 ; 1.10^{6}\right), a \sim U(0 ; 1)$ e $\tau \sim G a(0,1 ; 0,1) .139$ 
Figura 7.24 Densidades a posteriori de $s, a$ e $\tau$ obtidas a partir das 10800 amostras geradas pelas três cadeias considerando a população de capim colchão e as prioris: $s \sim N\left(209,6 ; 1.10^{6}\right), a \sim U(0 ; 1)$ e $\tau \sim G a(0,1 ; 0,1) .139$

Figura 7.25 Gráfico de caixa: densidade de sementes produzidas de leiteiro com (esquerda) e sem (direita) observações discrepantes. . . . . . . . . . 140

Figura 7.26 Gráfico de dispersão da variável independente versus variável dependente (esquerda) e histograma (direita) para as observações de capim guiné.

Figura 7.27 Gráficos de dispersão da variável independente versus variável dependente com a reta da regressão linear do modelo (4.8) (esquerda) e de normalidade dos resíduos (direita) para as observações de capim guiné. 142

Figura 7.28 Gráficos de dispersão da variável independente versus variável dependente com a curva da regressão não linear do modelo (6.9) (esquerda) e dos resíduos versus valores ajustados (direita) para as observações de capim guiné. . . . . . . . . . . . . . . . . . . . . . . . . 143

Figura 7.29 Histograma (esquerda) e gráfico de normalidade dos resíduos (direita) para as observações de capim guiné. . . . . . . . . . . . . 143

Figura 7.30 Traços a posteriori das três cadeias geradas de $s, a$ e $\tau$ considerando a população de capim guiné e as prioris: $s \sim N(994,6 ; 1)$, $a \sim N\left(5,7.10^{-2} ; 1\right)$ e $\tau \sim G a(1 ; 1)$ Nota-se uniformidade nos traços $a$ posteriori de $s, a$ e $\tau$ o que indica a convergência do algoritmo. . . . . . 146

Figura 7.31 Teste gráfico de Gelman e Rubin: verifica-se que houve convergência do algoritmo de Metropolis-Hastings na geração de amostras das três cadeias para os parâmetros $s, a$ e $\tau$ considerando a população de capim guiné e as prioris: $s \sim N(994,6 ; 1), a \sim N\left(5,7.10^{-2} ; 1\right)$ e $\tau \sim G a(1 ; 1) .146$

Figura 7.32 Densidades a posteriori de $s$, a e $\tau$ obtidas a partir das 18000 amostras geradas pelas três cadeias considerando a população de capim guiné e as prioris: $s \sim N(994,6 ; 1), a \sim N\left(5,7.10^{-2} ; 1\right)$ e $\tau \sim G a(1 ; 1) . \quad .147$ 
Figura 7.33 Traços a posteriori das duas cadeias geradas de $s, a$ e $\tau$ considerando a população de capim guiné e as prioris: $s \sim N(994,6 ; 1)$, $a \sim N\left(5,7.10^{-2} ; 1\right)$ e $\tau \sim G a(0,001 ; 0,001)$. Nota-se alguns pontos discrepantes, mas uniformidade nos traços a posteriori de $s, a$ e $\tau$. . . 148

Figura 7.34 Teste gráfico de Gelman e Rubin: verifica-se convergência do algoritmo de Metropolis-Hastings na geração de amostras das duas cadeias para os parâmetros $a$ e $\tau$ considerando a população de capim guiné e as prioris: $s \sim N(994,6 ; 1), a \sim N\left(5,7.10^{-2} ; 1\right)$ e $\tau \sim G a(0,001 ; 0,001) . \quad .148$

Figura 7.35 Densidades a posteriori de $s, a$ e $\tau$ obtidas a partir das 7200 amostras geradas pelas duas cadeias considerando a população de capim guiné e as prioris: $s \sim N(994,6 ; 1), a \sim N\left(5,7.10^{-2} ; 1\right)$ e $\tau \sim G a(0,001 ; 0,001) .149$

Figura 7.36 Traços a posteriori das três cadeias geradas de $s, a$ e $\tau$ considerando a população de capim guiné e as prioris: $s \sim N\left(994,6 ; 1.10^{6}\right)$, $a \sim N\left(5,7.10^{-2} ; 1.10^{6}\right)$ e $\tau \sim G a(0,1 ; 0,1)$. Nota-se pontos extremamente discrepantes nos traços a posteriori de $s, a$ e $\tau$. . . . . . . 149

Figura 7.37 Teste gráfico de Gelman e Rubin: verifica-se que apenas houve convergência do algoritmo de Metropolis-Hastings na geração de amostras das três cadeias para os parâmetros $\tau$ considerando a população de capim guiné e as prioris: $s \sim N\left(994,6 ; 1.10^{6}\right), a \sim N\left(5,7.10^{-2} ; 1.10^{6}\right)$ e $\tau \sim$ $G a(0,1 ; 0,1)$.

Figura 7.38 Densidades a posteriori de $s, a$ e $\tau$ obtidas a partir das 5400 amostras geradas pelas três cadeias considerando a população de capim guiné e as prioris: $s \sim N\left(994,6 ; 1.10^{6}\right), a \sim N\left(5,7.10^{-2} ; 1.10^{6}\right)$ e $\tau \sim$ $G a(0,1 ; 0,1)$.

Figura 7.39 Traços a posteriori das três cadeias geradas de $s, a$ e $\tau$ considerando a população de capim guiné e as prioris: $s \sim N(994,6 ; 1)$, $a \sim U(0 ; 1)$ e $\tau \sim G a(1 ; 1)$. Nota-se uniformidade nos traços a posteriori de $s$ e $\tau$, mas alguns pontos discrepantes nos traços de $a \ldots \ldots \ldots 1$ 
Figura 7.40 Teste gráfico de Gelman e Rubin: verifica-se que houve convergência do algoritmo "Slice-sampling" na geração de amostras das três cadeias para o parâmetro $s$ e $\tau$ considerando a população de capim guiné e as prioris: $s \sim N(994,6 ; 1), a \sim U(0 ; 1)$ e $\tau \sim G a(1 ; 1) \ldots \ldots 152$

Figura 7.41 Densidades a posteriori de $s, a$ e $\tau$ obtidas a partir das 27000 amostras geradas pelas três cadeias considerando a população de capim guiné e as prioris: $s \sim N(994,6 ; 1), a \sim U(0 ; 1)$ e $\tau \sim G a(1 ; 1)$.

Figura 7.42 Traços a posteriori das duas cadeias geradas de $s, a$ e $\tau$ considerando a população de capim guiné e as prioris: $s \sim N(994,6 ; 1)$, $a \sim U(0 ; 1)$ e $\tau \sim G a(0,001 ; 0,001)$. Nota-se poucos pontos discrepantes e uniformidade nos traços a posteriori de $s, a \tau \ldots \ldots \ldots \ldots$

Figura 7.43 Teste gráfico de Gelman e Rubin: verifica-se que houve convergência do algoritmo "Slice-sampling" na geração de amostras das duas cadeias para os parâmetros $s, a$ e $\tau$ considerando a população de capim guiné e as prioris: $s \sim N(994,6 ; 1), a \sim U(0 ; 1)$ e $\tau \sim G a(0,001 ; 0,001)$.

Figura 7.44 Densidades a posteriori de $s, a$ e $\tau$ obtidas a partir das 18000 amostras geradas pelas duas cadeias considerando a população de capim guiné e as prioris: $s \sim N(994,6 ; 1), a \sim U(0 ; 1)$ e $\tau \sim G a(0,001 ; 0,001)$.

Figura 7.45 Traços a posteriori das três cadeias geradas de $s, a$ e $\tau$ considerando a população de capim guiné e as prioris: $s \sim N\left(994,6 ; 1.10^{6}\right)$, $a \sim U(0 ; 1)$ e $\tau \sim G a(0,1 ; 0,1)$. Nota-se razoável uniformidade nos traços a posteriori de $s, a$ e $\tau \ldots \ldots \ldots \ldots \ldots \ldots$

Figura 7.46 Teste gráfico de Gelman e Rubin: verifica-se que houve convergência do algoritmo "Slice-sampling" na geração de amostras das três cadeias para os parâmetros $s, a$ e $\tau$ considerando a população de capim guiné e as prioris: $s \sim N\left(994,6 ; 1.10^{6}\right), a \sim U(0 ; 1)$ e $\tau \sim G a(0,1 ; 0,1) . \quad 156$

Figura 7.47 Densidades a posteriori de $s, a$ e $\tau$ obtidas a partir das 10800 amostras geradas pelas três cadeias considerando a população de capim guiné e as prioris: $s \sim N\left(994,6 ; 1.10^{6}\right), a \sim U(0 ; 1)$ e $\tau \sim G a(0,1 ; 0,1) . \quad 156$

Figura 7.48 Gráfico de caixa: densidade de sementes produzidas de leiteiro com (esquerda) e sem (direita) observações discrepantes. . . . . . . . . 157 
Figura 7.49 Gráfico de dispersão da variável independente versus variável dependente (esquerda) e histograma (direita) para as observações de leiteiro.158

Figura 7.50 Gráficos de dispersão da variável independente versus variável dependente com a reta da regressão linear do modelo (4.8) (esquerda) e de normalidade dos resíduos (direita) para as observações de leiteiro. . . 159

Figura 7.51 Gráficos de dispersão da variável independente versus variável dependente com a curva da regressão não linear do modelo (6.9) (esquerda) e dos resíduos versus valores ajustados (direita) para as observações de leiteiro. . . . . . . . . . . . . . . . . . . . . . 160

Figura 7.52 Histograma (esquerda) e gráfico de normalidade dos resíduos (direita) para as observações de leiteiro. . . . . . . . . . . . . . . 160

Figura 7.53 Traços a posteriori das três cadeias geradas de $s, a$ e $\tau$ considerando a população de leiteiro e as prioris: $s \sim N(13,9 ; 1), a \sim$ $N\left(9,9.10^{-3} ; 1\right)$ e $\tau \sim G a(1 ; 1)$. Nota-se poucos pontos discrepantes e uniformidade nos traços a posteriori de $s, a$ e $\tau$ o que indica a convergência do algoritmo. . . . . . . . . . . . . . . . . . . . 163

Figura 7.54 Teste gráfico de Gelman e Rubin: verifica-se que houve convergência do algoritmo de Metropolis-Hastings na geração de amostras das três cadeias para os parâmetros $s, a$ e $\tau$ considerando a população de leiteiro e as prioris: $s \sim N(13,9 ; 1), a \sim N\left(9,9.10^{-3} ; 1\right)$ e $\tau \sim G a(1 ; 1) . \quad 163$

Figura 7.55 Densidades a posteriori de $s, a$ e $\tau$ obtidas a partir das 6750 amostras geradas pelas três cadeias considerando a população de leiteiro e as prioris: $s \sim N(13,9 ; 1), a \sim N\left(9,9.10^{-3} ; 1\right)$ e $\tau \sim G a(1 ; 1) . \ldots 164$

Figura 7.56 Traços a posteriori das duas cadeias geradas de $s, a$ e $\tau$ considerando a população de leiteiro e as prioris: $s \sim N(13,9 ; 1), a \sim$ $N\left(9,9.10^{-3} ; 1\right)$ e $\tau \sim G a(0,001 ; 0,001)$. Nota-se pontos discrepantes mas razoável uniformidade nos traços a posteriori de $s, a$ e $\tau$. . . . . . . 165 
Figura 7.57 Teste gráfico de Gelman e Rubin: verifica-se que houve convergência do algoritmo de Metropolis-Hastings na geração de amostras das duas cadeias para os parâmetros $s$ e $\tau$ considerando a população de leiteiro e as prioris: $s \sim N(13,9 ; 1), a \sim N\left(9,9.10^{-3} ; 1\right)$ e $\tau \sim$

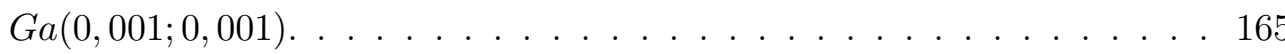

Figura 7.58 Densidades a posteriori de $s$, a e $\tau$ obtidas a partir das 4500 amostras geradas pelas duas cadeias considerando a população de leiteiro e as prioris: $s \sim N(13,9 ; 1), a \sim N\left(9,9.10^{-3} ; 1\right)$ e $\tau \sim G a(0,001 ; 0,001)$.

Figura 7.59 Traços a posteriori das três cadeias geradas de $s, a$ e $\tau$ considerando a população de leiteiro e as prioris: $s \sim N\left(13,9 ; 1.10^{6}\right), a \sim$ $N\left(9,9.10^{-3} ; 1.10^{6}\right)$ e $\tau \sim G a(0,1 ; 0,1)$. Nota-se uniformidade nos traços a posteriori de $s$ e $a$, mas alguns pontos discrepantes nos traços de $\tau$. . . 167

Figura 7.60 Teste gráfico de Gelman e Rubin: verifica-se que houve convergência do algoritmo de Metropolis-Hastings na geração de amostras das três cadeias para os parâmetros $s$ e $a$ considerando a população de leiteiro e as prioris: $s \sim N\left(13,9 ; 1.10^{6}\right), a \sim N\left(9,9.10^{-3} ; 1.10^{6}\right)$ e $\tau \sim G a(0,1 ; 0,1) .167$

Figura 7.61 Densidades a posteriori de $s, a$ e $\tau$ obtidas a partir das 18999 amostras geradas pelas três cadeias considerando a população de leiteiro e as prioris: $s \sim N\left(13,9 ; 1.10^{6}\right), a \sim N\left(9,9.10^{-3} ; 1.10^{6}\right)$ e $\tau \sim G a(0,1 ; 0,1) .168$

Figura 7.62 Traços a posteriori das três cadeias geradas de $s, a$ e $\tau$ considerando a população de leiteiro e as prioris: $s \sim N(13,9 ; 1), a \sim U(0 ; 1) \mathrm{e}$ $\tau \sim G a(1 ; 1)$. Nota-se uniformidade nos traços a posteriori de $s$ e $\tau$, mas alguns pontos discrepantes nos traços de $a \ldots \ldots$. . . . . . . 168

Figura 7.63 Teste gráfico de Gelman e Rubin: verifica-se que houve convergência do algoritmo "Slice-sampling" na geração de amostras das três cadeias para os parâmetros $s, a$ e $\tau$ considerando a população de leiteiro e as prioris: $s \sim N(13,9 ; 1), a \sim U(0 ; 1)$ e $\tau \sim G a(1 ; 1) \ldots \ldots 169$

Figura 7.64 Densidades a posteriori de $s, a$ e $\tau$ obtidas a partir das 27000 amostras geradas pelas três cadeias considerando a população de leiteiro e as prioris: $s \sim N(13,9 ; 1), a \sim U(0 ; 1)$ e $\tau \sim G a(1 ; 1) \ldots \ldots 169$ 
Figura 7.65 Traços a posteriori das duas cadeias geradas de $s, a$ e $\tau$ considerando a população de leiteiro e as prioris: $s \sim N(13,9 ; 1), a \sim U(0 ; 1)$ e $\tau \sim G a(0,001 ; 0,001)$. Nota-se uniformidade nos traços a posteriori de $s$ e $\tau$, mas pontos discrepantes nos traços de $a$.

Figura 7.66 Teste gráfico de Gelman e Rubin: verifica-se que houve convergência do algoritmo "Slice-sampling" na geração de amostras das duas cadeias para o parâmetro $s$ considerando a população de leiteiro e as prioris: $s \sim N(13,9 ; 1), a \sim U(0 ; 1)$ e $\tau \sim G a(0,001 ; 0,001)$.

Figura 7.67 Densidades a posteriori de $s, a$ e $\tau$ obtidas a partir das 18000 amostras geradas pelas duas cadeias considerando a população de leiteiro e as prioris: $s \sim N(13,9 ; 1), a \sim U(0 ; 1)$ e $\tau \sim G a(0,001 ; 0,001) \ldots \ldots$

Figura 7.68 Traços a posteriori das três cadeias geradas de $s, a$ e $\tau$ considerando a população de leiteiro e as prioris: $s \sim N\left(13,9 ; 1.10^{6}\right), a \sim U(0 ; 1)$ e $\tau \sim G a(0,1 ; 0,1)$. Nota-se uniformidade nos traços a posteriori de $s$ e a, e alguns pontos discrepantes nos traços de $\tau$. . . . . . . . 172

Figura 7.69 Teste gráfico de Gelman e Rubin: verifica-se que houve convergência do algoritmo "Slice-sampling" na geração de amostras das três cadeias para os parâmetros $s$ e $a$ considerando a população de leiteiro e as prioris: $s \sim N\left(13,9 ; 1.10^{6}\right), a \sim U(0 ; 1)$ e $\tau \sim G a(0,1 ; 0,1) \ldots \ldots$.

Figura 7.70 Densidades a posteriori de $s, a$ e $\tau$ obtidas a partir das 10800 amostras geradas pelas três cadeias considerando a população de leiteiro e as prioris: $s \sim N\left(13,9 ; 1.10^{6}\right), a \sim U(0 ; 1)$ e $\tau \sim G a(0,1 ; 0,1) \ldots \ldots 173$

Figura 7.71 Dinâmica simulada do modelo 7.4 para a população de capim colchão. Tem-se $\hat{s}=209,6 ; \hat{a}=0,065 ; X_{0}=1 ; g=0,1$ e densidade limiar de 4000 plântulas $/ m^{2}$ quando a taxa de produtividade de sementes é nula.

Figura 7.72 Dinâmica simulada do modelo 7.4 para a população de capim colchão. Tem-se $\hat{s}=832,6 ; \hat{a}=0,5875 ; X_{0}=1 ; g=0,1$ e densidade limiar de 4000 plântulas $/ \mathrm{m}^{2}$ quando a taxa de produtividade de sementes é nula. . . . . . . . . . . . . . . . . . . . . . . . . . . . . 177 
Figura 7.73 Dinâmica simulada do modelo 7.4 para a população de capim colchão. Tem-se $\hat{s}=625,4 ; \hat{a}=0,3884 ; X_{0}=1 ; g=0,1$ e densidade limiar de 4000 plântulas $/ \mathrm{m}^{2}$ quando a taxa de produtividade de sementes é nula.

Figura 7.74 Dinâmica simulada do modelo 7.4 para a população de capim guiné. Tem-se $\hat{s}=994,6 ; \hat{a}=0,062 ; X_{0}=1 ; g=0,1$ e densidade limiar de 4000 plântulas $/ m^{2}$ quando a taxa de produtividade de sementes é nula. 178

Figura 7.75 Dinâmicas simuladas do modelo 7.5 para a população de capim guiné. Tem-se $\hat{s}=994,6 ; \hat{a}=0,062 ; g=0,1 ; X_{0}=1$; densidade limiar de 4000 plântulas $/ m^{2}$ quando a taxa de produtividade de sementes é nula e $h=0,90$.

Figura 7.76 Dinâmica simulada do modelo 7.4 para a população de capim guiné. Tem-se $\hat{s}=994,6 ; \hat{a}=0,065 ; X_{0}=1 ; g=0,1$ e densidade limiar de 4000 plântulas $/ m^{2}$ quando a taxa de produtividade de sementes é nula. 179

Figura 7.77 Dinâmica simulada do modelo 7.4 para a população de capim guiné. Tem-se $\hat{s}=1242 ; \hat{a}=0,1139 ; X_{0}=1 ; g=0,1$ e densidade limiar de 4000 plântulas $/ m^{2}$ quando a taxa de produtividade de sementes é nula.179

Figura 7.78 Dinâmica simulada do modelo 7.4 para a população de leiteiro. Tem-se $\hat{s}=14 ; \hat{a}=0,01923 ; X_{0}=1 ; g=0,1$ e densidade limiar de 4000 plântulas $/ m^{2}$ quando a taxa de produtividade de sementes é nula. . . . . 180

Figura 7.79 Dinâmica simulada do modelo 7.4 para a população de leiteiro. Tem-se $\hat{s}=14,16 ; \hat{a}=0,02054 ; X_{0}=1 ; g=0,1$ e densidade limiar de 4000 plântulas $/ m^{2}$ quando a taxa de produtividade de sementes é nula. . 180

Figura 7.80 Dinâmica simulada do modelo 7.4 para a população de leiteiro. Tem-se $\hat{s}=14,02 ; \hat{a}=0,02407 ; X_{0}=1 ; g=0,1$ e densidade limiar de 4000 plântulas $/ m^{2}$ quando a taxa de produtividade de sementes é nula. . 181

Figura 7.81 Dinâmica simulada do modelo 7.4 para a população de leiteiro. Tem-se $\hat{s}=14,15 ; \hat{a}=0,02708 ; X_{0}=1 ; g=0,1$ e densidade limiar de 4000 plântulas $/ m^{2}$ quando a taxa de produtividade de sementes é nula. . 181 
Figura 7.82 Dinâmica simulada do modelo 7.4 para a população de leiteiro. Tem-se $\hat{s}=37,87 ; \hat{a}=0,2834 ; X_{0}=1 ; g=0,1$ e densidade limiar de 4000 plântulas $/ m^{2}$ quando a taxa de produtividade de sementes é nula.

Figura 7.83 Respostas do modelo (6.1) $\operatorname{com} b=1$ para as observações de capim colchão partindo-se do ajuste de regressão não linear da abordagem clássica e do ajuste bayesiano via prioris 4 . 5. e $6 \ldots \ldots \ldots$

Figura 7.84 Respostas do modelo (6.1) $\operatorname{com} b=1$ para as observações de capim guiné partindo-se do ajuste de regressão não linear da abordagem clássica e do ajuste bayesiano via prioris $4 ., 5$. e $6 . \ldots \ldots$. . . . . . 183

Figura 7.85 Respostas do modelo (6.1) $\operatorname{com} b=1$ para as observações de leiteiro partindo-se do ajuste de regressão não linear da abordagem clássica e do ajuste bayesiano via prioris $4 ., 5$. e $6 \ldots \ldots$. . . . . . . . . 184 


\section{Lista de Tabelas}

Tabela 5.1 Espécies de plantas daninhas encontradas nas parcelas experimentais do pivô. . . . . . . . . . . . . . . . . . 100

Tabela 5.2 Densidade de plantas daninhas e de sementes produzidas em cada parcela de Digitaria ciliaris (capim colchão) . . . . . . . . . . . . . 109

Tabela 5.3 Densidade de plantas daninhas e de sementes produzidas em cada parcela de Panicum maximum (capim guiné). . . . . . . . . . . . . 110

Tabela 5.4 Densidade de plantas daninhas e de sementes produzidas em cada parcela de Euphorbia heterophylla (leiteiro). . . . . . . . . . . . . 111

Tabela 7.1 Resumo dos resultados via abordagem clássica do modelo (6.9) para a população de Digitaria ciliaris (capim colchão) . . . . . . . . . . 125

Tabela 7.2 Resumo dos resultados via abordagem bayesiana do modelo (6.9) para a população de Digitaria ciliaris (capim colchão). . . . . . . . . . 128

Tabela 7.3 Resumo dos resultados via abordagem clássica do modelo (6.9) para a população de Panicum maximum (capim guiné). . . . . . . . . . 142

Tabela 7.4 Resumo dos resultados via abordagem bayesiana do modelo (6.9) para a população de Panicum maximum (capim guiné). . . . . . . . . . 145

Tabela 7.5 Resumo dos resultados via abordagem clássica do modelo (6.9) para a população de Euphorbia heterophylla (leiteiro). . . . . . . . . . 159

Tabela 7.6 Resumo dos resultados via abordagem bayesiana do modelo (6.9) para a população de Euphorbia heterophylla (leiteiro). . . . . . . . . . . 162 
Tabela 7.7 Resumo dos melhores resultados obtidos via abordagem bayesiana para as populações de capim colchão, capim guiné e leiteiro.

Tabela B.1 Localização das 41 parcelas experimentais obtida por uso do GPS.206

Tabela B.2 Densidade de plantas por espécie em cada quadro. . . . . . . . . 207

Tabela B.3 Densidade de plantas por espécie em cada quadro (continuação). 208

Tabela B.4 Densidade de plantas por espécie em cada quadro (continuação). 209

Tabela B.5 Densidade de plantas por espécie em cada quadro (continuação). 210

Tabela B.6 Densidade de plantas por espécie em cada quadro (continuação). 211

Tabela B.7 Densidade de plantas por espécie em cada quadro (continuação). 212

Tabela B.8 Densidade de plantas por espécie em cada quadro (continuação). 213

Tabela B.9 Densidade de plantas por espécie em cada quadro (continuação). 214

Tabela B.10 Densidade de plantas por espécie em cada quadro (continuação). 215

Tabela B.11 Densidade de plantas daninhas por $m^{2}$ por espécies em cada parcela. . . . . . . . . . . . . . . . . . . . 216

Tabela B.12 Densidade de plantas daninhas por $m^{2}$ por espécies em cada parcela (continuação) . . . . . . . . . . . . . . . . . . . 217

Tabela B.13 Densidade de plantas daninhas por $m^{2}$ por espécies em cada parcela (continuação). . . . . . . . . . . . . . . . . . . . 218

Tabela B.14 Densidade de plantas daninhas por $m^{2}$ por espécies em cada parcela (continuação). . . . . . . . . . . . . . . . . . . . . . . . 219

Tabela B.15 Densidade de plantas daninhas por $m^{2}$ em cada parcela segundo a classificação "folha larga" e "folha estreita". . . . . . . . . . . . . . . . . 220

Tabela B.16 Sementes produzidas por uma planta de cada espécie daninha por parcela. Espécie 1: trapoeraba, 2: mentrasto, 3: capim colchão, 4: braquiária, 5: capim marmelada, 6: leiteiro, 7: picão preto, 8: sorgo selvagem, 9: caruru branco, 10: capim guiné, 11: erva de santa luzia, 12: pé de galinha, 13: timbête. . . . . . . . . . . . . . . . . . . . . 
Tabela B.17 Sementes produzidas por uma planta de cada espécie daninha por parcela. Espécie 14: serralha, 15: cordão-de-frade. . . . . . . . . . 222

Tabela B.18 Total de sementes produzidas em cada parcela. . . . . . . . . . . 223 


\section{Resumo}

No ambiente agrícola, a possibilidade de prever eventos futuros para poder estabelecer prioridades e planejar atividades são indispensáveis para um manejo adequado. Modelos matemáticos têm se tornado ferramentas valiosas para o entendimento de fenômenos e simulação de soluções de um dado sistema de interesse para diferentes condições iniciais e valores de parâmetros.

O crescimento das plantas obedece a certos princípios fisiológicos que podem ser descritos, em termos quantitativos em resposta ao meio ambiente, através de equações matemáticas. Nos agrosistemas, a dinâmica da população de plantas daninhas pode ser descrita por modelos matemáticos que relacionam as densidades de sementes produzidas e de plântulas em áreas de cultivo. Os valores dos parâmetros dos modelos podem ser inferidos diretamente de experimentação e análise estatística, ou extraídos da literatura. O presente trabalho tem por objetivo investigar as particularidades dos parâmetros de modelos dinâmicos para populações de plantas daninhas, a partir de um experimento conduzido em campo, usando inferência bayesiana via método de Monte Carlo com cadeias de Markov e analisar situações que podem alterar a dinâmica do comportamento populacional por meio de simulações.

Palavras-chave: Modelos matemáticos, dinâmica populacional, plantas daninhas, banco de sementes, inferência bayesiana, método de Monte Carlo, simulação. 


\section{Abstract}

In the agricultural environment, the possibility to predict future events to establish priorities and to plan activities is indispensable for an appropriate management. Mathematical models have become precious tools for the understanding of phenomena and simulation of solutions of a given system for different initial conditions and values of parameters.

The growth of plants obeys the certain physiological principles that can be described, in quantitative terms in reply to the environment, through mathematical equations. In agrosystems, the dynamics of weed populations can be described by mathematical models that relates the produced seeds density and seedlings density in areas of a crop. The parameter models can be either directly inferred from experimentation and statistics analysis, or can be extracted from literature. The goals of this work is to investigate the particularitities of the dynamic models parameters for weed populations, from field experiment, using bayesian inference by Monte Carlo method with Markov chains and to analyze situations that can modify the population behavior by simulations.

Word-key: Mathematical models, population dynamics, weeds, bank of seeds, bayesian inference, simulation, Monte Carlo method. 


\section{Capítulo 1}

\section{Introdução}

\subsection{Objetivos e importância do trabalho}

Em um agrosistema, contextualizando-o como um supersistema, estão presentes, além dos aspectos físico e biótico, os aspectos sociocultural e político. São ambientes altamente perturbados e alterações nos sistemas de cultivo podem modificar os padrões de distúrbios. Por exemplo, as plantas daninhas e outras pragas agrícolas surgem como resultado do desequilíbrio causado pela intervenção antrópica em um agrosistema. Este desequilíbrio, condicionado por variáveis ambientais, torna propícia a explosão populacional de certos indivíduos, ocasionando infestações. Atualmente, o método mais usado para o controle dessas infestações é o químico.

O manejo integrado surge como uma alternativa ao manejo tradicional já que lança mão de avanços em tecnologias de posicionamento global de sistemas (GPS) e equipamentos baseados em computador para a agricultura. O monitoramento através destas geotecnologias junto à modelagem matemática e computacional possibilitam a discriminação local de infestações em áreas de cultivo. Em conseqüência, a taxa de aplicação de insumos químicos pode ser otimizada por considerar variações na distribuição espacial da densidade da infestação. Essa perspectiva, de aumento de produtividade e de redução de impacto ambiental, tem despertado o interesse na agricultura de precisão.

Nota-se, porém, que o Brasil é deficiente em ferramentas de previsão capazes de analisar com antecedência variáveis ambientais e indicar riscos de infestações de plantas daninhas nas áreas de cultivo. A partir de informações ambientais, pode-se inferir qual 
o nível de risco de infestações interferindo na produção agrícola. Por exemplo, a previsão das plantas daninhas pode ser eficientemente utilizada na prevenção de infestações com a aplicação de defensivos agrícolas em regiões precisas, tornando o ambiente agrícola melhor controlado, podendo reduzir os custos de produção (Judez et al., 2002) na aplicação de defensivos (Wu, 2001; Swinton e King, 1994) e por conseqüência o impacto ambiental (Park et al., 2003). Neste contexto, modelos matemáticos têm se tornado ferramentas valiosas para o entendimento e simulação de diferentes situações do problema, contribuindo para a implementação de estratégias integradas de controle.

Este trabalho tem por objetivo investigar as particularidades dos parâmetros de populações de plantas daninhas a partir do seu modelo dinâmico para analisar situações que possam ocorrer e alterar a trajetória populacional, visando contribuir para a obtenção de mapas de evolução de infestações por plantas daninhas em áreas de cultivo. A análise da dinâmica via parâmetros, requer métodos estatísticos para que se possa "diagnosticar" o comportamento da população de plantas daninhas, como por exemplo: erradicação, convergência para uma densidade estável e comportamentos complexos (ocorrência de oscilações amortecidas ou caóticas).

Este trabalho insere-se no projeto multidisciplinar: "Desenvolvimento de Sistemas de Análise e Controle Integrados para Populações de Plantas", cujos integrantes são professores, pesquisadores, graduandos, pós-graduandos e pós-doutorandos ligados ao Departamento de Engenharia Elétrica/EESC/USP, Departamento de Ciência da Computação e Estatística/IBILCE/UNESP e Empresa Brasileira de Pesquisa AgropecuáriaEmbrapa.

\subsection{Organização do trabalho}

O trabalho encontra-se dividido em capítulos. No restante do Capítulo 1, apresentam-se uma síntese bibliográfica no tema e alguns conceitos básicos de modelagem matemática, de estado, de equações a diferenças, bem como algumas técnicas de análise de soluções dessas equações.

No Capítulo 2, apresentam-se as práticas de controle de populações de plantas daninhas em sistemas agrícolas, as etapas envolvidas na regulação destas populações (semente, planta e reprodução vegetativa), os meios de propagação e dispersão de espécies 
daninhas e sua interferência em culturas agrícolas. Algumas relações matemáticas são estabelecidas, em especial um modelo hiperbólico para o cálculo da produção de sementes de plantas daninhas a partir de dados de perda de rendimento da cultura.

No Capítulo 3, estudam-se o comportamento dinâmico de populações de plantas daninhas por equações a diferenças. Primeiro, são apresentados modelos de único estádio que descrevem os processos intrínsecos da população, os quais ocorreriam se o habitat permanecesse constante de uma geração à seguinte. Um exemplo de simulação de um modelo de único estádio para a produção de sementes, visando discutir a incorporação de práticas de controle para redução da população de plantas daninhas sem a erradicação da mesma, é apresentado. Segundo, são considerados a indução a mortalidade e/ou os efeitos letais de um herbicida sobre a produção de sementes descritas por esses modelos. Terceiro, são apresentados modelos de múltiplos estádios para espécies daninhas que coexistem em diferentes estádios de desenvolvimento. Quarto, são apresentados modelos que descrevem o movimento vertical do banco de sementes no solo, úteis para simular práticas agrícolas ou para predizer as posições verticais de sementes no solo.

O Capítulo 4 apresenta uma breve distinção entre as abordagens clássica e bayesiana de inferência estatística, bem como de Monte Carlo simples e de cadeia de Markov.

Do Capítulo 5 ao Capítulo 7, são apresentados o delineamento do experimento realizado, aspectos botânicos de algumas espécies infestantes da cultura de milho cultivar BRS1030, análise via abordagens clássica e bayesiana do modelo de produção de sementes de plantas daninhas em agrosistemas, simulação do comportamento das espécies daninhas e discussão dos resultados obtidos.

No Capítulo 8, são apresentadas as conclusões e algumas proposições para trabalhos futuros com base nos resultados obtidos até este ponto.

No Apêndice A e no Apêndice B, conceitos de probabilidade e estatística e as tabelas dos dados coletados em campo são, respectivamente, apresentados.

\subsection{Síntese bibliográfica do tema}

O setor de agronegócio está se transformando em uma indústria de grande relevância, necessitando de ferramentas de automação industrial e metodologias de controle avançadas para melhorar a eficiência de operação e a qualidade dos produtos. A perspectiva 
de aumento de produtividade e de redução de impacto ambiental tem despertado o interesse na agricultura de precisão - prática que leva em conta a variabilidade espacial e temporal dos aspectos culturais e edafoclimáticos para viabilizar um processo mais adequado de gerenciamento da produção (Coghlan, 1995; Plucknett e Winkelmann, 1995).

As plantas cultivadas são aquelas espécies normalmente semeadas pelo homem, também denominadas 'plantas econômicas', cujo cultivo geralmente é de interesse econômico; em termos de nutrientes, apresentam as mesmas necessidades que as plantas daninhas, mas possuem menor habilidade em aproveitá-los (Lorenzi, 2000).

As plantas daninhas são todas e quaisquer plantas estranhas a uma cultura, que ocorre de modo espontâneo e prejudicial em locais relacionados com as atividades do homem. São consideradas apófitas ou selvagens, quando pertencem à flora nativa da própria região, ou autopófitas ou naturalizadas quando infestam áreas por disseminação voluntária ou involuntária do homem; possuem vantagem em relação às plantas cultivadas na competição pelos recursos vitais (água, luz e nutrientes) por se caracterizarem pela grande agressividade vegetativa, reprodutiva e multiplicadora; alta incidência; resistência ao controle exercido pelo homem e capacidade de sobrevivência em condições adversas de ambiente (Krejci e Lourenço, 1986; Lorenzi, 2000). De um modo geral, as plantas daninhas são vegetais que crescem onde não são desejados, o que permite enquadrar, dentro dessa definição, a tiguera de certas culturas que cresce na lavoura implantada em sucessão àquelas (Lorenzi, 2000).

As culturas agrícolas estão sujeitas a uma série de fatores do ambiente que influenciam no crescimento, desenvolvimento e produtividade econômica. Em termos médios, 30 a $40 \%$ de redução da produção agrícola no mundo tropical é atribuído à interferência das plantas daninhas, que reduzem a eficiência agrícola e aumentam os custos de produção (Lorenzi, 2000).

Muitos estudos relacionados à biologia de espécies daninhas fornecem subsídios para o controle eficiente das invasoras, bem como, para a criação de novas cultivares resistentes a diversas pragas (Mortimer, 1987; Freitas, 1990; Bicudo, 1998; Guimarães, 2000; Diggle et al., 2003; Lacerda, 2003; Monquero, 2003). Doenças que atacam diretamente a saúde da planta podem ser localmente sanadas com o plantio destas novas cultivares resistentes. Entretanto, as plantas daninhas interferem indiretamente no desenvolvimento da cultura, sendo usualmente controladas com aplicações de herbicidas. 
Por exemplo, a presença de plantas daninhas na cultura de soja (Figura 1.1) causa perdas no rendimento, na qualidade do produto, podendo até mesmo inviabilizar a colheita. O controle químico ainda é o preferido entre os agricultores da cultura, representando um dos maiores segmentos da indústria de herbicidas (Correia e Rezende, 2002; Voll et al., 2004).

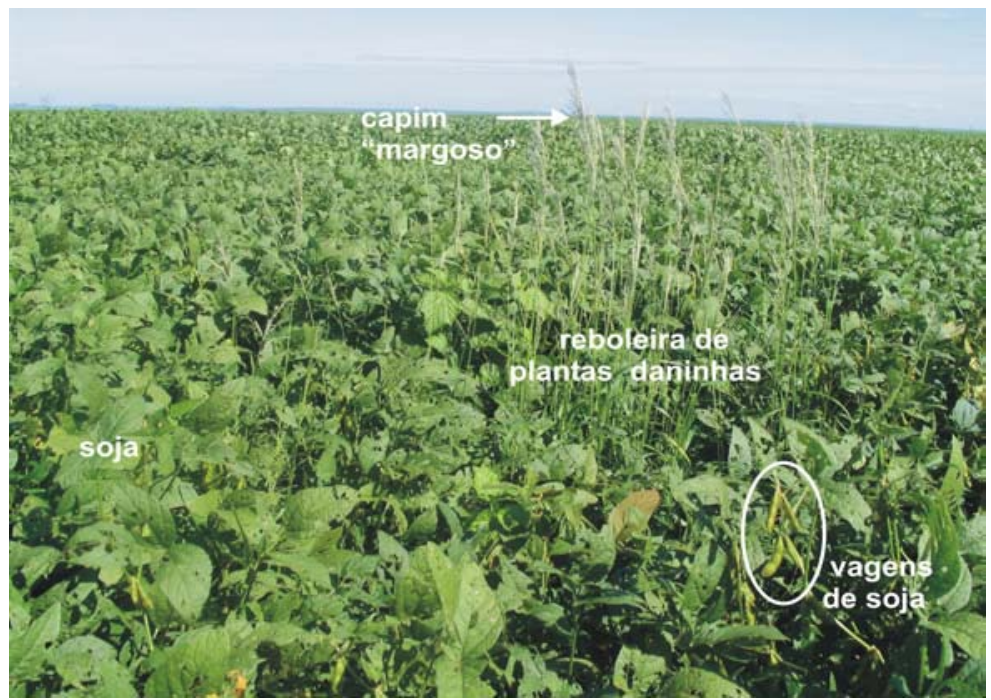

Figura 1.1: Plantação de soja infestada com plantas daninhas (São Gabriel D'Oeste, MS).

Contudo, a aplicação intensiva de insumos químicos tem gerado discussão pública sobre seus efeitos danosos ao meio ambiente e à saúde (Wu, 2001; Kim et al., 2002; Park et al., 2003). O uso intensivo de herbicidas, por exemplo, pode resultar em um aumento do número de espécies daninhas resistentes à este (Park et al., 2003). Neste contexto, o manejo integrado surge como uma alternativa ao manejo tradicional, o qual pode ser definido como a seleção e integração de práticas de controle e o conjunto de critérios para a sua utilização, com resultados favoráveis dos pontos de vista agronômico, econômico, ecológico e social (Doyle, 1997; Wu, 2001). De um modo geral, as tecnologias do manejo integrado, tendem a resultar em menor custo de controle das plantas daninhas do que o método convencional, utilizado pela maioria dos agricultores (Doyle, 1997; EMATER, 2002). A aplicação dessas técnicas, em geral, requer modelos dos sistemas tratados.

A modelagem matemática da dinâmica populacional tornou-se conhecida com Lotka e Volterra (Lotka, 1925; Monteiro, 2002), que descreveram a interação entre duas espécies. Doyle (1997) realizou uma análise do papel da modelagem matemática no de- 
senvolvimento de estratégias integradas, envolvendo a redução de elementos químicos, para o controle de pragas, plantas daninhas e doenças na cultura; afirmou que dada a complexidade dos sistemas de manejo, assim como os riscos ambientais envolvidos, a modelagem matemática deveria ser uma ferramenta potencialmente valiosa, tendo em vista que modelar as conseqüências antes da aplicação prática é imprescindível.

Um programa de gerenciamento integrado de plantas daninhas efetivo deve levar em conta a estrutura do banco de sementes (Buhler et al., 1997), por representar o 'status' de infestações da área agrícola. Um outro componente importante é a manipulação da relação de competição entre a cultura e as plantas daninhas (Cousens, 1985b). Na medida em que se estabelece a cultura em condições mais favoráveis, esta pode assumir uma posição dominante na comunidade e suprimir o crescimento das plantas daninhas (Rizzardi et al., 2003b). Em geral, as relações densidade-rendimento de plantas são determinadas pela disponibilidade de recursos finitos.

Existem alguns exemplos de modelagem de população de plantas daninhas em termos da dinâmica, em geral, não linear (Edelstein-Keshet, 1988; Sakai, 2001; Cousens e Mortimer, 1995). Estudos e levantamentos de populações de plantas daninhas em ambientes agrícolas, além de permitir a identificação da flora infestante e sua evolução numa área, podem ter aplicação na predição de infestantes em culturas agrícolas (Voll et al., 1996; Voll et al., 1997a). Taxas de emergência de espécies de um banco de sementes podem servir para adequar manejos, para a racionalização do uso de herbicidas (Voll et al., 1997a). Por exemplo, as emergências de espécies daninhas em pré-semeadura de uma cultura podem ser eliminadas pelas práticas de manejo, reduzindo as infestações e a sobrevivência da espécie (Voll et al., 1997b). Já a distribuição das sementes no perfil do solo é importante para determinar a intensidade de emergência na fase de desenvolvimento da cultura (Voll et al., 1997b) ou para simular práticas agrícolas (Cousens e Moss, 1990; Gonzalez-Andujar, 1997).

De um modo geral, o conhecimento da distribuição local de plantas daninhas e o uso adequado dos instrumentos de pulverização auxiliam a aplicação correta do herbicida, variando a taxa de aplicação conforme a distribuição das plantas daninhas (maior em áreas de alta densidade de plantas e menor em áreas de baixa densidade). Com um tratamento localmente diferenciado obtém-se vantagens econômicas e ambientais.

Deve-se destacar que o objetivo do controle das plantas daninhas não é a sua erra- 
dicação, mas a redução da densidade destas abaixo do nível econômico de danos.

\subsection{Modelagem matemática: conceitos básicos}

Modelos são as unidades básicas do desenvolvimento científico e tecnológico. Qualquer teoria científica pode ser vista como um modelo conceitual onde a realidade é apresentada de forma simplificada através de conceitos abstratos. Um sistema pode ser definido como um conjunto de objetos agrupados por alguma interação ou interdependência, de modo que existam relações de causa e efeito nos fenômenos que ocorrem com os elementos deste conjunto (Monteiro, 2002). Com efeito, a representação matemática de um sistema real é definida como modelo, sendo a modelagem matemática o processo de desenvolvimento dessa representação. Se algumas grandezas que caracterizam os objetivos constituintes de um sistema variam no tempo então este é dito dinâmico (Aguirre, 2000; Monteiro, 2002). Determinar, teoricamente, a evolução temporal das grandezas que caracterizam um sistema pode ser importante para explicar o comportamento de sistemas já existentes.

$\mathrm{Na}$ Teoria de Controle, os modelos de sistemas físicos são denominados sistemas e os sistemas físicos de processos ou plantas. O comportamento dos sistemas físicos é usualmente tão complexo que sua descrição completa se torna intratável pelos métodos matemáticos usuais. O recurso de que se dispõe é o de idealizar aquele comportamento, desprezando maior ou menor número de minúcias; a cada idealização corresponde um modelo matemático do comportamento do sistema (Castrucci e Batista, 1980).

Segundo Aguirre (2000), existem várias formas e técnicas de obtenção de modelos, uma delas é a modelagem caixa branca também conhecida como modelagem fenomenológica ou conceitual (pela física ou natureza do processo). Todavia, nem sempre é viável seguir este procedimento devido ao conhecimento e tempo necessário para modelar um sistema partindo do equacionamento dos fenômenos envolvidos. Assim, quando há pouco ou nenhum conhecimento prévio do sistema uma técnica alternativa é a modelagem caixa preta ou empírica. Esta técnica se propõe a obter um modelo matemático que explique, de forma aproximada, a relação causa e efeito presente nos dados. Neste caso, o tipo de modelos, as técnicas usadas e os requisitos necessários são bastante distintos dos análogos na modelagem pela natureza do processo. Uma outra maneira 
alternativa de se fazer a determinação de estrutura do modelo é usar conhecimento $a$ priori para tal. Pelo fato de se estar baseando em um conhecimento prévio do sistema (por exemplo, o conhecimento da estrutura do modelo) tal procedimento é chamado modelagem caixa cinza. Em particular, neste trabalho, os modelos apresentados são provenientes do conhecimento fenomenológico que se tem da dinâmica populacional de plantas daninhas.

O modelo matemático desenvolvido para um determinado sistema é apenas uma representação aproximada. Conseqüentemente, não existe apenas o modelo do sistema, mas uma família de modelos com características e desempenhos variados; a escolha de um destes modelos é um dos problemas não triviais a serem enfrentados. Além disso, espera-se que um modelo, sendo uma simplificação da realidade, mantenha as características fundamentais do fenômeno ou realidade que representa. Nesta visão, um modelo seria uma representação imperfeita mas relativamente fiel da verdade.

\subsubsection{Razões para a construção de modelos}

Os modelos são construídos, basicamente, como auxílio na interpretação de dados experimentais, ferramenta de desenvolvimento e pesquisa.

Muitos modelos relacionados à produção agrícola, ou parte dos mesmos, foram desenvolvidos com o objetivo de auxiliar pesquisadores a entender operações de alguma parte do sistema a fim de otimizá-la.

Em geral, a modelagem matemática estimula novas idéias, permite a previsão, resumindo convenientemente uma grande quantidade de informações. Além disso, pode-se dizer que a tentativa de construir um determinado modelo ajuda a detectar áreas onde o conhecimento e dados são escassos (Cousens e Mortimer, 1995; Doyle, 1997; Aguirre, 2000; Monteiro, 2002).

\subsubsection{Tipos de modelos}

Existem uma infinidade de modelos matemáticos. A seguir, mencionam-se, segundo Aguirre (2000), alguns dos mais comuns. 


\section{Modelos lineares e não lineares}

Nos modelos lineares vale o princípio da superposição, isto é, a resposta a dois estímulos quaisquer simultâneos é a soma das respostas aos dois estímulos separadamente. A consideração de linearidade normalmente simplifica bastante o modelo a ser desenvolvido, entretanto há situações em que esta consideração não é adequada, como, por exemplo, no caso em que se deseja estudar característica dinâmicas não lineares do sistema, tais como oscilações e bifurcações. Os não lineares não possuem classificação útil conhecida.

\section{Modelos estáticos e dinâmicos}

Modelos estáticos relacionam variáveis sem quantificar sua dependência temporal. Quando a evolução temporal de um sistema é desejada, modelos dinâmicos devem ser usados. Modelos estáticos são normalmente descritos por equações algébricas, ao passo que modelos dinâmicos são compostos por equações diferenciais ou a diferenças (no caso discreto no tempo), sendo que tais modelos podem também incluir equações algébricas.

Todo sistema real, é em última análise, dinâmico. A opção por descrever um sistema real por um modelo estático é viável quando a sua dinâmica não é relevante, ou seja, quando a dinâmica é muito rápida ou muito lenta, se comparada com a escala de tempo de interesse.

\section{Modelos discretos e contínuos}

Os termos discreto e contínuo se referem ao tempo. Modelos dinâmicos contínuos são descritos por equações diferenciais e representam a evolução do sistema continuamente no tempo. Em contraste, modelos dinâmicos discretos no tempo representam a evolução do sistema em instantes discretos e são descritos por equações a diferenças.

\section{Modelos monovariáveis e multivariáveis}

Um modelo com mais de uma entrada ou mais de uma saída é denominado multivariável. Modelos monovariáveis são aqueles que representam a relação causa e efeito de apenas um par de variáveis, ou seja, de uma entrada para uma saída. 


\section{Modelos determinísticos e estocásticos}

Modelos determinísticos são aqueles nos quais não estão representadas as incertezas presentes no contexto de um problema real. Por outro lado, os modelos estocásticos incluem incertezas. Conseqüentemente, a saída de um modelo estocástico não é, a rigor, um número determinístico, mas uma variável aleatória. Em outras palavras, um sistema (ou modelo) é estocástico se sua saída no instante $t$ não pode ser exatamente determinada a partir de dados referentes ao passado, $t_{p}<t$.

\subsubsection{Regras gerais para a construção de um modelo dinâmico}

De acordo com Monteiro (2002), um sistema dinâmico real pode ser estudado em três etapas:

- Representação: especifica-se o sistema a ser estudado e propõe-se um modelo cujo comportamento se assemelhe ao comportamento do sistema real. Nesta fase define-se as variáveis independentes, as dependentes e os parâmetros.

- Análise: estuda-se a influência dos parâmetros e das condições iniciais sobre a evolução temporal das variáveis dependentes do modelo e interpretam-se as soluções obtidas.

- Aperfeiçoamento: uma vez que o modelo foi determinado é necessário passar por uma fase de testes para verificar se está representando adequadamente o sistema real para o qual foi projetado. Assim, investigam-se alterações nas equações (ou regras) que tornem as previsões mais próximas dos dados que foram obtidos através de experiências ou de observações.

\subsection{O conceito de estado}

Segundo Ogata (2003), a tendência dos sistemas de engenharia é aumentar sua complexidade em virtude principalmente da necessidade de realizar tarefas complexas e de alta precisão. Por exemplo, sistemas complexos podem ter diversas entradas e saídas e podem ser lineares ou não lineares e variantes no tempo. Essa teoria tem como base o conceito de estado, o qual já existe há bastante tempo, no campo da dinâmica clássica 
e em outras áreas. A seguir, apresentam-se algumas definições, segundo Ogata (2003).

Definição 1.1 (estado) O estado de um sistema dinâmico é o menor conjunto de variáveis (chamadas de variáveis de estado), tais que o conhecimento dessas variáveis em $t=t_{0}$, juntamente com o conhecimento da entrada para $t \geq t_{0}$, determina completamente o comportamento do sistema para qualquer instante $t \geq t_{0}$.

Se pelo menos $n$ variáveis $x_{1}, x_{2}, \ldots, x_{n}$ são necessárias para descrever todo o comportamento de um sistema dinâmico (de tal modo que, sendo dada a entrada para $t \geq t_{0} \mathrm{e}$ especificado o estado inicial em $t=t_{0}$, o estado futuro do sistema fique completamente determinado), então essas $n$ variáveis formam um conjunto de variáveis de estado.

Definição 1.2 (espaço de estado) O espaço n-dimensional, cujos eixos coordenados são formados pelos eixos de $x_{1}, x_{2}, \ldots, x_{n}$ onde $x_{1}, x_{2}, \ldots, x_{n}$ são as variáveis de estado, é chamado de espaço de estados.

Qualquer estado pode ser representado por um ponto no espaço de estado.

\subsection{Equações a diferenças não lineares}

Em particular, tem-se interesse em modelos que descrevam a evolução temporal de populações de plantas daninhas. Como a população deve ser medida/observada em um tempo comum do ciclo de vida, é conveniente e mais simples representá-la por gerações discretas no tempo. Por exemplo, se o crescimento de uma espécie daninha é uma função não linear da densidade populacional, equações a diferenças não lineares são utilizadas para descrever a dinâmica da espécie. A teoria tratada a seguir, é baseada no texto de Edelstein-Keshet (1988) e tem por objetivo apresentar algumas técnicas para a determinação de soluções de equações a diferença de primeira ordem.

\subsubsection{Reconhecendo equações a diferenças não lineares}

Uma equação a diferença não linear é qualquer expressão da forma

$$
x_{t+1}=f\left(x_{t}, x_{t-1}, x_{t-2}, \cdots\right)
$$


onde $x_{i}$ é o valor de $x$ na geração $i$ e a função de recursão $f$ depende de uma combinação não linear de seus argumentos ( $f$ pode envolver formas quadráticas, exponenciais, polinomiais). Em particular, para uma população de plantas daninhas tem-se $f: \mathcal{R} \rightarrow \mathcal{R}$. Uma solução para (1.1) é uma fórmula geral que relaciona $x_{t}$ a uma geração $t$ e a algum valor inicial específico, por exemplo, $x_{0}, x_{1}, \cdots$. Em relativamente poucos casos pode-se obter diretamente uma solução analítica quando $f$ é não linear. Neste trabalho, aborda-se, especificamente, o caso de equações a diferença de primeira ordem, da forma

$$
x_{t+1}=f\left(x_{t}\right)
$$

A seguir, discute-se algumas técnicas para a obtenção de informações a respeito da natureza das soluções de (1.2).

\subsubsection{Estado de equilíbrio e estabilidade}

A concepção de equilíbrio descreve a ausência de variação em um sistema.

Definição 1.3 (equilíbrio) Uma solução de equilíbrio $x_{e}$ é definida como sendo o valor que satisfaz a relação

$$
x_{t+1}=x_{t}=x_{e}
$$

e portanto, nenhuma mudança ocorre entre a geração $t$ e a geração $t+1$.

De (1.2) segue que $x_{e}$ satisfaz a relação

$$
x_{e}=f\left(x_{e}\right)
$$

e também é $x_{e}$ freqüentemente denominado ponto fixo da função $f$.

Distinguem-se dois tipos de solução de equilíbrio: instável e estável. A Figura 1.2 exemplifica três situações: equilíbrio estável (bola 1), instável (bola 3) e ausência de equilíbrio (bola 2).

Esta distinção é de interesse biológico uma vez que em um estado de equilíbrio instável, grandes mudanças podem ocorrer. Por exemplo, se variações iminentes são de potencial importância, informações quantitativas provenientes de uma solução matemática exata não são convenientes. Neste contexto, considere que dada (1.2), tem-se 


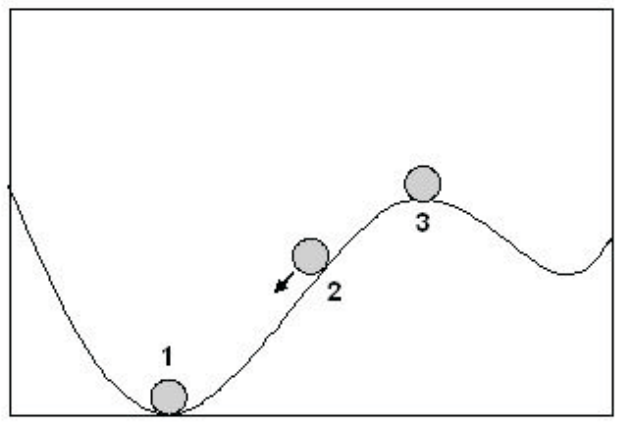

Figura 1.2: Exemplo de equilíbrio estável (bola 1), equilíbrio instável (bola 3) e ausência de equilíbrio (bola 2). As bolas 1 e 3 estão em repouso e representam situações de equilíbrio. A bola 1 é estável, sob uma perturbação suficientemente pequena a bola irá retornar a sua posição anterior. A bola 3 é instável, qualquer perturbação suficientemente pequena causará a queda para um dos vales. A bola 2 não está em equilíbrio desde que sua posição e velocidade estão variando continuamente.

determinado $x_{e}$, uma solução de estado de equilíbrio de acordo com (1.4). Dado algum valor $x_{t}$ próximo de $x_{e}$, irá $x_{t}$ tender rumo ao equilíbrio ou para longe deste?

A seguir, aborda-se o que ocorre ao sistema quando submetido a com perturbações próximas ao ponto de equilíbrio e algumas condições para determinar os tipos de soluções de (1.2).

\section{Condição para a estabilidade de soluções de equilíbrio}

Seja a solução de (1.2)

$$
x_{t}=x_{e}+\tilde{x}_{t}
$$

onde $\tilde{x}_{t}$ é um número suficientemente pequeno denominado perturbação do estado de equilíbrio $x_{e}$. De (1.2), (1.4) e (1.5) segue que a perturbação $\tilde{x}_{t}$ satisfaz

$$
\tilde{x}_{t+1}=x_{t+1}-x_{e}=f\left(x_{t}\right)-x_{e}=f\left(x_{e}+\tilde{x}_{t}\right)-x_{e} .
$$

Agora, expandindo $f$ em série de Taylor tem-se

$$
\begin{aligned}
f\left(x_{e}+\tilde{x}_{t}\right) & =f\left(x_{e}\right)+\left.\frac{d f}{d x}\right|_{x_{e}} \tilde{x}_{t}+\left.\frac{1}{2 !} \frac{d^{2} f}{d x^{2}}\right|_{x_{e}} \tilde{x}_{t}^{2}+\left.\frac{1}{3 !} \frac{d^{3} f}{d x^{3}}\right|_{x_{e}} \tilde{x}_{t}^{3}+ \\
& +\cdots+\left.\frac{1}{n !} \frac{d^{n} f}{d x^{n}}\right|_{x_{e}} \tilde{x}_{t}^{n}+\cdots
\end{aligned}
$$


Em (1.7), quando $\left(x_{t}-x_{e}\right)$ é um valor muito pequeno, os termos $\left(x_{t}-x_{e}\right)^{k}$ para $k>1$ podem usualmente ser negligenciados (desde que os coeficientes derivativos não sejam valores muito grande; ou seja, a função não possue variações abruptas). Neste caso,

$$
f\left(x_{e}+\tilde{x}_{t}\right) \approx f\left(x_{e}\right)+\left.\frac{d f}{d x}\right|_{x_{e}} \tilde{x}_{t}+\cdots+(\text { termos negligenciados }) .
$$

A proximação (1.8) resulta em cancelamentos de alguns termos em (1.6), pois $f\left(x_{e}\right)=x_{e}$ segundo a expressão (1.4). Logo,

$$
\begin{aligned}
\tilde{x}_{t+1} & \approx f\left(x_{e}\right)-x_{e}+\left.\frac{d f}{d x}\right|_{x_{e}} \tilde{x}_{t} \\
\Rightarrow \tilde{x}_{t+1} & \approx a \tilde{x}_{t}
\end{aligned}
$$

onde $a=\left(\left.\frac{d f}{d x}\right|_{x_{e}}\right)$ é um número conhecido. A expressão (1.9) descreve o que acontece próximo a algum estado de equilíbrio. Note que a constante $a$ é um valor conhecido, obtido através do cálculo da derivada de $f, d f / d x$, no ponto $x_{e}$.

Observação 1.1 Para que uma função seja representada pela série de Taylor é necessário que a função e todas as suas derivadas existam em $x=k$, onde $k$ é uma constante arbitrária. A existência da função e de suas derivadas, entretanto, não assegura uma tal representação da função. Toda série de potências em $\left(x_{t}-k\right)$ é convergente ao menos para um valor, $x=k$ de $x$. O conjunto dos valores de $x$ para os quais a série converge é chamado intervalo de convergência da série. O intervalo de convergência de uma série pode ser determinado por meio do teste da relação (Ayres-Junior, 1968).

Para entender se pequenos desvios a partir do ponto de equilíbrio crescem ou decrescem, técnicas de equações a diferenças lineares podem ser aplicadas. De fato, a magnitude de $a$ determina se a população aumenta ou declina com o decorrer do tempo $t$

$$
\begin{aligned}
& |a|>1 \text {, a solução } x_{t} \text { aumenta sobre sucessivas gerações } \\
& |a|<1 \text {, a solução } x_{t} \text { decresce sobre sucessivas gerações } \\
& |a|=1 \text {, a solução } x_{t} \text { é constante }
\end{aligned}
$$

Assim, a condição de estabilidade de soluções de (1.2) é 


$$
x_{e} \text { é estado de equilíbrio estável de (1.2) se e só se }\left|\left(\left.\frac{d f}{d x}\right|_{x_{e}}\right)\right|<1 \text {. }
$$

\section{Condição para a estabilidade de soluções de equilíbrio de ciclos estáveis}

Uma oscilação estável é um comportamento periódico que é mantido apesar de pequenos distúrbios. Por exemplo, oscilações de duplo período implicam que gerações sucessivas alternam-se entre dois pontos fixos, $x_{e_{1}}$ e $x_{e_{2}}$, de $x$. Então, oscilações de duplo período (também conhecidas como ciclo de dois pontos) simultaneamente satisfazem as equações

$$
\begin{aligned}
& x_{t+1}=f\left(x_{t}\right) \\
& x_{t+2}=x_{t} .
\end{aligned}
$$

Resultando,

$$
\begin{aligned}
f\left(x_{t+1}\right) & =f\left(f\left(x_{t}\right)\right) \\
x_{t+2} & =f\left(f\left(x_{t}\right)\right) .
\end{aligned}
$$

Seja $g$ uma função composta tal que $g(x)=f(f(x))$, e $k$ um novo índice que alterna de uma geração à seguinte: $k=t / 2$, para cada $x$. O sistema (1.13) torna-se

$$
x_{k+1}=g\left(x_{k}\right)
$$

e o estado de equilíbrio de (1.14), $x_{e}$ (ou ponto fixo da função $g$ ), é uma solução ciclo de dois pontos de (1.11), que oscila entre dois pontos fixos $x_{e_{1}}$ e $x_{e_{2}}$.

Supõe-se agora que $x_{0}=x_{e_{1}}+\epsilon_{0}$, onde $\epsilon_{0}$ é um termo suficientemente pequeno. A estabilidade de $x_{e_{i}}$ implica que o comportamento periódico pode ser reestabilizado desde que o desvio $\epsilon_{0}$ seja um termo suficientemente pequeno. Assim, usando a técnica apresentada anteriormente, tem-se

$$
\left|\left(\left.\frac{d g}{d x}\right|_{x_{e_{i}}}\right)\right|<1
$$

ou, analogamente

$$
x_{i} \text { é um ciclo de dois pontos estável se e só se }\left|\left(\left.\frac{d f}{d x}\right|_{x_{e_{1}}}\right)\left(\left.\frac{d f}{d x}\right|_{x_{e_{2}}}\right)\right|<1 \text {. }
$$


Portanto, conclui-se que a estabilidade de oscilações de duplo período dependem da magnitude de $d f / d x$ em $x_{e_{i}}$.

A técnica utilizada para explorar a existência de oscilações de duplo período também pode ser aplicada a períodos de qualquer ordem $p, p=3,4, \cdots$. No entanto, tal análise torna-se exaustiva para períodos de ordens superiores e, geralmente, não é aplicada. Neste caso, métodos gráficos podem ser utilizados para indicar a estabilidade do estado de equilíbrio.

\section{Soluções caóticas}

Quando as soluções são submetidas a um amplo intervalo de oscilações e de qualquer ordem, há algum fenômeno complexo influenciando o comportamento da população. Este fenômeno é denominado caos. Um aspecto deste tipo de solução é que dois valores iniciais muito próximos, em geral, diferem em poucas iterações. Contudo, a maioria dos sistemas biológicos operam dentro de um espaço de soluções de estabilidade de soluções de baixa ordem de periodicidade. Isto porque, a dinâmica populacional de plantas daninhas é, em geral, proveniente do resultado dos impactos causados por certas práticas culturais como, por exemplo, àquelas que promovem a inversão das camadas do solo, e da variabilidade temporal em números de indivíduos (Freckleton e Watkinson, 2002); sendo assim, é provável que a ocorrência de uma dinâmica caótica seja mínima (Cousens e Mortimer, 1995; Freckleton e Watkinson, 2002).

\subsubsection{Sistema de equações a diferenças não lineares}

O método apresentado para obtenção de informações a respeito da natureza das soluções de (1.2) foram desenvolvido para equações únicas. Para sistemas de $n$ equações a diferenças, com $n$ arbitrário, este método deve ser estendido. Logo, é necessário utilizar a expansão de série de Taylor para funções de $n$ variáveis para se obter um sistema de equações linearizado. Por simplicidade de notação, apresenta-se o caso em que $n=2$.

\section{Condição para a estabilidade de soluções de equilíbrio com $n=2$}

Considere que duas variáveis independentes $x$ e $y$ são relacionadas pelo sistema de equações

$$
x_{t+1}=f\left(x_{t}, y_{t}\right)
$$




$$
y_{t+1}=g\left(x_{t}, y_{t}\right)
$$

onde $f$ e $g$ são funções não lineares. A solução de equilíbrio $\left(x_{e}, y_{e}\right)$ satisfaz

$$
\begin{aligned}
& x_{e}=f\left(x_{e}, y_{e}\right) \\
& y_{e}=g\left(x_{e}, y_{e}\right) .
\end{aligned}
$$

Expandindo $f$ em série de Taylor, obtém-se

$$
f\left(x_{e}+\tilde{x}, y_{e}+\tilde{y}\right)=\left.f\left(x_{e}, y_{e}\right) \frac{\partial f}{\partial x}\right|_{x_{e}, y_{e}} \tilde{x}+\left.\frac{\partial f}{\partial y}\right|_{x_{e}, y_{e}} \tilde{y}+\cdots
$$

Os mesmos cálculos são realizados para expandir $g$ em série de Taylor.

Assim, analogamente, ao caso de funções de uma variável, obtém-se

$$
\begin{aligned}
\tilde{x}_{t+1} & =a_{11} \tilde{x}_{t}+a_{12} \tilde{y}_{t} \\
\tilde{y}_{t+1} & =a_{21} \tilde{x}_{t}+a_{22} \tilde{y}_{t} .
\end{aligned}
$$

onde a matriz $A$ de quatro componentes,

$$
A=\left(\begin{array}{ll}
a_{11} & a_{12} \\
a_{21} & a_{22}
\end{array}\right)=\left(\begin{array}{ll}
\left.\frac{\partial f}{\partial x}\right|_{x_{e}, y_{e}} & \left.\frac{\partial f}{\partial y}\right|_{x_{e}, y_{e}} \\
\left.\frac{\partial g}{\partial x}\right|_{x_{e}, y_{e}} & \left.\frac{\partial g}{\partial y}\right|_{x_{e}, y_{e}}
\end{array}\right)
$$

é chamada matriz Jacobiana do sistema de equações (1.16). Freqüentemente encontra-se a seguinte notação matricial representando o sistema (1.19)

$$
\tilde{x}_{t+1}=A \tilde{x}_{t},
$$

onde $\tilde{x}_{t}=\left(\begin{array}{c}\tilde{x}_{t} \\ \tilde{y}_{t}\end{array}\right)$.

O sistema (1.16) foi reduzido a um sistema linear de equações para o estado na proximidade do estado de equilíbrio $\left(x_{e}, y_{e}\right)$. Então, é possível determinar a estabilidade de $\left(x_{e}, y_{e}\right)$ através dos seguintes passos:

1. Encontre o polinômio característico de (1.19) calculando 


$$
\Delta(\lambda)=\operatorname{det}(A-\lambda I)=0
$$

O resultado é uma equação quadrática da forma

$$
\lambda^{2}-\beta \lambda+\gamma=0
$$

onde $\beta=a_{11}+a_{22}, \gamma=a_{11} a_{22}-a_{12} a_{21}$.

2. Determine se as raízes de (1.23) são menores que 1 , isto é, $\left|\lambda_{i}\right|<1, i=1,2$.

Se a resposta para o item 2 for afirmativa, pode-se concluir que os desvios do ponto de equilíbrio decrescem, isto é, o equilíbrio é estável. No caso em que $n=2$, é suficiente testar se a seguinte condição é satisfeita

$$
\left(x_{e}, y_{e}\right) \text { é solução de equilíbrio estável de (1.16) se e só se } 2>1+\gamma>|\beta| \text {. }
$$

onde $\gamma$ e $\beta$ são os coeficientes do polinômio característico (1.23).

Condição para a estabilidade de soluções de equilíbrio com $n$ arbitrário

Seja

$$
\Delta(\lambda)=\lambda^{n}+a_{1} \lambda^{n-1}+a_{2} \lambda^{n-2}+\cdots+a_{n-1} \lambda+a_{n}
$$

o polinômio característico de grau $n$ associado ao sistema de $n$ equações a diferenças. As técnicas de análise de estabilidade de soluções de equilíbrio, como a apresentada para $n=2$, são semelhantes para sistemas maiores. Ou seja, todas as raízes de (1.24) devem satisfazer

$$
\left|\lambda_{i}\right|<1, \quad i=1, \cdots, n
$$

\subsubsection{Método gráfico recursivo para visualizar soluções de equações a diferença de primeira ordem}

Um meio alternativo de descrever a trajetória de equações a diferença de primeira ordem do tipo (1.2) é na forma de um mapa de gerações em que a curva das densidades de gerações sucessivas são 'plotadas' umas contra as outras (isto é, $x_{t+1}$ versus $x_{t}$ ). 
Segundo Cousens e Mortimer (1995), os mapas de gerações são particularmente úteis por possibilitar predições gráficas sobre a dinâmica populacional. Esta simples técnica

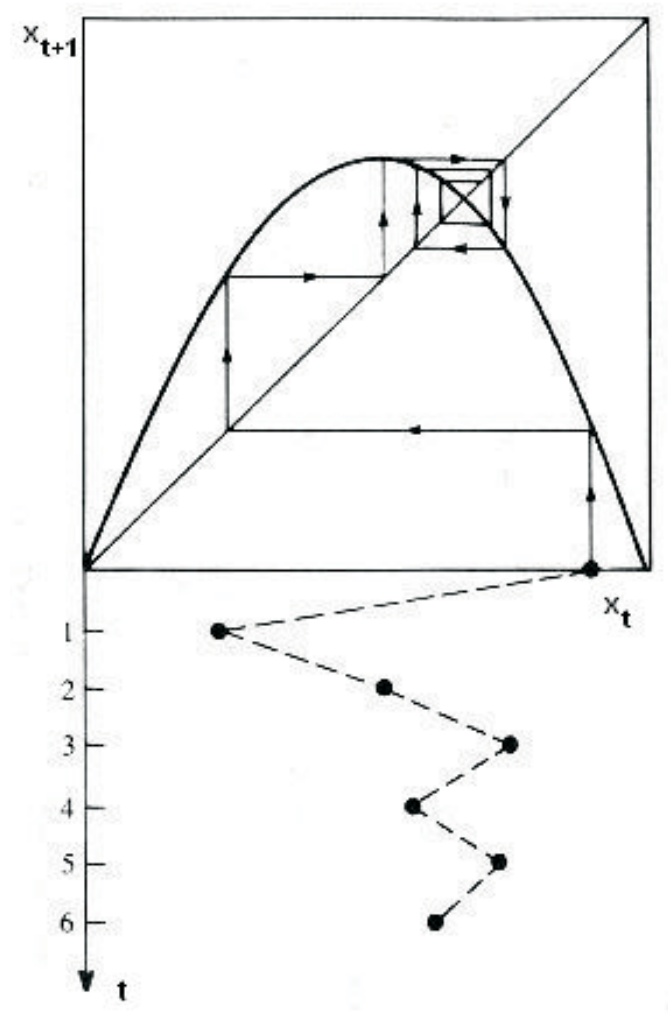

Figura 1.3: Método gráfico recursivo ('cobwebbing') para determinar o nível populacional no decorrer do tempo (Edelstein-Keshet, 1988). A parábola $x_{t+1}=f\left(x_{t}\right)$ e a linha $x_{t+1}=x_{t}$ são usadas para obter os valores sucessivos de $x_{t}, t=0,1,2, \cdots$. Abaixo mostra-se o mapa de gerações obtido, onde o eixo vertical representa o tempo $t$.

para visualizar as soluções de (1.2) é conhecida como 'cobwebbing'. A Figura 1.3 ilustra tal procedimento, segundo Edelstein-Keshet (1988), e consiste em obter o mapa de gerações e então traçar uma linha reta passando pela origem que satisfaça $x_{t+1}=x_{t}$. Pontos acima desta linha indicam um acréscimo de densidade no mapa de gerações e pontos abaixo um decréscimo. Para um dado valor $x_{t}$, por exemplo, traça-se uma linha vertical (para baixo ou para cima) até a curva; a partir deste ponto, traça-se uma linha horizontal até a reta $x_{t+1}=x_{t}$, donde outra linha vertical é traçada até a curva, e assim por diante (Edelstein-Keshet, 1988; Cousens e Mortimer, 1995). Este processo é equivalente a 'alternar-se' entre as curvas $x_{t+1}=f\left(x_{t}\right)$ e $x_{t+1}=x_{t}$ e coincide com o 
ponto de equilíbrio de (1.4). Um mapa de gerações assim obtido, pode ser usado para informar a estabilidade do sistema e os efeitos causados por variações nos parâmetros. 


\section{Capítulo 2}

\section{A dinâmica populacional de plantas daninhas e sua interferência em culturas agrícolas}

Uma população é um grupo de indivíduos da mesma espécie e que possue a mesma probabilidade de interagir com outros indivíduos. Em qualquer dado instante, uma população possui um conjunto de características (estado) que podem ser usadas para descrever a população. Estas características incluem os limites espaciais, tamanho total (número de indivíduos), densidade (número de indivíduos por área) e composição genética e fenotípica (por exemplo, distribuição por freqüência de tamanhos de plantas dentro da população) da população (Cousens e Mortimer, 1995). Neste trabalho, considera-se que a densidade de sementes no solo é a variável de estado do sistema populacional (veja Capítulo 1, Seção 1.5).

A partir do momento em que uma nova população é fundada, talvez proveniente de um único indivíduo, variações no estado da população irão ocorrer. É com essas variações que se está preocupado, ou seja: com a dinâmica da população.

A população pode variar em tamanho como resultado de fatores intrínsecos (interações intra-específicas) e extrínsecos (interações interespecíficas, fatores de gerenciamento e controle e clima). Diz-se que o crescimento de uma população é independente da den- 
sidade se as taxas de mortalidade e produtividade no desenvolvimento por indivíduo não dependem do tamanho total da população, do contrário o crescimento é dito ser dependente da densidade. É fato que todo o crescimento populacional é dependente da densidade (i.e., tanto a situação de 'independência' ou 'dependência' é determinada pelo número de indivíduos por área), entretanto tal subdivisão é utilizada, para fins de estudo e pesquisa, por diversos autores (por exemplo, Edelstein-Keshet (1988), Cousens e Mortimer (1995), Sakai (2001) entre outros) e também será adotada neste texto.

A seqüência de estádios de desenvolvimento na vida de uma população de plantas daninhas pode ser denominada ciclo de vida (ou tabela de vida). Por exemplo, o ciclo de vida da população de plantas daninhas anuais começa com a germinação no solo, seguida por crescimento vegetativo, floração, produção de sementes, disseminação de sementes, sobrevivência ou mortalidade de sementes no solo e, germinação no ciclo seguinte (Sakai, 2001). Características do ciclo de vida de uma planta individual ou espécie podem determinar sua habilidade competitiva; estas incluem: tamanho da semente, tamanho da plântula, tempo de emergência e tamanho da planta. Todas essas características influenciam ou refletem a habilidade de uma planta individual em capturar recursos (Park et al., 2003).

A divisão do ciclo de vida da planta em um número pequeno de simples categorias possibilita avaliar os ganhos/perdas (fluxos) em cada estádio, bem como investigar os fatores que causam essas variações. Logo, é possível indicar os estádios influenciados pelo processo populacional intrínseco e pelo conjunto de eventos ambientais extrínsecos, como a indução à mortalidade através do controle humano.

Os principais objetivos de pesquisa, a biologia da espécie, bem como o nível exigido de detalhes determinam a maneira de considerar o ciclo de vida da planta. Todavia, a divisão de um processo de desenvolvimento contínuo em estádios discretos no tempo é de difícil concepção e inevitavelmente haverá um certo grau de arbitrariedade. Por exemplo, as perdas de sementes podem ocorrer entre a maturação e entrada no solo. Em geral, considera-se que a semente entra na 'fase da semente' quando é capaz de sobreviver independente da planta progenitora; já a 'fase da planta' se dá após esta ter sido recrutada do banco de sementes, no ponto em que uma plântula é observada na superfície do solo.

Neste capítulo apresentam-se as práticas de controle de populações plantas daninhas 
em sistemas agrícolas, as etapas envolvidas na regulação destas populações, os meios de propagação e dispersão de espécies daninhas e a sua interferência em culturas agrícolas.

\subsection{Práticas de controle de plantas daninhas em culturas agrícolas}

A seleção imposta pela natureza tornou as plantas daninhas mais aptas que as cultivadas, colocando-as em vantagem na competição por recursos vitais. Contudo, em muitos dos habitats em que as plantas daninhas surgem, medidas de atuação são feitas para controlá-las. Tecnicamente, o controle é qualquer prática adotada na redução da população de plantas daninhas a fim de impedir sua competição com as plantas cultivadas, diminuindo, conseqüentemente, seus efeitos prejudiciais na produção e na qualidade do produto (Krejci e Lourenço, 1986). A seguir, apresenta-se, segundo Correia e Rezende (2002), algumas características do manejo preventivo, cultural, mecanizado, biológico e químico.

\section{Controle preventivo}

O manejo preventivo envolve a utilização de sementes puras e programas de redução de sementes de plantas daninhas na entressafra (mecânico e/ou químico) e a rotação de culturas. Associar a rotação de culturas com o sistema de semeadura direta tem sido a prática mais eficaz do ponto de vista do manejo de plantas daninhas; o não-revolvimento do solo mantém muitas sementes no perfil a profundidades nas quais não germinam, e a palha ou restos vegetais da cultura proporcionam a cobertura da superfície que além de evitar a germinação de diversas espécies também protege o solo. Havendo cultura na entressafra, em sucessão àquela, qualquer que seja o manejo adotado já é um fator positivo de redução de sementes.

\section{Controle cultural}

O manejo cultural se faz por meio da escolha de cultivares, do manejo populacional (consiste no arranjo espacial das plantas da cultura buscando-se o potencial produtivo do cultivar e reduzindo-se o espaço disponível a outras plantas indesejadas), de práticas fitotécnicas (especialmente as relacionadas com fertilidade do solo) e da rotação de 
culturas.

\section{Controle mecanizado}

O manejo mecânico inclui a capina manual e a utilização de implementos agrícolas (como roçadeira, rolo-faca e etc.). A capina manual é importante para um programa de catação de espécies em disseminação.

\section{Controle biológico}

São dois os métodos de controle biológico: o clássico (ou inoculativo) e o micoherbicida (ou inundativo). O método inundativo aplica-se melhor à soja e a outras culturas anuais cujo ambiente é freqüentemente perturbado pelo manejo do solo e da cultura. Tal método preconiza o uso de fungos, que após terem sido multiplicados e formulados, são aplicados como um herbicida qualquer.

\section{Controle químico}

O manejo químico ainda é o mais utilizado. As aplicações de herbicidas podem ser feitas antes da semeadura (somente no sistema de plantio convencional), após a semeadura e antes da emergência das plantas daninhas (pré-emergência) e após a emergência das plantas daninhas e da cultura (pós-emergência).

\subsection{Fases das plantas daninhas envolvidas na regulação populacional}

Se todos os fatores extrínsecos permanecem constantes, a população pode mudar devido a sua própria dinâmica intrínseca. Essas mudanças ocorrem devido ao processo regulatório interno originado a partir de interações entre indivíduos dentro da população (Cousens e Mortimer, 1995). Por exemplo, enquanto a densidade da população de plantas daninhas for baixa, cada indivíduo sofrerá pouca interferência dos outros e a população continuará aumentando sob uma taxa constante. Entretanto, este aumento de plantas daninhas influencia alguns fatores ecológicos como taxa de mortalidade e nascimento, fecundidade e produção. Deste modo, um acréscimo na densidade inicial 
de plantas resultaria em alta taxa de mortalidade e baixa taxa de crescimento, baixa fecundidade e decréscimo de produção de sementes (Sakai, 2001), fazendo com que a população alcance seu 'limite superior de densidade', ou seja, o nível de equilíbrio (Cousens e Mortimer, 1995). Este argumento presume que os recursos disponíveis no sistema para o crescimento da população são finitos.

\subsubsection{Semente}

A semente é um estádio latente no ciclo de vida da planta, capaz de sobreviver sob condições adversas e baixos níveis de atividade metabólica. Um dos principais mecanismos de sobrevivência das plantas daninhas em ambientes constantemente perturbados, em especial plantas anuais, é a alta produção de sementes (Lacerda, 2003). Além disso, a maioria das espécies daninhas possuem sementes dotadas de formas geométricas especiais que favorecem sua dispersão pelos agentes do meio (Lorenzi, 2000).

Enquanto a maioria das plantas cultivadas não conseguem produzir mais que algumas dezenas de sementes por planta, um único exemplar das principais espécies daninhas chega a produzir centenas de milhares de sementes: em termos médios uma planta daninha é capaz de produzir entre 50 e 150g de sementes (Lorenzi, 2000); fato que atribui importância ao estudo da dinâmica do banco de sementes (Freitas, 1990).

Banco de sementes é o nome atribuído à reserva destas ou de propágulos vegetativos viáveis no solo e que são capazes de recompor uma vegetação (Carmona, 1992; GonzalezAndujar, 1997; Christoffoleti e Caetano, 1998). A caracterização do banco de sementes fornece um histórico da influência das práticas de manejo adotadas nas áreas de cultivo, como também possibilita a previsão do potencial de futuras infestações (Freitas, 1990; Forcella, 1992; Cousens e Mortimer, 1995; Buhler et al., 1997; Christoffoleti e Caetano, 1998).

Segundo Monquero (2003), normalmente o tamanho do banco de sementes das plantas daninhas é comparativamente maior em áreas agrícolas do que em áreas não agrícolas. Esta tendência é devido à estratégia de sobrevivência das plantas daninhas de apresentar alta prolificidade em ambientes perturbados (plasticidade ambiental).

As características genéticas (fatores intrínsecos) da semente determinam o período de longevidade, já a interação entre os fatores genéticos e ambientais determina o período 
de viabilidade da semente, ou seja, o período em que a semente realmente permanece viva (Lacerda, 2003).

A dormência é um dos principais mecanismos de preservação de espécies daninhas em bancos de sementes, distribuindo a germinação ao longo do tempo (Freitas, 1990; Lacerda, 2003). Isto porque, a regeneração de plantas via sementes requer que uma porção das sementes contidas no banco seja fisiologicamente capaz de germinar junto as condições ambientais apropriadas (Buhler et al., 1997). Por exemplo, os fatores intrínsecos como a impermeabilidade da casca, presença de inibidores bioquímicos na semente, imaturidade do embrião associado aos fatores extrínsecos como água e temperatura impedem a germinação (Lacerda, 2003). Isto pode garantir a sobrevivência de certas espécies na forma de sementes, sob circunstâncias adversas, mesmo quando a população de plantas é eliminada completamente (Carmona, 1992). Segundo Monquero (2003), as principais causas da dormência são: impermeabilidade do tegumento a água e/ou oxigênio, embrião dormente, restrição mecânica ao desenvolvimento do embrião, imaturidade fisiológica do embrião, e presença de inibidores químicos. Algumas sementes para germinar precisam passar por processos de 'quebra de dormência'.

A germinação das sementes é resultado do balanço entre condições ambientais favoráveis e características intrínsecas das sementes, compreendendo uma seqüência ordenada de atividades metabólicas, resultando no desenvolvimento do embrião, originando assim, uma plântula (Monquero, 2003). A variabilidade de respostas germinativas ligada à diversidade dos estados de dormência das sementes que permanecem na superfície ou enterradas no solo, torna difícil a previsão das infestações de culturas (Freitas, 1990).

Para Freitas (1990), a dormência deve ser levada em conta na escolha de técnicas de controle, tendo em vista que é de interesse conhecer o possível período de tempo envolvido até a quebra da dormência da semente. No entanto, em condições de campo a dormência se torna um problema de difícil solução, pois os métodos que são empregados para quebra de dormência em laboratórios não são práticos e adequados em áreas agrícolas (Monquero, 2003).

As práticas culturais, como o preparo do solo, podem promover a dormência de algumas espécies e provocar a quebra de dormência em outras, bem como influenciar a distribuição vertical de sementes no solo, entre outros fatores. A modelagem da distribuição vertical do banco de sementes pode ser uma ferramenta para indicar estratégias 
de gerenciamento pois, segundo Freitas (1990), sementes colocadas em maiores profundidades abaixo da superfície do solo conservam melhor a sua capacidade de germinar. De uma forma geral, os métodos que não promovem a inversão de camadas do solo como o plantio direto, por exemplo, permitem que a maioria das sementes permaneçam próximas à superfície do solo, acelerando o decréscimo das sementes recém derrubadas por facilitar a predação, a perda de viabilidade (expondo as sementes à variações de temperatura e umidade) e auxiliar na quebra da dormência dessas (Carmona, 1992). Segundo Cousens e Mortimer (1995), a maioria dos estudos mostram que a germinação declina monotonicamente com a profundidade para a maioria destes casos a relação

$$
g=g_{s} e^{-g_{d} D}
$$

pode ser verificada, com $g$ sendo a proporção total de germinação; $D$ a profundidade; $g_{s}$ a proporção de germinação na superfície do solo; e $g_{d}$ o parâmetro que descreve a taxa de declínio da germinação com a profundidade.

A aplicação de herbicidas também pode influenciar as espécies que compõem o banco (Monquero, 2003) por causar grande impacto sobre a flora de plantas daninhas, mas quando utilizados por um longo período podem permitir que certas espécies se adaptem (Lacerda, 2003; EMATER, 2002). Até mesmo a rotação de culturas em determinada área pode resultar em alterações qualitativas e quantitativas no banco de sementes por promover variações nos modelos de competição plantas daninhas versus plantas cultivadas, nas interferências alelopáticas das plantas daninhas, nas condições do microambiente e nas estratégias de manejo de plantas daninhas (Buhler et al., 1997). Muitos modelos descrevem a relação matemática entre a mortalidade e/ou os efeitos letais de um herbicida sobre a produção de sementes ou de plântulas de daninhas (Cousens e Mortimer, 1995; Wu, 2001; Kim et al., 2002; Diggle et al., 2003). Alguns destes modelos são apresentados posteriormente no Capítulo 3.

Enfim, muitos processos estão envolvidos na geração e regulação do banco de sementes no solo. Práticas de manejo possuem maior impacto nestes processos e representam oportunidades para regulação das características do banco de sementes nos sistemas de produção agrícola (Buhler et al., 1997). Para Carmona (1992), a aceleração da taxa de decréscimo de sementes no solo, que naturalmente é lenta o suficiente para manter indivíduos invasores durante alguns anos, poderia contribuir largamente para programas 
de controle de plantas daninhas.

A matemática, como um método formal de montar e manipular o conhecimento quantitativo, pode ser usada para descrever a maneira pela qual as variáveis ou os processos são relacionados. Por exemplo, é possível descrever a relação entre o número de sementes produzidas por planta e o peso da planta por

$$
s=z w^{k}
$$

onde $s$ é o número de sementes produzidas por planta (produtividade de sementes); $w$ o peso da planta; e $z$ e $k$ são parâmetros (Cousens e Mortimer, 1995).

Também é possível descrever a relação entre a densidade de sementes $X$ e a densidade de planta $Y$ por uma hipérbole retangular

$$
X=\frac{r Y}{(1+D Y)}
$$

Se a densidade da cultura for considerada constante, como uma interferência aditiva, a expressão (2.3) pode ser usada, onde $Y$ é a densidade de plantas daninhas; $Y_{c}$ a densidade de plantas da cultura; e os parâmetros são: $r=\frac{s_{\max }}{\left(1+a \alpha Y_{c}\right)}$ o número de sementes por planta em baixa densidade; $D=\frac{a}{\left(1+a \alpha Y_{c}\right)} ; s_{\max }$ a produção de sementes de uma planta daninha isolada (i.e., sem competição intra-específica); $\alpha$ representa o efeito relativo de uma planta da cultura na comparação com o efeito de uma planta daninha; e $a$ um coeficiente que descreve a variação do rendimento de acordo com a densidade de plantas (reflete o grau de competição intra-específica). A relação ' $r / D$ ' representa o número de sementes produzidas por unidade de área sob alta densidade de plantas daninhas (Cousens e Mortimer, 1995)

A técnica mais utilizada na determinação do número de sementes é a estimativa da emergência de plântulas (ou estimativa da flora emergente) a partir de amostras de solo, utilizando certas técnicas, de modo a assegurar as condições ambientais favoráveis para o surgimento das plântulas. Existem também métodos de separação das sementes do solo para sua posterior identificação, como por exemplo, utilizando peneiras para a obtenção de grandes sementes (Lacerda, 2003). 


\subsubsection{Planta}

Segundo Lorenzi (2000), para fins de estudo, as plantas daninhas podem ser classificadas de acordo com o interesse:

- Como plantas 'anuais', 'bianuais' e 'perenes'para fins de controle e ou erradicação;

- Como espécies de 'folhas largas'(ou latifoliadas) e 'estreitas' para efeito de controle químico;

- Segundo sua textura como plantas 'herbáceas', 'arbustivas' e 'arbóreas'. As herbáceas compreendem a maioria das espécies encontradas em lavouras anuais e perenes e geralmente são de ciclo anual, já as arbustivas e arbóreas são as mais encontradas em pastagens e compreendem aquelas plantas de médio e grande porte; e

- De acordo com o meio em que vivem como plantas 'terrestres', 'aquáticas' e 'parasíticas'.

A classificação mais indicada para fins de controle é a que se baseia na duração do ciclo vital das plantas. De acordo com Lorenzi (2000), as espécies anuais são aquelas que germinam e completam o ciclo de maturação das sementes dentro da mesma estação de crescimento (60 a 140 dias); as bianuais germinam e crescem até a formação de folhas em roseta no primeiro ano completando o ciclo no segundo ano; e as perenes vivem indefinidamente durante muitos anos.

Em situações agronômicas, as espécies daninhas anuais representam a maior ameaça às perdas de produção na lavoura e elevação dos custos de controle (Buhler et al., 1997), pois são as principais constituintes do banco de sementes, normalmente alcançando $95 \%$ do total (Martins e Silva, 1994).

Os ganhos nesta 'fase-planta', em espécies que não possuem a fase de reprodução vegetativa, serão determinados a partir de sementes que obtiveram sucesso de germinação. No entanto, desde que muitas sementes possam germinar mas não produzir plântulas com sucesso, as perdas do banco de sementes e os ganhos de novas plântulas podem diferir. O estabelecimento de uma planta depende, dentre outros fatos, da germinação da semente e da densidade em que a população se encontra. O nível de mortalidade de plantas é resultado do processo populacional extrínseco (fatores independente da 
densidade) e intrínseco (fatores dependente da densidade), bem como a interação de ambos os fatores.

\section{Taxa de mortalidade independente da densidade de plantas daninhas}

As práticas de plantio e os herbicidas estão entre as causas mais importantes de mortalidade independente da densidade. Além disso, as condições climáticas contribuem para a mortalidade em habitats naturais e perturbados.

A probabilidade da morte em conseqüência de práticas de manejo é provável ser primeiramente uma função da eficiência das propriedades do solo e das condições climáticas durante e após o cultivo; se realizada eficazmente são capazes de matar até $100 \%$ das plantas que emergem nesse período (Cousens e Mortimer, 1995).

As aplicações de herbicidas podem ser categorizadas de acordo com o estádio de desenvolvimento da cultura ou da planta daninha em que são aplicados (Krejci e Lourenço, 1986; Cousens e Mortimer, 1995; Correia e Rezende, 2002); sendo que a mortalidade irá depender particularmente da espécie daninha, pois muitos herbicidas podem seletivamente matar algumas plantas e deixar outras (Cousens e Mortimer, 1995; Monquero, 2003). A expectativa de que o controle químico tenha $100 \%$ de eficiência é ilusória, pois algumas plântulas podem emergir atrasadas e escapar do herbicida, outras podem ser protegidas por plantas da cultura, bem como jatos do dispositivo de aplicação do produto podem não atingir certas plantas. Condições climáticas, como chuvas e temperatura também influenciam no desempenho químico.

O controle biológico pode ser independente ou dependente da densidade. Por exemplo, o método que preconiza o uso de agentes patogênicos que após multiplicação e formulação são aplicados como um herbicida qualquer é denominado inundativo (Correia e Rezende, 2002) e é independente da densidade (Cousens e Mortimer, 1995). O herbicida formulado a partir desse processo é denominado bioherbicida. Para Cousens e Mortimer (1995), o uso de agentes patogênicos podem obter êxito de 95 a 100\% de mortalidade.

Extremos de temperatura (calor, seca, frio) são freqüentemente causas de mortalidade de plantas. Dentre as espécies mais tolerantes, a sobrevivência pode depender das diferentes temperaturas e dos estádios de desenvolvimento das plantas. 


\section{Taxa de mortalidade dependente da densidade de plantas daninhas}

Numa população de plantas daninhas desenvolvendo-se a partir de plântulas, a primeira redução de plantas é no crescimento; somente depois, se a interferência se torna suficientemente intensa é que irá ocorrer mortalidade de plantas devido ao 'efeito densidade'. A mortalidade dependente da densidade é freqüentemente denominada 'self-thinning'. Formalmente, é a inter-relação entre a mortalidade e plasticidade do tamanho da planta.

Mortalidade causada por herbicidas usualmente é considerada independente da densidade de plantas. Porém, ao menos em tese, a indução à mortalidade por herbicidas pode ser dependente da densidade. Se um herbicida atua sobre as plantas daninhas próximo à germinação ou logo após a emergência, a taxa de mortalidade depende da eficácia com a qual o herbicida alcança o alvo e dos fatores ambientais. Isto porque as plântulas ainda dependem das reservas da sementes, o tamanho destas pode não ser afetado pela densidade populacional e todas as plantas podem ter probabilidade similar de morte. Entretanto, se um herbicida é aplicado depois que o tamanho da planta daninha sofre influência com a interferência de outras plantas, seus efeitos podem então ser diretamente dependentes da densidade de plantas (Cousens e Mortimer, 1995). Assim, em baixa densidade cada planta daninha terá uma similar probabilidade de morte independente da densidade. Também, em densidades muito elevadas, onde há intensa interferência, cada planta pode ser pequena e sem ramificações, novamente resultando numa baixa variação de tamanho e, conseqüentemente, na mortalidade por herbicidas independente da densidade. Porém, em densidades intermediárias a variação no tamanho das plantas pode ser maior devido a competição intra-específica o que, provavelmente, favorece a atuação do herbicida em diferentes estádios de desenvolvimento e tamanhos de plantas. Logo, a mortalidade devido a herbicidas pode ser menor em densidades intermediárias.

Outra causa de mortalidade dependente da densidade se dá através do controle biológico clássico ou inoculativo, onde um agente exótico é solto e desenvolve-se a partir das plantas daninhas da área. Desde que a abundância de agentes e, conseqüentemente, a mortalidade causada dependem da disponibilidade de plantas daninhas, a mortalidade é dependente da densidade. Devido a natureza particular das interações daninha/agente, algumas resultam diretamente da mortalidade de plantas daninhas, outras podem apenas reduzir a fecundidade ou diminuir o número de sementes produzidas (Cousens e Mortimer, 1995). 


\subsubsection{Reprodução vegetativa}

Algumas importantes plantas daninhas possuem a habilidade de se reproduzir vegetativamente (Lorenzi, 2000). Estruturas vegetativas são formadas acima e no solo e atuam como um banco de meristemas (embriões) semelhante a um banco de sementes. Estes são capazes de produzir propágulos vegetativos (ou brotos) quando estimulados a isso. A importância relativa da reprodução vegetativa e sexual para a produção total de propágulos varia, mas é freqüentemente encontrada em espécies que as sementes são menos importante para a manutenção da população que as estruturas vegetativas (Cousens e Mortimer, 1995).

As estruturas de reprodução vegetativa são morfologicamente diversas e incluem bulbos, tubérculos, pseudo-bulbos e raízes. Em geral, a produção dos propágulos é dependente da densidade e pode ser reduzida sob interferência de outras espécies.

Existem poucos trabalhos que relatam a dependência da densidade nas espécies que apresentam reprodução vegetativa: a maioria destes são estudos a curto prazo de progênie de um único tubérculo, ou bulbo, ou fragmento de raiz. Modelos dinâmicos matriciais para populações de plantas daninhas que se reproduzem tanto por sementes como por estruturas vegetativas são discutidos no Capítulo 3.

\subsection{Disseminação de espécies daninhas e sua interferência em culturas agrícolas}

A variabilidade e a densidade de uma população de sementes no solo em um dado momento é resultado do balanço de entrada e saída de sementes no solo (Lacerda, 2003); a Figura 2.1 representa essa dinâmica segundo Carmona (1992). A entrada de novas sementes no banco é denominada 'chuva' de sementes.

A disseminação (dispersão) de uma planta daninha através de sementes agrícolas é o método mais rápido de infestação de uma grande área num curto espaço de tempo. Segundo Lorenzi (2000), a tiririca (Cyperus rotundus) foi, provavelmente, introduzida dessa forma quando chegaram as primeiras sementes agrícolas no Brasil. De uma forma geral, as plantas daninhas são disseminadas, principalmente, pelo homem, por animais, pela água e pelo vento (Lorenzi, 2000; Lacerda, 2003). Em uma comunidade, o meio 


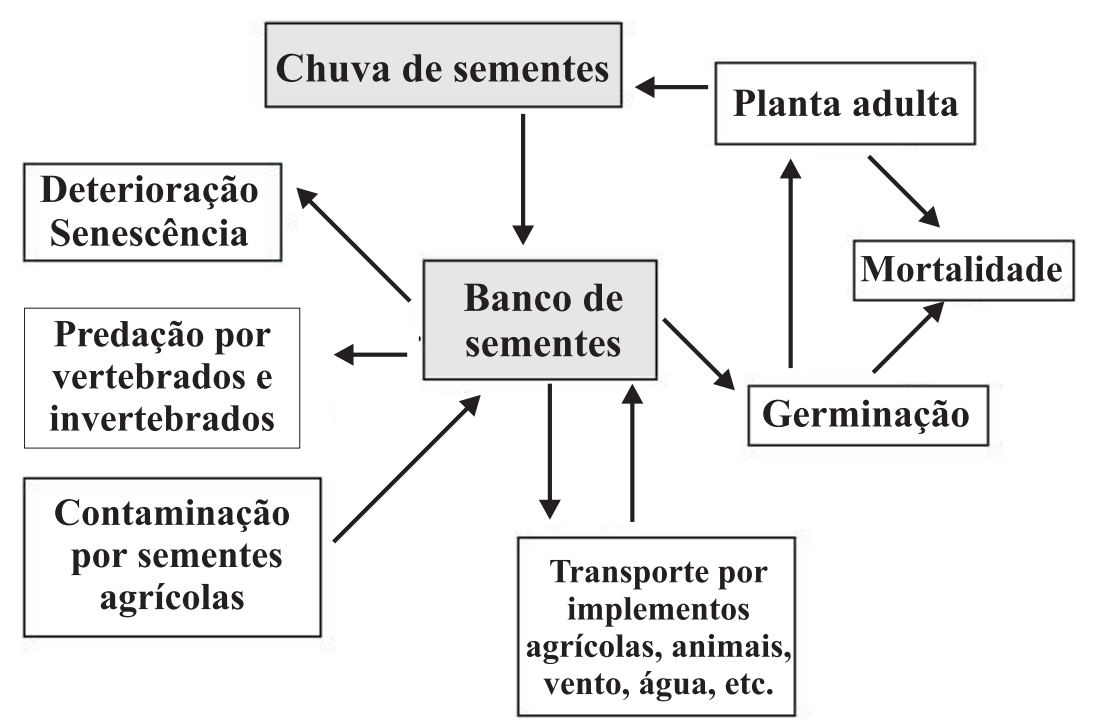

Figura 2.1: Dinâmica de uma população de sementes no solo como resultado do balanço entre entrada de novas sementes por emigração e reprodução e perdas por germinação, deterioração, predação, agentes patogênicos e imigração.

de dispersão local predomina, apesar de outras fontes longínquas possam contribuir na estrutura da vegetação (Lacerda, 2003).

A interação entre espécies daninhas e culturas freqüentemente tem sido descrita como 'competição' (Stoller et al., 1987). De fato, a competição é apenas um dos componentes da interação entre plantas daninhas e cultivadas. A interferência de plantas daninhas pode ocorrer através dos seguintes mecanismos: competição, alelopatia, interferência parasitária, hospedeiros intermediários (Stoller et al., 1987; Lorenzi, 2000). De acordo com os autores, a competição é a disputa por recursos vitais às plantas; a alelopatia é a inibição química exercida por uma planta sobre o desenvolvimento da outra; a interferência parasitária é um processo pelo qual uma planta se nutre da seiva da outra e; a interferência indireta se dá quando uma planta daninha hospeda animais herbívoros ou microorganismos patogênicos que atacam a cultura. Tanto a alelopatia como a interferência indireta nas culturas são fatos comuns, mas difíceis de serem quantificados (Lorenzi, 2000).

Segundo Lorenzi (2000), a interferência das plantas daninhas sobre as culturas agrícolas através da competição e alelopatia se traduzem em prejuízos diretos à agricultura; na ordem de 30 a $40 \%$ de alimentos deixam de ser produzidos anualmente. A relação de competição entre cultura e plantas daninhas pode ser descrita, por exemplo, pelo 
modelo geral (3.7) com a taxa de crescimento populacional representada por (3.12), (3.13) ou (3.14), apresentados no Capítulo 3.

\subsection{Representação matemática da relação plantas daninhas versus cultivadas}

Para facilitar a escolha das estratégias de controle de plantas daninhas, são necessárias predições confiáveis dos efeitos das infestantes daninhas no rendimento da cultura (Kropff et al., 1992). Neste contexto, os modelos de perda de rendimento da cultura são de potencial importância no desenvolvimento de ferramentas para tomada de decisão em sistemas agrícolas. Além disso, tais modelos podem contribuir para a obtenção de parâmetros de modelos de reprodução de plantas daninhas a partir de dados que descrevam a perda de rendimento da cultura em função da densidade de plantas daninhas (Canner et al., 2002); fato que motiva o estudo dessa relação.

De um modo geral, modelos hiperbólicos podem ser utilizados tanto para descrever a perda de rendimento da cultura (Cousens, 1985a; Cousens, 1985b) como a produção de sementes (Cousens, 1991; Norris, 1992) em função da densidade de plantas daninhas. Uma fórmula simples e geral que descreve dados que sugerem uma hipérbole

$$
R_{e}=U_{R_{e}} \frac{Y}{Y 50_{R_{e}}+Y}
$$

onde $R_{e}$ é a resposta que está sendo descrita (por exemplo, produção de sementes por unidade de área ou perda de rendimento por unidade de área); $U_{R_{e}}$ é o limite superior da resposta $R_{e}$ quando a densidade de plantas daninhas $Y$ se aproxima do infinito; e $Y 50_{R_{e}}$ é a densidade em que $50 \%$ de $U_{R_{e}}$ é atingido.

Esta formulação do modelo hiperbólico facilita a interpretação dos dois parâmetros: $Y 50_{R_{e}}$ é um parâmetro de forma que descreve a escala horizontal nas mesmas unidades de densidade que $Y$, e $U_{R_{e}}$ descrevendo a escala vertical nas mesmas unidades da resposta $R_{e}$. A relação $\frac{U_{R_{e}}}{Y 50_{R_{e}}}$ descreve o limite da inclinação da curva quando $Y$ se aproxima de 0 (zero). Conseqüentemente, enquanto $Y 50_{R_{e}}$ aumenta com uma constante $U_{R_{e}}$, a inclinação inicial da curva diminui (Figura 2.2). Quando $U_{R_{e}}$ varia enquanto $Y 50_{R_{e}}$ permanece constante, as curvas resultantes diferem somente na escala 
do eixo - y, possuindo a mesma forma (Figura 2.3).

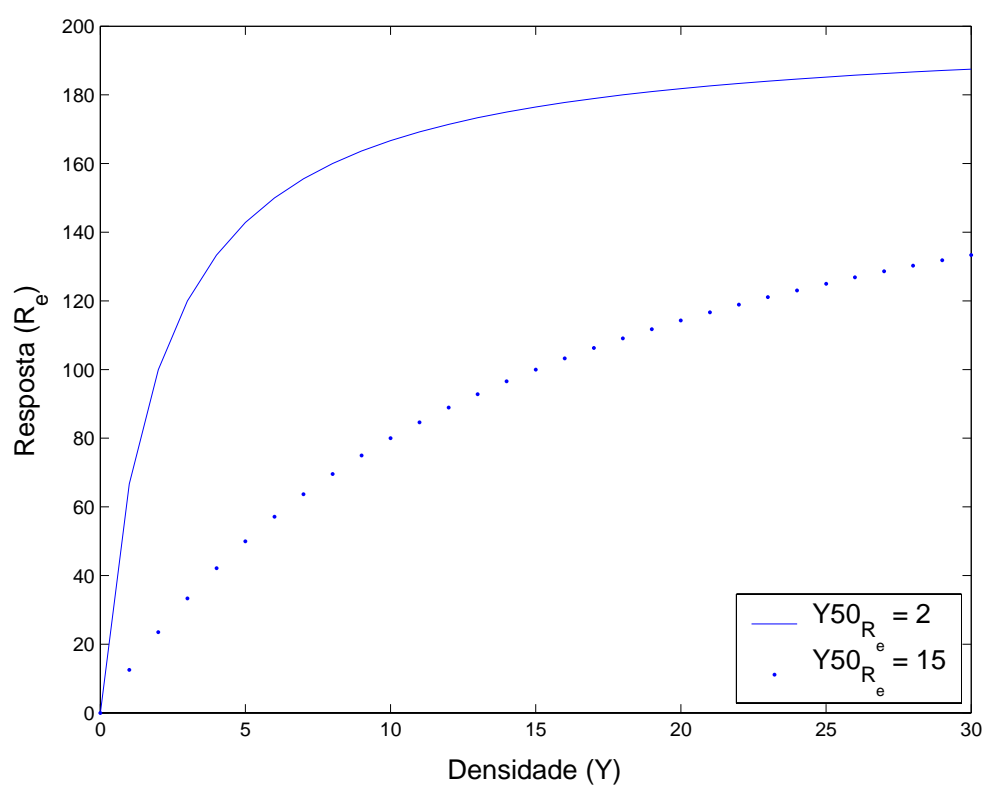

Figura 2.2: Resposta $R_{e}$ do modelo hiperbólico (2.4) com a variação do parâmetro de forma $Y 50_{R_{e}}$ (coeficiente de declividade) da expressão. Ambas as curvas possuem o mesmo valor $U_{R_{e}}=200$, mas, valores distintos de $Y 50_{R_{e}}$. A variação em $Y 50_{R_{e}}$ altera a forma das curvas para o mesmo valor de $U_{R_{e}} \cdot 50 \%=100$ (sem alterar a escala vertical).

A seguir, são apresentados modelos hiperbólicos: 1) de perda de rendimento da cultura em função da flora emergente e da época relativa de emergência das plantas daninhas e 2) de reprodução de plantas daninhas a partir de dados de perda de rendimento da cultura.

\subsubsection{Modelos de perda de rendimento da cultura}

Os modelos de perda de rendimento assumem, em geral, a forma da hipérbole retangular por esta descrever adequadamente a relação entre o rendimento da cultura e a densidade da planta daninha (Cousens, 1985a; Cousens, 1985b). Segundo Park et al. (2003), a popularidade do modelo hiperbólico em parte é devido à habilidade de satisfazer o que Cousens (1985a) julga ser as quatro verdades biológicas fundamentais na competição entre cultura e planta daninha: 1) existirá perda na ausência de plantas daninhas; 2) os efeitos do aumento do número de plantas daninhas será aditivo em baixas densidades; 3) o rendimento da cultura nunca pode exceder 100\%; e 4) existe uma resposta não linear de rendimento da cultura para altas densidade de plantas daninhas. 


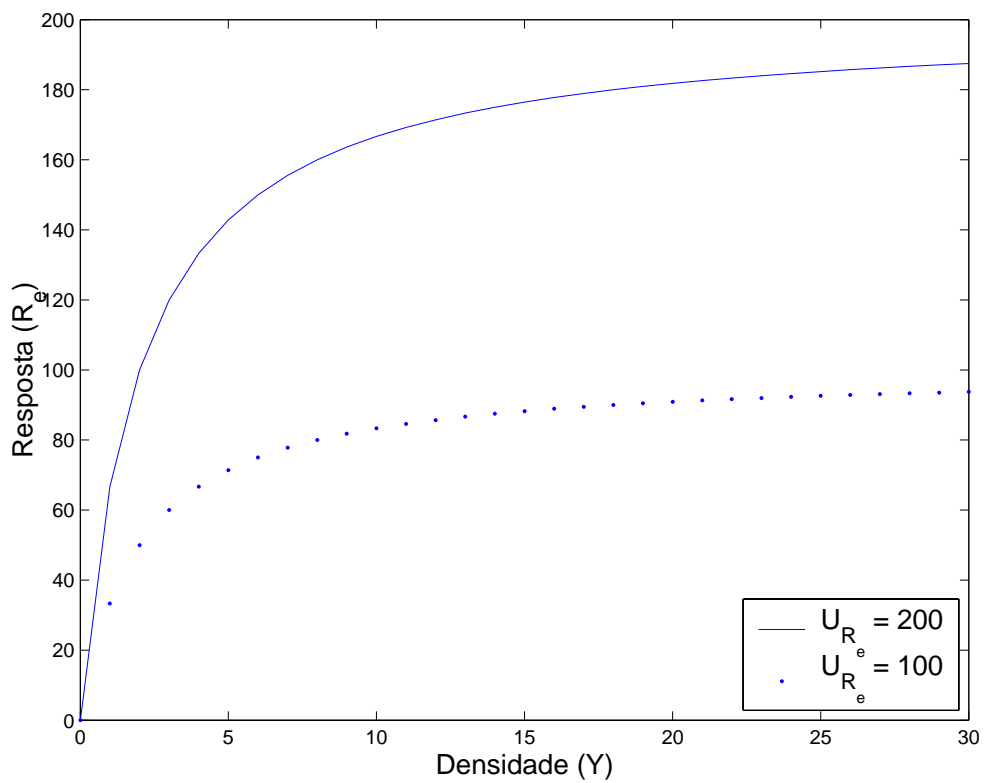

Figura 2.3: Resposta $R_{e}$ do modelo hiperbólico (2.4) com a variação do parâmetro $U_{R_{e}}$ (assíntota máxima) da expressão (2.4). Ambas as curvas têm o mesmo valor $Y 50_{R_{e}}=2$, mas, valores distintos de $U_{R_{e}}$. Há alteração para os valores de $U_{R_{e}} \cdot 50 \%$, logo, as curvas possuem a mesma forma mas são transladadas em relação ao eixo-y.

Cousens (1985a) mostrou que a relação entre perda de rendimento da cultura causada por uma única espécie daninha é bem descrita pela equação da hipérbole retangular, do tipo

$$
P_{r}=\frac{\rho Y}{1+\left(\frac{\rho}{\sigma} Y\right)}
$$

onde $P_{r}$ é a perda de rendimento para cada valor de densidade de planta daninha $Y$ $(\%) ; \rho$ pode ser interpretado como a inclinação inicial da curva, isto é, a quantidade de perda proporcional do rendimento da cultura por unidade de planta daninha por área quando a sua densidade se aproxima de zero; e $\sigma$ representa o limite superior de perda proporcional quando a densidade de plantas daninhas tende ao infinito. A relação ' $\rho / \sigma$ ' reflete o grau de competição intra-específica.

Intuitivamente, tem-se que $\rho$ decresce com o aumento da densidade da cultura. Em Cousens (1985b) é mostrado que a relação entre $\rho$ e a densidade da cultura também pode ser bem descrita por uma função hiperbólica, por exemplo

$$
\rho=\frac{\gamma}{1+\varphi C}
$$

onde $Y_{c}$ é a densidade da cultura; $\gamma$ e $\varphi$ são parâmetros. Agora, se o parâmetro $\rho$ for 
considerado constante, a equação (2.5) se torna

$$
P_{r}=\frac{\gamma Y}{\left(1+\varphi Y_{c}\right)\left(1+\frac{\gamma Y}{\rho\left(1+\varphi Y_{c}\right)}\right)}
$$

$\mathrm{Ou}$

$$
P_{r}=\frac{\gamma Y}{1+\varphi Y_{c}+\frac{\gamma Y}{\rho}}
$$

Note que reescrevendo (2.5) na forma geral (2.4) obtém-se

$$
P_{r}=\frac{\sigma Y}{\frac{\sigma}{\rho}+Y}
$$

Rizzardi et al. (2003a) avaliaram a possibilidade de uso do modelo hiperbólico proposto por Cousens (1985a) na previsão das perdas de rendimento de grãos de soja causadas por guanxuma (Sida rhombifolia L.) e picão-preto (Bidens spp.), a partir de dados de rendimento observados da cultura de soja

$$
P_{r}=\frac{100\left(R_{a}-R_{b}\right)}{R_{a}}
$$

onde $R_{a}$ é o rendimento da cultura livre de plantas daninhas e $R_{b}$ é o rendimento da cultura com plantas daninhas. O modelo (2.5) pode ajustar bem os dados observados, no entanto, é limitado uma vez que a época de emergência de plantas daninhas em relação à cultura, fluxos consecutivos ou variações no vigor das plantas daninhas não são consideradas (Rizzardi et al., 2003a).

Cousens et al. (1987) propuseram um modelo hiperbólico de perda de rendimento que inclui a densidade e época relativa de emergência das plantas daninhas

$$
P_{r}=\frac{\rho Y}{\left(e^{-\eta T}\right)+\left(\frac{\rho}{\sigma} Y\right)}
$$

onde $T$ representa a época relativa de emergência das plantas daninhas e $\eta$ o parâmetro que representa o indicativo de competitividade da cultura. Entretanto, para que se possa prever de modo confiável o resultado da competição entre as plantas daninhas e a cultura através da expressão (2.11) são necessárias informações precisas da época de emergência das plantas daninhas, em relação ao estádio de desenvolvimento da cultura (Rizzardi et al., 2003b). 
Segundo Kropff et al. (1992), uma limitação dos modelos de perda de rendimento em função da densidade de plantas daninhas (2.5) e tempo relativo de emergência (2.11), é que a densidade pode não ser um bom preditor do rendimento da cultura se as plantas daninhas variam muito em tamanho e/ou em tempo relativo de emergência. Além disso, o tempo relativo de emergência com relação a cultura é difícil de ser estimado, uma vez que as plantas daninhas nascem em fluxos discretos e sucessivos.

Para contornar tal dificuldade, Rizzardi et al. (2003b), ajustaram o modelo proposto por Cousens et al. (1987) substituindo a emergência de duas espécies daninhas (guanxuma e picão-preto) em relação à cultura da soja por outro indicativo: a época de semeadura da soja após a dessecação da cobertura vegetal, expressa em unidades calóricas. Os resultados indicaram que o ajuste do modelo (2.11) permitiu, com relação à guanxuma e principalmente ao picão-preto, prever adequadamente as perdas de rendimento em diferentes épocas de estabelecimento da soja em relação à data de dessecação da cobertura vegetal.

Note que a perda de rendimento não pode ser observada diretamente, somente é possível medir o rendimento (a produção da cultura), então, a expressão do rendimento da cultura por unidade de área

$$
R_{c}=R_{l d}\left[1-\frac{1}{100} P_{r}\right]
$$

onde $R$ é o rendimento da cultura e $R_{l d}$ o rendimento livre de plantas daninhas. Utilizando o modelo de perda de rendimento (2.5), por exemplo, tem-se

$$
R_{c}=R_{l d}\left[1-\frac{\rho Y}{100\left[1+\left(\frac{\rho}{\sigma} Y\right)\right]}\right]
$$

\subsubsection{Produção de sementes de plantas daninhas a partir de dados de perda de rendimento da cultura}

Experimentos para quantificar a relação que descreve a produção de sementes como uma função da densidade inicial da flora emergente são de alto custo e difícil execução (Cousens e Mortimer, 1995) tornando-os relativamente incomuns (Canner et al., 2002); fato que limita a parametrização de modelos dinâmicos de populações de plantas 
daninhas.

Uma alternativa para tal carência de dados seria a obtenção de parâmetros de modelos de reprodução de plantas daninhas a partir de dados que descrevam a perda de rendimento da cultura em função da densidade de plantas daninhas. Segundo os autores, observações empíricas e teóricas da relação entre as curvas de perda de rendimento da cultura e de produção de sementes de plantas daninhas conduzem a hipótese de haver uma forte relação entre as formas dessas curvas (Canner et al., 2002).

Segundo Canner et al. (2002), se o rendimento de biomassa de plantas daninhas é linear a perda de rendimento da cultura se aproxima de 0 (zero) quando a biomassa se aproxima de 0 (zero), e se a perda absoluta do rendimento de biomassa da cultura causada por plantas daninhas pode ser descrita por um modelo hiperbólico do tipo (2.4), então o rendimento de biomassa de plantas daninhas também pode ser descrito por um modelo hiperbólico

$$
B=U_{B} \frac{Y}{Y 50_{B}+Y}
$$

e, principalmente, a curva do modelo hiperbólico de rendimento de biomassa de plantas daninhas terá a mesma forma que a do modelo de perda de rendimento da cultura, diferindo do modelo hiperbólico de perda de rendimento da cultura somente por um fator de escala constante $f_{e}=\frac{U_{B}}{U_{P r}}$, onde $U_{P r}$ é o parâmetro que descreve o limite superior da resposta $\operatorname{Pr}$ (de perda de rendimento da cultura) quando a densidade de plantas daninhas $Y$ se aproxima do infinito, ou seja, $U_{P r}$ é o limite superior da perda de rendimento.

A produção de sementes de plantas daninhas também pode ser modelada com a hipérbole retangular do tipo (2.14). No caso desta modelagem, uma estimativa de $Y 50_{B}$ pode ser obtida usando um valor médio de $Y 50_{P r}$ estimado a partir de dados experimentais existentes que descrevam o efeito de variar densidades de plantas daninhas sobre a perda de rendimento da cultura. O parâmetro de escala $U_{B}$ pode ser estimado usando dados de rendimento de sementes apenas de uma única densidade elevada de plantas daninhas. Neste caso, utilizando o modelo de perda de rendimento (2.5) proposto por Cousens (1985a), têm-se $Y 50_{P r}=\frac{\sigma}{\rho}$ e $U_{P r}=\sigma$.

A utilidade de aplicar a sugestão de Canner et al. (2002), isto é, substituir $Y 50_{B}$ no modelo, depende de um série de fatores, incluindo os riscos e os benefícios associados 
com um dado nível de exatidão de um modelo de aplicação e dos custos de um outro método de modelagem mais exato e de seus dados requeridos.

\subsection{Discussão}

O banco de sementes apresenta um papel ecológico importante no suprimento de novos indivíduos para as comunidades vegetais. Entretanto, o número de plantas em determinado instante num solo agrícola não representa o potencial real de infestação, já que cada espécie necessita de condições específicas para a quebra de dormência e germinação. As diferentes práticas de manejo do solo e das culturas também influenciam a composição florística de uma área e, conseqüentemente, o banco de sementes. Além disso, as sementes que estão na superfície do solo estão sujeitas a deterioração, predação, parasitismo e imigração. O uso contínuo de herbicidas também pode ocasionar mudanças na comunidade de plantas daninhas selecionando espécies tolerantes ou biótipos resistentes.

Os principais meios de enriquecimento do banco de sementes são: produção de novas sementes por plantas remanescentes de controle, transporte de sementes por meio de maquinários, animais, vento, água e o homem. O decréscimo do banco de sementes no solo varia em função da espécie, dormência, condições ambientais, presença de microorganismos e predadores, sendo que a principal forma de decréscimo é a germinação das sementes. A germinação é bastante variável ao longo do tempo, ocorrendo fluxos de emergência das plantas daninhas em determinados períodos do ano. Estes fluxos são resultantes de condições ambientais favoráveis e da habilidade das sementes viáveis em responder a estes estímulos.

A fim de apresentar uma importante ferramenta para tomada de decisão em sistemas agrícolas, modelos hiperbólicos, tanto de reprodução de plantas daninhas (2.3) como de perda de rendimento da cultura em função da densidade de plantas daninhas (2.5), foram apresentados.

Modelos de perda de rendimento da cultura em relação a densidade de plantas daninhas e porcentagens de perdas de rendimento observada podem representar uma útil ferramenta de tomada de decisão em sistemas agrícolas. A disponibilidade de recursos finitos é um dos fatores que ditam a relação densidade-rendimento. Em geral, o grau de 
interferência mútua entre plantas daninhas e cultivadas pode ser afetado pelas espécies concorrentes, por seu nível populacional, pela duração da interferência e pelo nível dos elementos vitais disponíveis. Desta forma, é desejável que a competição exercida pela cultura possa ser usada na redução do crescimento das plantas daninhas, aumento da mortalidade destas, diminuindo assim, as perdas de rendimento.

Os níveis de danos usados para decidir se é necessário ou não controlar as plantas daninhas podem ser derivados de modelos de regressão que quantificam as perdas de rendimento em razão do nível de infestação de plantas daninhas logo após a emergência da cultura. As expressões (2.5) e (2.11) são exemplos.

Apesar do modelo (2.11) de perda de rendimento da cultura ser mais complexo que (2.5), por incluir duas variáveis e três parâmetros este pode apresentar vantagens devido a incorporação da época de semeadura da cultura. Por exemplo, mostra-se em Rizzardi et al. (2003b) que o ajuste do modelo (2.11) utilizando a época da semeadura da cultura da soja em relação à dessecação da cobertura vegetal da área, permitiu prever adequadamente as perdas de rendimento em diferentes épocas de plantio da soja.

Seguindo essa perspectiva, conjectura-se que modificações em modelos de perda de rendimento da cultura ou em outros modelos, podem, em diferentes situações, serem plausíveis e úteis na implementação de novas estratégias de controle que possam vir a reduzir os custos do controle químico e suas desvantagens em relação à saúde e ao meio ambiente (Vismara et al., 2004). É possível utilizar tais modelos matemáticos em conjunto com a experimentação para sintetizar os dados obtidos em um espectro de condições, fazer previsões de circunstâncias não abrangidas no experimento e entender as prováveis características biológicas da população. 


\section{Capítulo 3}

\section{Representação matemática da dinâmica populacional de plantas daninhas}

Os modelos matemáticos têm sido utilizados para os mais diversos fins: entender e explicar fenômenos observados, desenvolvimento de sistemas de monitoramento e controle, predição, estimação de estado e simulação de problemas em geral. O presente capítulo tem por objetivo apresentar modelos que descrevam o comportamento dinâmico não linear de populações de plantas daninhas. Primeiro, são apresentados modelos de um único estádio que descrevem os processos intrínsecos da população, os quais ocorreriam se o habitat permanecesse constante de uma geração a seguinte. Segundo, são considerados a indução a mortalidade e/ou os efeitos letais de um herbicida sobre a produção de sementes descritas por esses modelos. Terceiro, são apresentados modelos de múltiplos estádios para espécies daninhas que coexistem em diferentes estádios de desenvolvimento. Quarto, são apresentados modelos do movimento vertical do banco de sementes no solo, utéis para simular práticas agrícolas ou para predizer as posições verticais de sementes no solo. 


\subsection{Modelos de único estádio para a dinâmica populacional intrínseca}

No Capítulo 2, discutiu-se que a dinâmica populacional de plantas daninhas é resultado da influência de fatores intrínsecos e extrínsecos e dos ganhos/perdas de sementes em uma dada área através da imigração/emigração. Nesta seção, estuda-se essa dinâmica sob duas hipóteses: 1) todos os fatores extrínsecos permanecem constantes e 2) a imigração e emigração são balanceadas (tal como ocorre no centro de uma população homogênea, onde a migração em ambas as direções tende a ser cancelada). A suposição 2) é equivalente a dizer que os processos espaciais não exercem nenhuma influência na dinâmica das populações. A dinâmica de uma população de plantas ainda pode ser considerada em dois momentos: i) quando não há interferência intra-específica e a taxa de crescimento populacional é independente da densidade e ii) quando o nível populacional está alto tal que a taxa de crescimento é dita ser dependente da densidade. Neste contexto, apresentam-se a seguir modelos para descrever a evolução da população de plantas daninhas a partir de equações a diferenças.

\subsubsection{Modelos de único estádio para uma única espécie daninha}

Modelos que consideram somente a densidade da população (plantas ou sementes) em intervalos de uma geração individual a cada ciclo, descrevendo simplesmente mudanças de densidade, são denominados modelos de único estádio.

A densidade de plântulas de daninhas pode ser descrita por

$$
Y_{t}=g X_{t}
$$

onde $Y_{t}$ é o número de plântulas por área, $X_{t}$ o número de sementes por área, $t$ o ciclo de vida e $g$ a taxa de germinação.

A taxa de crescimento populacional será independente da densidade de plântulas de daninhas se os indivíduos na população estiverem amplamente espaçados, não havendo interferência intra-específica (Cousens e Mortimer, 1995; Sakai, 2001). Então, sob baixa densidade de plantas, a produção de sementes por área pode ser expressa por 


$$
X_{t+1}=R X_{t}
$$

onde $R$ é a taxa de crescimento em baixa densidade (Cousens e Mortimer, 1995). Assim, seja $X_{0}$ a densidade inicial de sementes, a expressão

$$
X_{t}=R^{t} X_{0}
$$

descreve a trajetória da densidade de sementes, a qual é dada pela solução de (3.2).

A Figura 3.1 representa um fluxograma simplificado do ciclo de vida de espécies daninhas anuais relacionado às principais causas de perdas de plantas e de redução de produção de sementes; $\operatorname{com} g, o, s$ e $v$ as taxas de germinação, floração, produtividade (número de sementes produzidas por planta) e de sementes viáveis no solo no ciclo seguinte, respectivamente.

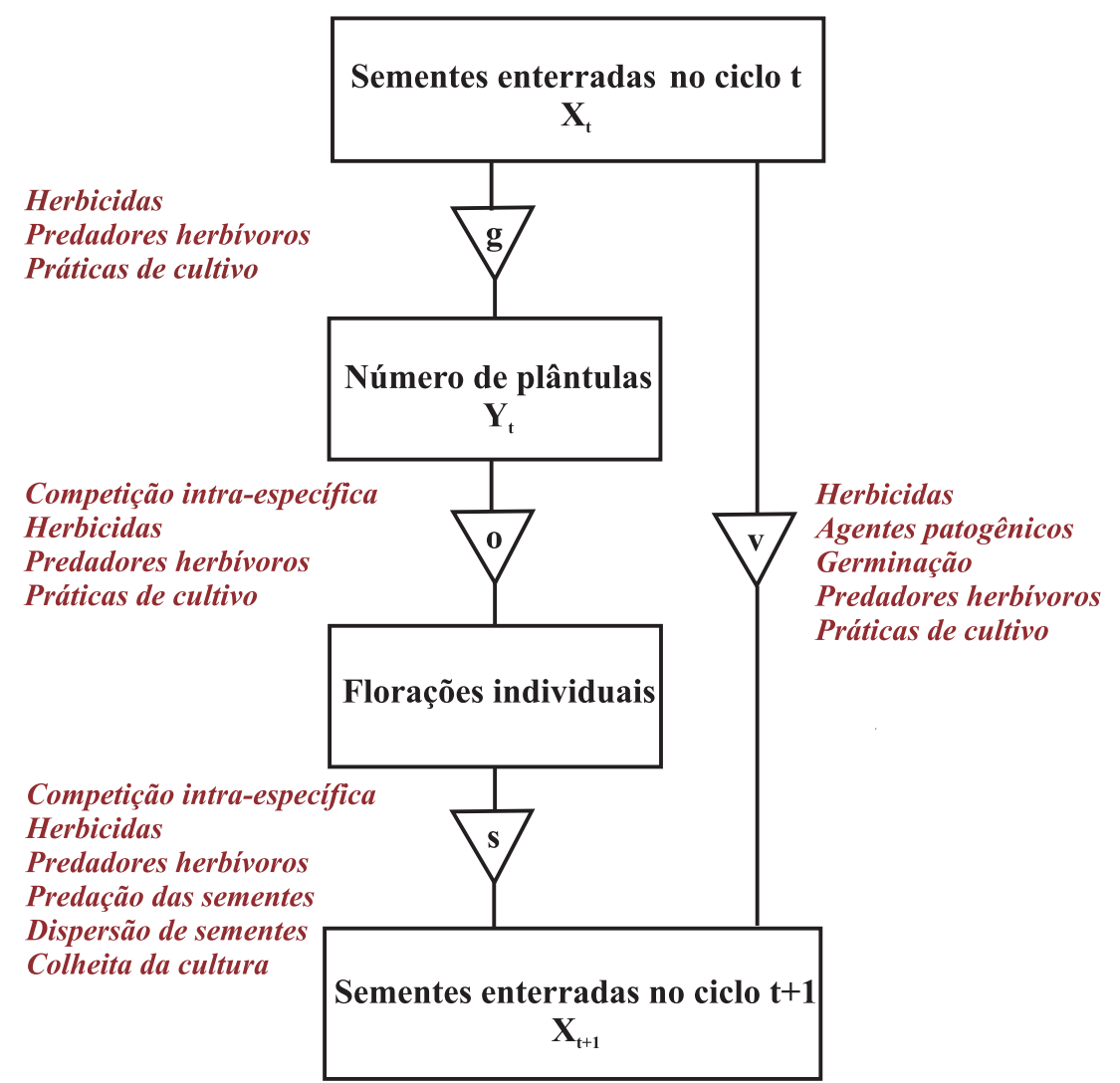

Figura 3.1: Representação da dinâmica do banco de sementes de espécies daninhas anuais. As letras nos triângulos indicam as taxas de germinação $(g)$, floração ou estabelecimento e sobrevivência à maturidade $(o)$, sementes viáveis no solo no ciclo seguinte $(v)$ e produtividade $(s)$. As principais causas de perdas de plantas e de redução de produção de sementes são indicadas ao lado dos triângulos. 
Desta forma, considerando $g, o, s$ e $v$ constantes, a densidade de sementes existentes no ciclo $t+1$ é determinada pela densidade de sementes do ciclo anterior $t$ (Sakai, 2001)

$$
X_{t+1}=g o s X_{t}+(1-g) v X_{t}
$$

Note que, neste caso $R=g o s+(1-g) v$. Com exceção da produtividade de sementes $s$, as taxas são probabilidades e encontram-se entre 0 (zero) e 1 (um). O segundo termo de (3.4) representa as gerações sobrepostas e quando não persistirem sementes viáveis no solo de um ciclo ao seguinte tem-se $v=0$.

Entretanto, a taxa de crescimento da população, a população em pleno vigor vegetativo, a população em floração e o número de sementes produzidas são dependentes da densidade, isto é, são funções da densidade de plântulas de daninhas. Já a taxa de sucesso de germinação é independente da densidade. Assim, o e $s$ em (3.4) não são constantes, mas funções da densidade de plântulas de daninhas (Cousens e Mortimer, 1995; Sakai, 2001). Então,

$$
X_{t+1}=F\left(Y_{t}\right), \quad t=1,2, \cdots
$$

é um modelo para a densidade de sementes produzidas expresso como função da densidade de plântulas de daninhas (Sakai, 2001); onde $F: \mathcal{R} \rightarrow \mathcal{R}$ é uma função não linear da densidade populacional e $t$ como já definido. Note que as equações (3.1) e (3.5) representam a independência e dependência da densidade, respectivamente.

A relação entre o número de sementes $X_{t}$ e $X_{t+1}$ também pode ser expressa por um sistema dinâmico discreto unidimensional com a densidade de sementes no solo sendo a variável de estado

$$
X_{t+1}=F\left(g X_{t}\right), \quad t=1,2, \cdots
$$

Modelos de sistemas dinâmicos da forma (3.6) acima, que refletem os padrões biológicos e físicos da espécie de planta daninha com medições em cada ciclo de vida da população, podem ser construídos. Uma vez obtido o modelo, deve-se considerar as incertezas na escolha dos intervalos de amostragem de área; a Geoestatística pode ser usada para caracterizar o modelo em locações não amostradas (Isaaks e Srivastana, 1989). Deve-se ressaltar que o tamanho da população deve ser medido em um tempo comum do ciclo de vida, o que de fato é mais simples em populações de plantas daninhas 
anuais representadas como gerações discretas no tempo (Cousens e Mortimer, 1995).

Para populações em que a produção de sementes se aproxima assintoticamente de um limite superior com o aumento de $X_{t},(3.6)$ pode possuir a forma

$$
X_{t+1}=\phi X_{t}
$$

onde $\phi$ é a taxa de crescimento populacional e pode ser definida como

$$
\phi(t)=\frac{R}{\left(1+d X_{t}\right)^{b}}
$$

com $d$ a taxa do declínio de $\phi$ com o aumento da densidade e $b$ taxa que reflete a intensidade do efeito da densidade de plantas daninhas na produção de sementes. O modelo (3.7) com $\phi$ dado por (3.8) foi proposto em Hassell (1975) segundo Edelstein-Keshet (1988). Neste caso, a dinâmica populacional em função da densidade de plantas daninhas pode ser dada, fazendo $R=s g$ e $d=a g$, com $a$ um parâmetro que relaciona a mortalidade de plantas com a dependência da densidade (Mortimer et al., 1989; GonzalezAndujar, 1996).

A solução de equilíbrio $X_{e}$ para (3.7) com $\phi$ dado por (3.8), é dada quando $X_{t+1}=X_{t}$ e neste caso é

$$
X_{e}=\frac{\left(R^{\frac{1}{b}}-1\right)}{d}
$$

Em particular, se $b=1$ em (3.8), a densidade de equilíbrio da população é

$$
X_{e}=\frac{(R-1)}{d}
$$

e a trajetória populacional descreve uma relação sigmoidal entre a densidade e o tempo.

\subsubsection{Análise da trajetória populacional via alteração de parâmetros do modelo de único estádio para a produção de sementes}

A trajetória da densidade da população pode ser caracterizada pela flutuação da taxa de crescimento $\phi$ com o tempo sobre as gerações do crescimento da população. O tipo de trajetória depende dos valores de $R$ e $b$ (Cousens e Mortimer, 1995). Mais precisamente,

1. Se $b \leq 1$ ou $R<e$ (e é o número de Euler ou neperiano e seu valor aproximado é 
2,72 ) a densidade da população converge monotonicamente e/ou assintoticamente (Figura 3.2) para o equilíbrio. Em particular, se $b=1$ e $R=1$ tem-se $X_{e}=0$ (Figura 3.3);

2. Se $1<b<2$ e $e<R<e^{2}$ a densidade da população converge para o equilíbrio com oscilações amortecidas (Figura 3.4);

3. Se $b>2$ e $R>e^{2}$ podem ocorrer comportamentos periódicos (Figura 3.5) ou complexos como o caos (Figura 3.6).

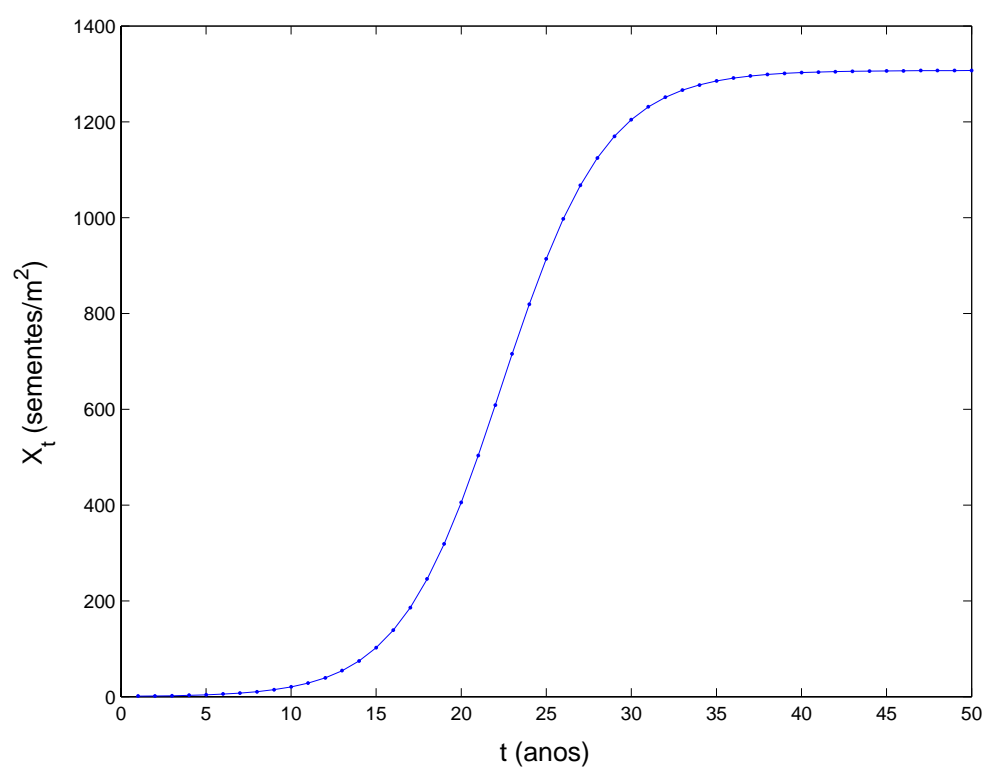

Figura 3.2: Trajetória simulada da dinâmica populacional do modelo (3.7) com $\phi$ dado por (3.8) para $R=1,4, b=0,8, d=0,004, X_{0}=1$ e densidade limiar de 4000 plântulas $/ m^{2}$ quando a taxa de produtividade de sementes é nula.

Os tipos de trajetória populacional definem quatro zonas no gráfico $R$ versus $b$ (Figura 3.7). Na prática, a densidade no campo de um ano para outro pode ser extremamente variável. Para estimar $R$ se faz necessário restringir nossa pesquisa para valores em que a população aumenta sob baixa densidade; para adequadamente estimar $b$ as densidades devem ser extremamente altas. Algumas estimativas, ou talvez indicações dos parâmetros, são encontrados na literatura (Selman, 1970; Wilson e Phipps, 1985; Mortimer, 1987; Lintell-Smith et al., 1991; Bazzaz et al., 1992). Poucos conjuntos de dados têm sido obtidos com $b$ significativamente maior que 2 (dois). Muitos dados para os quais (3.7) têm sido ajustada resultaram em valores de $b$ menores que 1 (um) ou não significativamente diferente de 1 (um). Comportamentos complexos tais 


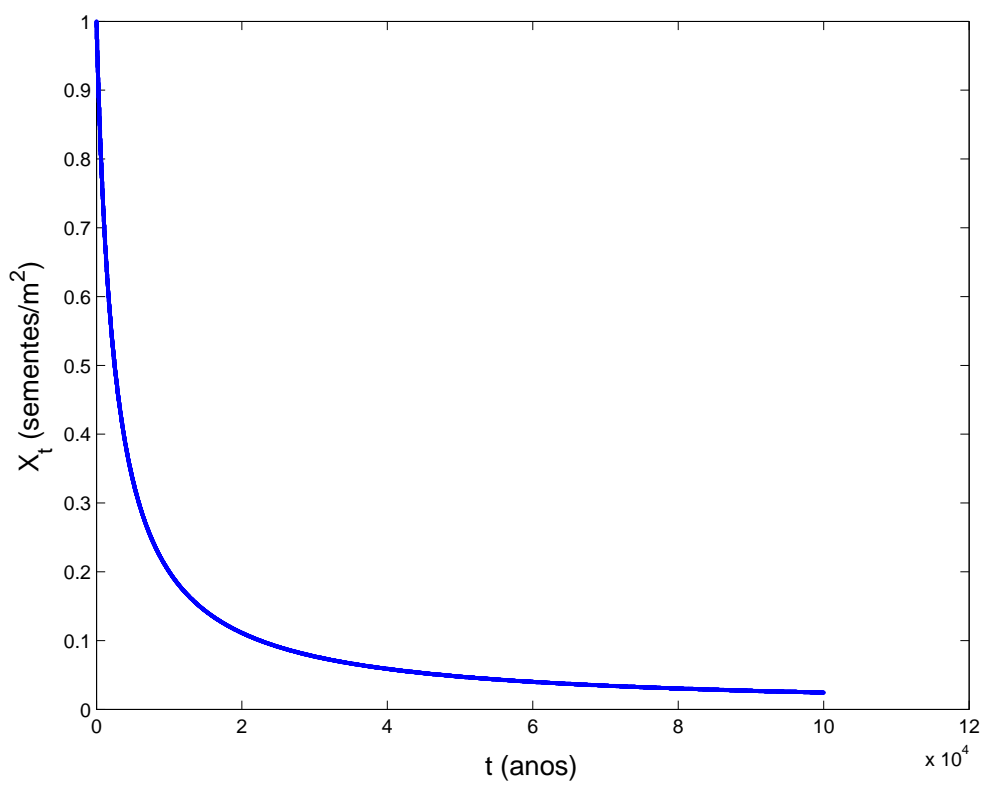

Figura 3.3: Trajetória simulada da dinâmica populacional do modelo (3.7) $\operatorname{com} \phi$ dado por (3.8) para $R=1$, $b=1, d=0,0004, X_{0}=1$ e densidade limiar de 4000 plântulas $/ \mathrm{m}^{2}$ quando a taxa de produtividade de sementes é nula.

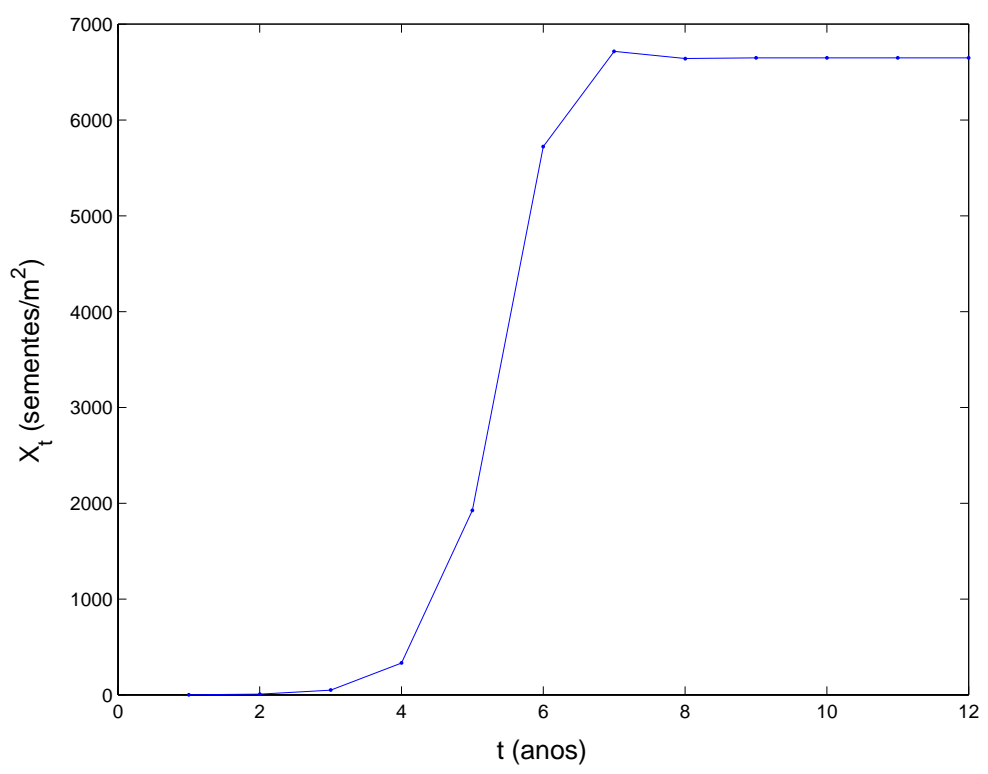

Figura 3.4: Trajetória simulada da dinâmica populacional do modelo (3.7) com $\phi$ dado por (3.8) para $R=6,8, b=1,5, d=0,0004, X_{0}=1$ e densidade limiar de 4000 plântulas $/ m^{2}$ quando a taxa de produtividade de sementes é nula. 


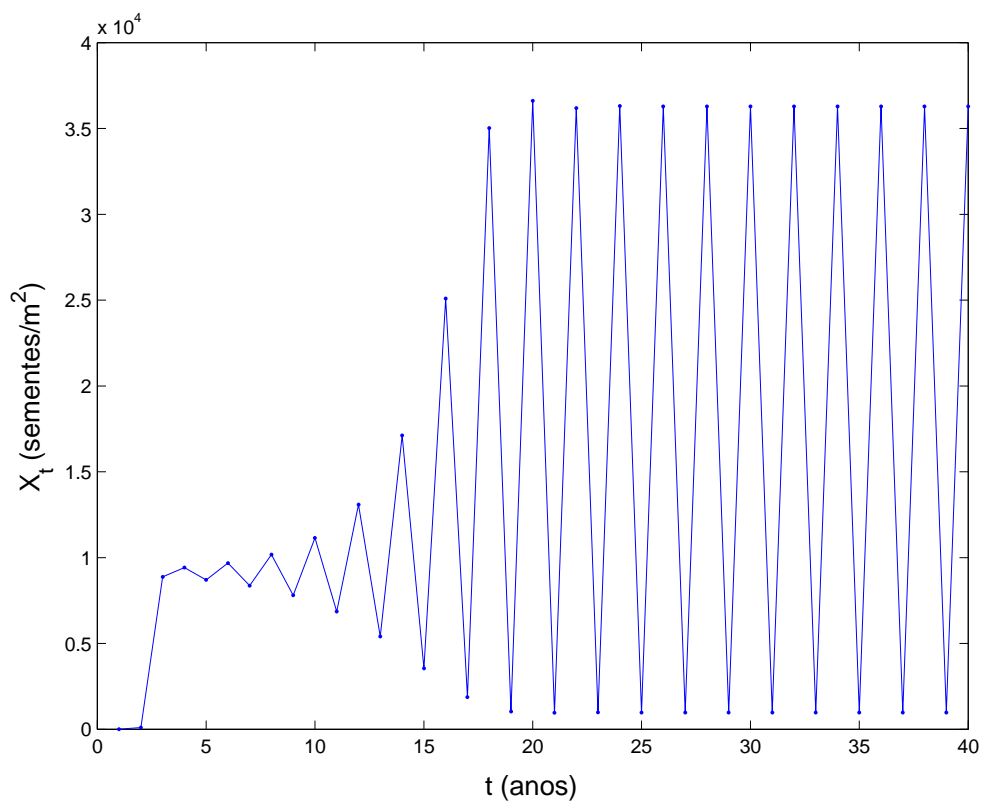

Figura 3.5: Trajetória simulada da dinâmica populacional do modelo (3.7) com $\phi$ dado por (3.8) para $R=100, b=3, d=0,0004, X_{0}=1$ e densidade limiar de 4000 plântulas $/ m^{2}$ quando a taxa de produtividade de sementes é nula.

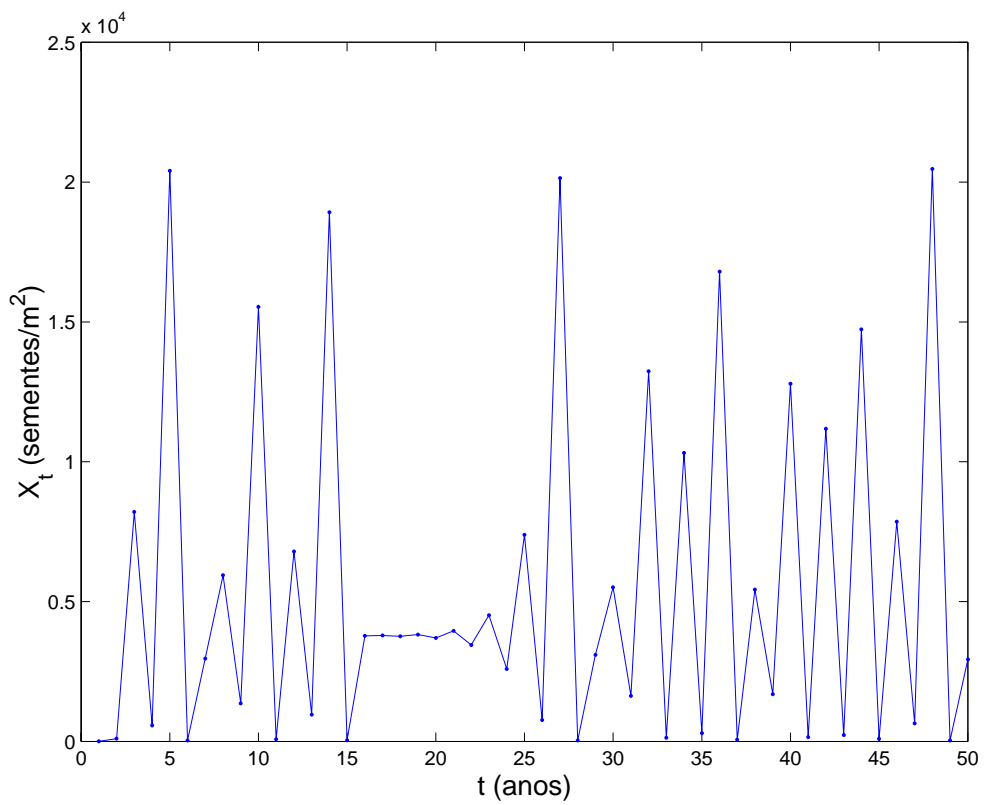

Figura 3.6: Trajetória simulada da dinâmica populacional do modelo (3.7) com $\phi$ dado por (3.8) para $R=100, b=5, d=0,0004, X_{0}=1$ e densidade limiar de 4000 plântulas $/ m^{2}$ quando a taxa de produtividade de sementes é nula. 


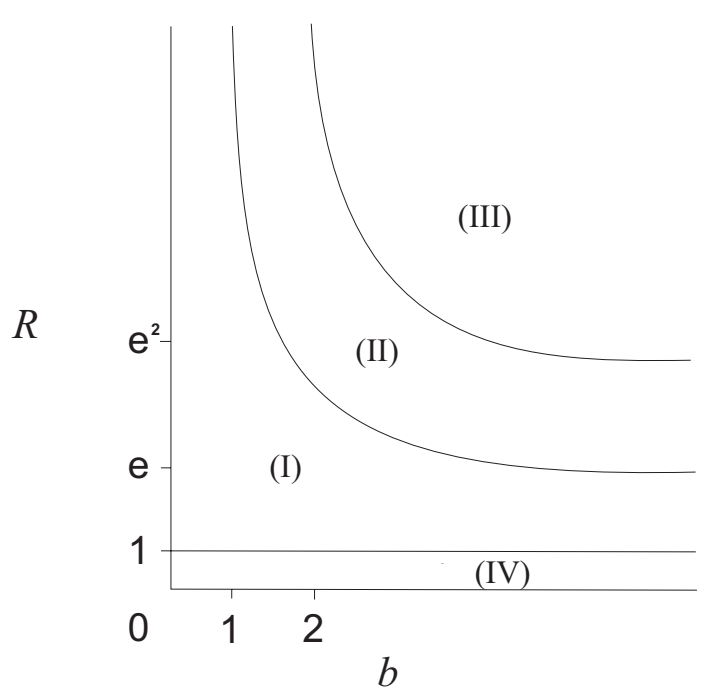

Figura 3.7: Comportamento populacional descrito por (3.7) com taxa de crescimento dada por (3.8) (Cousens e Mortimer, 1995). As trajetórias definem quatro zonas no gráfico: (I) a população aproxima-se assintoticamente do equilíbrio, (II) a população oscila e converge assintoticamente para o equilíbrio, (III) a população oscila e diverge e (IV) a população oscila e converge para zero.

como o caos (que requer $b>2$ ), provavelmente, seja mais uma propriedade matemática do modelo do que o comportamento esperado de uma população real de plantas daninhas anuais (Cousens e Mortimer, 1995), a menos que o caos seja induzido por alguma prática de manejo (por exemplo, técnicas que promovam a inversão das camadas do solo). Uma boa discussão sobre o caos pode ser encontrada em Hastings et al. (1993), Sakai (2001) e Freckleton e Watkinson (2002).

\subsubsection{Modelos de único estádio para mais de uma espécie daninha}

Como a dinâmica populacional de uma espécie pode ser afetada por níveis populacionais de outras espécies, pode-se estender o modelo proposto por Hassell (Hassell, 1975). Para representar duas espécies daninhas, por exemplo, a taxa de crescimento populacional é modificada para

$$
\begin{aligned}
& \phi_{1}(t)=\frac{R_{1}}{\left[1+d_{1}\left(X_{1, t}+\beta_{1} X_{2, t}\right)\right]^{b_{2}}} \\
& \phi_{2}(t)=\frac{R_{2}}{\left[1+d_{2}\left(X_{2, t}+\beta_{2} X_{1, t}\right)\right]^{b_{1}}}
\end{aligned}
$$


onde os subscritos referem-se as espécies 1 e 2 e $\beta$ é um parâmetro relacionado a cada espécie (Cousens e Mortimer, 1995).

Agora, se uma das espécies é uma planta daninha e a outra é a cultura semeadas em uma mesma densidade a cada ciclo, a taxa de crescimento populacional pode ser dada por

$$
\phi_{c}(t)=\frac{R}{\left[1+d\left(X_{t}+\alpha X_{c}\right)\right]^{b}}
$$

onde $X_{c}$ é a densidade da cultura e $\alpha$ um parâmetro relacionado à cultura (Cousens e Mortimer, 1995). Assim, seja $K=\frac{R}{\left(1+\alpha X_{c} d\right)^{b}}$ e $M=\frac{d}{\left(1+\alpha X_{c} d\right)}$ constantes, tem-se

$$
\phi(t)=\frac{K}{\left(1+M X_{t}\right)^{b}} .
$$

Estendendo (3.12) para uma comunidade de multi-espécies de plantas daninhas competindo com a cultura, a taxa de crescimento populacional para a espécie $i$ será

$$
\phi_{i}(t)=\frac{R_{i}}{\left[1+d_{i}\left(\sum X_{j} \beta_{i j}+\alpha X_{c}\right)\right]^{b}}
$$

onde $\sum$ se refere ao somatório dos efeitos das densidades de todas as espécies daninhas de interesse, incluindo os efeitos intra-específicos e $\beta$ um parâmetro relacionado às plantas daninhas (Cousens e Mortimer, 1995).

Devido à variabilidade usualmente encontrada na coleta de dados sobre uma seqüência de ciclos, os valores de $d$ e $b$ são usualmente tomados a partir da densidade de plantas, ao invés de observações diretas de $X_{t+1}$ e $X_{t}$ sobre as diversas gerações no campo (Cousens e Mortimer, 1995).

\subsection{Fatores extrínsecos que alteram a dinâmica popu- lacional}

Segundo Cousens e Mortimer (1995), em populações de plantas daninhas os fatores extrínsecos podem ser divididos convenientemente em três grupos: fatores de gerenciamento e controle, fatores atmosféricos e interações com outros organismos (incluindo insetos, agentes patogênicos, predadores herbívoros grandes e outras espécies de plantas). A importância relativa da interferência dos diferentes fatores (Figura 3.8) varia 
com tempo, posição geográfica e tipo de habitat.

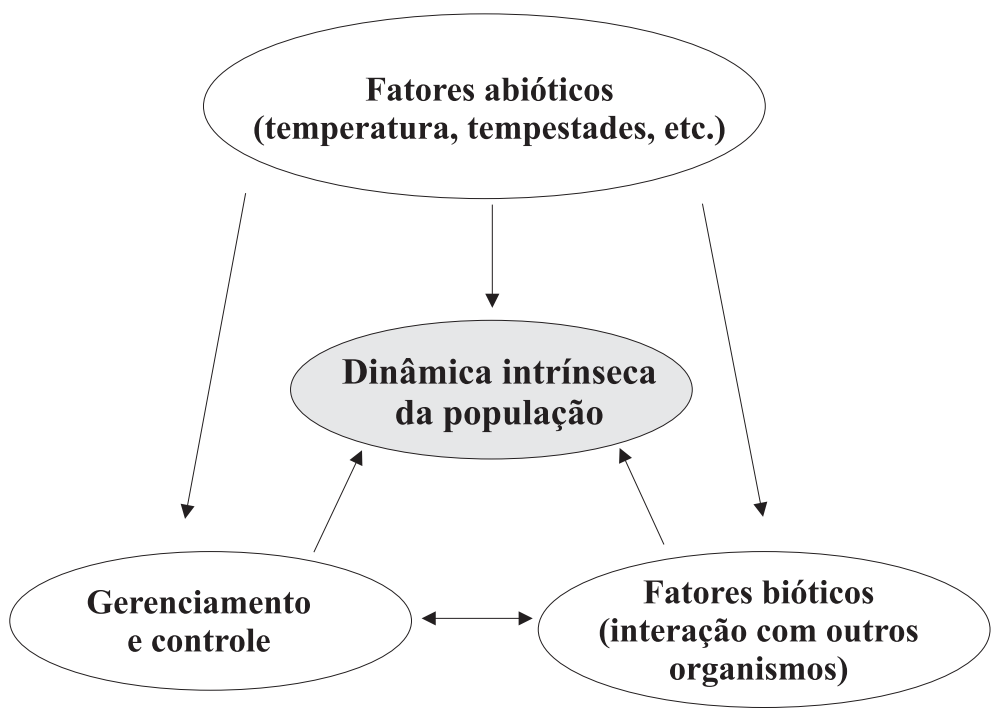

Figura 3.8: Diagrama de representação da interação entre os processos intrínsecos da população e os fatores extrínsecos.

É extremamente improvável que cada fator extrínseco atue isoladamente. Por exemplo, as condições atmosféricas e os fatores de gerenciamento provavelmente alteram em conjunto as densidades relativas de plântulas de diferentes espécies daninhas. Ao passo que, temperatura, chuvas, espécies de plantas cultivadas, densidade semeada e nível de aplicação de fertilizante podem afetar o vigor das plantas daninhas e a abundância de herbívoros. Logo, o resultado de todos esses fatores influencia a produção de sementes e, por conseqüência, a taxa de crescimento da população (Cousens e Mortimer, 1995). Entretanto, neste trabalho uma atenção maior será dada aos efeitos causados por aplicações de herbicidas em plantações.

\subsubsection{O efeito do uso de herbicidas em modelos de único estádio}

Um fator pode ser introduzido nos modelos dinâmicos de populações de plantas daninhas para representar a mortalidade e/ou os efeitos letais de um herbicida sobre a produção de sementes. Com a variação deste fator, questões podem ser levantadas sobre as implicações do uso a longo prazo de herbicidas (Vismara et al., 2005).

Seja $h$ a taxa de plantas mortas por um herbicida, o que implica que a proporção $(1-h)$ sobreviverá à aplicação do herbicida. Neste contexto, o modelo (3.2) é modificado 
para

$$
X_{t+1}=R(1-h) X_{t}
$$

Neste caso, o nível de mortes denotado $h^{\prime}$ que manteria a população em equilíbrio (isto é, $\left.X_{t+1}=X_{t}\right)$ é dado por

$$
h^{\prime}=1-\frac{1}{R}
$$

Portanto, dada uma densidade baixa de plantas daninhas e conhecendo-se $R$, pode-se calcular o desempenho mínimo requerido de um herbicida (Cousens e Mortimer, 1995). Por exemplo, se a densidade aumentar por um fator de $R=10$, então, $90 \%$ das plantas necessitam ser controladas. Isto, naturalmente, supõe que a reprodução das plantas que sobrevivem ao herbicida não serão afetadas.

Analogamente, o efeito de um herbicida pode ser introduzido no modelo (3.7) com $\phi$ dado por (3.8). Neste caso, considera-se que o número dos indivíduos, no extremo de uma geração, seja reduzido por $h$ ( $h$ inclui implicitamente a mortalidade de plantas e os efeitos subletais na produção de semente). Nestas condições, a taxa de crescimento populacional é modificada para

$$
\phi(t)=\frac{(1-h) R}{\left(1+d X_{t}\right)^{b}}
$$

com solução de equilíbrio

$$
X_{e}=\frac{[(1-h) R]^{\frac{1}{b}}-1}{d}
$$

Neste caso, o controle requerido para estabilizar a população depende da densidade da população no período de aplicação do herbicida (Cousens e Mortimer, 1995), ou seja,

$$
h^{\prime}=1-\frac{\left(1+d X_{t}\right)^{b}}{R}
$$

Em particular, para $b=1$, o modelo (3.7) com $\phi$ dado por (3.17) produz, para diferentes níveis de controle por herbicida, uma série de mapas de gerações com $X_{e}$ decrescendo com acréscimos de $h$ (Cousens e Mortimer, 1995).

Se fosse possível prever a mortalidade proporcional de plântulas por herbicidas antes que a interferência ocorresse (isto é, uma proporção fixada de herbicida reduz a densidade de plântulas), e supor que as plantas sobreviventes ao herbicida são tão re- 
produtivas quanto as plantas que não receberão tratamento, os efeitos do herbicida poderiam ser incorporados no modelo (3.7) do seguinte modo

$$
\phi(t)=\frac{R(1-h)}{\left[1+d X_{t}(1-h)\right]^{b}}
$$

com solução de equilíbrio

$$
X_{e}=\frac{[(1-h) R]^{\frac{1}{b}}-1}{[d(1-h)]}
$$

Embora isto também prenuncie um decréscimo no equilíbrio com acréscimos de $h$, as formas dos mapas de gerações para diferentes níveis de controle por herbicida (3.20), ou seja, para um conjunto de $h$ 's, diferem daquelas para o modelo (3.7) com $\phi$ dado por (3.17). Os tipos de trajetória dadas por (3.21) para $b=1$ podem ser representadas pela Figura 3.9 onde supõe-se que o herbicida reduz a densidade de plântulas para uma densidade constante (Cousens e Mortimer, 1995).

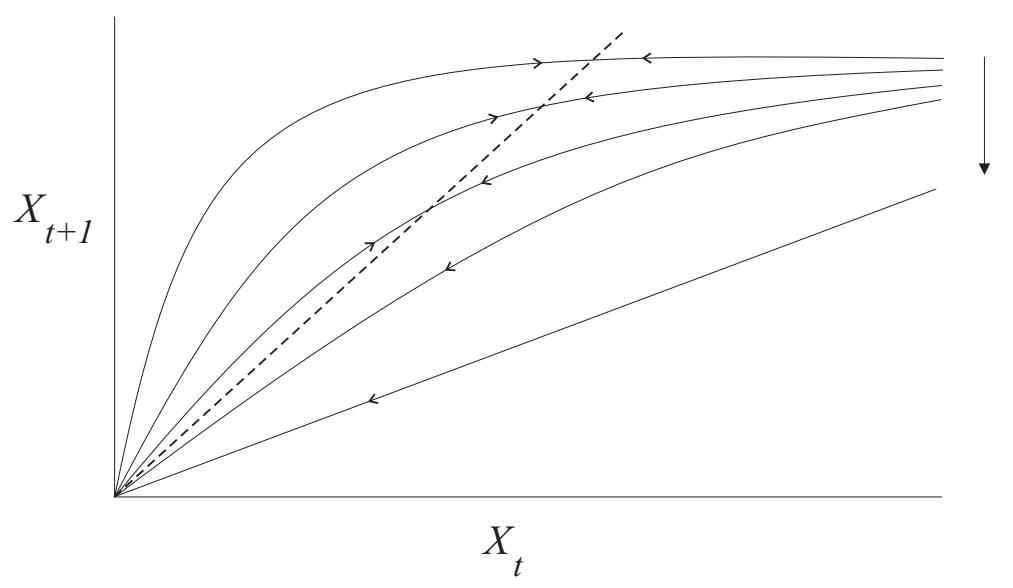

Figura 3.9: Trajetórias descritas pelo modelo (3.7) com $\phi$ dado por (3.20) para diferentes níveis de controle com herbicida, supondo que este reduz a densidade de plântulas sob uma taxa proporcional fixada (Cousens e Mortimer, 1995). A seta vertical indica o nível de aumento de controle de plantas daninhas. A linha tracejada indica $X_{t+1}=X_{t}$.

Uma outra alternativa é supor que o herbicida atua numa proporção fixa para reduzir $R$, ou seja

$$
\phi(t)=\frac{R-h R}{\left(1+d X_{t}\right)^{b}}
$$

onde a solução de equilíbrio é expressa por: 


$$
X_{e}=\frac{\left[\frac{R}{1+h R}\right]^{\frac{1}{b}}-1}{d} .
$$

Os mapas de gerações para este modelo são similares aos do modelo (3.7) com $\phi$ dado por (3.17). Assim, como o modelo original sem herbicidas com $\phi$ dado por (3.8), este modelo pode predizer aproximações assintóticas, com convergência oscilatória ou mais complexas, dependendo dos valores dos parâmetros (o valor de $h R$ deve ser mantido dentro de limites fixos).

Enfim, para modelos de único estádio, os efeitos causados por aplicações de herbicidas podem ser incorporados de várias maneiras (Cousens e Mortimer, 1995); tal como em (3.15), (3.17), (3.20) e (3.22).

\subsubsection{Simulação da dinâmica populacional de uma única espécie da- ninha via modelo de único estádio sem e com a introdução de um parâmetro de controle}

Uma vez obtido um modelo matemático, é necessário verificar se o comportamento deste equivale ao sistema real e quais são os seus limites de validade. A fim de avaliar o desempenho de um modelo, é necessário simulá-lo, ou seja, é necessário resolver as equações que o compõem (Aguirre, 2000). A simulação de modelos discretos, conseqüentemente, corresponde à solução de equações a diferenças.

Apresenta-se a seguir, um exemplo de simulação para o cálculo da produção de sementes a partir de um valor inicial de sementes por área e de parâmetros extraídos da literatura, visando discutir a incorporação de práticas de controle para redução da população de plantas daninhas sem a extinção da mesma.

Gonzalez-Andujar (1996) calculou a produção de sementes, para o modelo (3.7), em duas situações: 1) quando a população atinge uma densidade limiar de plântulas, e 2) quando uma prática de controle (rotação, herbicida, etc.) é introduzida ao modelo.

Para a primeira situação, o modelo (3.7) foi simulado com a taxa de crescimento populacional dada por

$$
\phi(t)=\frac{s g}{\left(1+a g X_{t}\right)^{b}},
$$

onde $a$ é um parâmetro que relaciona a mortalidade de plantas com a dependência da 
densidade, ou seja, representa a competição intra-específica (Mortimer et al., 1989).

Gonzalez-Andujar (1996) utilizou $s=248, a=0,004, b=2,77$ e $X_{0}=1$. Os parâmetros $s$, $a$ e $b$, foram retirados de Bazzaz et al. (1992) que ajustou (3.7) com $\phi$ (3.24) para examinar a sobrevivência e produtividade da espécie daninha anual Abutilon theophrasti Mill. Nestas condições e considerando que o comportamento dinâmico da população depende da taxa de germinação de sementes e de uma densidade limiar de 4000 plântulas $/ m^{2}$ quando a produtividade de sementes é nula, tem-se:

- Convergência da solução para uma densidade estável quando $0 \leq g \leq 0,13$ (Figura 3.10);

- Comportamento periódico da solução quando $0,14 \leq g \leq 0,39$ (Figura 3.11); e

- A população se extingue quando $0,4 \leq g \leq 1,0$ (Figura 3.12).

Lembrando que se $b>2$ e $R>e^{2}$ podem ocorrer comportamentos periódicos ou complexos como o caos (Cousens e Mortimer, 1995).

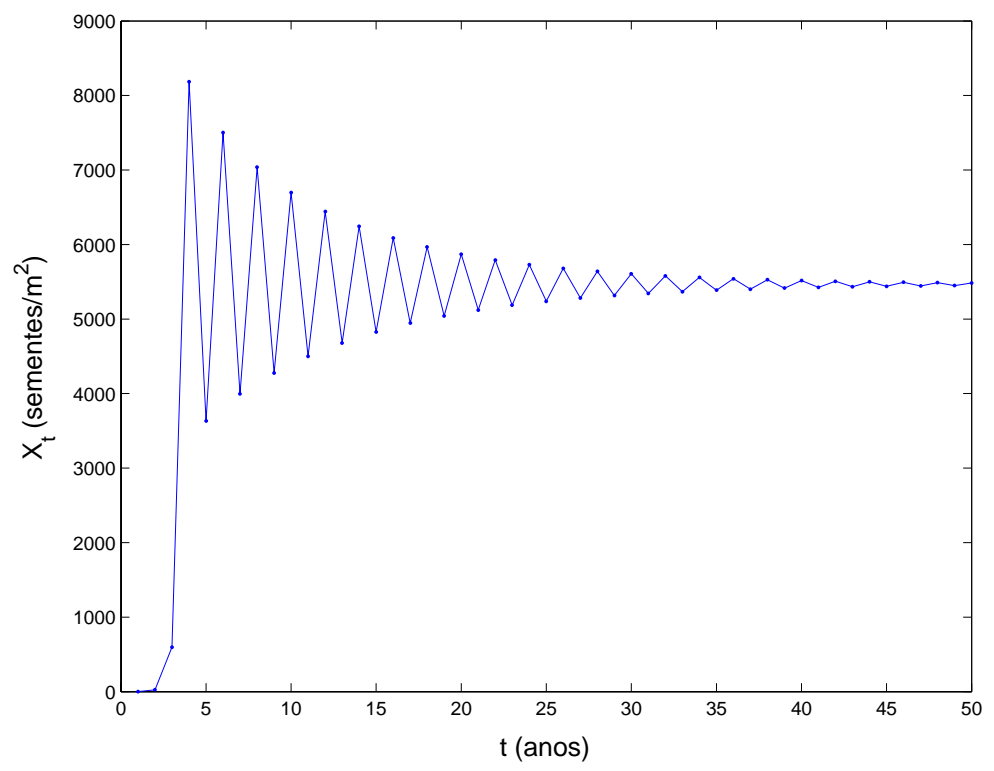

Figura 3.10: Dinâmica simulada de (3.7) com $\phi$ dado por (3.24), $s=248, a=0,004, b=2,77, g=0,1$, $X_{0}=1$ e e densidade limiar de 4000 plântulas $/ m^{2}$ quando a taxa de produtividade $s$ é nula. Tem-se $R=s g=24,8, d=a g=0,0004$ e a população de sementes converge para uma densidade estável por oscilações amortecidas.

Para a segunda situação, a taxa de crescimento populacional do modelo (3.7) é 


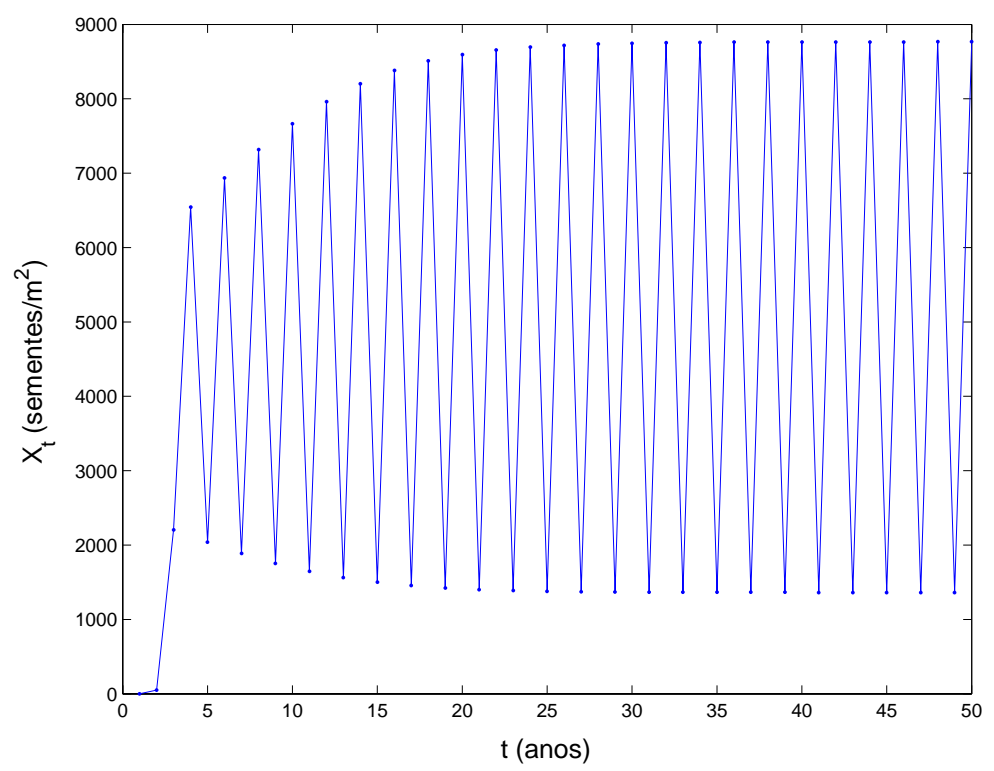

Figura 3.11: Dinâmica simulada de (3.7) com $\phi$ dado por (3.24), $s=248, a=0,004, b=2,77, g=0,2$, $X_{0}=1$ e e densidade limiar de 4000 plântulas $/ m^{2}$ quando a taxa de produtividade $s$ é nula. Tem-se $R=s g=49,2, d=a g=0,008$ e a população apresenta comportamento periódico.

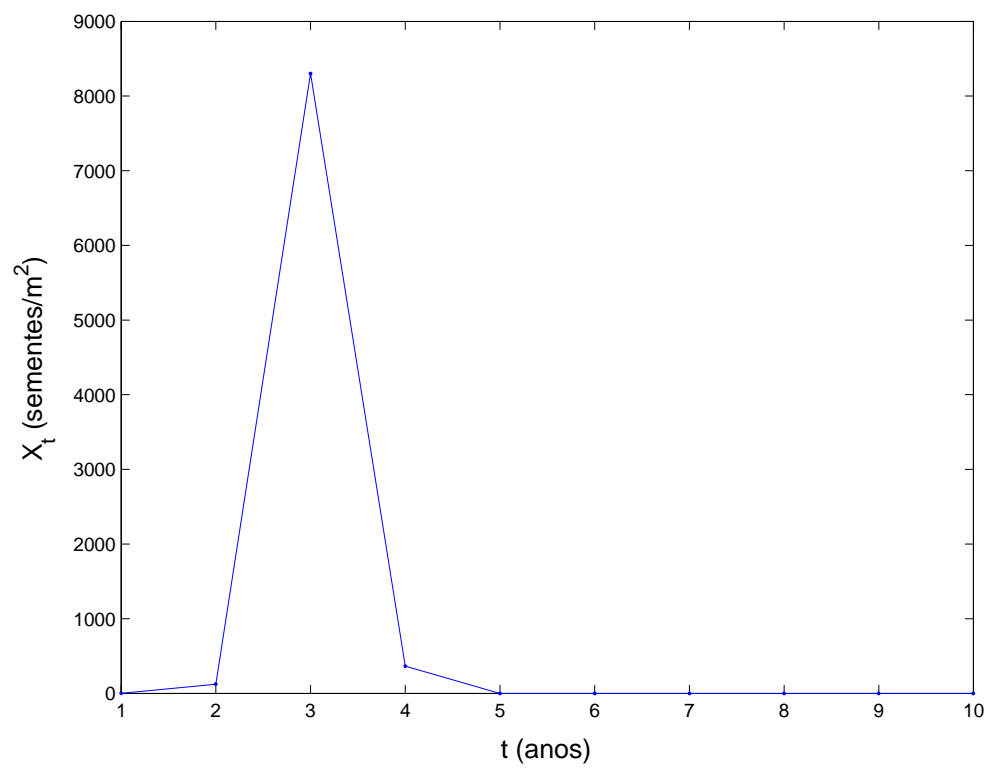

Figura 3.12: Dinâmica simulada de (3.7) com $\phi$ dado por (3.24), $s=248, a=0,004, b=2,77, g=0,5$, $X_{0}=1$ e densidade limiar de 4000 plântulas $/ m^{2}$ quando a taxa de produtividade $s$ é nula. Tem-se $R=s g=124, d=a g=0,002$ e a população é extinta. 
modificada para

$$
\phi(t)=\frac{(1-h) s g}{\left(1+a g X_{t}\right)^{b}}
$$

Note que aqui $h$ representa qualquer prática de controle (rotação, herbicida, etc.).

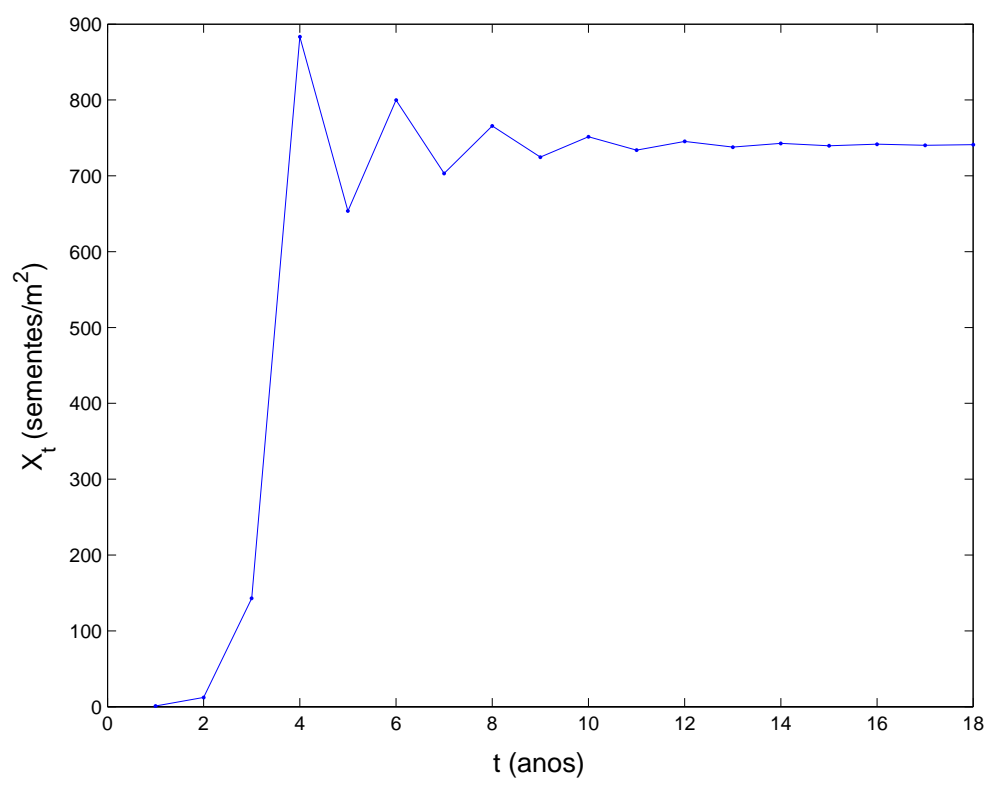

Figura 3.13: Dinâmica simulada de (3.7) com $\phi$ dado por (3.25), $s=248, a=0,004, b=2,77, g=0,5$, $h=0,9, X_{0}=1$ e densidade limiar de 4000 plântulas $/ \mathrm{m}^{2}$ quando a taxa de produtividade $s$ é nula. Tem-se $R=(1-h) s g=12,4, d=a g=0,002$ e, apesar do alto nível de controle efetuado e $g \in[0,4 ; 1,0]$, a população de sementes é reduzida sem ser extinta.

Com a medida de controle $h$ e $0,4 \leq g \leq 1,0$, somente ocorrerá extinção da população de plantas daninhas com $100 \%$ de controle (isto é, $h=1$ ). Entretanto, o controle médio da população atingido nas condições do campo pode ser $90 \%(h=0,90)$, desde modo a população não é erradicada apesar do alto nível de controle atingido (Figura 3.13). Logo, o parâmetro de controle $(h)$ pode ser introduzido para reduzir a sobrevivência de plântulas.

O exemplo simulado para a Abutilon theophrasti fornece uma provável explicação para a persistência de populações de plantas daninhas no campo apesar do alto nível de controle efetuado e da porcentagem de germinação estar dentro do intervalo de extinção da população (Gonzalez-Andujar, 1996), o que demonstra a necessidade de se conhecer o comportamento dinâmico de populações de plantas daninhas para que estas possam ser controladas eficientemente (Vismara et al., 2005). 


\subsubsection{Função resposta exponencial para aplicação de herbicidas}

Com base na modelagem da dinâmica intrínseca da população de plantas daninhas apresentada por Sakai (2001), considere o seguinte problema: As áreas de cultivo de uma fazenda estão infestados com uma planta daninha. Com o objetivo de maximizar o lucro atual, o agricultor deseja aplicar herbicidas para efetuar o controle das plantas invasoras. Neste contexto, Wu (2001) apresentou a dinâmica populacional de plantas daninhas em função da densidade de plântulas controladas com aplicação de herbicida, cuja forma funcional utilizada para função resposta da taxa de aplicação de herbicida é a exponencial. Neste caso, a expressão da densidade de plântulas (3.1) é modificada para

$$
Y_{t}=g X_{t} e^{-h H_{t}}
$$

onde agora $Y_{t}$ é a densidade de plântulas de daninhas sobreviventes à aplicação de herbicida (resposta da planta); $h$ a taxa de eficácia do herbicida (coeficiente de declividade da curva); e $H_{t}$ a dosagem do herbicida.

A curva dose-resposta gerada, por exemplo, a partir de (3.26), é uma ferramenta muito utilizada na ciência das plantas daninhas por permitir interpretação objetiva dos resultados e possibilitar comparações entre tratamentos, sendo também utilizada para a obtenção de cultivares resistentes ou tolerantes a determinados herbicidas (Lacerda, 2003).

A eficácia da aplicação de um herbicida é obtida através da razão da dose técnica requerida para controle de determinada população de plantas daninhas pela dose real empregada, multiplicada por cem. Portanto, quanto menor for o intervalo destas doses, isto é, quanto mais próxima for a dose utilizada para controle em relação a realmente necessária, maior será a eficácia da aplicação. Além disso, alguns pontos devem ser levados em consideração, como os relacionados ao aplicador, ao alvo, ao produto, à cobertura de gotas, ao complexo do equipamento utilizado e aos fatores de interferência, especialmente os climáticos. A experiência do aplicador e o conhecimento das características dos herbicidas também são de fundamental importância para a obtenção de um bom resultado (EMATER, 2002).

Em sua análise, Wu (2001) considerou que as densidades ótimas de plantas daninhas são atingidas alterando-se as taxas de aplicação do herbicida usado. Entretanto, segundo 
o autor, se há troca de herbicidas para atingir o nível desejado de controle de plantas daninhas, a variável $H_{t}$ pode ser interpretada como a 'toxidade' do herbicida usado. Neste caso, a densidade ótima de planta daninha pode ser atingida pela alteração da taxa de aplicação ou do herbicida usado.

Das plantas daninhas sobreviventes ao herbicida algumas produzem sementes e um novo ciclo é iniciado, assim seja a produção de sementes em $t+1$ dada por

$$
X_{t+1}=o s Y_{t}+(1-g) v X_{t}
$$

$o, s, g$ e $v$ como já definidos. Note que (3.27) é obtida substituindo (3.1) em (3.4).

Para simplificar, Wu (2001) considerou que todas as sementes ou germinaram $(g=1)$ ou morreram $(v=0)$, isto é: se $g=1$ ou $v=0$ então $(1-g) v X_{t}=0$ em (3.27), e que pode haver produção de sementes a partir das plantas daninhas sobreviventes à aplicação do herbicida $\left(s Y_{t}\right)$. Se a taxa de floração está em função da densidade então $o=1 \mathrm{em}$ (3.27). Sob tais hipóteses, a densidade de sementes no banco é dada por

$$
X_{t+1}=s Y_{t}=s g X_{t} e^{-h H_{t}} .
$$

Note que $\mathrm{Wu}$ (2001) incluiu uma variável e dois parâmetros ao modelo (3.5): $H_{t}, s$ e $h$, respectivamente, enquanto que Sakai (2001) considerou $s$ como uma função da densidade de plântulas no mesmo modelo. Em geral, $g, h$ e $s$ são parâmetros aleatórios porque são influenciados por tempestades, temperatura e outros fatores incertos.

\subsection{Modelos de múltiplos estádios para a dinâmica popu- lacional}

Até agora, foram apresentados modelos que descrevem os processos demográficos intrínsecos que ocorrem dentro das gerações e que podem interagir para determinar a produção de sementes da população ao todo. Para adicionar mais detalhes a esses modelos, pode-se deliberadamente 'separar' o ciclo de vida de uma espécie em vários processos que ocorrem dentro de uma geração (por exemplo, Figura 3.14), e então 'juntá-los' novamente para predizer a dinâmica sobre muitas gerações.

Modelos que dividem o ciclo de vida da espécie em um número de estádios discretos 
e consideram ganhos e perdas de um estádio para outro dentro do mesmo ciclo são denominados modelos de múltiplos estádios. Estes modelos são separados em duas categorias:

1. Modelos modulares para populações de plantas daninhas que se desenvolvem em sincronismo: todas as plantas emergem aproximadamente ao mesmo tempo e alcançam cada estádio de desenvolvimento em conjunto.

2. Modelos matriciais para populações de plantas daninhas que não se desenvolvem em sincronismo: diferentes estádios e tamanhos de plantas que coexistem.

Estudos visando quantificar as várias etapas do ciclo de vida de plantas daninhas começaram a aparecer nos anos 70 (Cousens e Mortimer, 1995). Em geral, a complexidade de modelos construídos nessa linha, dependem da disponibilidade de dados e do modo de observação dos processos. Segundo Cousens e Mortimer (1995), tem havido crescente interesse em modelos de múltiplos estádios de plantas daninhas, crescendo como uma monocultura ou mescladas às culturas agrícolas, devido a possibilidade de basear-se em muitos aspectos da biologia das plantas e de seu gerenciamento.

\subsubsection{Modelos modulares de múltiplos estádios}

Cousens e Mortimer (1995) apresentam um exemplo de uma população de plantas , em baixa densidade, tal que as transições entre um estádio e o seguinte é independente da densidade. A Figura 3.14 mostra um fluxograma de um simples ciclo de vida de plantas daninhas, onde os vários fluxos foram colocados ao lado das setas que conduzem de um estádio de desenvolvimento ao seguinte.

Neste exemplo, as principais causas identificadas de mortalidade de plantas são herbicidas, com taxa de mortalidade $h$, e os efeitos combinados de outros fatores extrínsecos denotados $m_{p}$. Como cada planta produz $s$ sementes, a mortalidade destas no período entre a produção e a entrada no banco de sementes no solo é por hipótese causada pela remoção provocada pela maquinaria de colheita denotada $r$, da predação e outros agentes naturais denotada $p$ e da queima da cobertura vegetal dessecada, denotada q. Perdas de sementes já contidas no solo resultam da germinação, denotada $g$, e da mortalidade combinada devido à deterioração por fungos, idade e predação denotada 


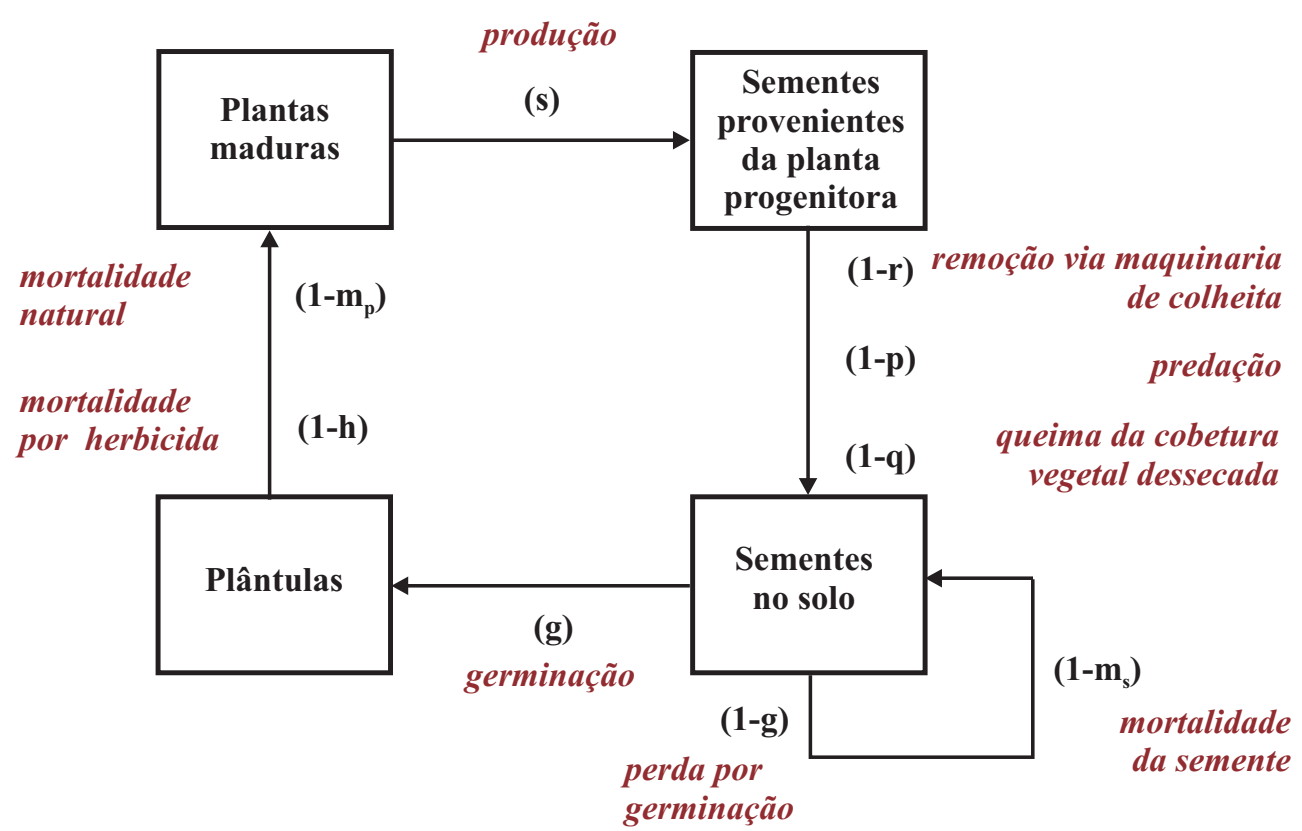

Figura 3.14: Ilustração do ciclo de vida de uma planta daninha anual. As probabilidades (fluxos) de uma fase à seguinte são mostradas nos parênteses. As letras referem-se a germinação $(g)$, mortalidade induzida por herbicida $(h)$, mortalidade natural da planta $\left(m_{p}\right)$, produção de semente $(s)$, remoção provocada pela maquinaria da colheita $(r)$, predação $(p)$, queima da cobertura vegetal dessecada $(q)$ e mortalidade da semente $\left(m_{s}\right)$.

$m_{s}$. Com exceção da produtividade de sementes $s$, todos os fluxos são probabilidades e encontram-se entre 0 (zero) e 1 (um).

Simulações podem ser feitas iniciando-se com um número dado de indivíduos em qualquer estádio particular de desenvolvimento, e multiplicando, por sua vez, por cada um dos fluxos na seqüência do fluxograma. Por exemplo, começando com $X_{0}$ sementes no banco, após uma única geração haverá

$$
X_{1}=g X_{0}(1-h)\left(1-m_{p}\right) s(1-r)(1-p)(1-q)+X_{0}\left(1-g-m_{s}\right)
$$

sementes remanescentes, onde $0<\left(1-g-m_{s}\right)<1$. Em geral, tem-se

$$
X_{t+1}=g X_{t}(1-h)\left(1-m_{p}\right) s(1-r)(1-p)(1-q)+X_{t}\left(1-g-m_{s}\right) .
$$

Desde que os termos no modelo exponencial discreto (3.30) são produtos simples de $X_{t}$, a taxa de crescimento $X_{t+1} / X_{t}$ é constante. De fato, a taxa de crescimento em baixa densidade foi separada em um número de componentes, isto é 


$$
R=g(1-h)\left(1-m_{p}\right) s(1-r)(1-p)(1-q)+\left(1-g-m_{s}\right) .
$$

Diversas abordagens podem ser consideradas para a construção de modelos modulares de múltiplos estádios , (3.30) é um exemplo. Segundo Cousens e Mortimer (1995), quando incorporados em um programa de computador, estes modelos podem ser utilizados para simular as densidades de populações futuras; donde se faz necessário especificar a densidade inicial $X_{0}$ da população para o cálculo recursivo ser iniciado. A taxa de crescimento pode ser calculada a partir das densidades em pares sucessivos de ciclos, isto é $X_{t+1} / X_{t}$. Entretanto, pode-se fazer um exame sobre diversas gerações para que $X_{t+1} / X_{t}$ estabilize tal que a suposição de independência da densidade não seja violada.

A atual popularidade dos modelos de múltiplos estádios se dá por sua estrutura modular, que concede basear-se em muitos aspectos da biologia e do manejo de plantas daninhas. Deste modo, é possível investigar os efeitos no modelo variando os valores de cada um dos seus parâmetros. Por exemplo, pode-se investigar os efeitos da queimada da cobertura vegetal dessecada ajustando este parâmetro de perda $(q(3.30))$ primeiramente a 0 (zero) e então a algum valor experimental determinado.

O modelo (3.30) aqui discutido não é realístico para densidades elevadas, desde que os vários processos de desenvolvimento são afetados pela densidade de planta com o aumento da competição intra-específica. Este fato pode ser considerado com a substituição dos fluxos constantes mostrados na Figura 3.14 por equações que os descrevam em função da densidade de plantas daninhas, por exemplo, o modelo hiperbólico (2.3). Simulações computacionais representam uma boa alternativa para analisar qualitativamente estes modelos mais complexos (Cousens e Mortimer, 1995). dentro do seu ciclo de vida.

\subsubsection{Modelos matriciais de múltiplos estádios}

Até agora, considerou-se que todas as plantas emergem, atravessam os vários estádios de seu ciclo de vida e se reproduzem ao mesmo tempo. Esta pode ser uma simplificação realística para muitas espécies daninhas, onde há freqüentemente um grande nível de emergência logo após a semeadura da cultura. Se houver plântulas emergindo posteriormente, pode ser que sejam insignificantes com relação ao número que emergiu 
mais cedo e, em conseqüência da interferência com a cultura e outras plantas daninhas, a produção de sementes pode ser negligenciada. No entanto, a suposição de uma população composta por indivíduos similares certamente não é válida para plantas bienais, perenes ou para plantas anuais que possuem episódios repetidos de produção de sementes e de germinação dentro de uma mesma estação de cultivo. Nestes casos, um simples fluxograma como o da Figura 3.14 não é adequado para representar estas espécies. Segundo Cousens e Mortimer (1995), modelos matriciais são ideais para esta finalidade e foram desenvolvidos para estudos de populações animais por Leslie (1945) e Lefkovit (1965) e estendido para populações de plantas por Usher (1973).

Para concepção deste modelo, primeiro é necessário descrever a população por variáveis de estado, tais como: sementes, várias idades de plantas ou estádios de desenvolvimento (tubérculos, plantas imaturas e plantas reprodutivas).

As várias probabilidades de sobrevivência e reprodução para cada variável de estado podem ser sumarizadas em uma matriz de 'projeção' ou 'transição', onde as colunas representam o estado corrente, e as linhas as probabilidades de sobrevivência no mesmo estado, levando uma planta a outro estádio de desenvolvimento ou de reproduzir dentro do intervalo de tempo. Neste contexto, uma matriz de transição de estado pode ser representada da seguinte maneira

$$
T=\left(\begin{array}{ccccc}
P_{s} & 0 & 0 & s & 0 \\
s_{p l} & P_{p l} & 0 & 0 & 0 \\
0 & p l_{i} & P_{p i} & 0 & r_{i} \\
0 & 0 & p i_{m} & P_{p m} & 0 \\
0 & 0 & 0 & r_{m} & P_{r_{d}}
\end{array}\right)
$$

onde $P_{s}$ é a probabilidade de uma semente sobreviver como semente (permanecer viável); $s$ o número de sementes produzidas por uma planta madura; $s_{p l}$ a proporção de sementes que se tornam plântulas; $P_{p l}$ a probabilidade de plântulas sobreviverem como plântulas; $p l_{i}$ a proporção de plântulas sobreviverem se tornarem plantas imaturas; $P_{p i}$ a probabilidade de plantas imaturas remanescentes permanecerem como plantas imaturas; $r_{i}$ a proporção de brotações da raiz (rizoma) produzindo plantas imaturas; $p i_{m}$ a proporção de plantas imaturas sobreviverem e tornarem plantas maduras; $P_{p m}$ a probabilidade de plantas maduras sobreviverem como plantas maduras; $r_{m}$ o número de brotações da 
raiz produzidos por uma planta madura; e $P_{r_{d}}$ a probabilidade de brotações da raiz sobreviverem como brotos dormentes.

Para a matriz (3.32), um vetor de estado corresponde a

$$
Z_{t}=\left(\begin{array}{c}
Z_{t, s} \\
Z_{t, p l} \\
Z_{t, p i_{m}} \\
Z_{t, p m} \\
Z_{t, r_{d}}
\end{array}\right)
$$

onde $Z_{t, i}$ é a densidade no tempo $t$ do estado $i$, com $i=s, p l, p_{i_{m}}, p_{m}, r_{d}$, representando sementes, plântulas, plantas imaturas tornando-se maduras, plantas maduras e brotações da raiz produzindo plantas imaturas, respectivamente.

A multiplicação da matriz $T$ das probabilidades e reproduções pelo vetor de estado $Z_{t}$ no início do intervalo de tempo $t$, fornece um vetor para o estado no tempo $t+1$, isto é

$$
Z_{t+1}=T Z_{t}
$$

Repetindo esta multiplicação para diversos intervalos de tempo, partindo de uma densidade inicial $Z_{0}$, na geração $t$ tem-se:

$$
Z_{t}=T^{t} Z_{0}
$$

Esta expressão é similar em estrutura à equação exponencial (3.3) e, uma vez que os valores na matriz não dependem da densidade, a dinâmica da população será exponencial.

Não foi considerado o 'comprimento' do intervalo $t$ entre as multiplicações sucessivas. Para populações de plantas perenes, este pode ser um intervalo de um ano. Entretanto, para gerações sobrepostas de plantas anuais ou perenes herbácias, espera-se que as probabilidades e reproduções mudem significativamente durante o ano. Então, é possível produzir matrizes de transição de estado para diferentes partes do ano e aplicar cada matriz de transição por sua vez.

Também é possível introduzir os efeitos dos herbicidas nos modelos matriciais de múltiplos estádios: se um herbicida matar uma proporção $k$ de plântulas, a probabi- 
lidade $P_{p l}$ pode ser substituída por $(1-k) P_{p l}$ e $(1-k) p l_{i}$ na matriz de transição de estado (3.32). Pode-se ter diferentes matrizes para diferentes cenários de gerenciamento de culturas.

\subsection{Modelos que descrevem o movimento vertical das se- mentes no solo}

O movimento vertical das sementes no solo é importante para descrever a dinâmica populacional das plantas daninhas (Cousens e Moss, 1990; Gonzalez-Andujar, 1997) e, conseqüentemente, o seu controle (Gonzalez-Andujar, 1997). As sementes se movem no solo devido as atividades humanas, predadores e fatores abióticos. Alguns pesquisadores estimaram que a quantidade de sementes enterradas na camada arável do solo pode atingir até 70000 (setenta mil) sementes por $m^{2}$ em diferentes agrosistemas e localidades (Monquero, 2003).

Os sistemas de cultivo são os principais responsáveis pela distribuição vertical de sementes (Gonzalez-Andujar, 1997; Lacerda, 2003), que varia de acordo com o tipo, velocidade e profundidade de trabalho do implemento agrícola utilizado, além da textura e umidade do solo (Carmona, 1992). Em geral, sementes colocadas em maiores profundidades abaixo da superfície do solo conservam melhor a sua capacidade de germinar (Freitas, 1990).

São raros na literatura os trabalhos que versam sobre a modelagem da distribuição vertical das sementes de plantas daninhas, o que já foi confirmado por Gonzalez-Andujar (1997), embora sua posição no solo provavelmente influencie a dinâmica populacional.

Antes de prosseguir, é apresentada um estudo introdutório sobre processo aleatório e cadeia de Markov, motivado pelo fato dos modelos que descrevem o movimento vertical de sementes no solo relacionarem as diversas transições de sementes de uma camada a outra no solo.

\subsubsection{Processo aleatório e cadeia de Markov}

Muitos processos que ocorrem na natureza podem ser estudados (pelo menos em primeira aproximação) como se o fenômeno estudado passasse, a partir de um estado 
inicial, por uma seqüência de estados, onde a transição de um determinado estado para o seguinte ocorreria segundo uma certa probabilidade. Segundo Boldrini et al. (1986), no caso em que esta probabilidade de transição depende apenas do estado em que o fenômeno se encontra e do estado seguinte, o processo é chamado processo de Markov e uma seqüência de estados seguindo este processo é chamada cadeia de Markov. Evidentemente, ao se supor tal restrição faz-se uma simplificação, uma vez que as probabilidades podem se modificar com o tempo. Assim mesmo, a informação que se obtém com este modelo já serve de auxílio para uma previsão do comportamento de certos fenômenos, em particular, o movimento vertical das sementes no solo.

A matriz das probabilidade de transição de ordem $n$ de um processo markoviano é dada por:

$$
M=\left(\begin{array}{cccc}
p_{11} & p_{12} & \cdots & p_{1 n} \\
p_{21} & p_{22} & \cdots & p_{2 n} \\
\vdots & \vdots & \ddots & \vdots \\
p_{n 1} & p_{n 2} & \cdots & p_{n n}
\end{array}\right)
$$

onde $p_{i j}$ é a probabilidade de transição de um estado $i$ para um estado $j$. Observe que $p_{i j} \geq 0$ e que a soma de cada coluna deve ser igual a 1.

Definição 3.1 (matriz de transição regular) Uma matriz de probabilidades de transição é regular se alguma de suas potências possuem todos os elementos não nulos.

\subsubsection{Modelos matriciais da distribuição vertical do banco de semen- tes}

Gonzalez-Andujar (1997) apresenta o modelo (3.37) abaixo para a distribuição vertical de sementes no solo, o qual pode ser usado para simular os efeitos de diferentes técnicas de cultivo sobre o banco de sementes

$$
D_{t+1}=L D_{t} \quad t=1,2, \cdots
$$

onde $D_{t}$ é o vetor da distribuição da idade no tempo $t$, 


$$
D_{t}=\left(\begin{array}{c}
D_{1} \\
D_{2} \\
\vdots \\
D_{n}
\end{array}\right)
$$

com $D_{i}$ representando o número de sementes na $i$-ésima classe de idade $(i=1, \cdots, n)$ no tempo $t$; $L$ é a matriz de Leslie (Leslie, 1945; Pielou, 1977) adaptada para as características do banco de sementes,

$$
L=\left(\begin{array}{cccccc}
f_{1} & f_{2} & f_{3} & \cdots & f_{n-1} & f_{n} \\
s_{1} & 0 & 0 & \cdots & 0 & 0 \\
0 & s_{2} & 0 & \cdots & 0 & 0 \\
\vdots & \vdots & \vdots & \ddots & \vdots & 0 \\
0 & 0 & 0 & \cdots & s_{n-1} & 0
\end{array}\right)
$$

com $f_{i}, i=1, \cdots, n$, a fração média de sementes produzidas a partir de uma simples semente pertencente à $i$-ésima classe de idade e $s_{i}$ o número de sementes na $i$-ésima classe de idade que pode sobreviver e se mover para a $(i+1)$-ésima classe de idade. Deve-se ressaltar que $s_{i}$ é composto pela mortalidade $(m)$ e germinação $(g)$ de sementes, ou seja

$$
s_{i}=1-\left(m_{i}+g_{i}\right)
$$

Conseqüentemente, $0<s_{i} \leq 1$ para $i=1,2, \cdots, n-1$ e $f_{i} \geq 0$ para $i=1,2, \cdots, n$.

Portanto, conhecendo-se o vetor inicial $D_{0}$ da distribuição da idade e a matriz de Leslie $L$, a distribuição da idade da semente em qualquer tempo $t$ pode ser determinada

$$
D_{t}=L^{t} D_{0} \quad t=1,2, \cdots
$$

Para grandes valores de $t$,

$$
D_{t}=c v \lambda^{t}
$$

onde $\lambda$ é o autovalor dominante (o valor $\lambda_{i}$ de maior magnitude) de $L, v$ é o autovetor correspondente com elementos positivos e $c$ é uma constante. 
Uma extensão do modelo matricial de Leslie, para considerar o movimento vertical das sementes no solo, pode ser realizada de duas maneiras:

1. Construindo uma matriz $n \times p$ para incorporar a profundidade das sementes além da distribuição de sementes por idade $D_{t}$

$$
D_{t}=\left(\begin{array}{cccc}
D_{11} & D_{12} & \cdots & D_{1 p} \\
D_{21} & D_{22} & \cdots & D_{2 p} \\
\vdots & \vdots & \ddots & \vdots \\
D_{n 1} & D_{n 2} & \cdots & D_{n p}
\end{array}\right)
$$

onde o termo geral $D_{i j}$ é o número das sementes da classe de idade $i$ na profundidade $j$; e

2. Utilizando a matriz de Markov $M$ (3.36) no modelo 3.37 para considerar a probabilidade do movimento vertical das sementes. Neste caso, o termo geral $p_{i j}$ da matriz $M$ representa a probabilidade do movimento das sementes da profundidade $i$ à profundidade $j$, com $0 \leq p_{i j} \leq 1 ; i, j=1, \cdots, n$ e $\sum_{j=1}^{n} p_{i j}=1$. Neste caso, supõe-se que todas as sementes da mesma classe de idade possuem a mesma probabilidade de movimento. Geralmente, considera-se o efeito do movimento das sementes depois da reprodução, assim a matriz $M$ pode ser incluída em (3.37) como segue,

$$
D_{t+1}=L D_{t} M \quad t=1,2, \cdots
$$

cuja solução geral é expressa por:

$$
D_{t+1}=L^{t} D_{0} M^{t} \quad t=1,2, \cdots
$$

O comportamento, a longo prazo, da população é representado por:

$$
D_{t}=c v \lambda^{t} D_{e}
$$

onde $D_{e}$ é a matriz que representa o limite da matriz $M$, ou seja, a distribuição de profundidade estável.

É importante ressaltar, que o modelo matricial da distribuição vertical das sementes no solo apresentado por Gonzalez-Andujar (1997), não considera os efeitos de regulação 
populacional dependentes da densidade e, conseqüentemente, apresenta um crescimento exponencial não realístico da população. No entanto, fornece uma idéia de como a matriz de Leslie, adaptada para as características do banco de sementes, pode ser introduzida em modelos dinâmicos de comunidades de plantas daninhas.

\subsubsection{A inserção dos efeitos dependentes da densidade em modelos que descrevem a posição vertical de sementes no solo}

Cousens e Moss (1990) apresentaram um estudo de obtenção de dados do movimento vertical de grânulos plásticos enterrados em profundidades específicas para predizer as posições verticais de sementes de Alopecurus myosuroides a longo prazo. O modelo utilizado foi baseado no modelo dependente da densidade publicado por Doyle et al. (1986), o qual foi adaptado a partir do modelo independente da densidade de Cussans e Moss (1982). Especificamente, os dois níveis de solo nos modelos precedentes são substituídos por quatro níveis que correspondem aos intervalos de $5 \mathrm{~cm}$ de profundidade. Supõe-se que o movimento dentro do solo resulta somente do cultivo anual, isto é, os efeitos da chuva, geada, vento, etc. não são considerados. O modelo do movimento vertical de sementes é uma forma baseada no modelo matricial de Leslie (Leslie, 1945; Pielou, 1977), geralmente usado na Ecologia para predizer o número de organismos por classes de idade.

Foi construída uma matriz $M$ de probabilidades do movimento de sementes de uma profundidade a outra, em conseqüência das técnicas de cultivo. A multiplicação da matriz $M$ por um vetor $D_{i, t}$ do número de sementes presente em cada nível fornece um vetor $D_{i, t+1}$ do número de sementes em cada nível após o cultivo no tempo $t+1$ :

$$
\left(\begin{array}{llll}
p_{11} & p_{21} & p_{31} & p_{41} \\
p_{12} & p_{22} & p_{32} & p_{42} \\
p_{13} & p_{23} & p_{33} & p_{43} \\
p_{14} & p_{24} & p_{34} & p_{44}
\end{array}\right)\left(\begin{array}{c}
D_{1, t} \\
D_{2, t} \\
D_{3, t} \\
D_{4, t}
\end{array}\right)=\left(\begin{array}{c}
D_{1, t+1} \\
D_{2, t+1} \\
D_{3, t+1} \\
D_{4, t+1}
\end{array}\right)
$$

Uma expressão mais concisa para a distribuição vertical de sementes é:

$$
D_{t+1}=m D_{t} \quad t=1,2, \cdots
$$


onde $D_{t}$ é o vetor que representa o número de sementes em cada camada de solo.

Reservas de sementes existentes no solo diminuirão, com o decorrer do tempo, em conseqüência da germinação e da mortalidade. No entanto, sementes também são adicionadas à camada superficial do solo através da produção de sementes pelas plantas maduras. Seja $X_{t}$ o número de sementes produzidas em $t$ e que são adicionadas somente à camada superficial do solo. Assim, o número de sementes em cada profundidade é dado por:

$$
D_{t+1}=M\left(S_{t}+v_{r} D_{t}\right) \quad t=1,2, \cdots
$$

em que $v_{r}$ é a proporção de sementes restantes nas camadas inferiores do solo de um ciclo ao seguinte e:

$$
S_{t}=\left(\begin{array}{llll}
X_{t} & 0 & 0 & 0
\end{array}\right)^{\prime}
$$

relembrando que $X_{t}$ é a densidade de sementes na geração $t$.

Supondo que as plântulas somente são produzidas por sementes que estão na camada superficial do solo, o número de plântulas de daninhas produzidas será:

$$
W_{t}=\frac{h_{s} g D_{1, t}}{\left(1+a g D_{1, t}\right)}
$$

onde $h_{s}$ proporção sobrevivente às aplicações de herbicidas; $a$ e $g$ como já definidos. Neste caso, tem-se $D_{1, t}=X_{t}$, e conseqüentemente, $W_{t}=Y_{t}$. Nestas condições, o número de sementes viáveis que retornam ao solo em $t$ é

$$
X_{t}=v(1-p)(1-q) s \frac{Y_{t}}{\left(1+a Y_{t}\right)}
$$

com $p$ a proporção removida pelo vento ou pela predação por pequenos mamíferos, pássaros, fauna do solo e fungos ou que germinam e morrem antes de perfurar a camada superficial do solo; $q$ a proporção das sementes mortas pela queima de palha no solo; $s$ e $v$ como já definidos.

\subsection{Discussão}

Num agrosistema sob baixa densidade de plantas, quando a disputa por recursos vitais (água, luz e nutrientes) é menor, a dinâmica populacional de plantas daninhas pode 
ser descrita pelo modelo linear (3.2) em que a taxa de crescimento populacional $R$ é independente da densidade de plantas daninhas. A introdução de um parâmetro para a proporção de plantas daninhas mortas por um herbicida neste modelo, como visto em (3.15), pode ser utilizada como uma ferramenta de análise do desempenho de um herbicida de acordo com o mínimo exigido pelo Ministério da Agricultura, o que é de suma importância para o registro do produto (Vismara et al., 2005).

Conseqüentemente, com a ausência de competição, a tendência da população é aumentar em tamanho e com os acréscimos de plantas daninhas a população passa a competir, e a partir deste ponto diz-se que a taxa de crescimento populacional é dependente da densidade.

Em linhas gerais, a dinâmica populacional não linear de plantas daninhas em agrosistemas pode ser descrita pelo modelo (3.5), o qual relaciona as densidades de plântulas e de sementes produzidas em áreas de cultivo. Neste contexto, o modelo (3.7) com a taxa de crescimento populacional dada por (3.8), (3.11), (3.12), (3.13), (3.14) e (3.17) são exemplos de funções para o modelo (3.5) e são denominados modelos de único estádio, os quais descrevem apenas mudanças de densidade de um ciclo ao seguinte.

Para espécies daninhas que coexistem em diferentes estádios de desenvolvimento os modelos de único estádio não são adequados. Neste caso, são necessários modelos de múltiplos estádios, nos quais há divisão do ciclo de vida da espécie daninha em um número de estádios discretos e consideram ganhos e perdas de um estádio para outro dentro do mesmo ciclo.

Assim, se for possível considerar que todas as plantas emergem aproximadamente ao mesmo tempo e alcançam cada estádio de desenvolvimento em conjunto os modelos modulares de múltiplos estádios são apropriados. O modelo (3.30) é um exemplo de construção modular, para baixas densidades de plantas daninhas, onde os vários estádios de desenvolvimento da planta são relacionados aos ganhos/perdas de um estádio de desenvolvimento ao seguinte. Um caminho para relacionar a dependência e a independência da densidade neste modelo seria substituir os fluxos constantes por equações que determinam os fluxos em função da densidade de plantas daninhas. Agora, se para cada espécie é necessário determinar os diferentes estádios e tamanhos de plantas que coexistem, modelos matriciais de múltiplos estádios do tipo (3.34) são indicados.

Modelos que descrevem a posição vertical das sementes no solo podem ser utiliza- 
dos para simular práticas agrícolas ou para predizer as posições verticais de sementes no solo e, conseqüentemente, prever a capacidade germinativa da semente em função da sua profundidade no solo. O modelo (3.44) pode ser usado para este fim, porém não considera os efeitos que regulam o crescimento populacional dependentes da densidade, apenas fornecem uma idéia de como a matriz de Leslie pode ser adaptada às características do banco de sementes em modelos dinâmicos. 


\section{Capítulo 4}

\section{A inferência estatística e o método de Monte Carlo}

A informação que se tem sobre uma quantidade de interesse denotada $\theta$ é fundamental na Estatística. O verdadeiro valor de $\theta$ é desconhecido e a idéia é reduzir este desconhecimento. Além disso, a intensidade da incerteza a respeito de $\theta$ pode assumir diferentes graus (Ehlers, 2004b). Desta forma, um problema importante da inferência estatística é a estimação dos parâmetros de um modelo deduzidos de um conjunto de dados amostrais (Favoretti, 1995). Na prática, tem-se interesse em tomar decisões sobre os parâmetros baseados nas informações das amostras.

Usualmente, inferências sobre os parâmetros baseiam-se em métodos estatísticos clássicos, os quais consistem da obtenção de estimadores de mínimos quadrados e estimadores de máxima verossimilhança e da suposição de propriedades assintóticas para estes estimadores. Porém na presença de pequenas amostras, faz-se uso de métodos bayesianos, os quais consideram os parâmetros como variáveis aleatórias e permitem expressar a opinião a priori do pesquisador (Fishman, 1996; Mena, 2000). Assim, a distribuição a posteriori pode ser obtida, em alguns casos, eliminando-se o uso de resultados assintóticos (Mena, 2000).

A seguir, faz-se uma breve distinção entre o paradigma estatístico clássico e o bayesiano, apresentam-se uma introdução básica sobre as duas metodologias de inferência de acordo com Gelman et al. (2000), Paulino et al. (2003), Ehlers (2004a) e Ehlers (2004b) e, por fim apresentam-se os métodos baseados em simulação de Monte Carlo simples 
e via cadeias de Markov segundo Ehlers (2004b). No Apêndice A, são apresentadas algumas definições segundo Dantas e Rodrigues (1979) relevantes para o entendimento do presente Capítulo.

\subsection{A estatística clássica versus a bayesiana}

No quadro clássico, para estabelecer inferências, é necessário se ter em mente que os dados observados formam apenas um dos muitos conjuntos que poderiam ter sido obtidos nas mesmas circunstâncias (Paulino et al., 2003). Segundo tal perspectiva, a interpretação dos dados também depende de hipóteses acerca dos possíveis conjuntos alternativos de dados. Neste contexto, a inferência clássica contém uma vasta gama de procedimentos que se destinam a explorar o tipo de conclusões que podem ser extrair-se da amostra sobre as características do modelo representativo da população.

Por outro lado, a filosofia bayesiana possui seus alicerces na idéia de 'probabilidade' como grau de 'credibilidade'. A idéia de coerência de um sistema de graus de credibilidade pode ser ilustrada através da seguinte afirmação: "a atitude de um indivíduo ao apostar na veracidade de uma dada proposição está associada com o grau de credibilidade que esse individuo lhe atribui" (Paulino et al., 2003).

Em certo sentido, os métodos bayesianos passam por uma extensão do modelo clássico. Por exemplo, no modelo clássico o parâmetro do modelo representativo da população é um escalar ou vetor desconhecido mas fixo, e descreve 'apropriadamente' o sistema físico que gera as observações. A filosofia bayesiana é, neste ponto a seguinte: o que é desconhecido é incerto e toda a incerteza deve ser quantificada em termos de probabilidade (Paulino et al., 2003). Correlativamente, os bayesianos defendem que a informação inicial ou a priori pode traduzir-se formalmente por uma distribuição de probabilidade, a qual exprime o grau de credibilidade que o pesquisador que realiza a análise atribui ao parâmetro em particular considerado (Paulino et al., 2003).

De acordo com Manly (1997), um estatístico clássico ainda pode discutir se o conhecimento real de informações a priori é freqüentemente mínimo; já um bayesiano pode discorrer que todas as decisões importantes sobre o mundo real são em parte subjetivas, e que em qualquer caso este conhecimento a priori aplicado surte pouco efeito quando dos dados provêm uma quantia razoável de informação. Desta forma, a abordagem 
bayesiana tem a vantagem de que qualquer informação prévia do sistema de interesse pode ser incorporada ao conjunto de dados.

\subsection{A inferência clássica}

Um aspecto importante da inferência estatística clássica consiste em reconhecer a variabilidade que se verifica de amostra para amostra (Ara et al., 2003). Neste contexto, a interpretação dos dados depende não apenas do particular conjunto observado mas também das hipóteses acerca dos possíveis conjuntos alternativos de dados (Paulino et al., 2003). A seguir, faz-se uma breve distinção entre regressão linear e regressão não linear segundo Favoretti (1995), Ara et al. (2003) e Batista (2004); apresentam-se também o teste de significância dos parâmetros do modelo de regressão e o procedimento para construção de intervalos de confiança.

\subsubsection{Regressão linear}

Nos modelos lineares, o problema de estimação dos parâmetros resume-se no problema de resolver um sistema de equações lineares com relação a parâmetros desconhecidos. Existe uma solução única e, portanto, obtém-se uma forma analítica de estimação dos parâmetros. Esta solução é a mesma para qualquer modelo e qualquer conjunto de dados.

A regressão linear é subdividida em simples e múltipla. A regressão linear simples apresenta apenas uma variável independente, já a regressão múltipla apresenta mais de uma variável independente. O caso mais simples de regressão é quando tem-se duas variáveis, uma independente e outra dependente, e a relação entre estas pode ser representada por uma linha reta, que é a regressão linear simples.

Um modelo de regressão linear múltipla é representado por

$$
y_{i}=\beta_{0}+\beta_{1} x_{i 1}+\beta_{2} x_{i 2}+\ldots+\beta_{p} x_{i p}+\epsilon_{i}
$$

onde $y_{i}, i=1,2, \ldots, n$ representa a variável dependente, $x_{i 1}, \ldots, x_{i p}$ são variáveis independentes, $\beta$ é o vetor de parâmetros, $\epsilon_{i}$ é o erro ou resíduo do modelo descrito por um processo estocástico e os subscritos $n$ e $p$ representam o número de amostras e o número 
de parâmetros do modelo, respectivamente.

As variáveis independentes também são chamadas de variáveis explicativas ou regressoras; por sua vez, a variável dependente também é chamada de variável resposta.

As pressuposições para o modelo linear são

1. A variável $X$ é não aleatória, isto é, seus valores são fixados ou determinados com erro desprezível;

2. Para cada valor da variável $X$ a variação residual $\epsilon$ tem distribuição normal, com média zero e variância constante: $\epsilon_{i} \sim N\left(0, \sigma^{2}\right)$.

3. Os resíduos são não correlacionados, isto é, para cada valor de $X$ os valores dos resíduos são independentes entre si: $\operatorname{Cov}\left[\epsilon_{i}, \epsilon_{j}\right]=0$, para $i \neq j$.

Com essas suposições, a reta de regressão fornece os valores médios de $Y$ em função dos valores de $X$.

O erro de estimação, ou resíduo, pode ser calculado por

$$
\epsilon_{i}=y_{i}-\hat{y}_{i}=y_{i}-\left[\hat{\beta}_{0}+\sum_{j=1}^{p} \hat{\beta}_{j} x_{i j}\right] \text {. }
$$

Em geral, para encontrar uma estimativa para os parâmetros do modelo linear utiliza-se o método dos mínimos quadrados, minimizando-se a soma dos quadrados dos resíduos. Então, deve-se encontrar um valor de $\beta$ que minimize a função $S(\beta)$ dada por

$$
S(\beta)=\sum_{i=1}^{n}\left[y_{i}-\left(\beta_{0}+\sum_{j=1}^{p} \beta_{j} x_{i j}\right)\right]^{2} .
$$

A partir da função (4.3), deriva-se e iguala-se a zero, obtendo assim as equações normais com a finalidade de encontrar a solução mínima de (4.3).

Algumas das propriedades dos estimadores de mínimos quadrados, respeitadas as pressuposições do modelo linear, são

。 o estimador de mínimos quadrados é não viesado, ou seja, $E[\hat{\beta}]=\beta$;

- a variância do erro, $\sigma^{2}$, é constante. 
Uma estimativa para $\sigma^{2}$ é dada por

$$
s^{2}=\frac{S(\beta)}{n-p} .
$$

Deve-se ressaltar que para calcular a variância sempre eleva-se ao quadrado as unidades de medida, gerando escalas sem sentido prático. Para recuperar as unidades originais utiliza-se a raiz quadrada da variância denominada desvio padrão e indicada por $s$.

Para modelos lineares, o coeficiente de determinação (ou explicação), denotado $R^{2}$, é freqüentemente usado como indicador de quão bom foi o ajuste dos dados ao modelo de regressão, pois representa a proporção da variabilidade de $y_{i}$ que é explicada por $x_{i}$

$$
R^{2}=\frac{S Q T-S Q R}{S Q T}=1-\frac{S Q R}{S Q T}
$$

onde $S Q T=\sum_{i=1}^{n}\left(y_{i}-\bar{y}\right)^{2}$ mede a proporção da variabilidade total das observações e $S Q R=\sum_{i=1}^{n}\left(y_{i}-\hat{y}_{i}\right)^{2}$ é a soma dos quadrados dos erros de regressão. O coeficiente de determinação tem valores entre zero e um $\left(0<R^{2}<1\right)$. Um valor de $R^{2}$ próximo de 1 (um) indica que a maioria da variação de $y$ é explicada pelos diferentes valores de $x$, já um valor próximo de 0 (zero) indica que pouco desta variação é explicada.

O coeficiente de determinação ajustado é dado por

$$
R_{a j}^{2}=1-\left(\frac{n-1}{n-p}\right)\left(1-R^{2}\right)
$$

Desta forma, se as pressuposições sobre os erros são satisfeitas, pode-se calcular os intervalos de confiança para os parâmetros e para a resposta estimada em um certo ponto $x_{0}$.

\section{Linearização do modelo de produção de sementes}

Para ajustar um modelo de regressão linear entre duas variáveis, deve-se verificar se existe uma correlação linear entre elas. No entanto, mesmo que a função que relaciona as variáveis não seja linear, muitas vezes é possível torná-la por meio de uma transformação conveniente. Por exemplo, considere o modelo (3.7) com a taxa de crescimento 
populacional dada por (3.8), repetido abaixo

$$
X_{t+1}=\frac{R X_{t}}{\left(1+d X_{t}\right)^{b}}
$$

dividindo por $X_{t}$ e aplicando o logaritmo natural em ambos os lados, obtem-se:

$$
\ln \left(\frac{X_{t+1}}{X_{t}}\right)=\ln (R)-b \ln \left(1+d X_{t}\right)
$$

Para $d X_{t}>>1$ tem-se $\ln \left(1+d X_{t}\right) \approx \ln \left(d X_{t}\right)$, assim a expressão

$$
\ln \left(\frac{X_{t+1}}{X_{t}}\right) \approx \ln (R)-\ln (d)-b \ln \left(X_{t}\right)
$$

é o modelo linearizado de (3.7) com taxa de crescimento (3.8) (Freckleton e Watkinson, 2002).

A formulação estatística de (4.7) é

$$
y_{i}=\beta_{0}+\beta_{1} x_{i}+\epsilon_{i}
$$

onde $y_{i}=\ln \left(X_{t+1} / X_{t}\right)$ é a variável dependente, $x_{i}=-\ln \left(X_{t}\right)$ a variável independente, $\beta_{0}=\ln (R)-\ln (d)$ e $\beta_{1}=b$.

\subsubsection{Regressão não linear}

Um modelo de regressão é dito não linear, se é não linear nos seus parâmetros. Isto implica que as derivadas da função com respeito aos parâmetros envolvem pelo menos um dos parâmetros (Favoretti, 1995). Assim, considere uma situação em que os dados consistem de uma resposta $y_{i}$ que depende de $n$ variáveis independentes $x_{i}$, e que pode ser representada pelo modelo de regressão não linear com $p$ parâmetros

$$
y_{i}=f\left(x_{i}, \theta\right)+\epsilon_{i}, \quad i=1, \cdots, n
$$

onde $\theta$ é o vetor de parâmetros pertencente a um subconjunto de $\mathcal{R}^{p}, f\left(x_{i}, \theta\right)$, $f: \mathcal{R} \rightarrow \mathcal{R}$ é uma função não linear, $y_{i}$ é a variável dependente do modelo $x_{i}$ é a variável independente do modelo e $\epsilon_{i}$ representa o erro descrito por um processo esto- 
cástico.

A diferença entre o estimador de mínimos quadrados da regressão linear para a regressão não linear é que os estimadores dos parâmetros apesar de não enviesado, normalmente distribuído e de variância mínima, encontram estas propriedades somente assintoticamente (quando o tamanho da amostra tende ao infinito). Desta forma, nem sempre é possível encontrar formas analíticas para os estimadores de mínimos quadrados, e portanto, a solução das equações normais usualmente requer a utilização de métodos numéricos. Isto tipicamente envolve o uso de um aplicativo computacional, pois os cálculos podem ser muito extensos (Favoretti, 1995; Batista, 2004).

\subsubsection{Testes de hipóteses sobre os parâmetros do modelo de regressão}

Embora a curva de regressão estimada seja a curva que melhor se ajusta aos pontos amostrais, deve-se levar em consideração que esta curva foi estimada a partir de uma amostra de pontos experimentais e pode não representar bem a relação entre as variáveis na população, especialmente quando a amostra contem poucos pontos (Ara et al., 2003). Faz-se necessário, portanto, testar hipóteses sobre os verdadeiros valores dos parâmetros do modelo de regressão a partir de suas estimativas.

Considerando-se o modelo de regressão e suas pressuposições, pode-se realizar o teste de significância de seus parâmetros. Assim, o teste da hipótese

$$
\begin{aligned}
& H_{0}: \theta=0 \\
& H_{1}: \theta \neq 0
\end{aligned}
$$

pode ser feito por meio da estatística $t$-Student, rejeitando-se $H_{0}$ a um nível de significância desejado $\alpha$ (por exemplo, $\alpha=0,05$ ) e, concluindo-se que os parâmetros testados são significativos se $t>t_{0}$, onde $t_{0}$ é o valor crítico da distribuição $t$-Student, com $(n-p)$ graus de liberdade (Ara et al., 2003).

\subsubsection{Intervalos de confiança}

Para encontrar o verdadeiro valor do parâmetro, constrói-se, a partir de observações amostrais, um intervalo que tenha uma probabilidade conhecida de encerrar esse valor. 
Essa probabilidade conhecida e fixada pelo pesquisador recebe o nome de grau ou nivel de confiança e é indicada por $1-\alpha$, onde $\alpha$ é a probabilidade de que o intervalo construído não contenha o valor do parâmetro.

Procedimento geral para construção de um intervalo de confiança

O procedimento geral para construção de um intervalo de confiança consiste nos seguintes passos (Ehlers, 2004a)

1. Obter uma estatística que depende de $\theta, U=G(X, \theta)$, mas cuja distribuição não depende de $\theta$;

2. Usando a distribuição de $U$, encontrar as constantes $a$ e $b$ tais que $P(a \leq U \leq$ b) $\geq 1-\alpha$

3. Definir $\{\theta: P(a \leq G(X, \theta) \leq b)\}$ como o intervalo (ou região) de confiança $100(1-\alpha) \%$ para $\theta$.

É importante notar que este intervalo não pode ser interpretado como um intervalo de probabilidade para $\theta$ já que a aleatoriedade presente é devida à amostra $X$. Ou seja, o procedimento leva a construção de um intervalo probabilístico para $U$ e não para $\theta$.

Tecnicamente, diz-se que 100(1- $\alpha) \%$ de todos os intervalos de confiança construídos a partir deste procedimento contém o verdadeiro valor do parâmetro (dado que todas as suposições envolvidas estejam corretas). A probabilidade $1-\alpha$ é denominada nível de confiança e sua escolha depende da precisão com que se deseja estimar o parâmetro, sendo que 0,90, 0,95 e 0,99 são os valores mais comuns na prática.

\subsection{Princípio da verossimilhança}

A função de verossimilhança tem papel fundamental, quer na inferência clássica, quer na inferência bayesiana, como veículo portador da informação dada pela amostra. O princípio da verossimilhança sustenta que toda a informação dada pela amostra ou pela experiência está contida na função de verossimilhança (Paulino et al., 2003). Em outras palavras, tal princípio postula que para fazer inferência sobre uma quantidade de interesse $\theta$ só importa aquilo que foi realmente observado e não aquilo que 'poderia' ter ocorrido mas efetivamente não ocorreu (Ehlers, 2004b). 
O conceito de função de verossimilhança se aplica a qualquer distribuição estatística. No caso de variáveis contínuas, a função de verossimilhança é obtida a partir da função de densidade probabilística.

\section{Função de verossimilhança}

Seja $X_{1}, \ldots, X_{n}$ uma amostra aleatória de $p(x \mid \theta), \theta \in \Theta$. A função de verossimilhança de $\theta$ correspondente a esta amostra aleatória é definida por

$$
L(\theta ; x)=\prod_{i=1}^{n} p\left(x_{i} \mid \theta\right) .
$$

\section{Estimador de máxima verossimilhança}

O estimador de máxima verossimilhança de $\theta$ é, por definição, o valor de $\hat{\theta} \in \Theta$ que maximiza $L(\theta ; x)$.

\section{Propriedades assintóticas do estimador de máxima verossimilhança}

Em muitas situações o problema de obter o estimador de máxima verossimilhança (4.11) tem solução analítica explícita, porém, pode ser uma tarefa difícil verificar a eficiência do estimador de máxima verossimilhança, já que este em geral é uma função complicada da amostra (Ehlers, 2004a). Uma alternativa é estudar o comportamento do estimador quando o tamanho da amostra $n$ tende a infinito. Como na prática o tamanho da amostra é finito os resultados obtidos são aproximadamente corretos para $n$ suficientemente grande (Ehlers, 2004a).

\subsection{Introdução à inferência bayesiana}

Do ponto de vista bayesiano, os diferentes graus de incerteza sobre uma quantidade de interesse denotada $\theta$ são representados através de modelos probabilísticos para $\theta$. Sendo assim, não existe nenhuma distinção entre quantidades observáveis e os parâmetros de um modelo estatístico, todos são considerados quantidades aleatórias. 


\subsubsection{Fórmula de Bayes}

Considere uma quantidade de interesse desconhecida $\theta$. A informação disponível sobre $\theta$, resumida probabilisticamente através da distribuição ou função de densidade de probabilidade $p(\theta)$, pode ser aumentada observando-se uma variável aleatória $X$ relacionada $\operatorname{com} \theta$. A distribuição amostral $p(x \mid \theta)$ define esta relação. Assim, a função de probabilidade conjunta $p(\theta, x)$ pode ser escrita como produto de duas densidades que são freqüentemente denominadas distribuição amostral $p(x \mid \theta)$ e a distribuição (ou função de densidade) a priori $p(\theta)$, respectivamente,

$$
p(\theta, x)=p(x \mid \theta) p(\theta) .
$$

Assim, a idéia de que após observar $X=x$ a quantidade de informação sobre $\theta$ aumenta é bastante intuitiva e o teorema de Bayes é a regra de atualização utilizada para quantificar este aumento de informação produzindo a densidade a posteriori $p(\theta \mid x)$.

$$
p(\theta \mid x)=\frac{p(\theta, x)}{p(x)}=\frac{p(x \mid \theta) p(\theta)}{p(x)} .
$$

onde $p(x)=\sum_{\theta} p(x \mid \theta) p(\theta)$, e o somatório é sobre todos os valores possíveis de $\theta$ (ou $p(x)=\int p(x \mid \theta) p(\theta) d \theta$ no caso de $\theta$ contínuo). Note que $1 / p(x)$, que não depende de $\theta$, funciona como uma constante normalizadora de $p(\theta \mid x)$.

Para um valor fixo de $x$, a função $L(\theta ; x):=p(x \mid \theta)$ fornece a plausibilidade ou verossimilhança de cada um dos possíveis valores de $\theta$. Estas duas fontes de informação, priori e verossimilhança, são combinadas levando à densidade a posteriori de $\theta, p(\theta \mid x)$. Assim, a forma usual do teorema de Bayes é

$$
p(\theta \mid x) \propto L(\theta ; x) p(\theta)
$$

ou seja, a densidade a posteriori é proporcional à função verossimilhança vezes a densidade a priori.

É intuitivo, que a probabilidade a posteriori de um particular conjunto de valores de $\theta$ será pequena se $p(\theta)$ ou $L(\theta ; x)$ for pequena para este conjunto. Em particular, se for atribuída probabilidade a priori igual a 0 (zero) para um conjunto de valores de $\theta$, então, a probabilidade a posteriori será 0 (zero) qualquer que seja a amostra observada. 
A constante normalizadora da posteriori pode ser facilmente recuperada pois

$$
p(\theta \mid x)=k p(\theta) p(x \mid \theta)
$$

onde

$$
k^{-1}=\int p(\theta) p(x \mid \theta) d(\theta)=p(x)
$$

é chamada distribuição preditiva, ou seja, é a distribuição esperada para a observação $x$ dado $\theta$.

Agora, observando-se $x_{1}, x_{2}, \cdots, x_{n}$ independentes dado $\theta$ e relacionadas a $\theta$ através de $p_{i}\left(x_{i} \mid \theta\right)$ segue que:

$$
p\left(\theta \mid x_{n}, x_{n-1}, \cdots, x_{1}\right) \propto\left[\prod_{i=1}^{n} L_{i}\left(\theta ; x_{i}\right)\right] p(\theta) .
$$

Ou seja, os conceitos de priori e posteriori são relativos àquela observação que está sendo considerada no momento. Por exemplo, $p\left(\theta \mid x_{1}\right)$ é a posteriori de $\theta$ em relação a $X_{1}$ (que já foi observado), mas é a priori de $\theta$ em relação a $X_{2}$ (que não foi observado ainda). Após observar $X_{2}=x_{2}$ uma nova posteriori (relativa a $X_{1}=x_{1}$ e $X_{2}=x_{2}$ ) é obtida aplicando-se novamente o Teorema de Bayes. Logo, a ordem em que as observações são processadas pelo Teorema de Bayes é irrelevante. Na verdade, estas podem até ser processadas em subgrupos.

\subsubsection{Distribuição ou função de densidade a priori}

A utilização de informação a priori em inferência bayesiana requer a especificação de uma distribuição a priori para a quantidade de interesse $\theta$. Esta distribuição deve representar, probabilisticamente, o conhecimento que se tem sobre $\theta$ antes da realização do experimento. A Figura 4.1 apresenta algumas das várias distribuições que podem ser utilizadas como fontes de informação a priori.

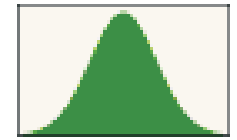

Normal

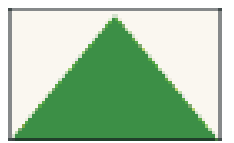

Triangular

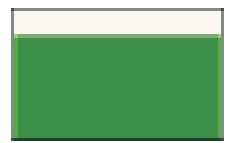

Uniforme

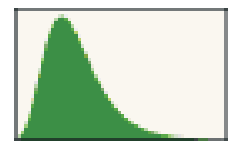

Lognormal

Figura 4.1: Exemplos de distribuições de probabilidade: normal, triangular, uniforme e lognormal. 


\section{Priori não informativa}

$\mathrm{Na}$ abordagem bayesiana, a informação a priori do pesquisador a respeito da interpretação dos parâmetros pode ser expressa utilizando-se prioris informativas. Caso não haja opinião sólida sobre os parâmetros em estudo, então expressa-se o não conhecimento a priori através de uma priori não informativa. Os conceitos de 'conhecimento vago', 'não informação', ou 'ignorância a priori' claramente não são únicos e o problema de caracterizar prioris com tais características pode se tornar bastante complexo.

Por outro lado, reconhece-se a necessidade de alguma forma de análise que, em algum sentido, consiga captar esta noção de uma priori que tenha um efeito mínimo, relativamente aos dados, na inferência final. Tal análise pode ser pensada como um ponto de partida quando não se consegue fazer uma elicitação detalhada do 'verdadeiro' conhecimento a priori.

A primeira idéia de 'não informação' a priori que se pode ter é pensar em todos os possíveis valores de $\theta$ como igualmente prováveis, isto é, com uma distribuição $a$ priori uniforme (Paulino et al., 2003). Neste caso, fazendo $p(\theta) \propto k$ para $\theta$ variando em um subconjunto da reta significa que nenhum valor particular tem preferência (Ehlers, 2004b). Porém esta escolha de priori pode trazer algumas dificuldades técnicas, por exemplo, se o intervalo de variação de $\theta$ for ilimitado então a distribuição a priori não informativa é imprópria, pois a integral associada é indefinida. Na prática, o interesse é voltado para a distribuição a posteriori.

\subsubsection{Distribuição ou função de densidade a posteriori}

A densidade a posteriori pode ser convenientemente resumida em termos de esperanças de funções particulares do parâmetro $\theta$, isto é:

$$
E[g(\theta) \mid x]=\int g(\theta) p(\theta \mid x) d \theta
$$

ou densidades a posteriori marginais quando $\theta$ for multidimensional, ou seja,

$$
p\left(\theta_{1} \mid x\right)=\int p(\theta \mid x) d \theta_{2}
$$


onde $\theta=\left(\theta_{1}, \theta_{2}\right)$. Assim, o problema geral da inferência bayesiana consiste em calcular tais valores esperados segundo a densidade a posteriori de $\theta$.

A habilidade de integrar funções, muitas vezes complexas e multidimensionais, é extremamente importante em inferência bayesiana. Geralmente, a resolução direta destas integrais não é possível e, tradicionalmente é empregado o uso da integração numérica ou técnicas de aproximação analítica. O método de simulação de Monte Carlo é uma alternativa de amostrar diretamente da posteriori, obtendo estimativas amostrais de quantidades de interesse, prescindindo do cálculo de integração (Melo, 1999).

\subsubsection{Estimadores de Bayes}

Um estimador bayesiano para o parâmetro de interesse pode ser dado pela moda da densidade a posteriori (Favoretti, 1995), o qual é chamado de estimador de máxima verossimilhança generalizado (EMVG) (Ehlers, 2004b).

Uma outra forma de obter estimativas bayesianas é considerar funções de perda para o parâmetro de interesse. Uma função de perda muito comum é a função de perda quadrática dada por:

$$
P(\theta)=(\theta-\hat{\theta})^{2}
$$

onde $\hat{\theta}$ é o estimador que minimiza a perda esperada em relação à densidade a posteriori (Favoretti, 1995). No entanto, a perda quadrática é as vezes criticada por penalizar demais o erro de estimação (Ehlers, 2004b).

Em um problema de inferência o valor de $\theta$ deve ser estimado a partir dos valores observados na amostra da população de interesse $X_{1}=x_{1}, \cdots, X_{n}=x_{n}$. Se $\theta \in \Theta$ então é razoável que os possíveis valores de um estimador também devam pertencer ao espaço paramétrico $\Theta$. Para cada possível valor de $\theta$ e cada possível estimativa $\hat{\theta} \in \Theta$ é associada uma perda $P(\theta, \hat{\theta})$ de modo que quanto maior a distância entre $\hat{\theta}$ e $\theta$ maior o valor da perda. Neste caso, a perda esperada a posteriori é dada por:

$$
E[P(\theta, \hat{\theta}) \mid x]=\int P(\theta, \hat{\theta}) p(\theta \mid x) d \theta
$$

e a regra de Bayes consiste em escolher a estimativa que minimiza esta perda esperada (Ehlers, 2004b). 


\subsubsection{Intervalos de confiança bayesianos}

É necessário enfatizar que a forma mais adequada de expressar a informação que se tem sobre um parâmetro é através de sua distribuição a posteriori. A principal restrição da estimação pontual é que quando estima-se um parâmetro através de um único valor numérico toda a informação presente na distribuição a posteriori é resumida através deste número. É importante também associar alguma informação sobre o quão precisa é a especificação deste número (Ehlers, 2004b).

Definição 4.1 C é um intervalo de credibilidade, também denominado intervalo de confiança bayesiano, de 100(1- $\alpha) \%$, ou nivel de credibilidade (ou confiança) $1-\alpha$, para $\theta$ se $P(\theta \in C) \geq 1-\alpha$.

Note que a definição expressa de forma probabilística a pertinência ou não de $\theta$ ao intervalo. Assim, quanto menor for o tamanho do intervalo mais concentrada é a distribuição do parâmetro, ou seja o tamanho do intervalo informa sobre a dispersão de $\theta$.

\subsection{O método de Monte Carlo}

Existem várias formas de resumir a informação descrita na distribuição a posteriori. Esta etapa freqüentemente envolve a avaliação de probabilidades ou esperanças. De acordo com Ehlers (2004b), em geral, a única limitação para o número de simulações são o tempo de computação e a capacidade de armazenamento dos valores simulados. Assim, se houver qualquer suspeita de que o número de simulações é insuficiente, a abordagem mais simples consiste em simular mais valores.

\subsubsection{Método de Monte Carlo simples}

A idéia do método é justamente escrever a integral que se deseja calcular como um valor esperado (Ehlers, 2004b). Para introduzir o método considere o problema de calcular a integral de uma função $g(\theta)$ no intervalo $(a, b)$, ou seja,

$$
I=\int_{a}^{b} g(\theta) d \theta
$$

Esta integral pode ser reescrita como: 


$$
I=\int_{a}^{b}(b-a) g(\theta) \frac{1}{b-a} d \theta=(b-a) E[g(\theta)]
$$

identificando $\theta$ como uma variável aleatória com distribuição $U(a, b)$. Assim, o problema de avaliar a integral foi transformado no problema estatístico de estimar uma média, $E[g(\theta)]$. Supondo que se tenha uma amostra aleatória de tamanho $n$, $\theta_{1}, \cdots, \theta_{n}$ da distribuição uniforme no intervalo $(a, b)$ tem-se também uma amostra de valores $g\left(\theta_{1}\right), \cdots, g\left(\theta_{n}\right)$ da função $g(\theta)$ e a integral (4.23) pode ser estimada pela média amostral:

$$
\hat{I}=(b-a) \frac{1}{n} \sum_{i=1}^{n} g\left(\theta_{i}\right) .
$$

Esta estimativa é não viesada já que

$$
E[\hat{I}]=\frac{(b-a)}{n} \sum_{i=1}^{n} E\left[g\left(\theta_{i}\right)\right]=(b-a) E[g(\theta)]=\int_{a}^{b} g(\theta) d(\theta) .
$$

Nestas condições, pode-se usar o algoritmo abaixo.

\section{Algoritmo 4.1}

1. Gere $\theta_{1}, \cdots, \theta_{2}$ da distribuição $U(a, b)$;

2. Calcule $g\left(\theta_{1}\right), \cdots, g\left(\theta_{n}\right)$;

3. Calcule a média amostral $\bar{g}=\sum_{i=1}^{n} g\left(\theta_{i}\right) / n$;

4. Calcule $\hat{I}=(b-a) \bar{g}$.

A generalização é bem simples para o caso em que a integral é a esperança matemática de uma função $g(\theta)$ onde $\theta$ tem função de densidade de probabilidade $p(\theta)$, ou seja,

$$
I=\int_{a}^{b} g(\theta) p(\theta) d \theta=E[g(\theta)]
$$

Neste caso, é possível usar o mesmo algoritmo descrito acima modificando o passo 1 para gerar $\theta_{1}, \cdots, \theta_{n}$ da densidade $p(\theta)$ e calculando $\hat{I}=\bar{g}$.

No caso multivariável a extensão também é direta. Seja $\theta=\left(\theta_{1}, \cdots, \theta_{k}\right)^{\prime}$ um vetor aleatório de dimensão $k$ com função de densidade $p(\theta)$. Neste caso os valores gerados serão também vetores $\theta_{1}, \cdots, \theta_{n}$ e o estimador de Monte Carlo fica: 


$$
\hat{I}=\frac{1}{n} \sum_{i=1}^{n} g\left(\theta_{i}\right) .
$$

O algoritmo aqui apresentado é não determinístico, ou seja requer a simulação de números (pseudo) aleatórios de alguma distribuição de probabilidades (Ehlers, 2004b).

\subsubsection{Método de Monte Carlo via cadeias de Markov}

No método de simulação de Monte Carlo simples, obtém-se uma amostra da distribuição a posteriori em um único passo. Os valores são gerados de forma independente e não há preocupação com a convergência do algoritmo, bastando que o tamanho da amostra seja suficientemente grande (Ehlers, 2004b). Por este motivo estes métodos são chamados de não iterativos. No entanto, em muitos problemas pode ser bastante difícil, ou mesmo impossível, encontrar uma densidade de importância que seja simultaneamente uma boa aproximação da posteriori e fácil de ser amostrada. Os métodos de Monte Carlo via cadeias de Markov (MCMC) são uma alternativa aos métodos não iterativos em problemas complexos (Paulino et al., 2003). A idéia ainda é obter uma amostra da distribuição a posteriori e calcular estimativas amostrais de características desta distribuição. A diferença é que técnicas de simulação iterativa serão utilizadas, baseadas em cadeias de Markov, e assim os valores gerados não serão mais independentes o que garante a convergência do algoritmo (Ehlers, 2004b). Uns dos métodos MCMC mais utilizados são o amostrador de Gibbs e o algoritmo de Metropolis-Hastings (Fishman, 1996; Gelman et al., 2000; Paulino et al., 2003).

O algoritmo de Metropolis-Hastings permite gerar uma amostra da distribuição conjunta a posteriori, a partir das distribuições condicionais completas, que podem ou não possuir forma fechada; já o amostrador de Gibbs é um caso especial do MetropolisHastings em que as distribuições condicionais possuem forma fechada, no sentido que é fácil amostrar de seus elementos (Cespedes, 2003; Paulino et al., 2003; Ehlers, 2004b). Segundo Cespedes (2003), uma outra alternativa para amostrar de distribuições condicionais completas a posteriori que não possuem forma fechada é o método "Slicesampling" proposto por Neal (2003). 


\section{Processos estocásticos}

Um processo estocástico é definido como uma coleção de variáveis randômicas $W(t)$ indexadas por um parâmetro $t$ pertencente a um conjunto $T$. Estes processos são de interesse para descrever o procedimento de um sistema operando sobre algum período de tempo, com isso, a variável randômica $\omega_{t}$ representa o estado do sistema no parâmetro, geralmente tempo, $t$. Portanto, pode-se afirmar que $W(t)$ é definido em um espaço de estados (Nogueira, 2004).

\section{Processos markovianos}

Resumidamente, um processo estocástico é dito ser um processo markoviano se o estado futuro depende apenas do estado presente e não dos estados passados (Nogueira, 2004). Mais precisamente,

$P\left\{W\left(t_{k+1}\right) \leq w_{k+1} \mid W\left(t_{k}\right)=w_{k}, \cdots, W\left(t_{0}\right)=w_{0}\right\}=P\left\{W\left(t_{k+1}\right) \leq w_{k+1} \mid W\left(t_{k}\right)=w_{k}\right\}$

para $t_{0} \leq t_{1} \leq \cdots \leq t_{k} \leq t_{k+1}=0,1, \cdots$ e toda seqüência $k_{0}, k_{1}, \cdots, k_{t-1}, k_{t}, k_{t+1}$.

\section{Cadeias de Markov}

Um processo markoviano é dito ser uma cadeia de Markov quando as variáveis randômicas $W(t)$ estão definidas em um espaço de estados discreto. Quando o tempo é discreto, a cadeia de Markov é dita ser uma cadeia de Markov em tempo discreto. Neste caso, tem-se:

$P\left\{W(k+1)=w_{k+1} \mid W(k)=w_{k}, \cdots, W(0)=w_{0}\right\}=P\left\{W(k+1)=w_{k+1} \mid W(k)=w_{k}\right\}$

para $t_{0} \leq t_{1} \leq \cdots \leq t_{k} \leq t_{k+1}=0,1, \cdots$ e toda seqüência $k_{0}, k_{1}, \cdots, k_{t-1}, k_{t}, k_{t+1}$. para toda seqüência $k_{0}, k_{1}, \cdots, k_{t-1}, k_{t}, k_{t+1}$ (Nogueira, 2004).

Assim, as probabilidades de transição $P\left\{W(k+1)=w_{k+1} \mid W(k)=w_{k}\right\}$ representam a probabilidade do estado $W(k+1)$ ser $w_{k+1}$ no tempo $k+1$ dado que o estado $W(k)$ é $w_{k}$ no tempo $k$ (Nogueira, 2004).

Segundo Ehlers (2004b), os métodos MCMC requerem ainda que a cadeia seja: 
- homogênea: as probabilidade de transição de um estado para o outro são invariantes.

- irredutível: cada estado pode ser atingido a partir de qualquer outro em um número finito de iterações.

- aperiódica: não haja estados absorventes.

Uma questão importante e de ordem prática é como os valores iniciais tomados para iniciar o processo iterativo influenciam o comportamento da cadeia. A idéia é que conforme o número de iterações aumenta, a cadeia gradualmente esquece os valores iniciais e eventualmente converge para uma distribuição de equilíbrio. Assim, em aplicações práticas é comum que as iterações iniciais sejam descartadas, como se formassem uma amostra de aquecimento (Ehlers, 2004b).

\section{Algoritmo de Metropolis-Hastings}

Nos algoritmos de Metropolis-Hastings um valor é gerado a partir de uma distribuição auxiliar e aceito com uma dada probabilidade, este mecanismo de correção garante a convergência da cadeia para a distribuição de equilíbrio, que neste caso é a distribuição a posteriori (Paulino et al., 2003; Ehlers, 2004b).

Suponha que no instante $t$ a cadeia esteja no estado $\theta$ e um valor $\theta^{\prime}$ é gerado de uma distribuição proposta, uma função de probabilidade de transição de estado apropriada, $q(\cdot \mid \theta)$. O novo valor $\theta^{\prime}$ é aceito com probabilidade

$$
\alpha\left(\theta, \theta^{\prime}\right)=\min \left(1, \frac{\pi\left(\theta^{\prime}\right) q\left(\theta \mid \theta^{\prime}\right)}{\pi(\theta) q\left(\theta^{\prime} \mid \theta\right)}\right)
$$

como o novo estado da cadeia no instante $t+1$, ou é rejeitado com probabilidade $1-\alpha\left(\theta, \theta^{\prime}\right)$ e a cadeia permanece no estado $\theta$. Tem-se $\pi:=p(\theta \mid x)$ a distribuição de equilíbrio e $q(\cdot \mid \theta)$ poderia ser, por exemplo, uma distribuição normal centrada em $\theta$ (Ehlers, 2004b).

Uma característica importante é que só é preciso conhecer $\pi$ parcialmente, ou seja a menos de uma constante de proporcionalidade (Paulino et al., 2003) já que neste caso a probabilidade (4.30) não se altera; o que é fundamental em aplicações bayesianas onde não se conhece completamente a posteriori (Ehlers, 2004b). Note também que a 
cadeia pode permanecer no mesmo estado por muitas iterações e na prática costuma-se monitorar isto calculando a porcentagem média de iterações para as quais novos valores são aceitos.

O algoritmo de Metropolis-Hastings pode ser resumido nos seguintes passos (Ehlers, 2004b):

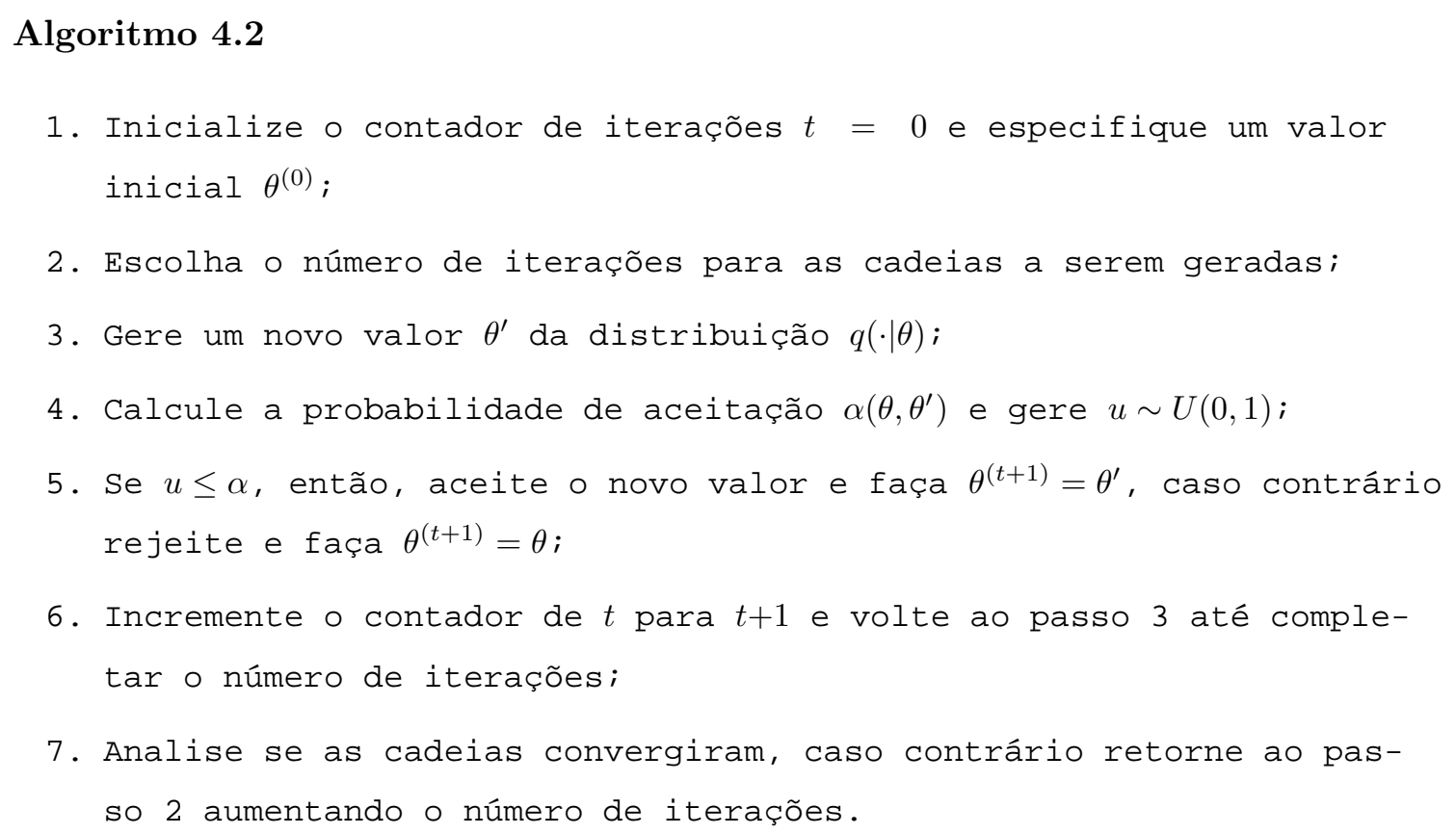

\section{Amostrador de Gibbs}

No amostrador de Gibbs a cadeia sempre se move para um novo valor, ou seja, não existe mecanismo de aceitação-rejeição. As transições de um estado para o seguinte são feitas de acordo com as distribuições condicionais completas $\pi\left(\theta_{i}, \theta_{-i}\right)$, onde $\theta_{-i}=$ $\left(\theta_{1}, \cdots, \theta_{i-1}, \theta_{i+1}, \cdots, \theta_{d}\right)^{\prime}$.

A distribuição condicional completa, distribuição da $i$-ésima componente de $\theta$ condicionada em todas as outras componentes, é obtida a partir da distribuição conjunta como,

$$
\pi\left(\theta_{i}, \theta_{-i}\right)=\frac{\pi(\theta)}{\int \pi(\theta) d \theta_{i}}
$$

Em muitas situações, a geração de uma amostra diretamente de $\pi(\theta)$ pode ser complicada ou simplesmente impossível. Mas se as distribuições condicionais completas forem completamente conhecidas, então o amostrador de Gibbs é definido pelos seguintes passos (Ehlers, 2004b): 


\section{Algoritmo 4.3}

1. Inicialize o contador de iterações da cadeia $t=0$;

2. Especifique valores iniciais $\theta^{(0)}=\left(\theta_{1}^{(0)}, \cdots, \theta_{d}^{(0)}\right)^{\prime}$;

3. Obtenha um novo valor de $\theta^{(t)}$ a partir de $\theta^{(t-1)}$ através da geração sucessiva dos valores

$$
\begin{gathered}
\theta_{1}^{(t)} \sim \pi\left(\theta_{1} \mid \theta_{2}^{(t-1)}, \theta_{3}^{(t-1)}, \cdots, \theta_{d}^{(t-1)}\right) \\
\theta_{2}^{(t)} \sim \pi\left(\theta_{2} \mid \theta_{1}^{(t)}, \theta_{3}^{(t-1)}, \cdots, \theta_{d}^{(t-1)}\right) \\
\vdots \\
\theta_{d}^{(t)} \sim \pi\left(\theta_{d} \mid \theta_{1}^{(t)}, \theta_{2}^{(t)}, \cdots, \theta_{d-1}^{(t)}\right)
\end{gathered}
$$

4. Incremente o contador de $t$ para $t+1$ e retorne ao passo 2 até obter convergência.

Cada iteração se completa após se obter as $d$ componente de $\theta$. Após a convergência, os valores resultantes formam uma amostra de $\pi(\theta)$.

O amostrador de Gibbs é um caso especial do algoritmo de Metropolis-Hastings, no qual os elementos de $\theta$ são atualizados um de cada vez (ou em blocos), a partir da obtenção da distribuição condicional completa e probabilidade de aceitação igual a 1 (Gelman et al., 2000; Paulino et al., 2003; Ehlers, 2004b).

\section{"Slice-sampling"}

De acordo com Cespedes (2003), o método "Slice-sampling" consiste em amostrar de uma distribuição para uma variável $\theta$, cuja função de densidade de probabilidade é proporcional a uma função de $\theta, f(\theta)$. Isto pode ser realizado via introdução de uma variável auxiliar $\psi$ e definindo a distribuição conjunta de $\theta$ e $\psi$ abaixo da curva definida por $f(\theta)$, a qual é uniforme sobre a região $U=\{(\theta, \psi): 0<\psi<f(\theta)\}$. Assim, a função de densidade conjunta para $(\theta, \psi)$ é dada por:

$$
p(\theta, \psi)=\left\{\begin{array}{l}
\frac{1}{Z}, \text { se } 0<\psi<f(\theta), \\
0, \text { caso contrário }
\end{array}\right.
$$


em que $Z=\int f(\theta) d \theta$ e a densidade marginal de $\theta$ é dada por:

$$
p(\theta)=\int_{0}^{f(\theta)} \frac{1}{Z} d y=\frac{f(\theta)}{Z} .
$$

Assim, para amostrar $\theta$ basta amostrar conjuntamente $(\theta, \psi)$. Neal (2003) propôs um método alternativo para amostrar $\theta$ de qualquer distribuição contínua, sendo apenas necessário calcular algumas funções $f(\theta)$ proporcionais a densidade de $\theta$, seguindo as etapas (Cespedes, 2003) definidas pelo algoritmo abaixo.

\section{Algoritmo 4.4}

1. Inicialize o contador de iterações $t=0$;

2. Escolha o número de iterações para as cadeias a serem geradas;

3. Especifique um valor inicial $\theta^{(t)}$ pertencente a $f\left(\theta^{(t)}\right)$;

4. Amostre um valor $\psi$, uniformemente de $\left(0, f(\theta)^{(t)}\right)$, definindo uma fatia horizontal $S=\{\theta: \psi<f(\theta)\}$ em que $\theta^{(t)} \in S$;

5. Encontre um intervalo $I=\left(S_{0}, S_{1}\right)$ ao redor de $\theta^{(t)}$ que contenha a maior parte da fatia;

6. Incremente 0 contador de $t$ para $t+1$;

7. Amostre um novo ponto $\theta^{(t+1)}$ parte da fatia deste intervalo, ou seja $\theta_{(t+1)} \in I \cap S$;

8. Retorne ao passo 5 até completar o número de iterações;

9. Analise se as cadeias convergiram, caso contrário retorne ao passo 2 aumentando o número de iterações.

O algoritmo "Slice-sampling" é um caso especial do algoritmo de Metropolis-Hastings, em que as distribuições condicionais completas a posteriori não possuem forma fechada, mas cuja função de densidade de probabilidade é proporcional a uma função do parâmetro de interesse.

\subsection{Discussão}

O objetivo da inferência estatística é a obtenção de informações sobre aspectos de uma população de interesse no estudo por meio de resultados obtidos na observação de 
uma ou mais amostras extraídas desta população. Neste trabalho em particular, tem-se interesse em obter informações sobre os parâmetros do modelo de produção de sementes de populações de plantas daninhas.

Os verdadeiros valores dos parâmetros são desconhecidos e a idéia é reduzir este desconhecimento a partir de observações experimentais. Desta forma, a intensidade da incerteza a respeito destes parâmetros pode assumir diferentes graus. Além disso, as condições edafoclimáticas e outros fatores pertencentes ao ambiente agrícola contribuem para esta incerteza. Do ponto de vista bayesiano, estes diferentes graus de incerteza são representados através de modelos probabilísticos para os parâmetros.

Inferências sobre os parâmetros geralmente se baseiam em métodos estatísticos clássicos, os quais consistem da obtenção de estimadores de mínimos quadrados e/ou estimadores de máxima verossimilhança e da suposição de propriedades assintóticas para estes estimadores. Contudo, na presença de pequenas amostras, faz-se uso de métodos bayesianos.

O procedimento bayesiano tem a vantagem de que qualquer informação disponível pode ser incorporada aos dados e uma distribuição a posteriori pode ser obtida eliminando-se o uso de resultados assintóticos. Neste contexto, o método de Monte Carlo surge como uma técnica alternativa para gerar amostras dos parâmetros de interesse e, conseqüentemente, estudar o comportamento de populações de plantas daninhas e a produção de sementes destas. 


\section{Capítulo 5}

\section{Experimento de campo}

O conjunto de dados utilizado neste estudo foram coletados a partir de um experimento conduzido em campo, em uma cultura de milho por plantio direto, no período da safra 2004/2005, na área experimental da Embrapa Milho e Sorgo, localizada no município de Sete Lagoas, MG. A foto aérea do pivô experimental pode ser vista na Figura 5.1.

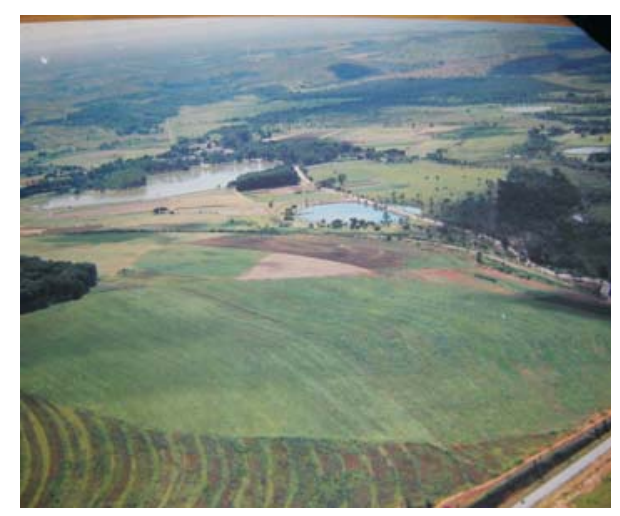

Figura 5.1: Foto aérea do pivô experimental - Sete Lagoas, MG.

O milho cultivar BRS1030 do tipo híbrido simples foi cultivado em uma área de 38 hectares, com pivô central em sistema de plantio direto, onde o solo não é revolvido após a colheita nem antes do próximo plantio. A data do plantio ocorreu de 16 a 20 de novembro de 2004 e, concomitantemente, foi realizada uma adubação do solo com 22, $56 \mathrm{~kg} \mathrm{ha^{-1 }}$ de nitrogênio (N), 78, $96 k g h a^{-1}$ de fósforo (P), 45, $12 k g h a^{-1}$ de potássio (K) e $0,564 \mathrm{~kg} \mathrm{ha}^{-1}$ de Zinco.

A cultura foi alocada em 41 pontos de amostragem distando cem metros uma das outras em cada direção (leste-oeste e norte-sul). Cada parcela possui forma retangular, 
medindo $12 \mathrm{~m}^{2}$, sendo $4 \mathrm{~m}$ de comprimento e $3 \mathrm{~m}$ de largura, com 5 linhas de cultura equiespaçadas $0,7 \mathrm{~m}$, com $0,1 \mathrm{~m}$ nas bordas superior e inferior. Durante a aplicação de herbicidas no pivô, estas parcelas foram cobertas com lona, como pode ser visto pela Figura 5.2, para que estas não sofressem a ação do herbicida. O tratamento com herbicidas foi realizado em aplicação pré-emergente (antes da emergência da cultura) e pós-emergente (depois da emergência da cultura). A aplicação pré-emergente ocorreu logo após o plantio com dessecantes glifosato $\left(2,4 k g h a^{-1}\right)$. A aplicação pós-emergente foi realizada nos dias 13 e 14 de dezembro de 2004 com nicosulfuron $\left(0,04 \mathrm{~kg} \mathrm{ha}^{-1}\right)$ e atrazine $\left(1 \mathrm{~kg} \mathrm{ha}^{-1}\right)$. Foi realizada também, a aplicação de inseticidas $(0,6$ litros por hectare de Lannat) nos dias 20 e 21 de dezembro de 2004.

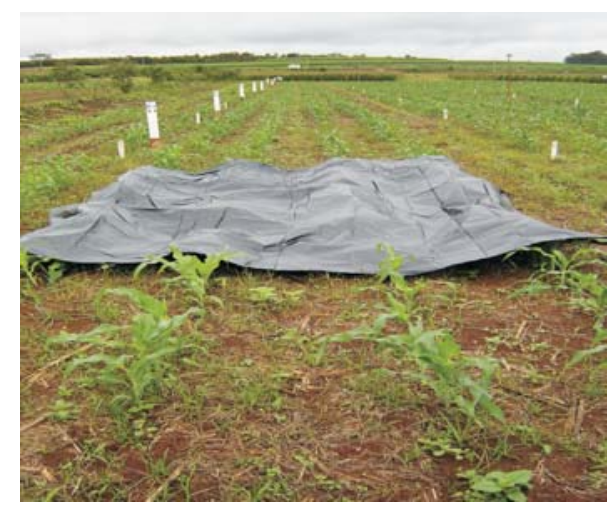

Figura 5.2: Cobertura de uma parcela para que esta não sofra a ação do herbicida aplicado.

A Figura 5.3 ilustra a distribuição das 41 parcelas experimentais distribuídas pelo campo. A localização das parcelas foram georeferenciadas e as latitudes e longitudes estão na Tabela B.1. A colheita do milho foi realizada para apenas trinta e oito das quarenta e uma parcelas experimentais devido a realização de outro experimento que impediu o acesso às parcelas 20, 21 e 22.

\subsection{Dados obtidos}

No dia 18 de janeiro de 2005 foi feita uma análise visual do milho cultivar BRS1030 do tipo híbrido simples, comparando áreas que sofreram e áreas que não sofreram tratamentos com herbicidas. As áreas sem tratamentos com herbicidas continham plantas da cultura com pigmentos amarelos em sua coloração. Nestas condições, acredita-se que houve uma deficiência de nitrogênio devido, provavelmente, à competição por recursos 


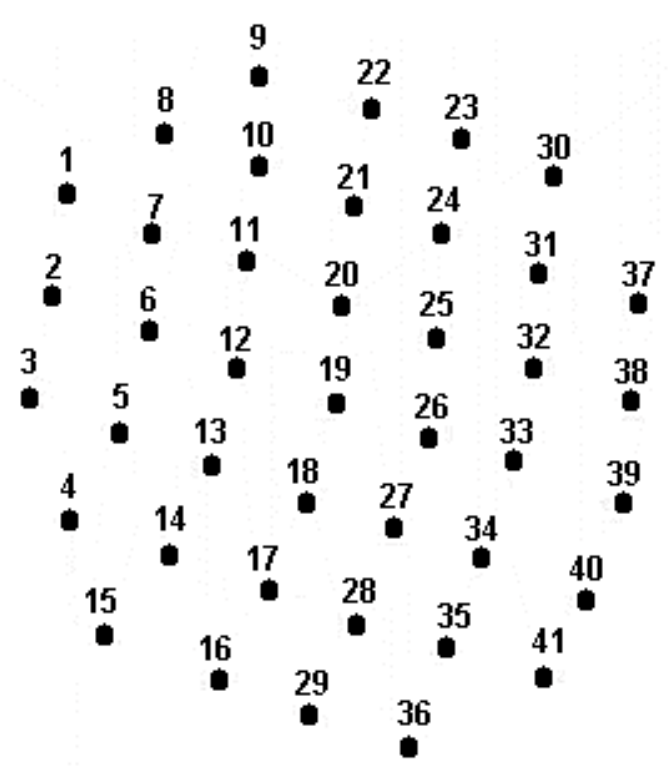

Figura 5.3: Distribuição das 41 parcelas experimentais pelo pivô.

vitais entre a cultura e as infestantes da área.

\subsubsection{Coleta dos dados}

Nos dias 17, 18 e 21 de março de 2005 foram coletados as seguintes dados nas 41 parcelas experimentais da cultura:

1. Densidade de plantas por parcela, obtida com o auxílio de um quadro de madeira de $0,5 \mathrm{~m}$ por $0,5 \mathrm{~m}$, que pode ser visualizado na Figura 5.4. Este quadro foi colocado aleatoriamente quatro vezes dentro das 3 linhas centrais de cultura em cada parcela. Dentro deste, foram colhidas e contadas todas as espécies de plantas daninhas;

2. Um indivíduo contendo sementes de cada espécie daninha dentro de cada parcela para medir a produtividade de sementes;

3. Quatro coletas de solo dentro de cada parcela, entre as 3 linhas centrais de cultura, para que seja levantado o banco de sementes de plantas daninhas, e quatro coletas fora da parcela, uma em cada direção (leste, oeste, norte e sul), chamadas testemunhas, para que seja comparado o banco de sementes dentro da parcela, onde não houve aplicação de herbicida, com o banco de sementes fora da parcela, 


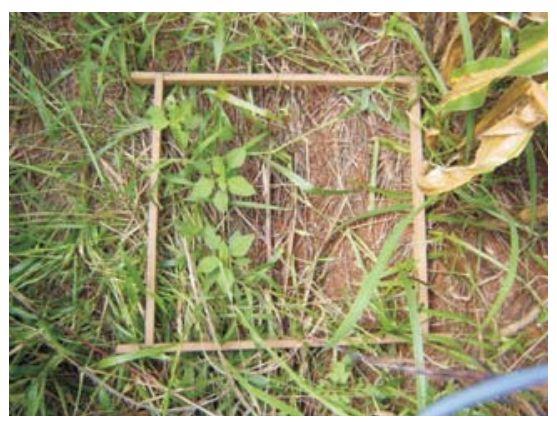

Figura 5.4: Quadro utilizado em campo para coletar amostras de plantas daninhas.

onde houve a ação do herbicida. O instrumento de coleta de solo é denominado trado, e pode ser visto na Figura 5.5.

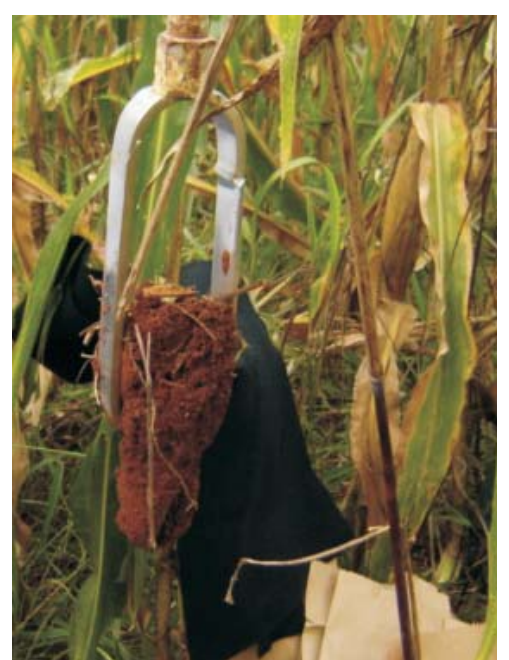

Figura 5.5: Instrumento para realizar a coleta de solo: trado.

\subsubsection{Espécies daninhas encontradas na área experimental}

As espécies de "folha larga", também chamadas de latifoliadas, compreendem as espécies dicotiledôneas. As plantas de folhas estreitas compreendem as espécies da família Gramineae e Cyperaceae. Neste contexto, as espécies de plantas daninhas encontradas nas 41 parcelas experimentais podem ser identificadas na Tabela 5.1.

O número de espécies de plantas daninhas encontradas em cada quadro pode ser consultado nas Tabelas B.2-B.10, que fornece o valor da densidade de plantas por 0,25 $m^{2}$, correspondente à área do quadro. Estes valores são agrupados em número de espécies de plantas daninhas encontradas em cada parcela, obtendo-se a densidade de plantas por espécie, ou seja, o número de espécies por metro quadrado encontrado 
Tabela 5.1: Espécies de plantas daninhas encontradas nas parcelas experimentais do pivô.

\begin{tabular}{cc}
\hline Folha Larga & Folha Estreita \\
\hline caruru branco (Amaranthus hybridus) & timbête (Cenchrus echinatus L.) \\
\hline picão preto (Bidens pilosa) & sorgo selvagem (Sorghum arundinaceum) \\
\hline trapoeraba (Commelina benghalensis) & braquiária (Brachiaria decumbens) \\
\hline mentrasto (Ageratum conyzoides) & capim colchão (Digitaria ciliaris) \\
\hline erva de touro (Tridax procumbens) & capim guiné (Panicum maximum) \\
\hline erva de santa luzia (Euphorbia hirta L.) & capim-marmelada (Brachiaria plantaginea) \\
\hline erva quente (Spermacoce latifolia) & pé de galinha (Eleusine indica) \\
\hline poaia (Richardia brasiliensis) & tiririca (Cyperus rotundus) \\
\hline botão de ouro (Melampodium perfoliatum) & \\
\hline leiteiro (Euphorbia heterophylla) & \\
\hline
\end{tabular}

em cada parcela, o qual é mostrado na Tabela B.11. Como as plantas daninhas são classificadas em folha estreita e folha larga, obtém-se também a densidade de plantas por metro quadrado do tipo folha larga e folha estreita, apresentada na Tabela B.15.

Pode-se observar a porcentagem de ocorrência de cada planta daninha coletada nas parcelas pelo gráfico da Figura 5.7. O mentrasto (folha larga) e a capim colchão (folha estreita) foram as plantas que apresentaram maior número de indivíduos nas parcelas percorridas, resultando cerca de $25 \%$ e $22 \%$ de ocupação, respectivamente. A Figura 5.6 mostra o mentrasto e o capim colchão.
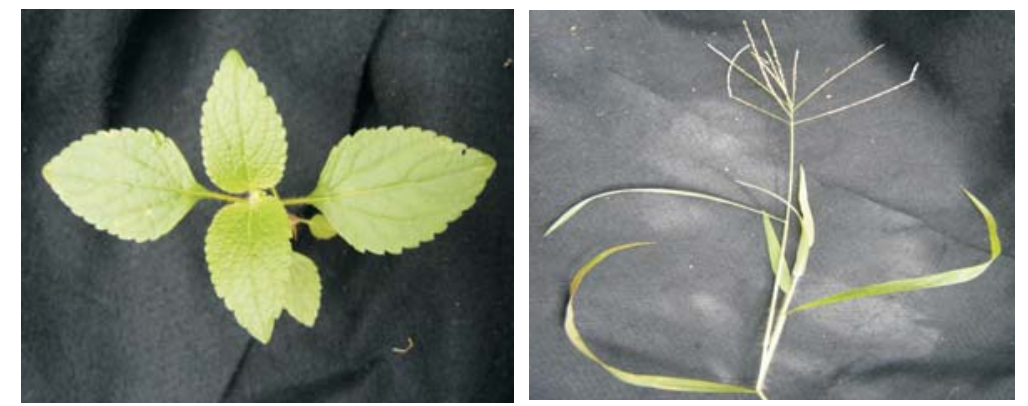

Figura 5.6: Plantas daninhas: mentrasto (esquerda) e capim colchão (direita).

Observou-se ainda, que as parcelas que se localizam na periferia da cultura apresentam maior número de espécies de plantas daninhas, possivelmente por possuírem maior incidência de luz e por sofrerem mais influências externas das outras culturas existentes no campo. Este fato pode ser verificado pelo gráfico da Figura 5.8.

Amostras de solo foram coletadas, conforme já descrito, com o trado exibido na Figura 5.5, em maio de 2005, antes da colheita do milho. A contagem das sementes presentes no banco de sementes dentro das parcelas, onde não houve tratamento com 


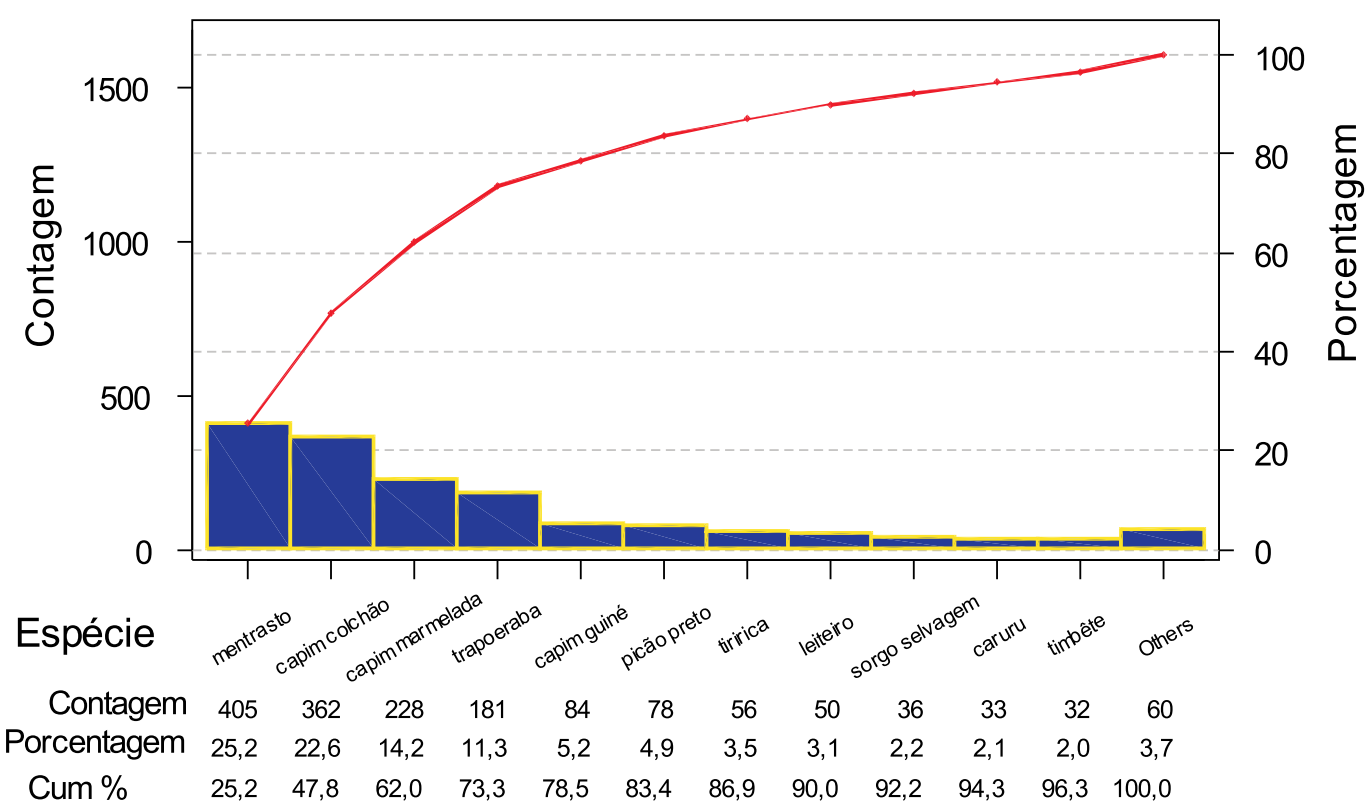

Figura 5.7: Contagem de espécies de plantas daninhas nas parcelas.

herbicida, e fora das parcelas, onde houve tratamento. Para esta contagem, o solo é lavado e passado por várias peneiras para que as sementes sejam separadas. Um microscópio é utilizado para distinguir a qual das espécies de plantas daninhas a semente pertence. Sendo assim, a densidade de sementes por parcela, número de sementes por $m^{2}$, é calculada contando-se as sementes coletadas nas amostras de solo pelo trado mais as sementes presentes nas plantas daninhas. No entanto, os dados relativos ao banco de sementes no solo não chegaram a tempo de serem utilizados neste trabalho; assim, utilizou-se o número de sementes encontrado nos indivíduos de cada espécie daninha dentro de cada parcela (Tabelas B.16 e B.17).

Como a área é cultivada em sistema de plantio direto, o banco de sementes pode conter sementes de outras espécies de plantas daninhas, diferentes das espécies que estão sobre o solo, o que não acontece em plantio convencional no qual o solo é revolvido. Desta forma, as sementes nas camadas inferiores do banco de sementes de um sistema de plantio direto dificilmente germinarão pela ausência de luz e pela dificuldade de virem à tona. Portanto, as sementes que indicam a probabilidade de infestação da geração seguinte correspondem às sementes presentes nas plantas daninhas, que cairão sobre o solo, ou seja, a chuva de sementes. Estas sementes podem germinar e constituir a 


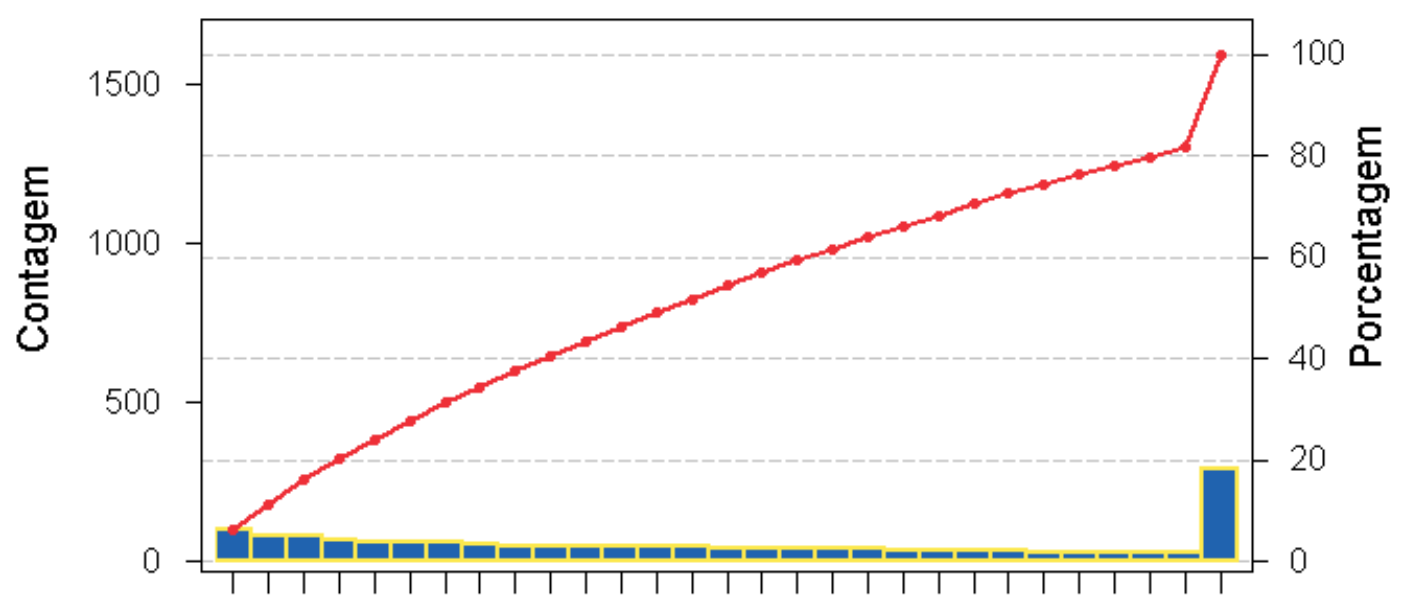

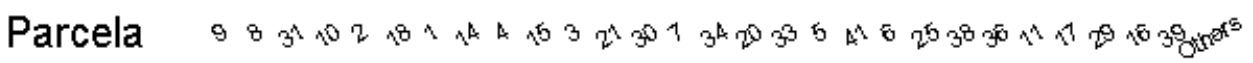

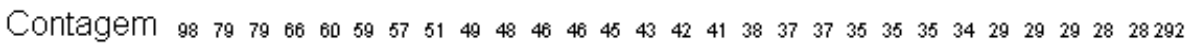

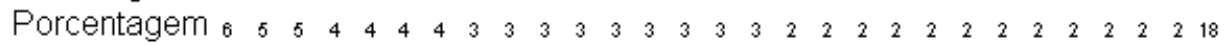

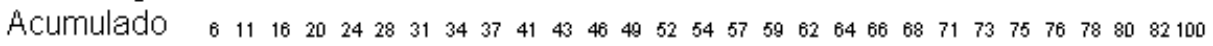

Figura 5.8: Número de plantas daninhas por parcela.

próxima geração de plantas daninhas. As Tabelas B.16 e B.17 exibem a produtividade de sementes de um indivíduo de cada espécie daninha em cada parcela e a Tabela B.18 o total densidade de sementes em cada parcela. Deve-se ressaltar que não foram encontradas plantas contendo sementes de botão de ouro, erva de touro, erva quente, poaia e tiririca e foram encontradas duas únicas plantas contendo sementes de serralha e cordãode-frade, as quais não foram coletadas com o quadro de madeira, e conseqüentemente, não foram consideradas como parte da densidade de plantas daninhas encontradas no campo.

Todas as tabelas de dados coletados em campo estão dispostas no Apêndice B.

\subsection{Aspectos botânicos das espécies daninhas encontradas em campo}

A seguir, apresenta-se aspectos botânicos das plantas daninhas coletadas em campo. 


\subsubsection{Espécies de "folha larga"}

Ageratum conyzoides

Popularmente conhecida como mentrasto, a Ageratum conyzoides é uma planta anual, ereta, ramificada, com caules revestidos de pelos alvos, de 30 a $80 \mathrm{~cm}$ de altura; propagase exclusivamente por sementes, infestando tanto lavouras anuais como perenes, hortas e terrenos baldios. Uma única planta chega a produzir 40 mil sementes. Nativa da América do Sul pode ser encontrada em todas as regiões brasileiras. (Lorenzi, 2000).

\section{Amaranthus hybridus}

O caruru branco (Amaranthus hybridus) pode ser encontrado em todas as regiões brasileiras. É uma planta anual, muito ramificada e com porte variando de 50 a $100 \mathrm{~cm}$ de altura; propaga-se por sementes e possui uma grande capacidade reprodutiva. Essa planta é hospedeira de nematóides e vírus (Lorenzi, 2000).

\section{Bidens pilosa $\mathbf{L}$.}

Popularmente conhecida como picão preto ou carrapicho, é uma planta nativa da América Tropical, anual, herbácea, ereta, de 40-120 cm de altura e propaga-se exclusivamente por sementes (Lorenzi, 2000). Segundo Lacerda (2003), essa espécie de planta daninha possui teor de água de 86 e $87 \%$ de sua biomassa verde e desenvolve-se em solos na faixa de $\mathrm{pH} 5,0$ a 7,0 .

De acordo com Lorenzi (2000), representa uma das mais sérias infestações encontradas em lavouras anuais e perenes do Centro-Sul do país, por ser muito prolífica e de ciclo curto: capaz de produzir até três gerações por ano, podendo formar densas infestações. É muito usada na medicina caseira. A espécie pode ocasionar perdas de até $30 \%$ na produtividade em culturas, por exemplo, de soja com o dano em função do período de convivência e densidade de plantas daninhas (Lacerda, 2003).

O gênero Bidens pertence a família Asteraceae comportando cerca de 15 espécies, sendo que as espécies mais comuns no Brasil são Bidens pilosa e subalternans (Lacerda, 2003), diferenciando-se principalmente pelo número de aristas dos aquênios (frutos) e pela presença de flores periféricas nos capítulos com lígulas bem desenvolvidas, além 
disso, a espécie Bidens subalternans é hospedeira de nematóides prejudiciais às culturas agrícolas (Lorenzi, 2000).

\section{Commelina benghalensis $\mathbf{L}$.}

A trapoeraba (Commelina benghalensis L.) é comumente encontrada nas regiões tropicais e subtropicais, sendo que no Brasil é encontrada em quase todas as regiões. É uma planta perene e herbácea com porte variando de 30 a $70 \mathrm{~cm}$ de altura; propaga-se por sementes aéreas e subterrâneas (formadas nos rizomas). Apresenta preferência por solos férteis, com boa umidade e sombreados (Lorenzi, 2000).

\section{Euphorbia heterophylla $\mathbf{L}$.}

Também conhecida como amendoim-bravo ou leiteiro, é uma planta nativa do Continente Americano, da família Euphorbiaceae, anual, ereta, herbácea, leitosa, de folhas muito variáveis, com caule glabro ou variavelmente pubescente, de 30 a $80 \mathrm{~cm}$ de altura. Propaga-se por sementes que germinam no verão, emergindo de até $12 \mathrm{~cm}$ de profundidade, e mantém sua viabilidade germinativa por alguns anos. É bastante freqüente em todo o país ocorrendo, principalmente, em lavouras anuais e perenes sendo a mais temida pelos plantadores de soja devido a dificuldade de controle (Lorenzi, 2000).

\section{Euphorbia hirta $\mathbf{L}$.}

A erva de santa luzia ou Euphorbia hirta é uma planta amplamente distribuída pelo território brasileiro. É uma planta anual, pubescente e pouco ramificada com porte variando de 10 a $50 \mathrm{~cm}$ de altura; propaga-se por sementes. É um hospedeiro de nematóides e fitopatógenos (Lorenzi, 2000).

\section{Melampodium perfoliatum}

O botão de ouro (Melampodium perfoliatum) é predominantemente encontrado nas regiões de Minas Gerais e Goiás do Brasil. É uma planta anual, herbácea e com porte variando de 50 a $200 \mathrm{~cm}$ de altura; propaga-se por sementes (Lorenzi, 2000). 


\section{Richardia brasiliensis}

A poaia (Richardia brasiliensis) pode ser mais freqüentemente encontrada nas regiões brasileiras Sul e Centro-Oeste. É uma planta anual, herbácea, com porte variando entre 30 e $70 \mathrm{~cm}$ de comprimento; propaga-se por meio de sementes (Lorenzi, 2000).

\section{Spermacoce latifolia}

A Spermacoce latifolia ou erva quente pode ser encontrada mais freqüentemente no Sudeste, Centro-Oeste e Nordeste brasileiro. É uma planta anual, herbácea e com porte variando entre 20 e $30 \mathrm{~cm}$ de comprimento. Apresenta preferência por solos ácidos. Propaga-se por meio de sementes (Lorenzi, 2000).

\section{Tridax procumbens $\mathbf{L}$.}

A erva de touro (Tridax procumbens), muito comum em áreas urbanas do centro-oeste brasileiro, tornou-se representativa nos campos de cultivo de soja em Mato Grosso em meados da década de 80, apresentando desde então grande disseminação, atingindo outras culturas e regiões (Guimarães, 2000).

É uma planta anual ou bianual, herbácea, prostrada ou ascendente, ramificada, com enraizamento nos nós em contato com o solo, de caule denso-pubescente, com 20-40 cm de altura, pertence a família Asteraceae, propaga-se apenas por sementes e apresenta nítida preferência por solos arenosos e secos, vegetando predominantemente durante o período quente do ano (Lorenzi, 2000). Como os aquênios possuem papilho com cerca de 20 pêlos de $5 \mathrm{~mm}$ de comprimento é facilmente dispersa pelo vento (Lacerda, 2003), sendo muito freqüente em beira de estradas, pastagens, lavouras anuais e perenes, pomares e terrenos baldios (Lorenzi, 2000).

Nos Estados Unidos, esta espécie faz parte de uma lista de plantas daninhas, objeto de lei federal, para as quais são enviados esforços visando à erradicação ou evitar a disseminação (Guimarães, 2000). 


\subsubsection{Espécies de "folha estreita"}

\section{Brachiaria decumbens}

A braquiária é comumente encontrada em São Paulo, Minas Gerais e Centro-Oeste. É uma planta perene com porte variando de 30 a $90 \mathrm{~cm}$ de altura; propaga-se por sementes e através de rizomas (Lorenzi, 2000).

\section{Brachiaria plantaginea}

De acordo com Lorenzi (2000), a Brachiaria plantaginea ou capim marmelada é uma planta anual, ereta, de 50 a $80 \mathrm{~cm}$ de altura, propaga-se apenas por sementes e vegeta somente no período quente do ano. É uma espécie mais freqüente nos solos cultivados das regiões Centro e Sul do país, infestando diversas culturas agrícolas (Lorenzi, 2000).

\section{Cenchrus echinatus $\mathbf{L}$.}

Popularmente conhecido como timbête, a Cenchrus echinatus L. pode ser encontrada em todo o território brasileiro. É uma planta anual, herbácea e com porte variando entre 20 e $60 \mathrm{~cm}$ de altura; propaga-se por sementes (Lorenzi, 2000).

\section{Cyperus rotundus}

A tiririca (Cyperus rotundus) pode ser encontrada em todo o território brasileiro. É uma planta perene, herbácea e com porte variando de 10 a $60 \mathrm{~cm}$ de altura; propaga-se por meio de sementes e tubérculos (Lorenzi, 2000).

\section{Digitaria ciliaris}

A Digitaria ciliaris, popularmente conhecida como capim colchão, é uma planta anual e subereta, de 40 a $80 \mathrm{~cm}$ de altura, propaga-se exclusivamente por sementes. É uma planta daninha medianamente freqüente nas regiões mais tropicais do território brasileiro, onde infesta lavouras anuais e perenes, beira de estradas e terrenos baldios. Prefere solos férteis, formando infestações densas (Lorenzi, 2000). 
Eleusine indica

O pé de galinha pode ser encontrada em quase todas as regiões brasileiras, principalmente no norte. É uma planta anual, perene e com porte variando de 30 a $70 \mathrm{~cm}$ de altura; propaga-se por sementes e é hospedeiro de agentes patogênicos (Lorenzi, 2000).

\section{Panicum maximum}

O capim guiné (Panicum maximum) é uma planta perene e robusta, de 1 a $2 m$ de altura, originária da África. Propaga-se por sementes e rizomas, infestando beira de estradas e solos cultivados. Muito vigorosa e de grande porte, interfere significativamente com a culturas infestadas (Lorenzi, 2000).

\section{Sorghum arundinaceum}

O sorgo selvagem (Sorghum arundinaceum) é freqüentemente encontrado em quase todo o território brasileiro. É uma planta anual, herbácea e com porte variando de 150 a 250 cm de altura; propaga-se por sementes (Lorenzi, 2000).

\subsection{Seleção de espécies daninhas para análise do compor- tamento populacional}

Tem-se por objetivo investigar as particularidades dos parâmetros de populações de plantas daninhas a partir do seu modelo dinâmico para analisar situações que possam ocorrer e alterar a trajetória populacional, visando contribuir para a implementação de estratégias de manejo que venham reduzir o uso de defensivos químicos em agrosistemas. Para efeito de controle químico, as plantas daninhas têm sido freqüentemente classificadas como espécies de "folha larga" e "folha estreita" (Lorenzi, 2000).

A seleção de espécies daninhas para inferência estatística levou em consideração o tamanho $n$ da amostra. Além disso, procurou-se estudar tanto espécies daninhas de "folha estreita" como de "folha larga". Nestas condições, foram escolhidas as seguintes espécies cujo o número de observações $(n \geq 9)$ permitia realizar algum tipo de inferência: Digitaria ciliaris e Panicum maximum de "folha estreita" e Euphorbia heterophylla de "folha larga". Na Figura 5.9 são apresentadas as três espécies daninhas selecionadas 
para estudo, na qual nota-se claramente a classificação segundo o tipo de folha (estreita ou larga).
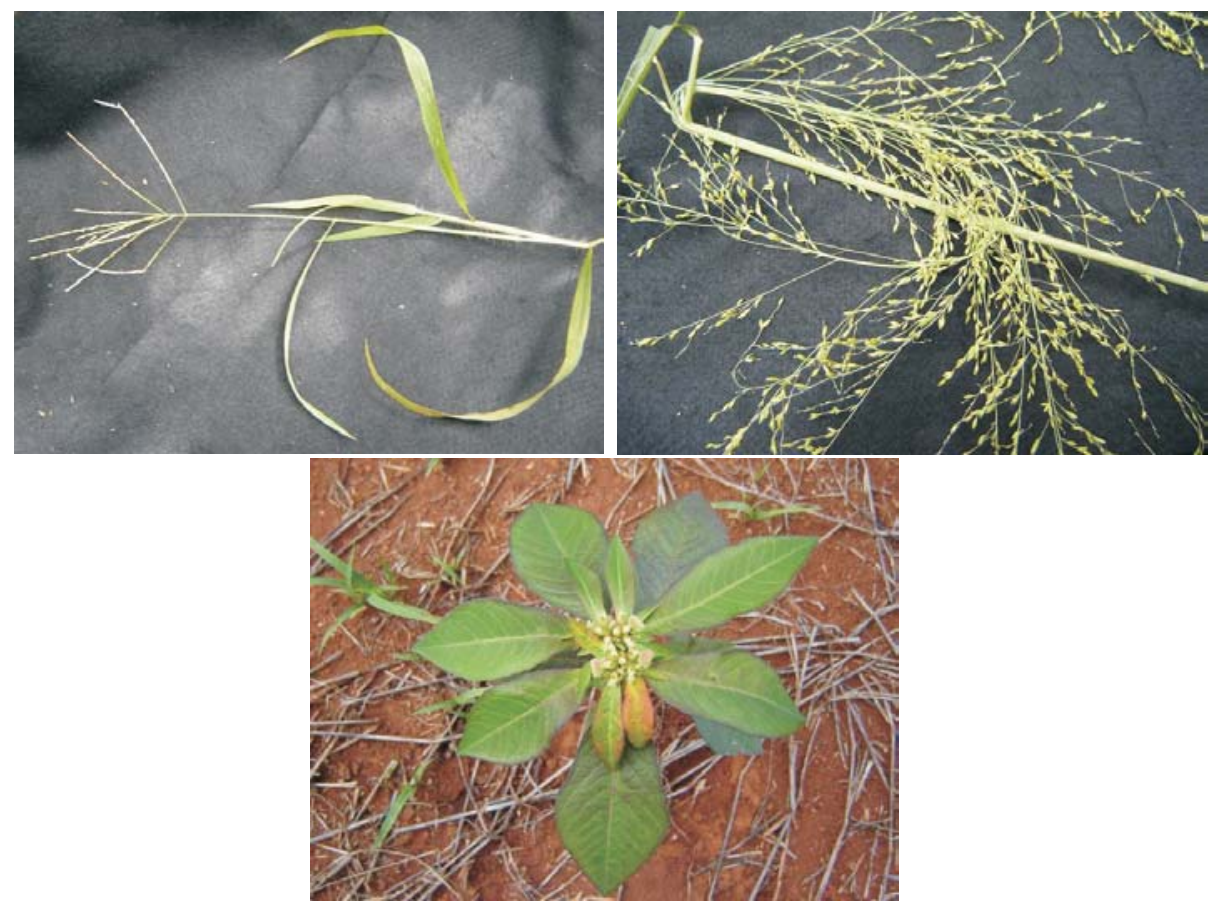

Figura 5.9: Espécies daninhas selecionadas para análise do comportamento populacional: capim colchão (esquerda) e capim guiné (direita) espécies de "folha estreita" e leiteiro (centro) de "folha larga".

\subsubsection{Tabelas dos dados utilizados para análise do comportamento populacional}

Os dados relativos a densidade de plantas daninhas foram retirados da Tabela B.11 e a densidade de sementes foi calculada a partir da Tabela B.16. Para uniformizar as unidades das variáveis foi feita a seguinte transformação: multiplicou-se o número de sementes produzidas por planta daninha (produtividade de sementes) pela densidade de plantas daninhas, obtendo-se a estimativa da densidade de sementes produzidas. Nas Tabelas 5.2, 5.3 e 5.4 são apresentadas as densidade de plantas daninhas e de sementes produzidas em cada parcela das espécies: Digitaria ciliaris (capim colchão), Panicum maximum (capim guiné) e Euphorbia heterophylla (leiteiro), respectivamente. 
Tabela 5.2: Densidade de plantas daninhas e de sementes produzidas em cada parcela de Digitaria ciliaris (capim colchão).

\begin{tabular}{|c|c|c|c|}
\hline Parcela & Densidade de plantas & Produtividade de sementes & Densidade de sementes \\
\hline 1 & 15 & & \\
\hline 2 & 37 & 146 & 5402 \\
\hline 3 & 2 & & \\
\hline \multicolumn{4}{|l|}{4} \\
\hline \multicolumn{4}{|l|}{5} \\
\hline 6 & 7 & & \\
\hline 7 & 16 & & \\
\hline 8 & 15 & & \\
\hline 9 & 4 & & \\
\hline 10 & 12 & 115 & 1380 \\
\hline 11 & 10 & 119 & 1190 \\
\hline \multicolumn{4}{|l|}{12} \\
\hline \multicolumn{4}{|l|}{13} \\
\hline 14 & 27 & & \\
\hline 15 & 26 & & \\
\hline 16 & 16 & & \\
\hline 17 & & 135 & \\
\hline 18 & 13 & & \\
\hline 19 & 3 & & \\
\hline 20 & 14 & & \\
\hline 21 & 9 & 41 & 369 \\
\hline 22 & 1 & 138 & 138 \\
\hline 23 & 16 & 269 & 4304 \\
\hline 24 & 3 & 160 & 480 \\
\hline 25 & 24 & 103 & 2472 \\
\hline 26 & 14 & 95 & 1330 \\
\hline 27 & 5 & 123 & 615 \\
\hline 28 & 6 & 156 & 936 \\
\hline 29 & 13 & 73 & 949 \\
\hline \multicolumn{4}{|l|}{30} \\
\hline \multicolumn{4}{|l|}{31} \\
\hline 32 & & 228 & \\
\hline 33 & 3 & & \\
\hline 34 & 5 & 331 & 1655 \\
\hline \multicolumn{4}{|l|}{35} \\
\hline \multicolumn{4}{|l|}{36} \\
\hline 37 & 3 & & \\
\hline 38 & 9 & 205 & 1845 \\
\hline 39 & 4 & & \\
\hline 40 & 9 & 96 & 864 \\
\hline 41 & 9 & 238 & 2142 \\
\hline
\end{tabular}


Tabela 5.3: Densidade de plantas daninhas e de sementes produzidas em cada parcela de Panicum maximum (capim guiné).

\begin{tabular}{|c|c|c|c|}
\hline Parcela & Densidade de plantas & Produtividade de sementes & Densidade de sementes \\
\hline \multicolumn{4}{|l|}{1} \\
\hline 2 & 3 & 1197 & 3591 \\
\hline \multicolumn{4}{|l|}{3} \\
\hline \multicolumn{4}{|l|}{4} \\
\hline \multicolumn{4}{|l|}{5} \\
\hline \multicolumn{4}{|l|}{6} \\
\hline \multicolumn{4}{|l|}{7} \\
\hline \multicolumn{4}{|l|}{8} \\
\hline 9 & 1 & 735 & 735 \\
\hline 10 & 2 & 41 & 82 \\
\hline 11 & & 1269 & \\
\hline \multicolumn{4}{|l|}{12} \\
\hline \multicolumn{4}{|l|}{13} \\
\hline \multicolumn{4}{|l|}{14} \\
\hline \multicolumn{4}{|l|}{15} \\
\hline \multicolumn{4}{|l|}{16} \\
\hline \multicolumn{4}{|l|}{17} \\
\hline \multicolumn{4}{|l|}{18} \\
\hline 19 & 1 & & \\
\hline \multicolumn{4}{|l|}{20} \\
\hline \multicolumn{4}{|l|}{21} \\
\hline \multicolumn{4}{|l|}{22} \\
\hline 23 & 11 & & \\
\hline 24 & 3 & & \\
\hline 25 & & 41 & \\
\hline \multicolumn{4}{|l|}{26} \\
\hline 27 & 4 & 998 & 3992 \\
\hline 28 & 1 & 759 & 759 \\
\hline \multicolumn{4}{|l|}{29} \\
\hline \multicolumn{4}{|l|}{30} \\
\hline 31 & 23 & 897 & 20631 \\
\hline 32 & 8 & 819 & 6552 \\
\hline 33 & 6 & & \\
\hline 34 & 14 & 517 & 7238 \\
\hline 35 & 2 & & \\
\hline 36 & 3 & 331 & 993 \\
\hline \multicolumn{4}{|l|}{37} \\
\hline \multicolumn{4}{|l|}{38} \\
\hline 39 & 2 & 1039 & 2078 \\
\hline \multicolumn{4}{|l|}{40} \\
\hline 41 & & & \\
\hline
\end{tabular}


Tabela 5.4: Densidade de plantas daninhas e de sementes produzidas em cada parcela de Euphorbia heterophylla (leiteiro).

\begin{tabular}{|c|c|c|c|}
\hline Parcela & Densidade de plantas & Produtividade de sementes & Densidade de sementes \\
\hline \multicolumn{4}{|c|}{ 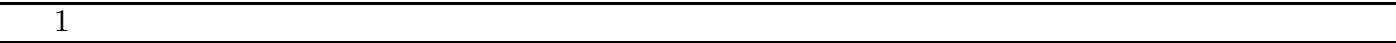 } \\
\hline \multicolumn{4}{|l|}{2} \\
\hline \multicolumn{4}{|l|}{3} \\
\hline \multicolumn{4}{|l|}{4} \\
\hline 5 & & 68 & \\
\hline \multicolumn{4}{|l|}{6} \\
\hline 7 & 1 & & \\
\hline \multicolumn{4}{|l|}{8} \\
\hline 9 & & 61 & \\
\hline \multicolumn{4}{|l|}{10} \\
\hline 11 & & 12 & \\
\hline 12 & & 64 & \\
\hline \multicolumn{4}{|l|}{13} \\
\hline 14 & 9 & 14 & 126 \\
\hline \multicolumn{4}{|l|}{15} \\
\hline 16 & 4 & 16 & 64 \\
\hline 17 & & 28 & \\
\hline 18 & 5 & 3 & 15 \\
\hline 19 & 5 & 21 & 105 \\
\hline 20 & 2 & 5 & 10 \\
\hline 21 & 13 & 12 & 156 \\
\hline \multicolumn{4}{|l|}{22} \\
\hline \multicolumn{4}{|l|}{23} \\
\hline \multicolumn{4}{|l|}{24} \\
\hline \multicolumn{4}{|l|}{25} \\
\hline \multicolumn{4}{|l|}{26} \\
\hline 27 & 1 & 18 & 18 \\
\hline \multicolumn{4}{|l|}{28} \\
\hline 29 & & 21 & \\
\hline \multicolumn{4}{|l|}{30} \\
\hline 31 & & 19 & \\
\hline 32 & & 103 & \\
\hline 33 & 3 & 231 & 693 \\
\hline \multicolumn{4}{|l|}{34} \\
\hline 35 & & 12 & \\
\hline 36 & 2 & 16 & 32 \\
\hline 37 & & 12 & \\
\hline \multicolumn{4}{|l|}{38} \\
\hline 39 & & 39 & \\
\hline 40 & & 52 & \\
\hline 41 & 1 & & \\
\hline
\end{tabular}




\section{Capítulo 6}

\section{Formulação do problema de inferência estatística}

A metodologia e análise do modelo de produção de sementes se dá via observações realizadas na área experimental da Embrapa Milho e Sorgo. A área é cultivada em sistema de plantio direto no qual o solo não é revolvido, assim as sementes nas camadas inferiores do banco de sementes dificilmente germinarão devido à ausência de luz e pela dificuldade de virem à tona. Desta forma, e utilizou-se neste trabalho o número de sementes produzidas por um único indivíduo de cada espécie daninha em cada parcela experimental.

Adota-se o modelo de produção de sementes (3.7) com taxa de crescimento (3.24), repetido a seguir para fácil referência:

$$
X_{t+1}=\frac{s g X_{t}}{\left(1+a g X_{t}\right)^{b}}
$$

Devido a natureza do conjunto de dados disponível, e de acordo com a expressão (3.1), o modelo acima é reescrito da seguinte maneira

$$
X_{t+1}=\frac{s Y_{t}}{\left(1+a Y_{t}\right)^{b}}
$$

onde $Y_{t}$ é a densidade de plantas daninhas.

Investiga-se neste trabalho duas abordagens estatística para obtenção dos parâmetros do modelo: a clássica e a bayesiana. Para o ajuste clássico foi utilizado o aplicativo 
estatístico R (Venables e Smith, 2005), já para o bayesiano, o aplicativo WinBUGS (Spiegelhalter et al., 2006). Após a inferência, faz-se uma simulação da dinâmica populacional via MATLAB (MathWorks, 2006). Deve-se ressaltar que tanto o R e como o WinBUGS são aplicativos livres.

\subsection{Inferência clássica do modelo de produção de sementes}

A abordagem clássica de inferência do modelo (6.1), caracteriza-se pela obtenção de estimadores pontuais e de variância mínima para os parâmetros do modelo via método dos mínimos quadrados. Em uma amostra de tamanho $n$, a relação entre a variável dependente $X_{i}$ e a variável independente $Y_{i}$ é descrita pelo modelo de regressão não linear (4.9), repetido abaixo

$$
X_{i}=f\left(Y_{i}, \theta\right)+\epsilon_{i}, \quad i=1, \cdots, n
$$

onde $\sigma^{2}$ é a variância desconhecida e $\epsilon=\left(\epsilon_{1}, \cdots, \epsilon_{n}\right), \epsilon_{i} \sim N\left(0, \sigma^{2} I\right)$ com $I$ a matriz identidade de ordem $n$. Em particular, tem-se

$$
X_{i}=\frac{s Y_{i}}{\left(1+a Y_{i}\right)^{b}}+\epsilon_{i}, \quad i=1, \cdots, n
$$

onde $\theta=\left(\theta_{1}, \theta_{2}, \theta_{3}\right):=(s, a, b), X_{i}$ é a densidade de sementes (variável dependente) e $Y_{i}$ a densidade de plantas daninhas (variável independente). Sob a suposição de homocedasticidade para os erros, tem-se

$$
\operatorname{Var}(\epsilon)=\sigma^{2} I
$$

\subsubsection{Função de verossimilhança}

A função de verossimilhança de $\theta=(s, a, b)$ e $\sigma$ dado as observações de $X$ e $Y$ é expressa por: 


$$
L(\theta, \sigma \mid Y, X)=L(\theta, \sigma \mid Y, X)=\left(2 \pi \sigma^{2}\right)^{-\frac{n}{2}} \exp \left(-\frac{1}{2 \sigma^{2}} \sum_{i=1}^{n}\left[X_{i}-f\left(Y_{i}, \theta\right)\right]^{2}\right)
$$

\section{Função de log-verossimilhança}

A função de verossimilhança para múltiplas observações é de tratamento matemático complicado pois envolve o produtório da função de densidade para cada observação. Uma vez que os valores da função de densidade são sempre menores que um, a função de verossimilhança rapidamente se aproxima do zero, o que é problemático no uso de computadores (Batista, 2004). Então, trabalha-se com a função de log-verossimilhança. O logaritmo natural de (6.4) é dado por

$$
\ln [L(\theta, \sigma \mid Y, X)]=-\frac{n}{2} \ln \left(\sigma^{2}\right)-\frac{1}{2 \sigma^{2}} \sum_{i=1}^{n}\left[X_{i}-f\left(Y_{i}, \theta\right)\right] .
$$

\subsubsection{Inferência sobre os parâmetros do modelo}

A partir dos estimadores de máxima verossimilhança $\hat{\theta}$ e $\hat{\sigma}^{2}$ pode-se obter intervalos de confiança e testes de hipóteses para os parâmetros do modelo, usando a teoria assintótica baseada na matriz de informação de Fisher ou informação observada (Favoretti, 1995).

Considere

$$
\left(\hat{\theta}, \hat{\sigma}^{2}\right) \sim N\left\{\left(\theta, \sigma^{2}\right) ; I^{-1}\left(\hat{\theta}, \hat{\sigma}^{2}\right)\right\}
$$

onde $I\left(\hat{\theta}, \hat{\sigma}^{2}\right)$ é a matriz de informação de Fisher, calculada por

$$
I\left(\hat{\theta}, \hat{\sigma}^{2}\right)=\frac{1}{\sigma^{2}}\left(\begin{array}{cc}
\sum_{i=1}^{n} \frac{\partial f\left(Y_{i}, \theta\right)}{\partial \theta_{j}} \frac{\partial f\left(Y_{i}, \theta\right)}{\partial \theta_{l}} & 0 \\
0 & \frac{n}{2 \sigma^{2}}
\end{array}\right), \quad j, l=1, \cdots, p .
$$

A estimativa da matriz de informação de Fisher é obtida substituindo-se as estimativas de $\hat{\theta}$ e $\hat{\sigma}^{2}$ na expressão (6.7). Desta forma, cada elemento da diagonal da matriz inversa da matriz de informação de Fisher é a variância mínima da estimativa do parâmetro 
correspondente. Para $b=1(\theta=(s, a))$ a matriz de informação de Fisher é

$$
I\left(\hat{\theta}, \hat{\sigma}^{2}\right)=\frac{1}{\sigma^{2}}\left(\begin{array}{ccc}
\sum_{i=1}^{n} \frac{X_{i}^{2}}{\left(1+a X_{i}\right)^{2}} & \sum_{i=1}^{n}-\frac{s X_{i}^{3}}{\left(1+a X_{i}\right)^{3}} & 0 \\
\sum_{i=1}^{n}-\frac{s X_{i}^{3}}{\left(1+a X_{i}\right)^{3}} & \sum_{i=1}^{n} \frac{s^{2} X_{i}^{4}}{\left(1+a X_{i}\right)^{4}} & 0 \\
0 & 0 & \frac{n}{2 \sigma^{2}}
\end{array}\right) .
$$

Quando os elementos da matriz (6.8) são invariantes no tempo, tem-se uma boa aproximação normal assintótica para os estimadores de máxima verossimilhança de $\hat{\theta}_{1}=$ $\hat{s}, \hat{\theta}_{2}=\hat{a}$ e $\hat{\sigma}^{2}$ e a inferência sobre $\theta_{1}, \theta_{2}$ e $\sigma^{2}$ pode ser caracterizada por (6.6) (Favoretti, 1995).

\subsubsection{Problema de inferência clássica}

Para efetuar o ajuste do modelo não linear (6.2) escolhe-se o vetor $\theta=(s, a, b)$ de valores iniciais para iniciar o processo iterativo de obtenção das estimativas dos parâmetros do modelo. Deste modo, a escolha deste vetor foi realizada a partir do ajuste do modelo de regressão linear (4.8) em que $y_{i}=\ln \left(X_{t+1} / Y_{t}\right)$ e $x_{i}=-\ln \left(Y_{t}\right)$.

A solução do problema de regressão não linear do modelo (6.2) não foi possível devido, provavelmente, ao tamanho pequeno da mostra e/ou aos valores iniciais para os parâmetros obtidos via regressão linear. Sendo assim, os resultados foram obtidos com $b=1$, isto é

$$
X_{i}=\frac{s Y_{i}}{1+a Y_{i}}+\epsilon_{i}, \quad i=1, \cdots, n .
$$

Como citado na literatura, muitos dados para os quais o modelo (6.2) tem sido ajustado resultaram em valores de $b$ não significativamente diferente de 1 (Cousens e Mortimer, 1995).

\subsection{Inferência bayesiana do modelo de produção de sementes}

A formulação estatística do modelo de produção de sementes (6.2) e a função de verossimilhança (6.4) apresentados na inferência clássica são adotadas nesta abordagem. Entretanto, na abordagem bayesiana, os parâmetros são variáveis aleatórias e não mais constantes desconhecidas. Sendo assim, incorpora-se aos parâmetros uma determinada 
incerteza, através de uma densidade de probabilidade a priori e considera-se o modelo Gaussiano para $Y_{i}$.

\subsubsection{Densidade a priori para os parâmetros}

A informação a priori a respeito da interpretação dos parâmetros pode ser expressa utilizando-se prioris informativas. Caso não haja opinião sólida sobre os parâmetros em estudo, então expressa-se o não conhecimento a priori através de uma priori não informativa. Nesta seção, apresentam-se densidades a priori, com médias e variâncias conhecidas, para representar o grau de conhecimento sobre os parâmetros $\theta$ e $\sigma$.

Definindo precisão, denotada $\tau$, como o inverso da variância

$$
\tau=\frac{1}{\sigma^{2}}
$$

segue que a precisão a posteriori é a soma das precisões a priori e da verossimilhança e não depende da variável independente de (6.9). Note que quanto maior a precisão menor a variância e vice-versa.

Como a intensidade da incerteza a respeito de $\theta=(s, a)$ e $\tau$ podem assumir diferentes graus, adota-se:

1. Prioris totalmente informativas Normais para $s$ e $a$, com a média dada pela estimativa clássica e variância 1; e totalmente informativa Gama para $\tau, \operatorname{com} E(\tau)=1$ e $\operatorname{Var}(\tau)=1$, ou seja:

$$
s \sim N(\hat{s} ; 1), a \sim N(\hat{a} ; 1) \text { e } \tau \sim G a(1 ; 1)
$$

2. Prioris totalmente informativas Normais para $s$ e $a$, com a média dada pela estimativa clássica e variância 1; e priori não informativa Gama para $\tau$, $\operatorname{com} E(\tau)=1$ e $\operatorname{Var}(\tau)=1000$, ou seja:

$$
s \sim N(\hat{s} ; 1), a \sim N(\hat{a} ; 1) \text { e } \tau \sim G a(0,001 ; 0,001)
$$

3. Prioris moderadamente informativas ${ }^{1}$ Normais para $s$ e $a$, com a média

\footnotetext{
${ }^{1}$ Neste caso a informação a priori é dita moderadamente informativa por apresentar um certo grau
} 
dada pela estimativa clássica e variância $1.10^{6}$; e moderadamente informativa Gama para $\tau$, $\operatorname{com} E(\tau)=1$ e $\operatorname{Var}(\tau)=10$, ou seja:

$$
s \sim N\left(\hat{s} ; 1.10^{6}\right), a \sim N\left(\hat{a} ; 1.10^{6}\right) \text { e } \tau \sim G a(0,1 ; 0,1)
$$

4. Prioris totalmente informativas Normal para $s$, com a média dada pela estimativa clássica e variância 1 ; Uniforme para $a$, com $0<a<1$; e totalmente informativa Gama para $\tau, \operatorname{com} E(\tau)=1$ e $\operatorname{Var}(\tau)=1$, ou seja:

$$
s \sim N(\hat{s} ; 1), a \sim U(0 ; 1) \text { e } \tau \sim G a(1 ; 1)
$$

5. Prioris totalmente informativa Normal para $s$, com a média dada pela estimativa clássica e variância 1; Uniforme para $a$, com $0<a<1$; e não informativa Gama para $\tau, \operatorname{com} E(\tau)=1$ e $\operatorname{Var}(\tau)=1000$, ou seja:

$$
s \sim N(\hat{s} ; 1), a \sim U(0 ; 1) \text { e } \tau \sim G a(0,001 ; 0,001)
$$

6. Prioris moderadamente informativa Normal para $s$, com a média dada pela estimativa clássica e variância $1.10^{6}$; Uniforme para $a$, com $0<a<1$; e moderadamente informativa Gama para $\tau, \operatorname{com} E(\tau)=1$ e $\operatorname{Var}(\tau)=10$, ou seja:

$$
s \sim N\left(\hat{s} ; 1.10^{6}\right), a \sim U(0 ; 1) \text { e } \tau \sim G a(0,1 ; 0,1) .
$$

Detalhes sobre as distribuições Normal e Gama vide Apêndice A.

\subsubsection{Densidade a posteriori para os parâmetros}

As informações a priori para $s, a$ e $\tau$ descritas anteriormente são independentes, conseqüentemente o próximo passo é obter a densidade a posteriori condicional dos parâmetros e por fim obter as densidades a posteriori marginais. Métodos de simulação estocástica são necessários para simular valores das distribuições condicionais, as quais na maioria das aplicações não assumem formas conhecidas, tornando o problema da sua simulação numa tarefa complicada. Entretanto, há métodos sofisticados de geração que podem

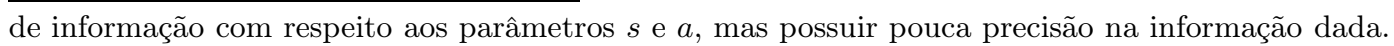


ser utilizados para amostrar estas distribuições, por exemplo: quando as densidade $a$ posteriori condicional é uma distribuição desconhecida a inferência sobre os parâmetros pode ser realizada via o algoritmo de Metropolis-Hastings ou algoritmo "Slice-sampling"; quando tem-se a densidade a posteriori condicional completa utiliza-se o Amostrador de Gibbs (Favoretti, 1995; Melo, 1999; Gelman et al., 2000; Mena, 2000; Cespedes, 2003; Paulino et al., 2003).

\subsubsection{Programas para a inferência bayesiana}

Para a obtenção das densidades a posteriori dos parâmetros foi utilizado o aplicativo WinBUGS (Spiegelhalter et al., 2006), no qual foram implementas seis sub-rotinas para incorporar os diferentes graus de informação a priori com respeito a $s, a$ e $\tau$.

A escolha do algoritmo de simulação das amostras de interesse no WinBUGS depende das densidades a priori adotadas para estes parâmetros e, conseqüentemente, da densidade a posteriori condicional obtida. Em particular, para distribuições que não são log-côncavas e que variam dentro de certos limites, como a Uniforme, foi usado o algoritmo "Slice-sampling". Para distribuições Normais adotou-se o algoritmo de MetropolisHastings, o qual baseia-se numa distribuição simétrica Normal.

1. Prioris totalmente informativas Normais para $s$ e $a$ e totalmente informativa Gama para $\tau$

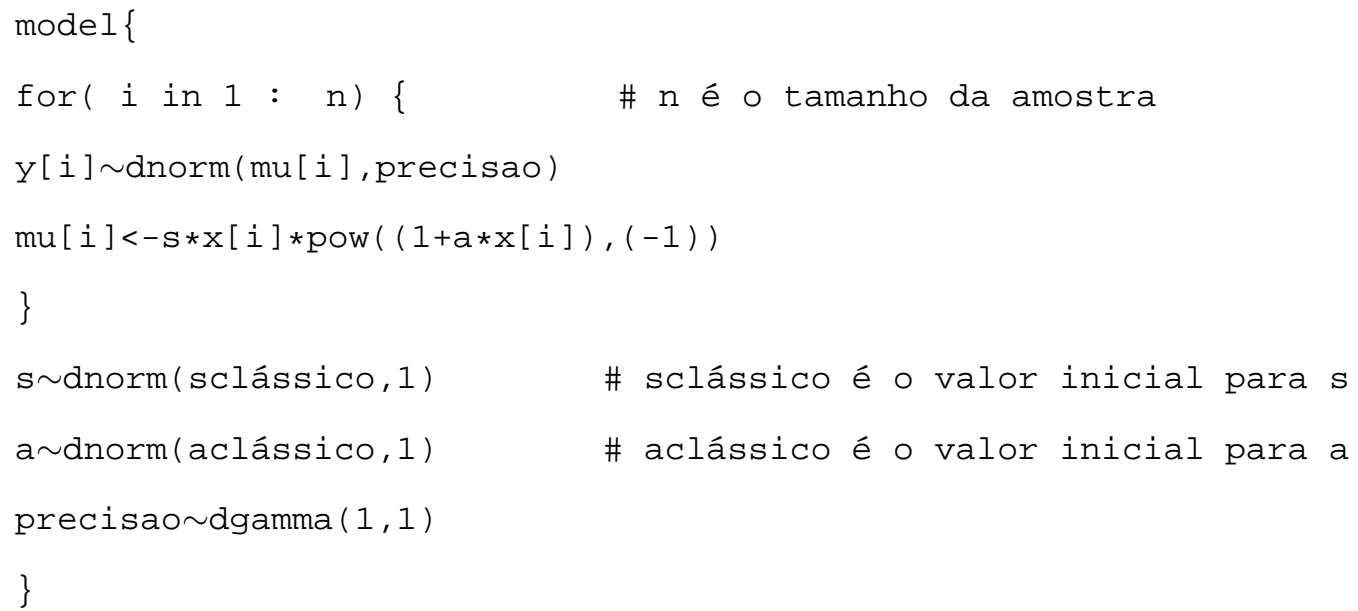

2. Prioris totalmente informativas Normais para $s$ e $a$ e não informativa Gama para $\tau$

model \{ 


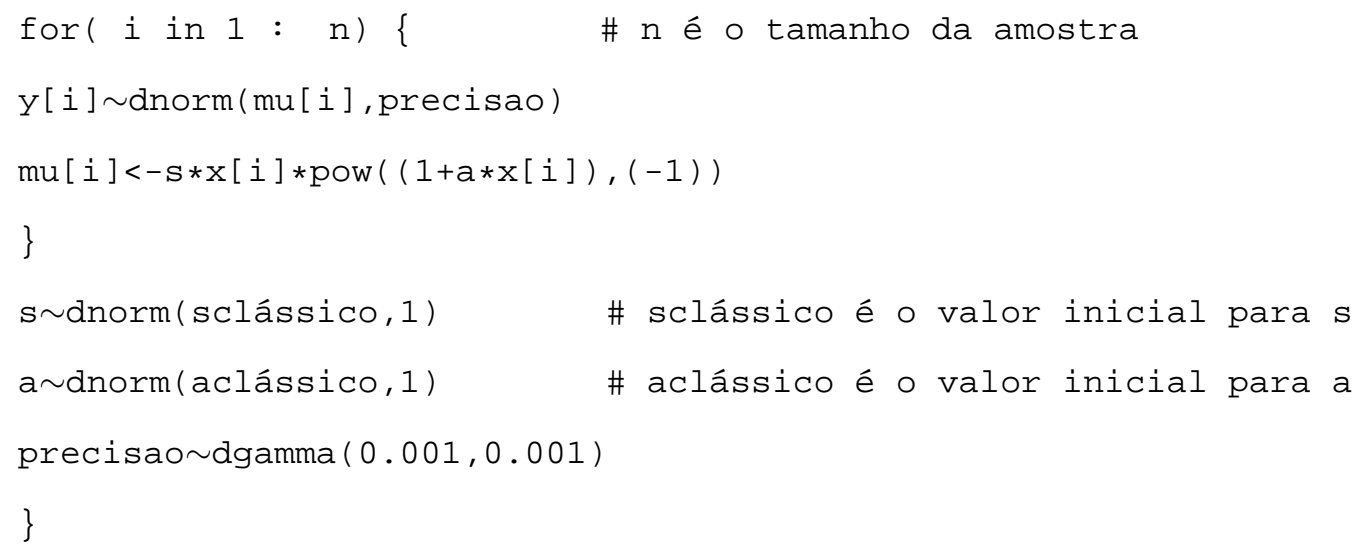

3. Prioris moderadamente informativas Normais para $s$ e $a$ e e moderadamente informativa Gama para $\tau$

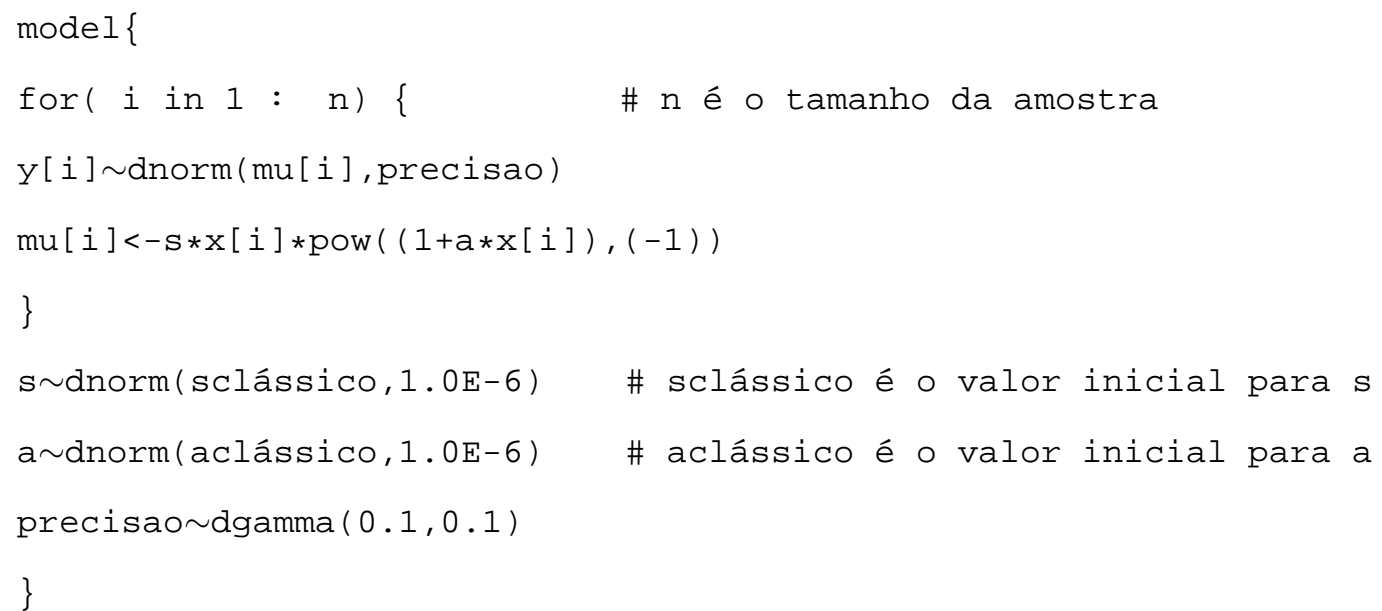

4. Prioris totalmente informativas Normal para $s$ e Gama para $\tau$, e Uniforme para $a$

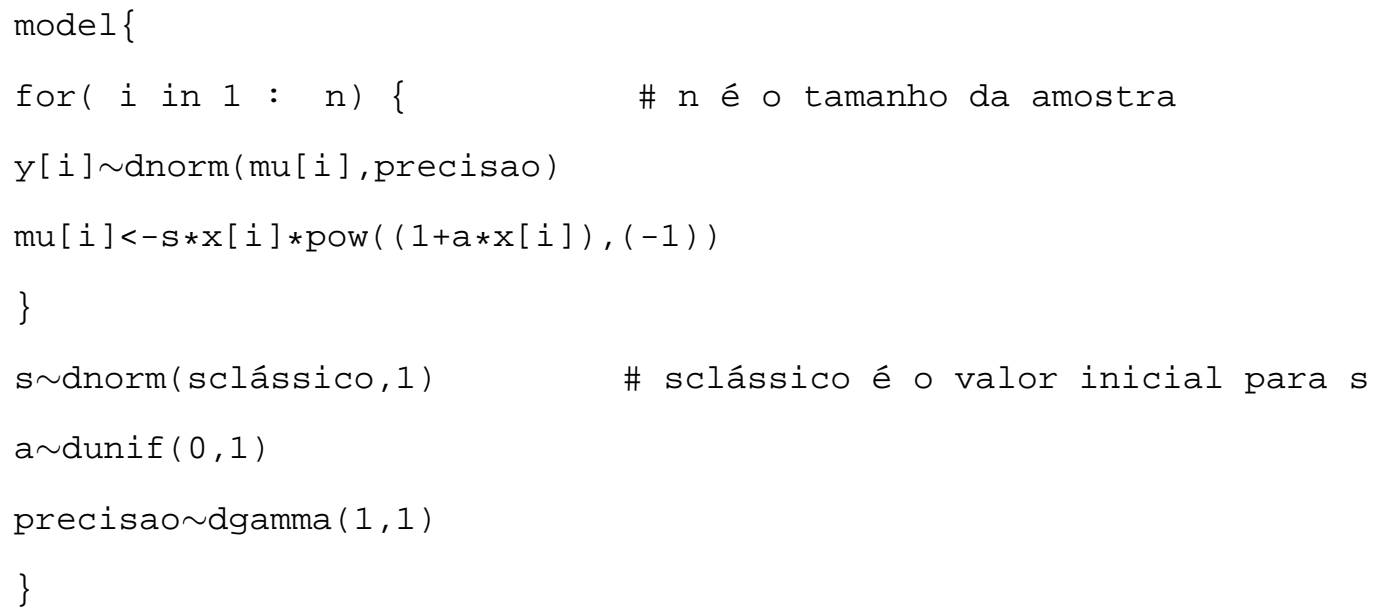

5. Prioris totalmente informativa Normal para $s$, não informativa Gama para $\tau$ e Uniforme para $a$ 


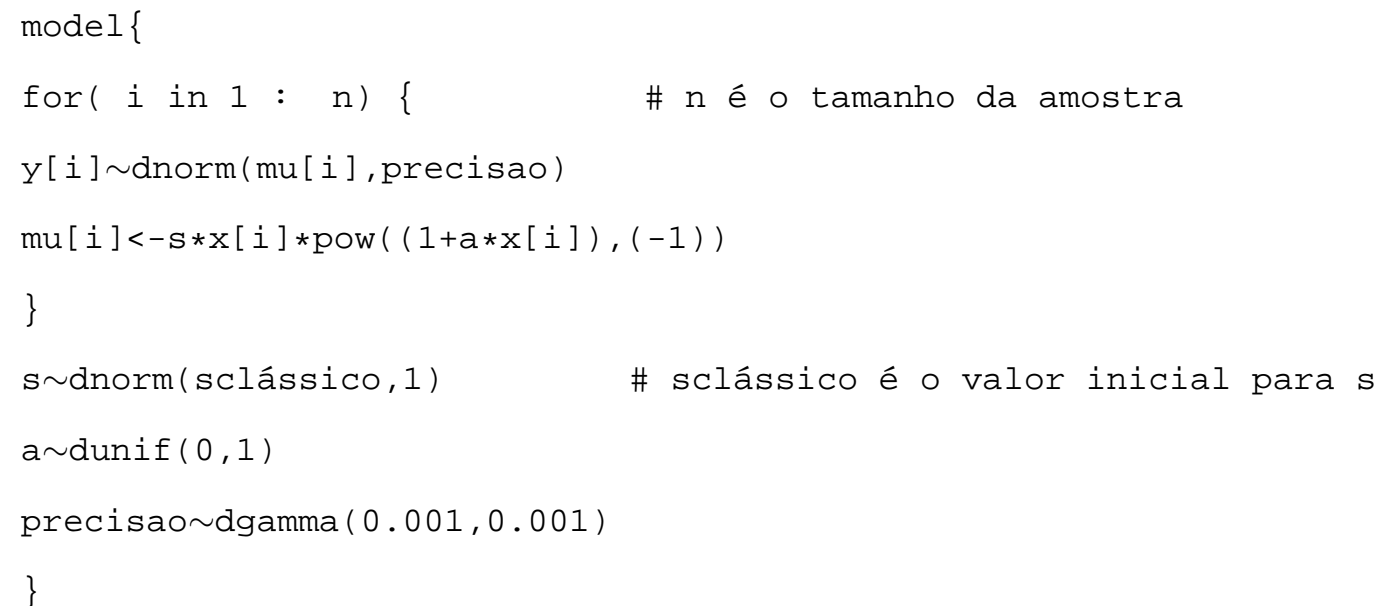

6. Prioris moderadamente informativas Normal para $s$ e Gama para $\tau$, e Uniforme para $a$

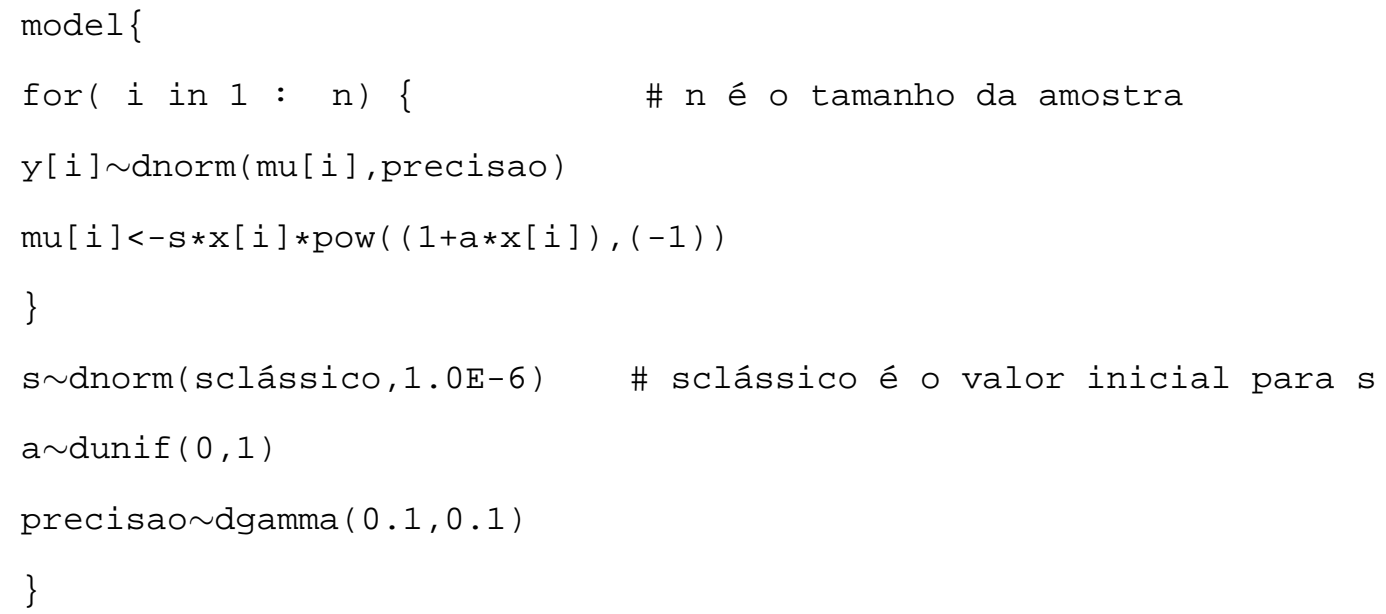

Obviamente o tamanho $n$ da amostra difere para as espécies daninhas estudadas, bem como as estimativas clássica de $s$ e $a$ ( $\operatorname{sclássico=} \hat{s}$ e aclássico $=\hat{a}$, respectivamente). Para 1., 2. e 3. utilizou-se o algoritmo de Metropolis-Hastings, já para 4., 5. e 6. o algoritmo "Slice-sampling". 


\section{Capítulo 7}

\section{Resultados e discussão}

Neste Capítulo, apresentam-se os resultados obtidos para o experimento conduzido em campo, ilustrando a utilização do modelo de produção de sementes em função de sua flora emergente.

A abordagem de diagnósticos gráfico-visual privilegia a utilização de gráficos sobre testes e análises numéricas, envolvendo geralmente a utilização de gráficos de caixa ("box-plot"), histograma e dispersão das variáveis dependente versus independente. O objetivo principal é detectar tendências relativas a assimetria e observações discrepantes (Batista, 2004). A Figura 7.1 mostra a estrutura do gráfico de caixa, o qual investiga a forma da distribuição enfatizando os quantis da distribuição (primeiro quantil, mediana, terceiro quantil), a distância inter-quartil e presença de valores atípicos (Batista, 2004). Já o histograma permite visualizar a forma da distribuição da variável de interesse; e o gráfico de dispersão fornece uma idéia sobre a relação existente entre as variáveis.

Na inferência clássica, tendo em vista as pressuposições para a utilização dos modelos de regressão linear e não linear, a análise do resíduo é fundamental. Uma série de problemas envolvendo o modelo, inclusive violações das pressuposições, podem ser diagnosticados através da análise do resíduo, por exemplo: a variância do erro não é constante (heterocedasticidade) ou o modelo se ajusta bem à maioria das observações, com exceção de algumas observações discrepantes. Realiza-se também o teste de significância dos parâmetros do modelo de regressão via o teste da hipótese (4.10).

Na abordagem bayesiana, a procura de uma densidade geradora de amostras se deu via algoritmo de Metropolis-Hastings ou algoritmo "Slice-sampling". Para cada parâme- 


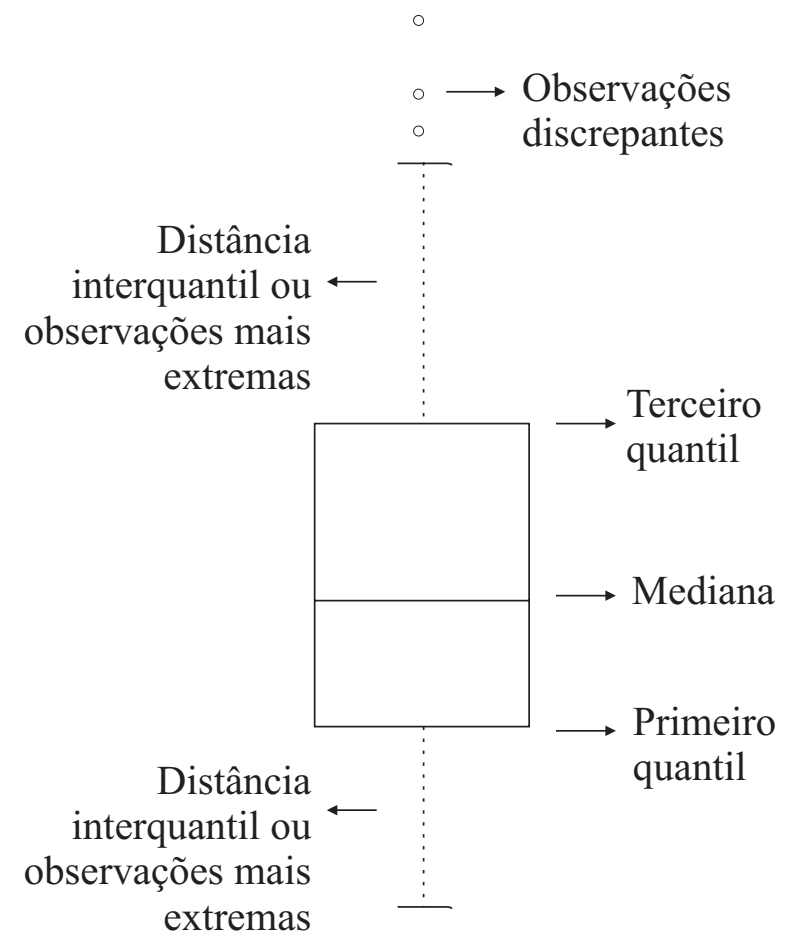

Figura 7.1: Gráfico de caixa segundo Batista (2004): a caixa é delimitada pelo primeiro e terceiro quartil, tendo a mediana como uma linha interior. As linhas que saem da caixa se expandem até 1,5 vezes a distância interquartil ou até a observação mais extrema. A partir da distância interquantil, as observações são marcadas individualmente como observações discrepantes.

tro gerou-se de duas a três cadeias distintas e foi verificado se houve convergência das amostras a posteriori para uma região em torno de seus possíveis valores verdadeiros. Para cada cadeia foram realizadas no mínimo 100000 iterações, das quais foram descartadas pelo menos 4000 amostras iniciais. Também, foi atribuído saltos apropriados para redução da autocorrelação entre os valores gerados. Para verificar a convergência dos algoritmos utilizou-se os traços a posteriori dos parâmetros e o teste gráfico de Gelman e Rubin (Gelman et al., 2000).

Deve-se ressaltar que para realizar a inferência estatística o conjunto de dados foi organizado por espécie daninha. Assim, as espécies daninhas cujo número de observações permitia realizar algum tipo de inferência foram Digitaria ciliaris (capim colchão), Panicum maximum (capim guiné) e Euphorbia heterophylla (leiteiro). As Tabelas 5.2, 5.3 e 5.4, respectivamente, apresentam o conjunto de dados referente a cada espécie. 


\subsection{Digitaria ciliaris (capim colchão)}

\subsubsection{Diagnósticos envolvendo a variável dependente}

Notou-se a presença de valores discrepantes na amostra (Figura 7.2 (esquerda)), que acentua a assimetria da distribuição da densidade de sementes produzidas de capim colchão.
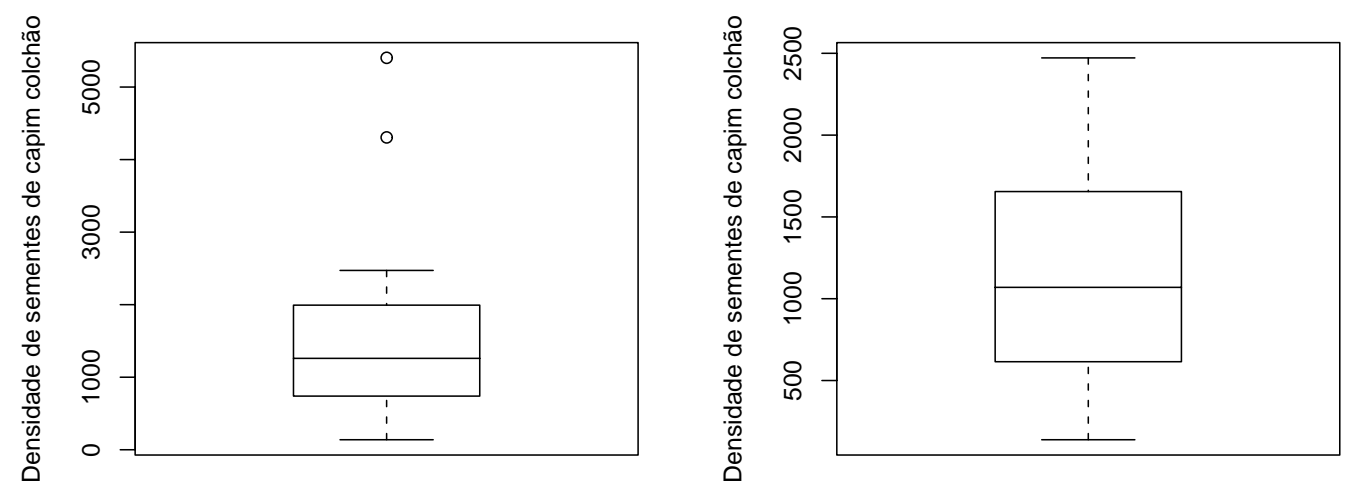

Figura 7.2: Gráfico de caixa: densidade de sementes produzidas de capim colchão com (esquerda) e sem (direita) observações discrepantes.

Com a remoção dos valores atípicos (Figura 7.2 (direita)) esta assimetria foi suavizada, tornando a distribuição quase simétrica o que permitiu realizar a inferência clássica via regressão não linear com mais segurança.

A Figura 7.3 apresenta o gráfico de dispersão das observações de densidade de plantas daninhas versus densidade de sementes produzidas (esquerda) e histograma (direita) para a população de capim colchão, o qual fornece uma idéia da forma da distribuição da variável densidade de sementes produzidas de capim colchão.

Como observado na Figura 7.2, o histograma de freqüência mostra uma suave assimetria à esquerda na distribuição de $X_{i}$ (Figura 7.3 (direita)). No gráfico de dispersão das variáveis (Figura 7.3 (esquerda)) foi observada, apesar do reduzido número de observações, uma relação que aproxima-se da logarítmica. 

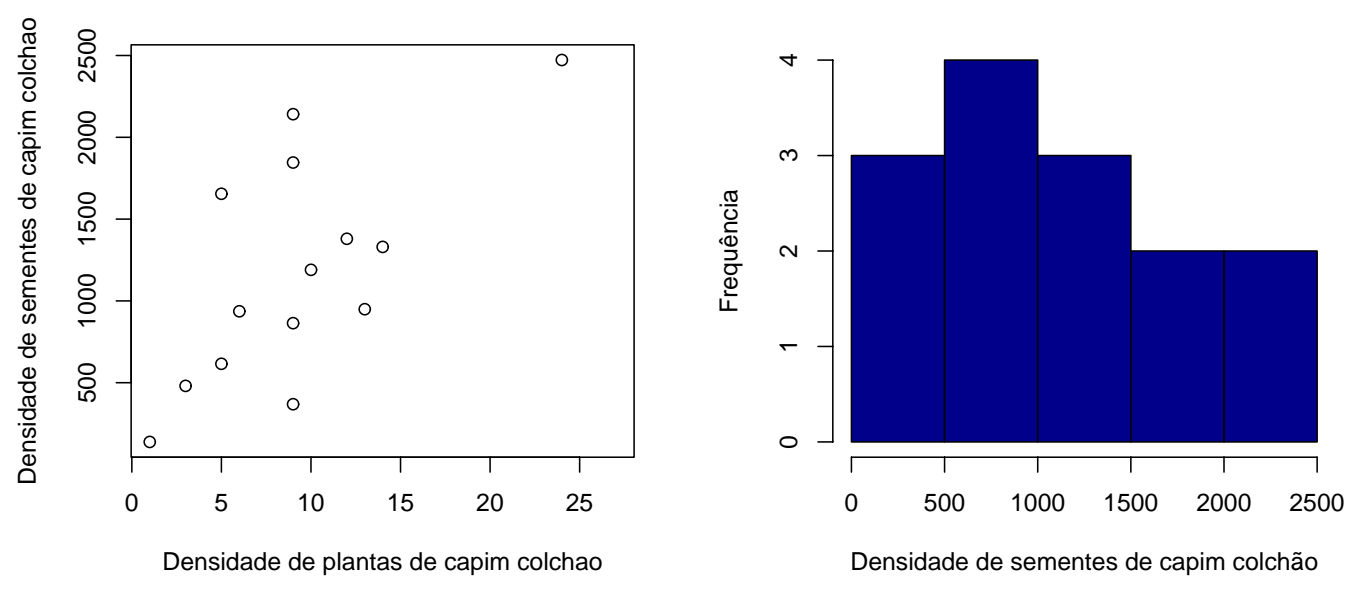

Figura 7.3: Gráfico de dispersão da variável independente versus variável dependente (esquerda) e histograma (direita) para as observações de capim colchão.

\subsubsection{Abordagem clássica do modelo de produção de sementes}

\section{Regressão do modelo linearizado}

A escolha dos valores iniciais para as estimativas dos parâmetros do modelo de regressão não linear foi realizada a partir do ajuste do modelo linearizado de (6.2). O modelo de regressão linear ajustado de (4.8) é

$$
y_{i}=5,2655+0,2128 x_{i}
$$

em que $y_{i}=\ln \left(X_{t+1} / Y_{t}\right)$ é a variável dependente e $x_{i}=-\ln \left(Y_{t}\right)$ a variável independente.

A Figura 7.4 (esquerda) apresenta o gráfico de dispersão das variável independente versus variável dependente com a reta da regressão linear. A análise da normalidade dos resíduos foi verificada através do gráfico de normalidade apresentado na Figura 7.4 (direita). Para verificação da qualidade do ajuste linear foi utilizado o coeficiente de determinação $R^{2}$. Para analisar as estimativas dos parâmetros foi feito o teste $t$-Student de significância dos parâmetros.

Tem-se que $R^{2}=0,1019$, o que indica que a variável $x_{i}$ explica apenas $10,19 \%$ da variabilidade de $y_{i}$. Considerando um nível de significância de $\alpha=0,05$, testa-se $H_{01}: \beta_{0}=0$ versus $H_{11}: \beta_{0} \neq 0$, utilizando a estatística $t$-Student; tem-se $t=13,496$ 

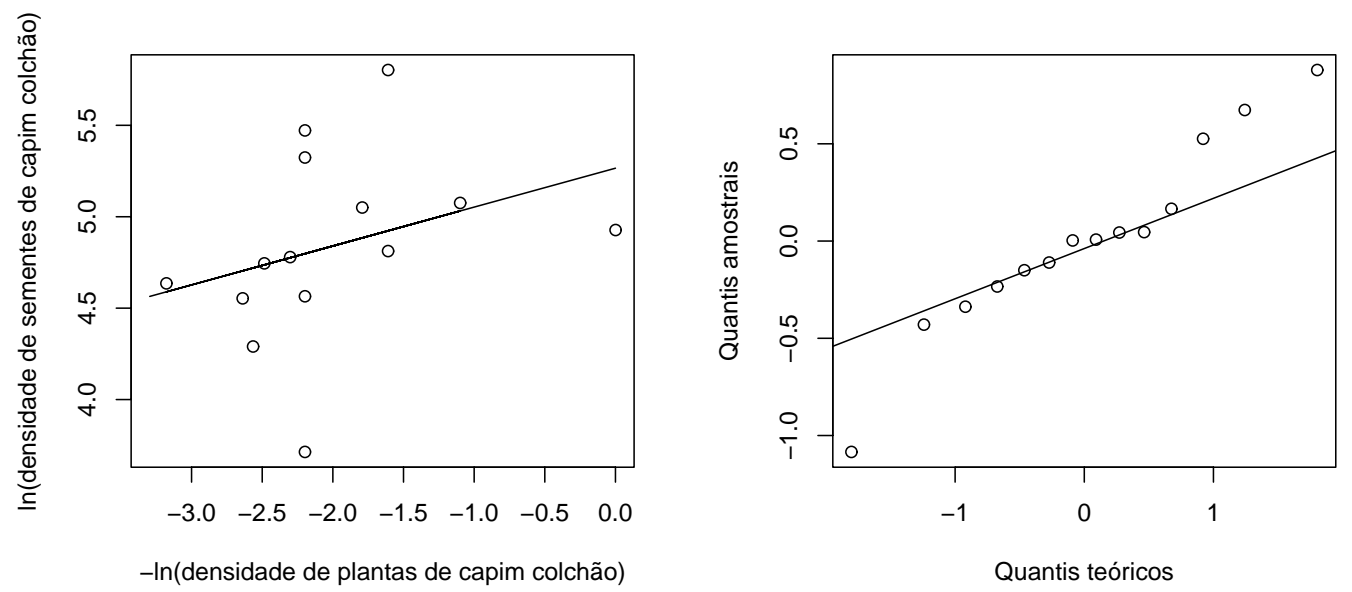

Figura 7.4: Gráficos de dispersão da variável independente versus variável dependente com a reta da regressão linear do modelo (4.8) (esquerda) e de normalidade dos resíduos (direita) para as observações de capim colchão.

e $t_{0}=1,29.10^{-8}$ e como $t>t_{0}$ rejeita-se a hipótese $H_{0}$, o que indica que o parâmetro é significativo. Analogamente, testa-se $H_{02}: \beta_{1}=0$ versus $H_{12}: \beta_{1} \neq 0$ obtendo-se $t=0,2128$ e $t_{0}=0,266$ e como $t<t_{0}$ não se rejeita a hipótese $H_{0}$ ao nível $\alpha=0,05$ de significância, o que indica que o parâmetro não é significativo.

Apesar da má qualidade do ajuste, as estimativas encontradas para $\beta_{0}$ e $\beta_{1}$ foram utilizadas como valores iniciais para as estimativas dos parâmetros do modelo de regressão não linear, pois de certa maneira trazem alguma informação com respeito aos parâmetros $s$ e $a$.

\section{Regressão do modelo não linear}

A Figura 7.5 (esquerda) apresenta o gráfico de dispersão da variável independente versus variável dependente com a curva da regressão não linear do modelo (6.9) para as observações de capim colchão, confirmando a pressuposição de relação logarítmica entre as variáveis. A Tabela 7.1 apresenta as estimativas clássica e as medidas de precisão para os parâmetros do modelo (6.9).

Tabela 7.1: Resumo dos resultados via abordagem clássica do modelo (6.9) para a população de Digitaria ciliaris (capim colchão).

\begin{tabular}{cccccc}
\hline Parâmetros & Estimativa & Desvio padrão & IC $(95 \%)$ & $t$ & $t_{0}$ \\
\hline $\mathrm{s}$ & 209,6 & 94,9 & {$[2,9 ; 416,3]$} & 2,2 & $4,7.10^{-2}$ \\
$\mathrm{a}$ & $5,9.10^{-2}$ & $6,3.10^{-2}$ & {$\left[-7,8.10^{-2} ; 2,0.10^{-1}\right]$} & $9,4.10^{-1}$ & $3,7.10^{-1}$ \\
\hline
\end{tabular}


A homocedasticidade (ou heterocedasticidade) da variância dos resíduos do modelo (6.9) foi verificada pela análise do gráfico dos resíduos versus valores ajustados apresentado na Figura 7.5 (direita). A forma da distribuição e a normalidade dos resíduos podem ser analisadas nas Figuras 7.6 através do histograma (esquerda) e do gráfico de normalidade (direita), respectivamente.
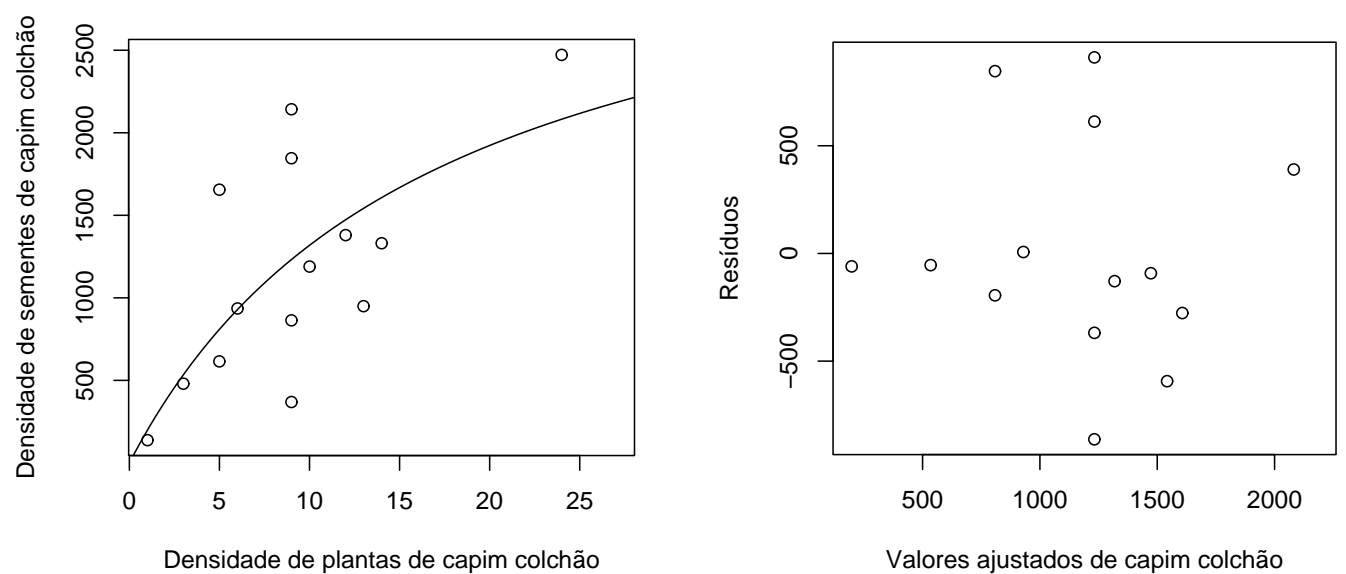

Figura 7.5: Gráficos de dispersão da variável independente versus variável dependente com a curva da regressão não linear do modelo (6.9) (esquerda) e dos resíduos versus valores ajustados (direita) para as observações de capim colchão.
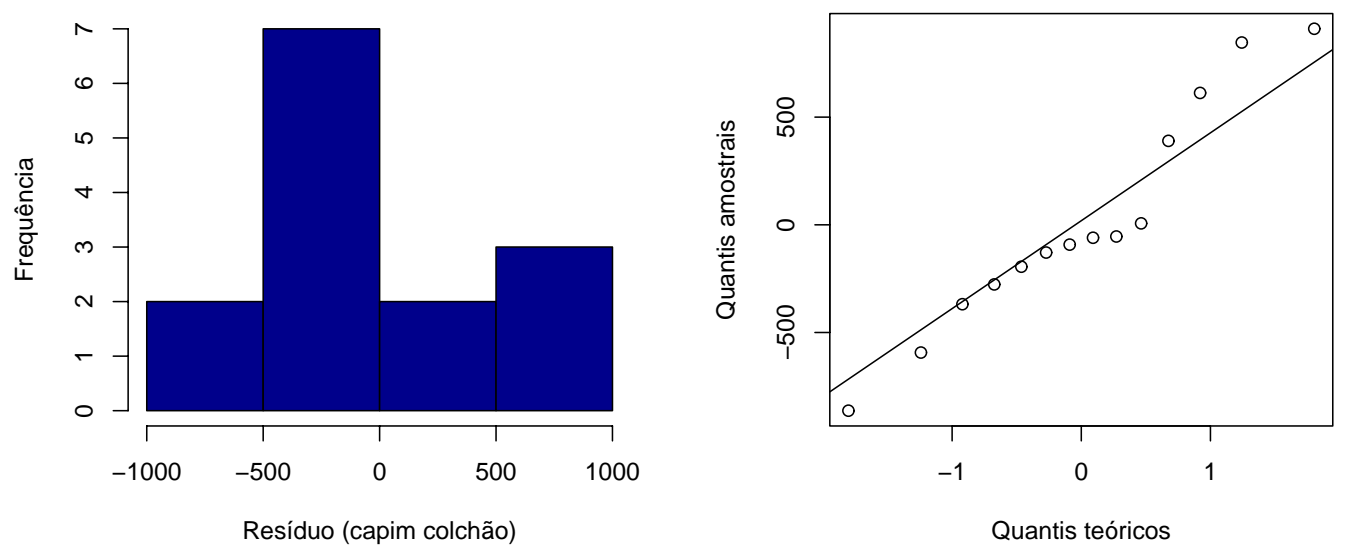

Figura 7.6: Histograma (esquerda) e gráfico de normalidade dos resíduos (direita) para as observações de capim colchão.

O gráfico de dispersão com a curva da regressão não linear apresentado na Figura 7.5 (esquerda), confirma a suposição da relação entre as variáveis ser logarítmica. Provavelmente, isto se deve ao fato de que a população encontrava-se sob alta densidade de 
plantas de capim colchão e, neste caso, os efeitos do aumento do número de sementes por área é não linear.

Nota-se uma ligeira heterocedasticidade na variância dos resíduos (Figura 7.5 (direita)) e assimetria a esquerda na distribuição dos resíduos (Figura 7.6 (esquerda)), no entanto seria necessário um maior número de observações para uma análise gráfica mais criteriosa e eficiente.

\subsubsection{Abordagem bayesiana do modelo de produção de sementes}

Para obtenção da densidade a posteriori dos parâmetros $s, a$ e $\tau$, gerou-se de duas a três cadeias a partir de valores iniciais distintos. Para a primeira cadeia utilizou-se as estimativas de regressão não linear $\hat{s}$ e $\hat{a}$ e para a segunda cadeia as estimativas de regressão linear. Já para a terceira cadeia os valores iniciais foram gerados pelo aplicativo WinBUGS (Spiegelhalter et al., 2006), o qual parte de valores extremos das densidades a priori. Sendo assim, não foi possível gerar amostras a partir da terceira cadeia quando adotou-se prioris não informativas para algum parâmetro, o que se justifica pela pouca precisão da informação a priori adotada para o parâmetro.

A análise dos traços a posteriori dos parâmetros apresentou convergência em alguns casos. Assim, também foi utilizado o teste de Gelman e Rubin (Gelman et al., 2000) como critério de verificação dos algoritmos.

Na Tabela 7.2, apresenta-se o resumo dos resultados bayesianos do modelo (6.9) para a população de capim colchão, adotando-se diferentes densidades a priori para os parâmetros. Apresenta-se a seguir a análise detalhada com relação a cada priori adotada.

Prioris totalmente informativas Normais para $s$ e $a$ e Gama para $\tau$ $\left(s \sim N(209,6 ; 1), a \sim N\left(5,9.10^{-2} ; 1\right)\right.$ e $\left.\tau \sim G a(1 ; 1)\right)$

Foram realizadas 100000 iterações para gerar as amostras dos parâmetros partindo-se de três cadeias distintas, destas descartou-se as 9999 amostras iniciais com saltos de 10 para diminuir a autocorrelação entre os parâmetros, perfazendo um total de 27000 amostras geradas dos parâmetros $s, a$ e $\tau$ utilizando-se o algoritmo Metropolis-Hastings.

O algoritmo de Metropolis-Hastings se adaptou ao conjunto de dados e às densida- 
Tabela 7.2: Resumo dos resultados via abordagem bayesiana do modelo (6.9) para a população de Digitaria ciliaris (capim colchão).

\begin{tabular}{|c|c|c|c|c|}
\hline \multirow[t]{2}{*}{ Prioris } & & \multicolumn{3}{|c|}{ Parâmetros } \\
\hline & & $s$ & $a$ & $\tau$ (precisão) \\
\hline$s \sim N(209,6 ; 1)$ & Média & 209,6 & $6,5.10^{-2}$ & $4,6.10^{-6}$ \\
\hline$a \sim N\left(5,9.10^{-2} ; 1\right)$ & Mediana & 209,6 & $6,3.10^{-2}$ & $4,4.10^{-6}$ \\
\hline \multirow[t]{2}{*}{$\tau \sim G a(1 ; 1)$} & Desvio padrão & $9,9.10^{-1}$ & $1,8.10^{-2}$ & $1,6.10^{-6}$ \\
\hline & IC $(95 \%)$ & {$[207,6 ; 211,5]$} & {$\left[3,8.10^{-2} ; 1,1.10^{-2}\right]$} & {$\left[2,0.10^{-6} ; 8,3.10^{-6}\right]$} \\
\hline$s \sim N(209,6 ; 1)$ & Média & 209,6 & $6,6.10^{-2}$ & $4,0.10^{-6}$ \\
\hline$a \sim N\left(5,9.10^{-2} ; 1\right)$ & Mediana & 209,6 & $6,3.10^{-2}$ & $3,9.10^{-6}$ \\
\hline \multirow[t]{2}{*}{$\tau \sim G a(0,001 ; 0,001)$} & Desvio padrão & 1,0 & $2,0.10^{-2}$ & $1,6.10^{-6}$ \\
\hline & IC $(95 \%)$ & {$[207,7 ; 211,6]$} & {$\left[3,6.10^{-1} ; 1,1.10^{-1}\right]$} & {$\left[1,6.10^{-6} ; 7,6.10^{-6}\right]$} \\
\hline$s \sim N\left(209,6 ; 1.10^{6}\right)$ & Média & 832,6 & $5,9.10^{-1}$ & $3,4.10^{-6}$ \\
\hline$a \sim N\left(5,9.10^{-2} ; 1.10^{6}\right)$ & Mediana & 689,5 & $4,4.10^{-1}$ & $3,1.10^{-6}$ \\
\hline \multirow[t]{2}{*}{$\tau \sim G a(0,1 ; 0,1)$} & Desvio padrão & 554,9 & $5,2.10^{-1}$ & $1,4.10^{-6}$ \\
\hline & IC $(95 \%)$ & {$[178,7 ; 2225]$} & {$\left[4,0.10^{-2} ; 2,0\right]$} & {$\left[1,3.10^{-6} ; 6,6.10^{-6}\right]$} \\
\hline$s \sim N(209,6 ; 1)$ & Média & 209,6 & $6,5.10^{-2}$ & $4,6.10^{-6}$ \\
\hline$a \sim U(0 ; 1)$ & Mediana & 209,6 & $6,2.10^{-2}$ & $4,4.10^{-6}$ \\
\hline \multirow[t]{2}{*}{$\tau \sim G a(1 ; 1)$} & Desvio padrão & 1,0 & $1,8.10^{-2}$ & $1,7.10^{-6}$ \\
\hline & IC $(95 \%)$ & {$[207,6 ; 211,6]$} & {$\left[3,7.10^{-2} ; 1,1.10^{-1}\right]$} & {$\left[2,0.10^{-6} ; 8,4.10^{-6}\right]$} \\
\hline$s \sim N(209,6 ; 1)$ & Média & 209,6 & $6,6.10^{-2}$ & $4,0.10^{-6}$ \\
\hline$a \sim U(0 ; 1)$ & Mediana & 209,6 & $6,3.10^{-2}$ & $3,8.10^{-6}$ \\
\hline \multirow[t]{2}{*}{$\tau \sim G a(0,001 ; 0,001)$} & Desvio padrão & 1,0 & $2,0.10^{-2}$ & $1,5.10^{-6}$ \\
\hline & IC $(95 \%)$ & {$[207,6 ; 211,5]$} & {$\left[3,7.10^{-2} ; 1,1.10^{-1}\right]$} & {$\left[1,6.10^{-6} ; 7,6.10^{-6}\right]$} \\
\hline$s \sim N\left(209,6 ; 1.10^{6}\right)$ & Média & 625,4 & $3,9.10^{-1}$ & $3,5.10^{-6}$ \\
\hline$a \sim U(0 ; 1)$ & Mediana & 566,2 & $3,4.10^{-1}$ & $3,3.10^{-6}$ \\
\hline \multirow[t]{2}{*}{$\tau \sim G a(0,1 ; 0,1)$} & Desvio padrão & 329,6 & $2,6.10^{-1}$ & $1,4.10^{-6}$ \\
\hline & IC $(95 \%)$ & {$[167,1 ; 1342]$} & {$\left[3,3.10^{-2} ; 9,4.10^{-1}\right]$} & {$\left[1,4.10^{-6} ; 6,8.10^{-6}\right]$} \\
\hline
\end{tabular}

des a priori adotadas para os parâmetros. Na Figura 7.7 observou-se poucos pontos discrepantes e uniformidade nos traços a posteriori de $s, a$ e $\tau$ o que indica convergência do algoritmo. O teste gráfico de Gelman e Rubin (Figura 7.8) confirma a convergência do algoritmo de Metropolis-Hastings para os parâmetros $s$ e $\tau$. Para $a$ o fator de Gelman e Rubin $(0,9999)$ indica um nível aceitável de convergência do algoritmo. Na Figura 7.9 apresentam-se as densidades a posteriori de $s, a$ e $\tau$.

As análises foram repetidas para três cadeias, descartando-se apenas as 4000 amostras iniciais, com saltos de 10 entre as amostras geradas para diminuir a autocorrelação entre os parâmetros, perfazendo um total de 28800 amostras geradas. Nestas condições, obteve-se estatísticas muito próximas das obtidas quando são descartadas 9999 amostras diferindo a partir da quarta casa decimal. 

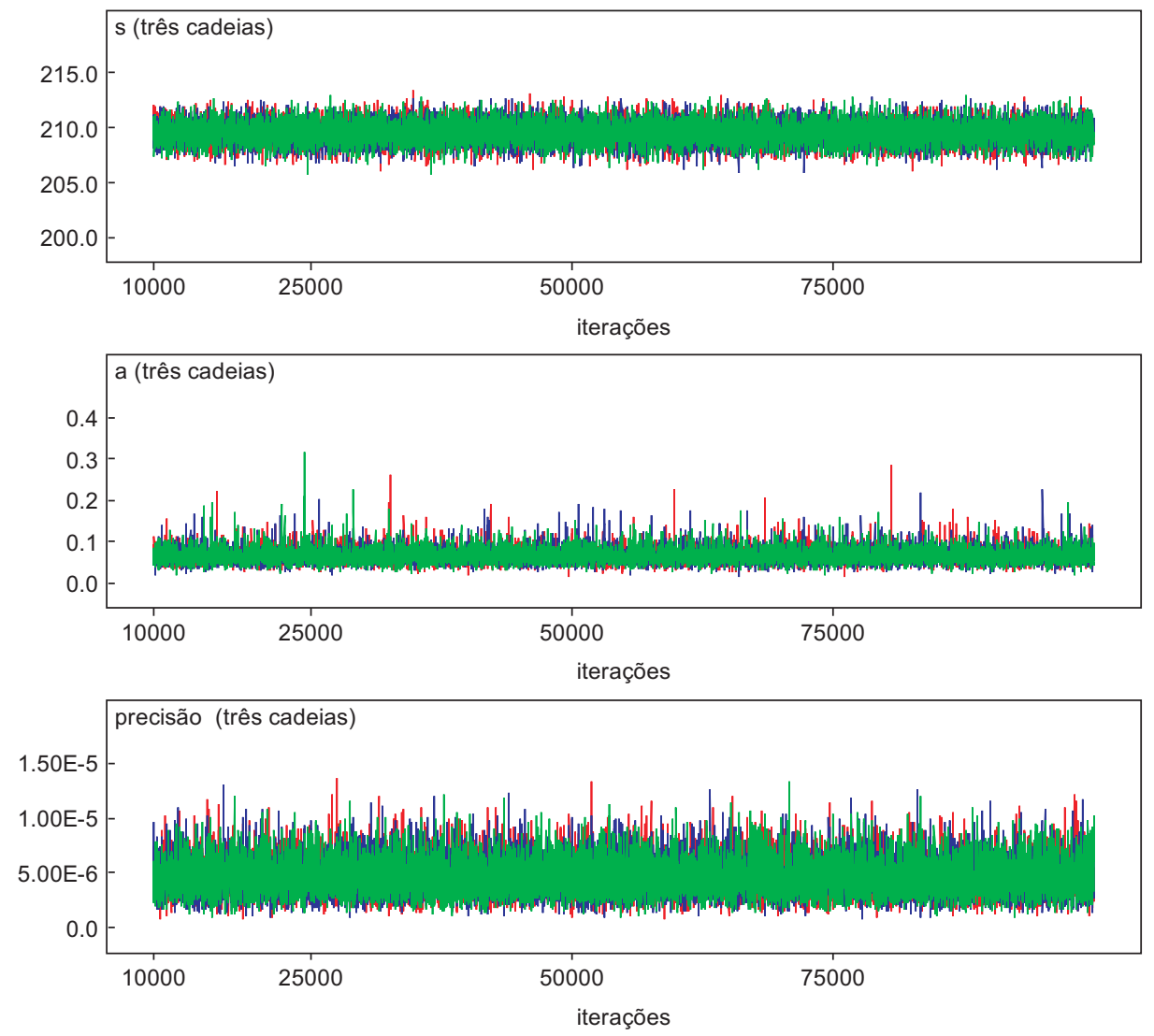

Figura 7.7: Traços a posteriori das três cadeias geradas de $s, a$ e $\tau$ considerando a população de capim colchão e as prioris: $s \sim N(209,6 ; 1), a \sim N\left(5,9.10^{-2} ; 1\right)$ e $\tau \sim G a(1 ; 1)$. Nota-se uniformidade nos traços a posteriori de $s$, $a$ e $\tau$ o que indica a convergência do algoritmo.
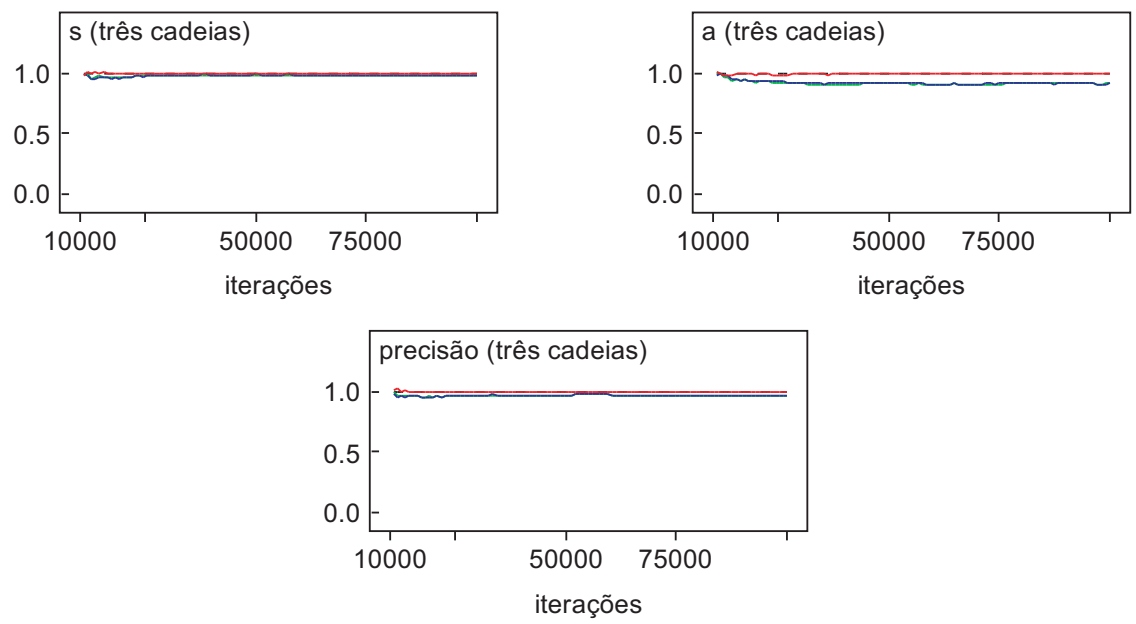

Figura 7.8: Teste gráfico de Gelman e Rubin: verifica-se que houve convergência do algoritmo de MetropolisHastings na geração de amostras das três cadeias para os parâmetros $s$ e $\tau$ considerando a população de capim colchão e as prioris: $s \sim N(209,6 ; 1), a \sim N\left(5,9.10^{-2} ; 1\right)$ e $\tau \sim G a(1 ; 1)$. 

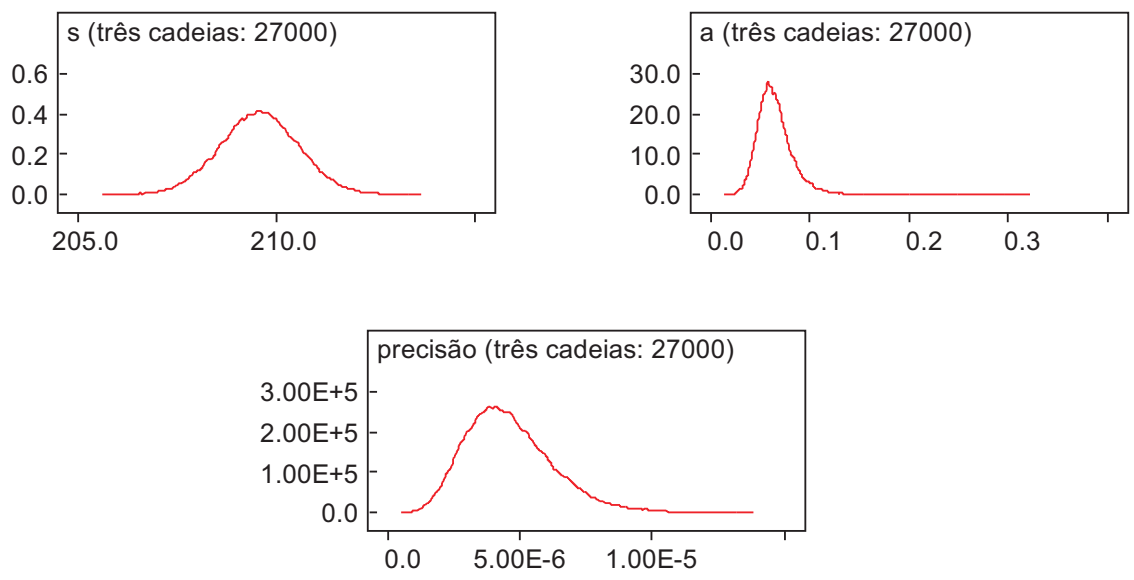

Figura 7.9: Densidades a posteriori de $s$, a e $\tau$ obtidas a partir das 27000 amostras geradas pelas três cadeias considerando a população de capim colchão e as prioris: $s \sim N(209,6 ; 1), a \sim N\left(5,9.10^{-2} ; 1\right)$ e $\tau \sim G a(1 ; 1)$.

Prioris totalmente informativas Normais para $s$ e $a$ e não informativa Gama para $\tau$ $\left(s \sim N(209,6 ; 1), a \sim N\left(5,9.10^{-2} ; 1\right)\right.$ e $\left.\tau \sim G a(0,001 ; 0,001)\right)$

Foram realizadas 100000 iterações para gerar as amostras dos parâmetros com duas cadeias, destas 9999 foram descartadas e foi dado um salto de 10 para diminuir a autocorrelação entre os parâmetros, perfazendo um total de 18000 amostras geradas dos parâmetros $s, a$ e $\tau$ utilizando-se o algoritmo Metropolis-Hastings.

O algoritmo de Metropolis-Hastings se adaptou ao conjunto de dados e às densidades a priori adotadas para os parâmetros. Na Figura 7.10 notou-se poucos pontos discrepantes e uniformidade nos traços a posteriori de $s, a$ e $\tau$ o que indica convergência do algoritmo. Contudo, pelo teste gráfico de Gelman e Rubin (Figura 7.11) não se confirma a convergência do algoritmo de Metropolis-Hastings, mas os fatores de Gelman e Rubin de $s(1,001), a(1.001)$ e $\tau$ (1.0) indicam um nível aceitável de convergência do algoritmo. As densidades a posteriori de $s, a$ e $\tau$ são apresentadas na Figura 7.12.

\section{Prioris moderadamente informativas Normais para $s$ e $a$ e Gama para $\tau$} $\left(s \sim N\left(209,6 ; 1.10^{6}\right), a \sim N\left(5,9.10^{-2} ; 1.10^{6}\right)\right.$ e $\left.\tau \sim G a(0,1 ; 0,1)\right)$

Foram realizadas 100000 iterações para gerar as amostras dos parâmetros partindo-se de três cadeias distintas, destas 4000 foram descartadas com saltos de 30 para diminuir a autocorrelação entre os parâmetros, perfazendo um total de 9600 amostras geradas 

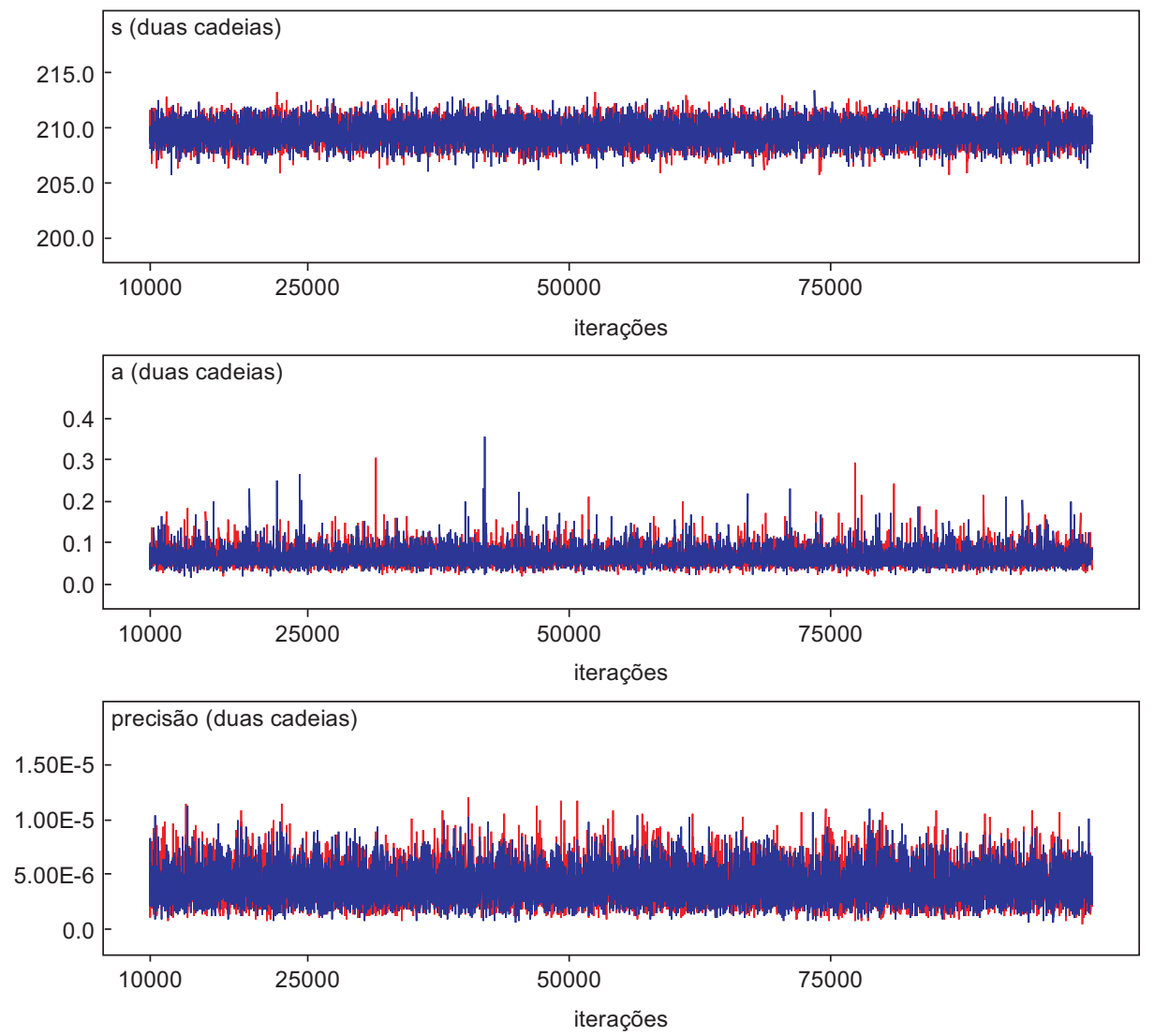

Figura 7.10: Traços a posteriori das duas cadeias geradas de $s, a$ e $\tau$ considerando a população de capim colchão e as prioris: $s \sim N(209,6 ; 1), a \sim N\left(5,9.10^{-2} ; 1\right)$ e $\tau \sim G a(0,001 ; 0,001)$. Nota-se uniformidade nos traços a posteriori de $s$ e $\tau$, mas alguns pontos discrepantes nos traços de $a$.
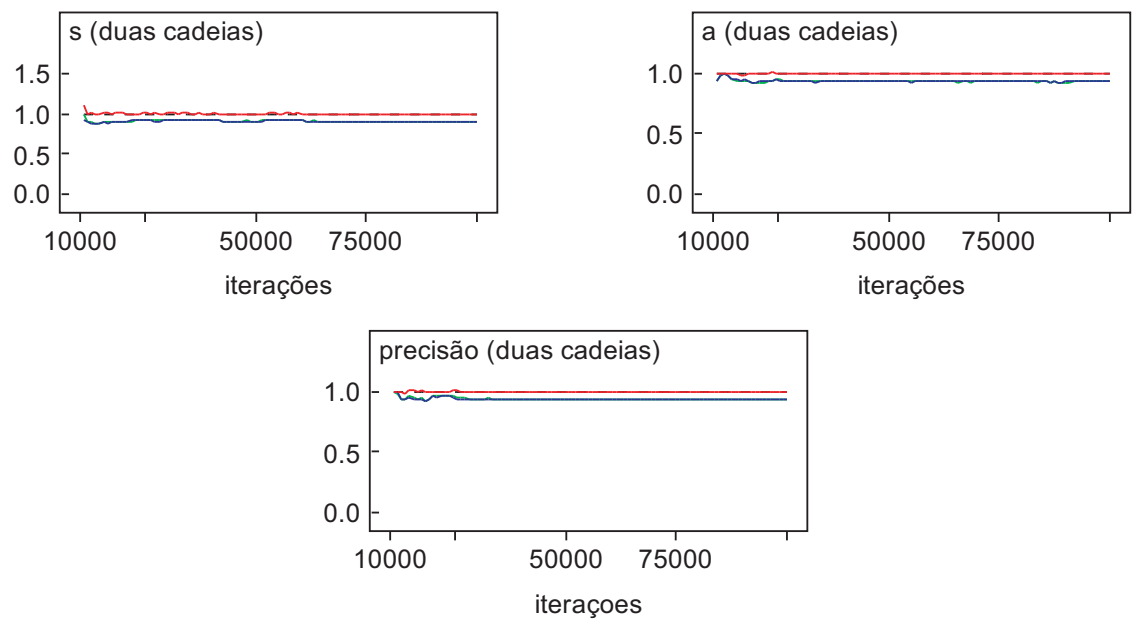

Figura 7.11: Teste gráfico de Gelman e Rubin: verifica-se um nível aceitável de convergência do algoritmo de Metropolis-Hastings na geração de amostras das duas cadeias para os parâmetros $s$ e $\tau$ considerando a população de capim colchão e as prioris: $s \sim N(209,6 ; 1), a \sim N\left(5,9.10^{-2} ; 1\right)$ e $\tau \sim G a(0,001 ; 0,001)$. 

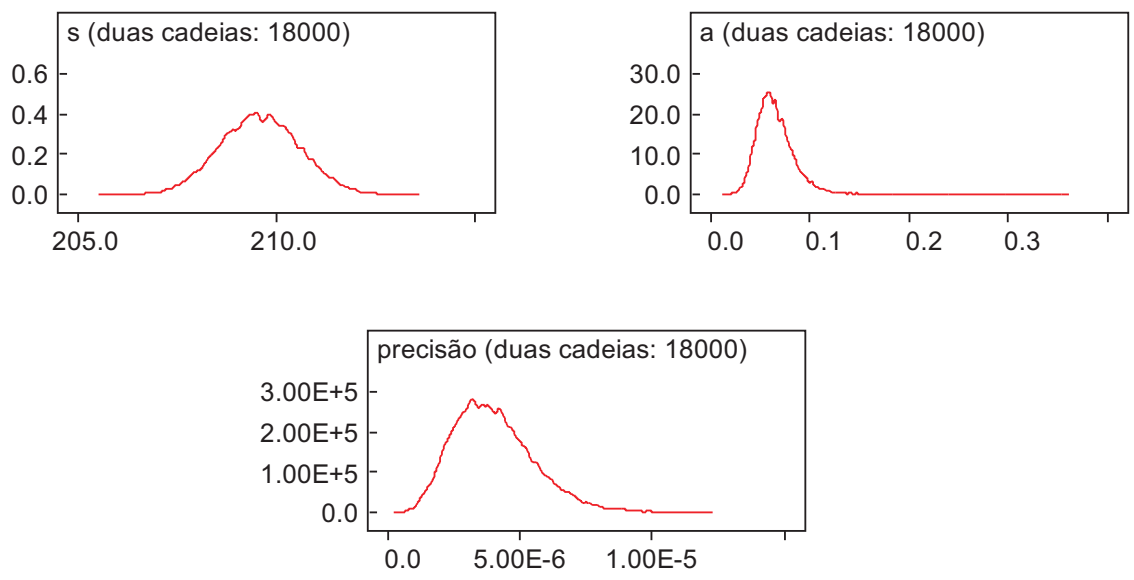

Figura 7.12: Densidades a posteriori de $s, a$ e $\tau$ obtidas a partir das 18000 amostras geradas pelas duas cadeias considerando a população de capim colchão e as prioris: $s \sim N(209,6 ; 1), a \sim N\left(5,9.10^{-2} ; 1\right)$ e $\tau \sim G a(0,001 ; 0,001)$.

dos parâmetros $s, a$ e $\tau$ utilizando-se o algoritmo Metropolis-Hastings.

O algoritmo de Metropolis-Hastings se adaptou ao conjunto de dados e às densidades a priori adotadas para os parâmetros. Na Figura 7.13 notou-se pontos discrepantes nos traços a posteriori de $s, a$ e $\tau$, mas razoável uniformidade o que indica convergência do algoritmo, o que é confirmado na Figura 7.14. Além disso, para $\tau$ o fator de Gelman e Rubin $(0,9999)$ garante um nível aceitável de convergência do algoritmo. Na Figura 7.15 apresentam-se as densidades a posteriori de $s, a$ e $\tau$.

Prioris totalmente informativas Normal para $s$ e Gama para $\tau$, e Uniforme para $a$ $(s \sim N(209,6 ; 1), a \sim U(0 ; 1)$ e $\tau \sim G a(1 ; 1))$

Foram realizadas 100000 iterações para gerar as amostras dos parâmetros partindo-se de três cadeias distintas, das quais foram descartadas as 9999 amostras iniciais com saltos de 10 para diminuir a autocorrelação entre os parâmetros, perfazendo um total de 27000 amostras geradas dos parâmetros $s, a$ e $\tau$ utilizando-se o algoritmo "Slice-sampling".

O algoritmo "Slice-sampling" se adaptou ao conjunto de dados e às densidades $a$ priori adotadas para os parâmetros. Na Figura 7.16 verificou-se uniformidade nos traços a posteriori dos parâmetros $s$ e $\tau$, e apenas alguns pontos discrepantes nos traços de a. A convergência do algoritmo para o parâmetro $\tau$ é confirmada na Figura 7.17, e os fatores de Gelman e Rubin garantem um nível de aceitável convergência de $s(0,9997)$ 

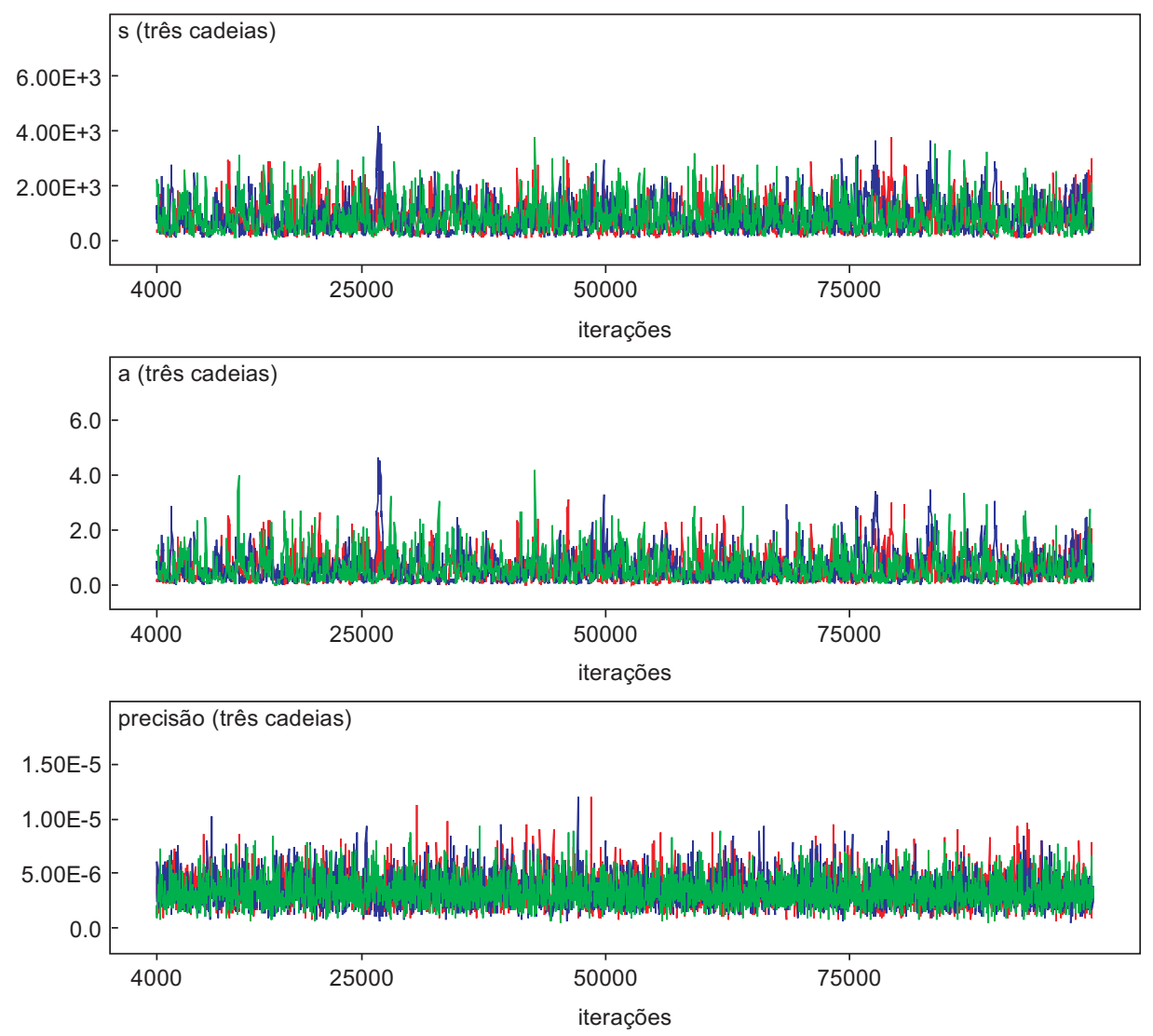

Figura 7.13: Traços a posteriori das três cadeias geradas de $s$, a e $\tau$ considerando a população de capim colchão e as prioris: $s \sim N\left(209,6 ; 1.10^{6}\right), a \sim N\left(5,9.10^{-2} ; 1.10^{6}\right)$ e $\tau \sim G a(0,1 ; 0,1)$. Nota-se razoável uniformidade nos traços a posteriori de $s, a$ e $\tau$ o que indica a convergência do algoritmo.
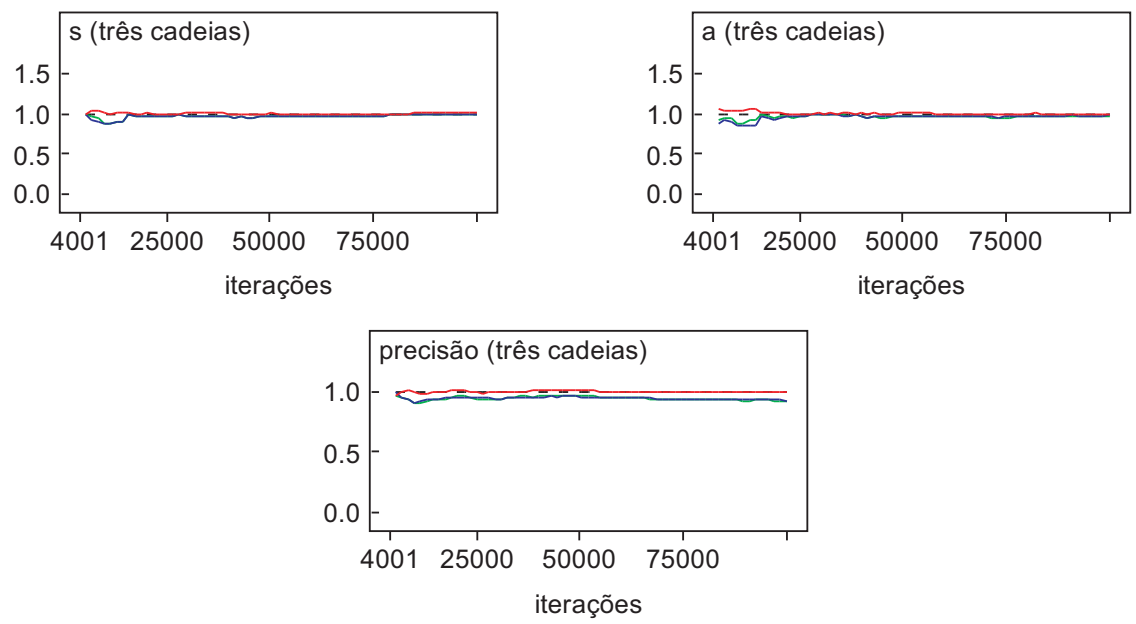

Figura 7.14: Teste gráfico de Gelman e Rubin: verifica-se que houve convergência do algoritmo de Metropolis-Hastings na geração de amostras das três cadeias para os parâmetros $s$ e a considerando a população de capim colchão e as prioris: $s \sim N\left(209,6 ; 1.10^{6}\right), a \sim N\left(5,9.10^{-2} ; 1.10^{6}\right)$ e $\tau \sim G a(0,1 ; 0,1)$. 

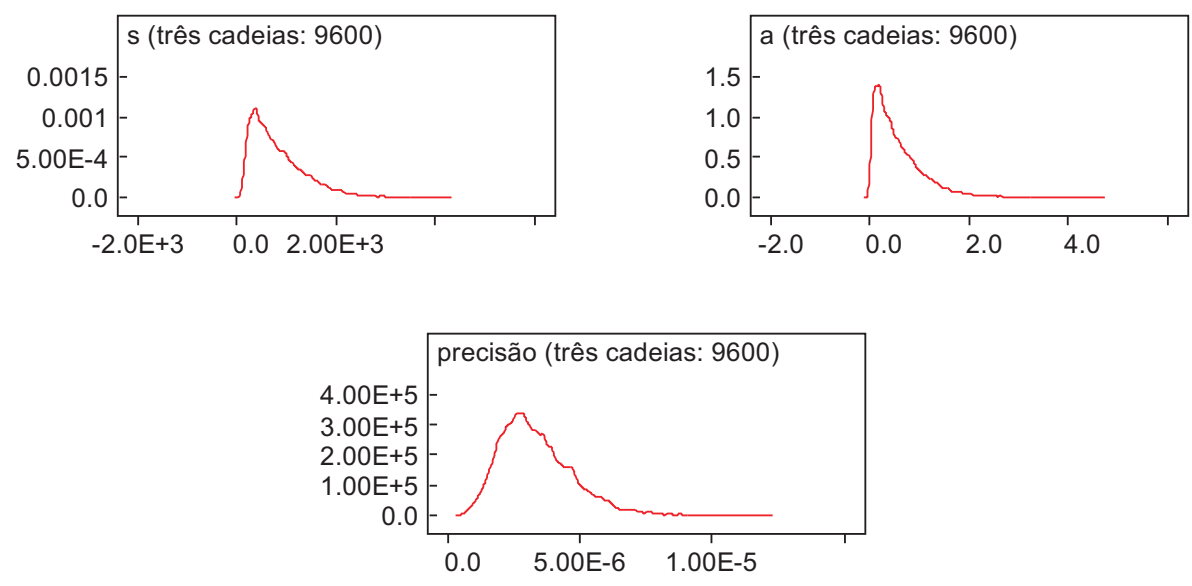

Figura 7.15: Densidades a posteriori de $s, a$ e $\tau$ obtidas a partir das 9600 amostras geradas pelas três cadeias considerando a população de capim colchão e as prioris: $s \sim N\left(209,6 ; 1.10^{6}\right), a \sim N\left(5,9.10^{-2} ; 1.10^{6}\right)$ e $\tau \sim \operatorname{Ga}(0,1 ; 0,1)$.

e $a(1,0)$. Na Figura 7.18 apresentam-se as densidades a posteriori de $s, a$ e $\tau$.

As análises foram repetidas para três cadeias, descartando-se apenas as 4000 amostras iniciais, com saltos de 10 entre as amostras geradas para diminuir a autocorrelação entre os parâmetros. Nestas condições, o teste gráfico de Gelman e Rubin apresentou convergência para $s, a$ e $\tau$, porém obteve-se estatísticas melhores quando descartou-se 9999 amostras.

Prioris totalmente informativa Normal para $s$, não informativa Gama para $\tau$ e Uniforme para $a \quad(s \sim N(209,6 ; 1), a \sim U(0 ; 1)$ e $\tau \sim G a(0,001 ; 0,001))$

Foram realizadas 100000 iterações para gerar as amostras dos parâmetros partindo-se de duas cadeias distintas, das quais foram descartadas as 9999 amostras iniciais com saltos de 10 para diminuir a autocorrelação entre os parâmetros, perfazendo um total de 18000 amostras geradas dos parâmetros $s, a$ e $\tau$ utilizando-se o algoritmo "Slice-sampling".

O algoritmo "Slice-sampling" se adaptou ao conjunto de dados e às densidades $a$ priori adotadas para os parâmetros. Na Figura 7.19 verificou-se uniformidade nos traços a posteriori dos parâmetros $s, a$ e $\tau$, o que indica convergência do algoritmo. Através da Figura 7.20 confirma-se a convergência do algoritmo para $a$ e $\tau$; já para $s$ o fator de Gelman e Rubin $(1,001)$ garante um nível aceitável de convergência do algoritmo. Na Figura 7.21 apresentam-se as densidades a posteriori de $s, a$ e $\tau$. 

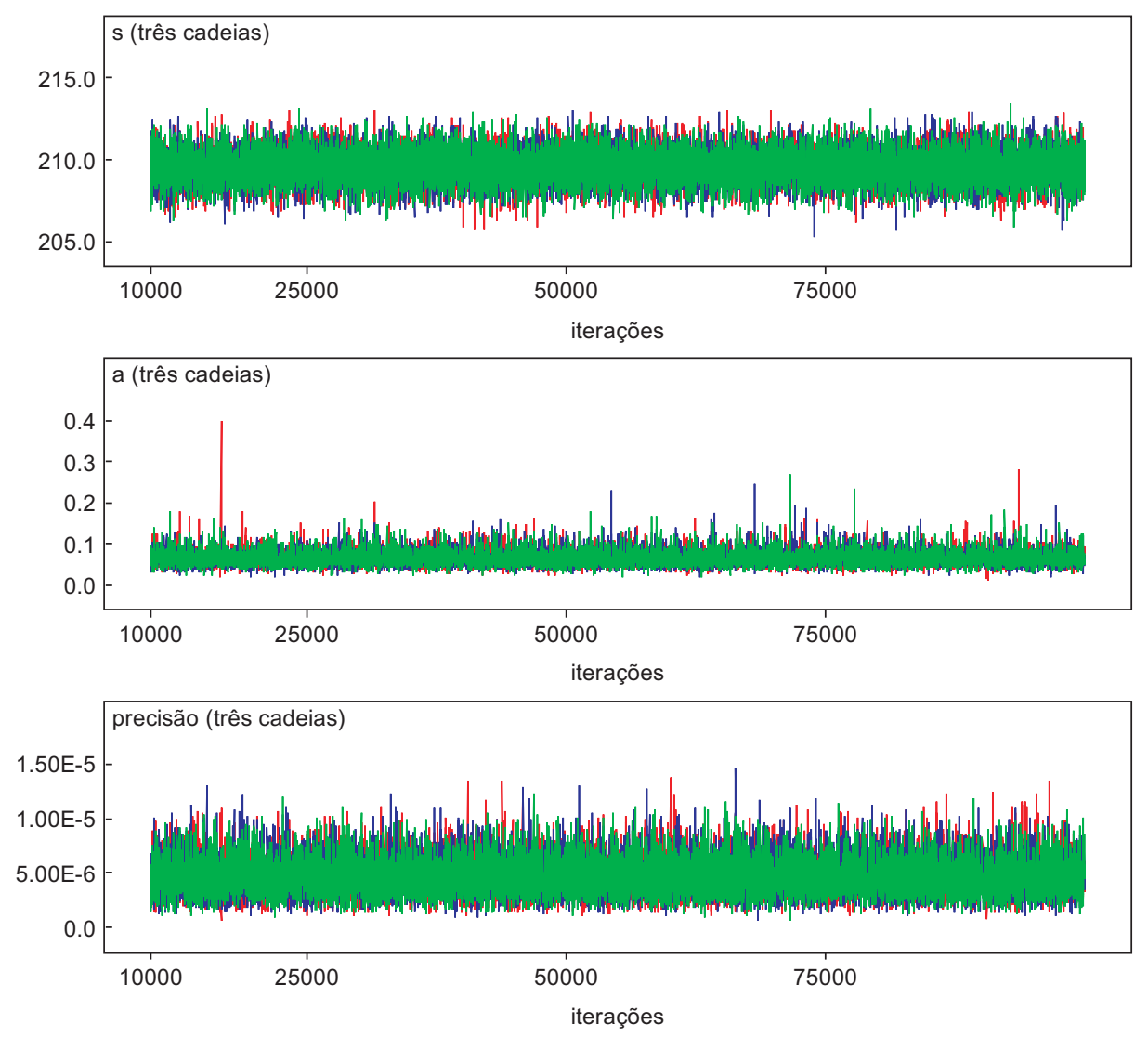

Figura 7.16: Traços a posteriori das três cadeias geradas de $s, a$ e $\tau$ considerando a população de capim colchão e as prioris: $s \sim N(209,6 ; 1), a \sim U(0 ; 1)$ e $\tau \sim G a(1 ; 1)$. Nota-se uniformidade nos traços $a$ posteriori de $s$ e $\tau$, mas alguns pontos discrepantes nos traços de $a$.
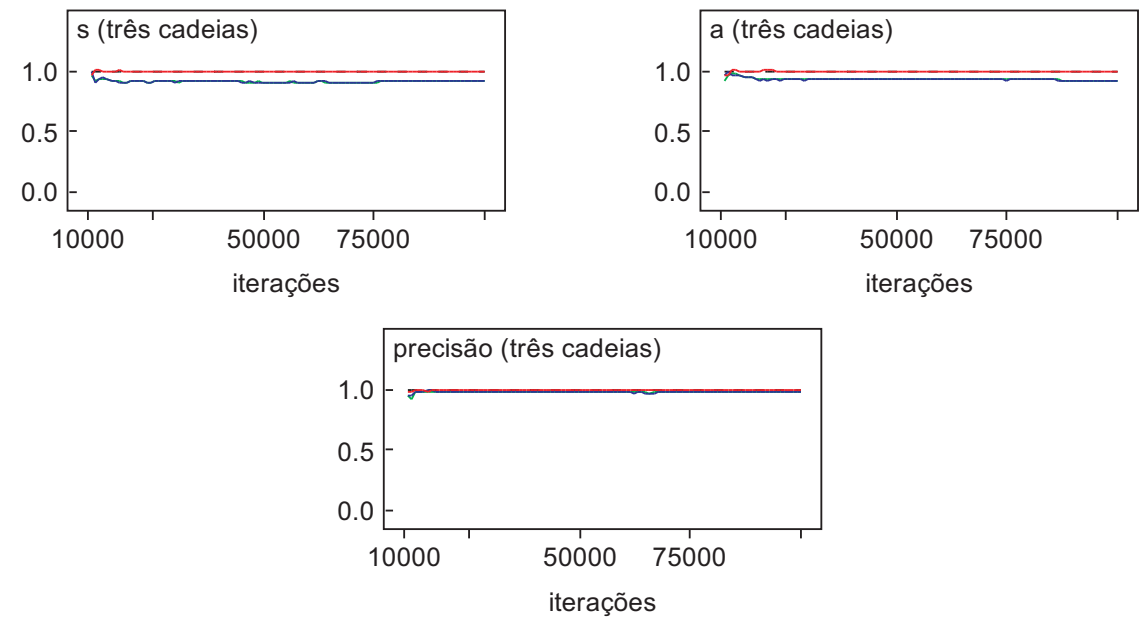

Figura 7.17: Teste gráfico de Gelman e Rubin: verifica-se que houve convergência do algoritmo "Slicesampling" na geração de amostras das três cadeias para o parâmetro $\tau$ considerando a população de capim colchão e as prioris: $s \sim N(209,6 ; 1), a \sim U(0 ; 1)$ e $\tau \sim G a(1 ; 1)$. 

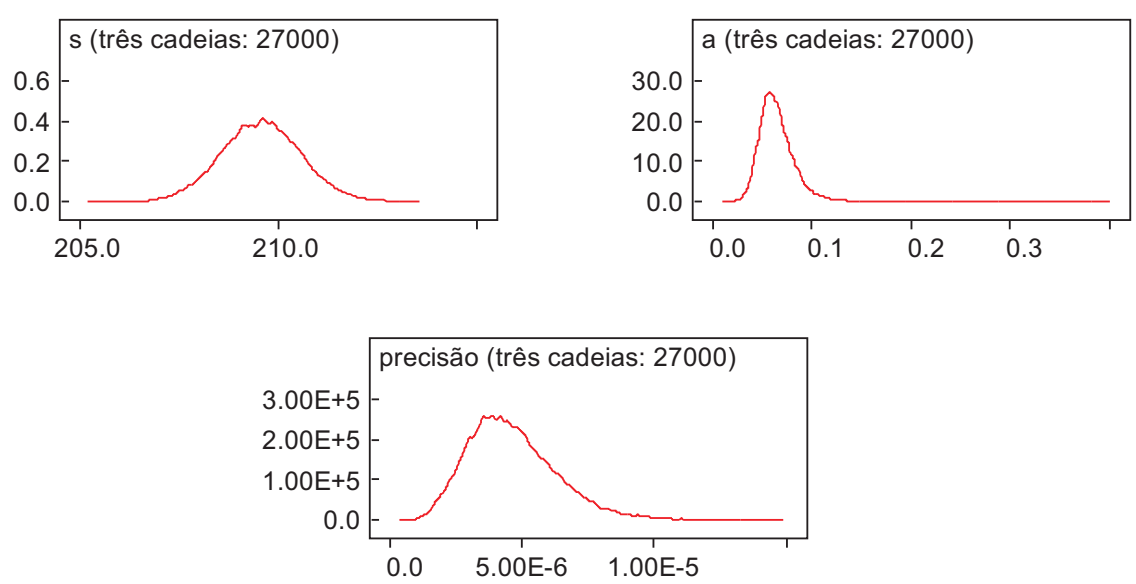

Figura 7.18: Densidades a posteriori de $s, a$ e $\tau$ obtidas a partir das 27000 amostras geradas pelas três cadeias considerando a população de capim colchão e as prioris: $s \sim N(209,6 ; 1), a \sim U(0 ; 1)$ e $\tau \sim G a(1 ; 1)$.
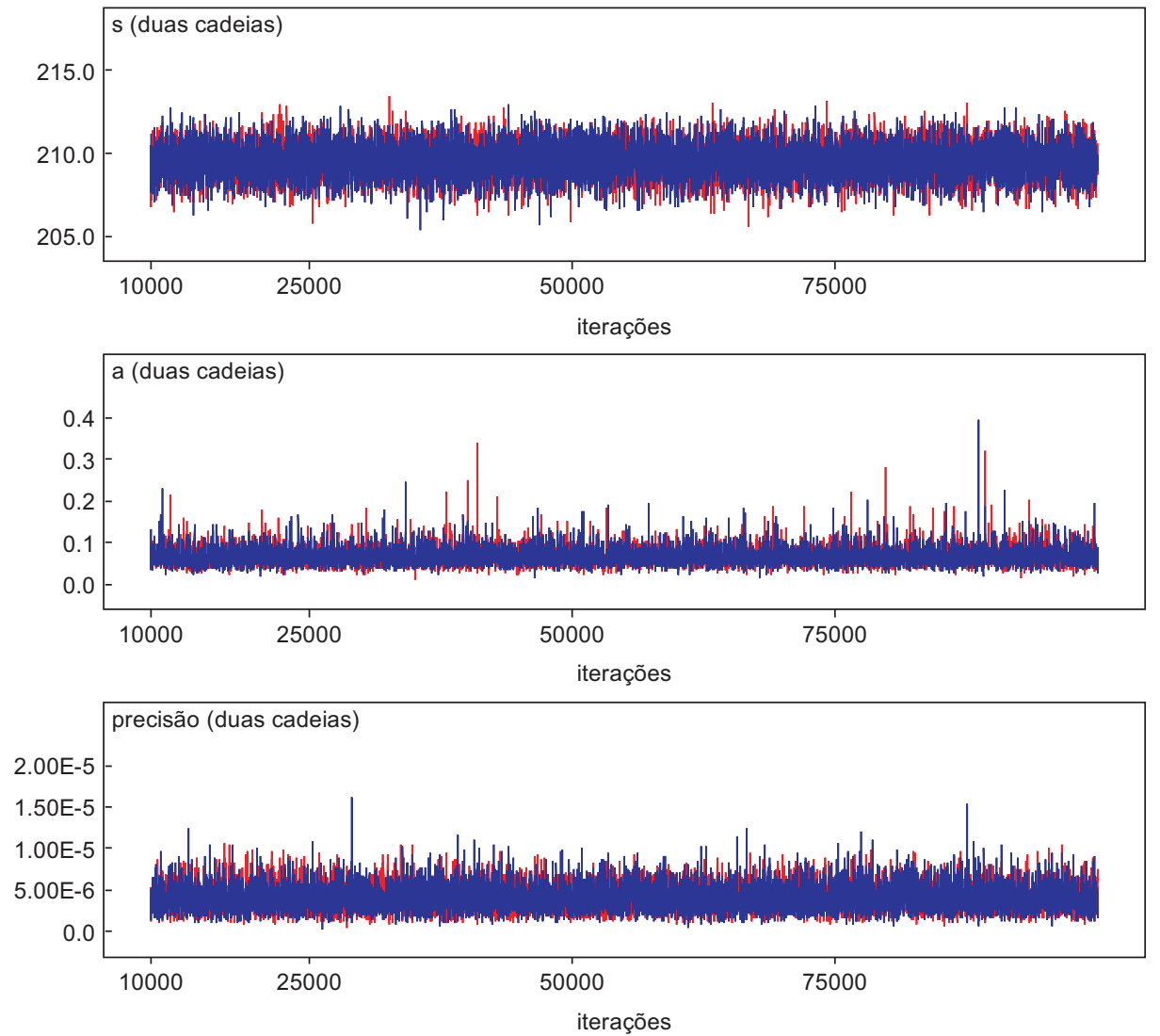

Figura 7.19: Traços a posteriori das duas cadeias geradas de $s, a$ e $\tau$ considerando a população de capim colchão e as prioris: $s \sim N(209,6 ; 1), a \sim U(0 ; 1)$ e $\tau \sim G a(0,001 ; 0,001)$. Nota-se poucos pontos discrepantes e uniformidade nos traços a posteriori de $s, a \tau$. 

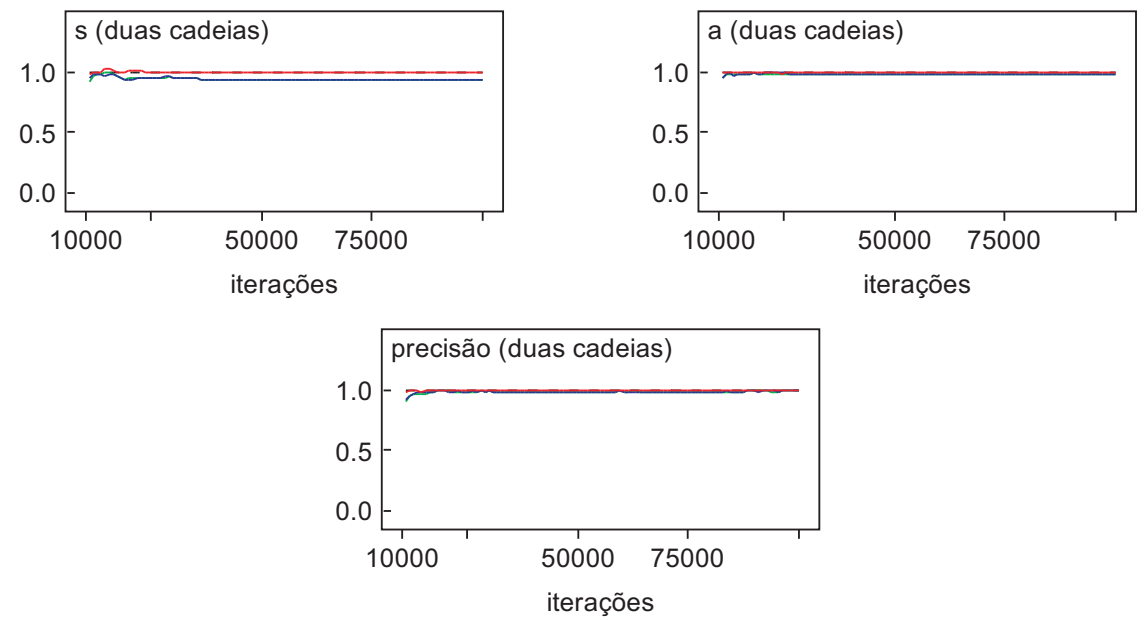

Figura 7.20: Teste gráfico de Gelman e Rubin: verifica-se que houve convergência do algoritmo "Slicesampling" na geração de amostras das duas cadeias para os parâmetros $a$ e $\tau$ considerando a população de capim colchão e as prioris: $s \sim N(209,6 ; 1), a \sim U(0 ; 1)$ e $\tau \sim G a(0,001 ; 0,001)$.
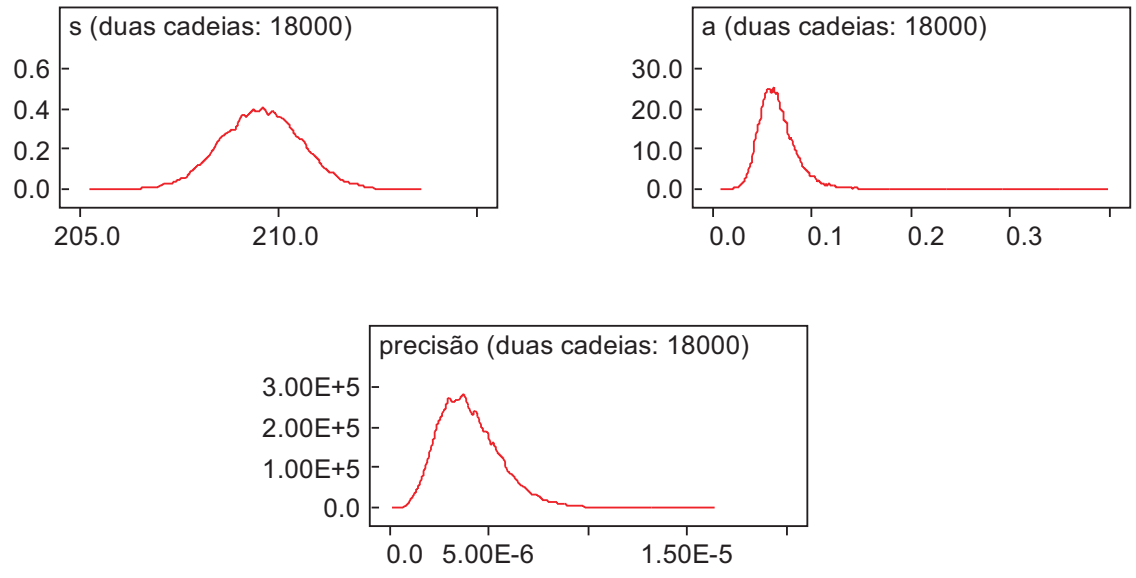

Figura 7.21: Densidades a posteriori de $s, a$ e $\tau$ obtidas a partir das 18000 amostras geradas pelas duas cadeias considerando a população de capim colchão e as prioris: $s \sim N(209,6 ; 1), a \sim U(0 ; 1)$ e $\tau \sim G a(0,001 ; 0,001)$. 
Prioris moderadamente informativas Normal para $s$ e Gama para $\tau$, e Uniforme para $a \quad\left(s \sim N\left(209,6 ; 1.10^{6}\right), a \sim U(0 ; 1)\right.$ e $\left.\tau \sim G a(0,1 ; 0,1)\right)$

Foram realizadas 100000 iterações para gerar as amostras dos parâmetros partindo-se de três cadeias distintas, das quais foram descartadas as 9999 amostras iniciais com saltos de 25 para diminuir a autocorrelação entre os parâmetros, perfazendo um total de 10800 amostras geradas dos parâmetros $s, a$ e $\tau$ utilizando-se o algoritmo "Slice-sampling".

O algoritmo "Slice-sampling" se adaptou ao conjunto de dados e às densidades $a$ priori adotadas para os parâmetros. Na Figura 7.22 verificou-se uniformidade nos traços a posteriori dos parâmetros $s$ e a e poucos pontos discrepantes nos traços de $\tau$. A convergência do algoritmo é confirmada na Figura 7.23 para os parâmetros $s$ e $a$. Para $\tau$ o fator de Gelman e Rubin (1,0) garante um nível aceitável de convergência do algoritmo. Na Figura 7.24 apresentam-se as densidades a posteriori de $s, a$ e $\tau$.
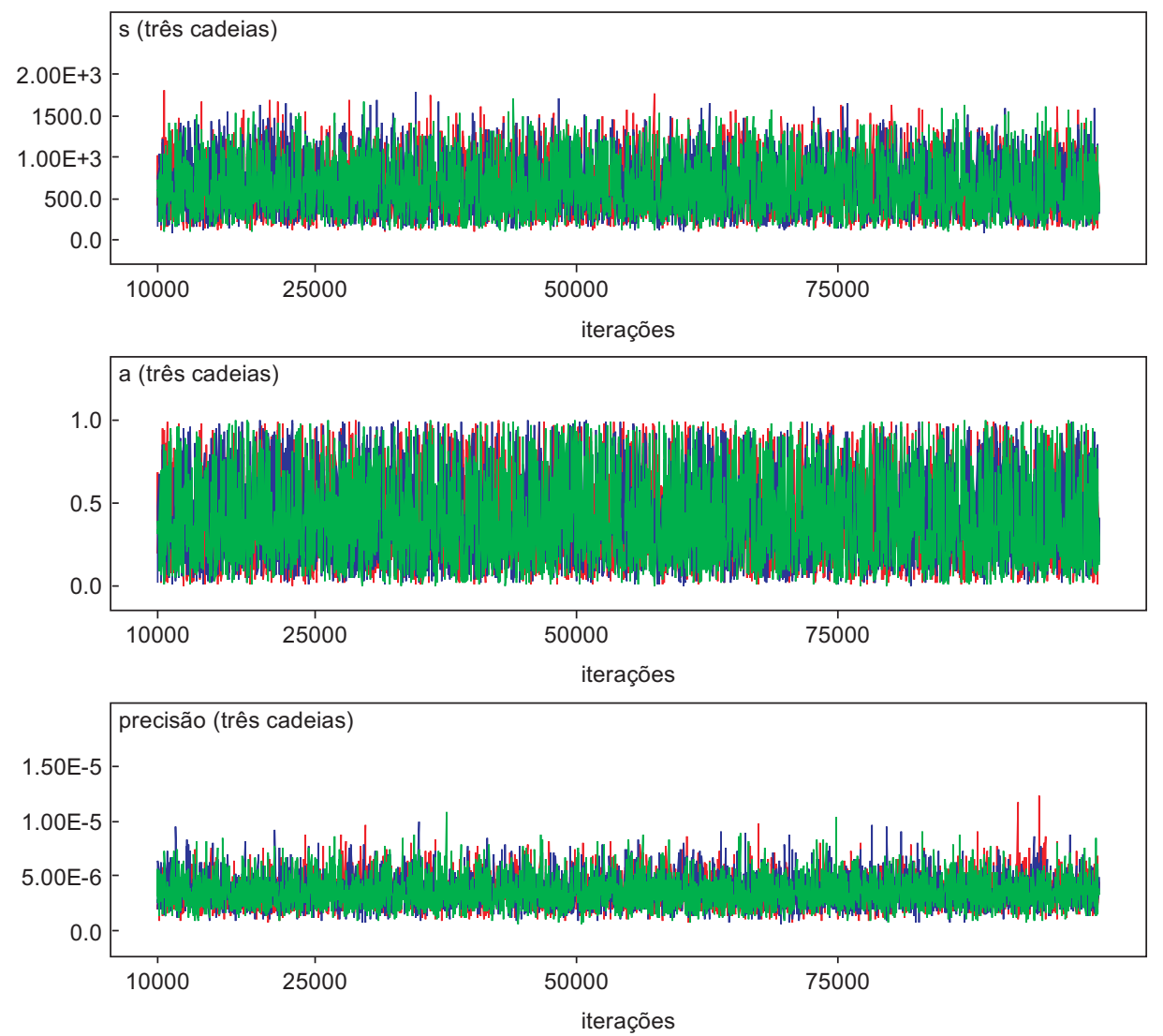

Figura 7.22: Traços a posteriori das três cadeias geradas de $s, a$ e $\tau$ considerando a população de capim colchão e as prioris: $s \sim N\left(209,6 ; 1.10^{6}\right), a \sim U(0 ; 1)$ e $\tau \sim G a(0,1 ; 0,1)$. Nota-se uniformidade nos traços a posteriori de $s$ e $a$, e apenas alguns pontos discrepantes nos traços de $\tau$. 

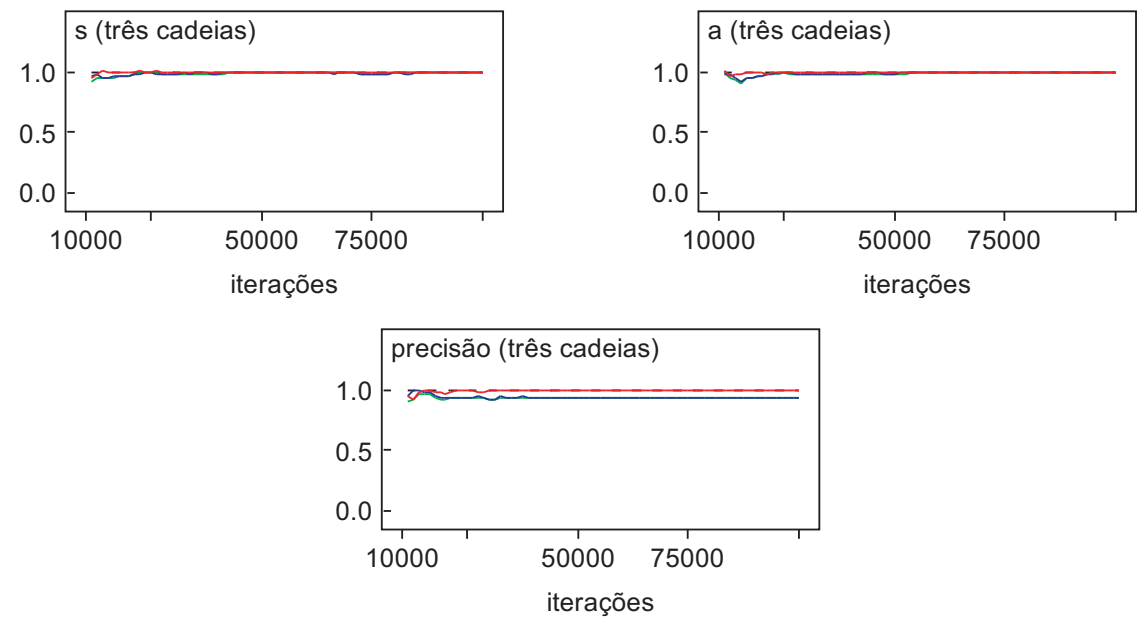

Figura 7.23: Teste gráfico de Gelman e Rubin: verifica-se que houve convergência do algoritmo "Slicesampling" na geração de amostras das três cadeias para os parâmetros $s$ e $a$ considerando a população de capim colchão e as prioris: $s \sim N\left(209,6 ; 1.10^{6}\right), a \sim U(0 ; 1)$ e $\tau \sim G a(0,1 ; 0,1)$.
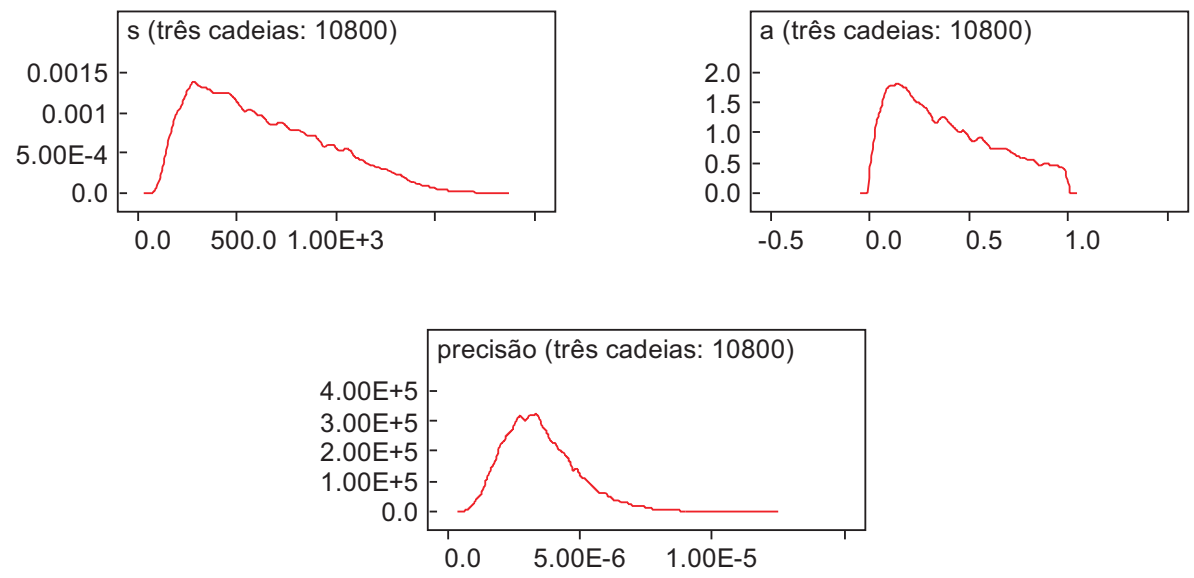

Figura 7.24: Densidades a posteriori de $s, a$ e $\tau$ obtidas a partir das 10800 amostras geradas pelas três cadeias considerando a população de capim colchão e as prioris: $s \sim N\left(209,6 ; 1.10^{6}\right), a \sim U(0 ; 1)$ e $\tau \sim G a(0,1 ; 0,1)$. 


\subsection{Panicum maximum (capim guiné)}

\subsubsection{Diagnósticos envolvendo a variável dependente}

Notou-se acentuada assimetria à esquerda com relação a distribuição da variável densidade de sementes produzidas de capim guiné (Figura 7.25 (esqueda)), o que indica a presença de valores discrepantes na amostra.
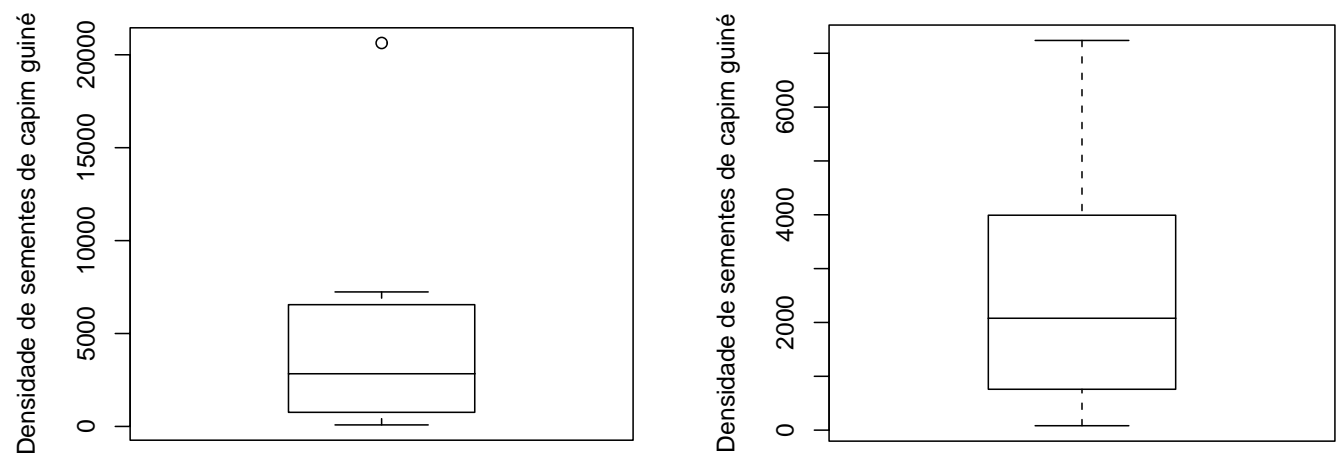

Figura 7.25: Gráfico de caixa: densidade de sementes produzidas de leiteiro com (esquerda) e sem (direita) observações discrepantes.

Com a remoção do valor atípico (Figura 7.25 (direita)) esta assimetria foi suavizada permitindo realizar a inferência clássica via regressão não linear.

A Figura 7.26 apresenta o gráfico de dispersão das observações de densidade de plantas daninhas versus densidade de sementes produzidas (esquerda) e histograma (direita) para a população de capim guiné, o qual fornece uma idéia da forma da distribuição da variável densidade de sementes produzidas de capim guiné.

Como observado na Figura 7.25, o histograma de freqüência mostra uma clara assimetria à esquerda na distribuição de $X_{i}$ (Figura 7.26 (direita)). No gráfico de dispersão das variáveis (Figura 7.26 (esquerda)) foi observada, apesar do reduzido número de observações, uma relação que aproxima-se da logarítmica. 

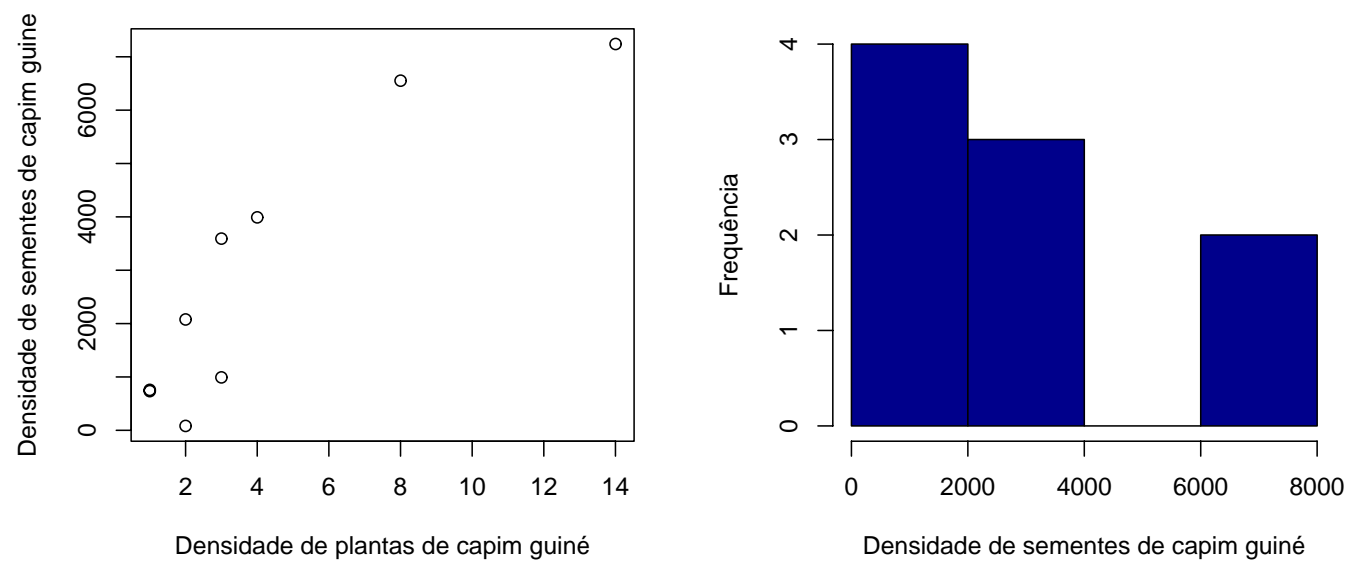

Figura 7.26: Gráfico de dispersão da variável independente versus variável dependente (esquerda) e histograma (direita) para as observações de capim guiné.

\subsubsection{Abordagem clássica do modelo de produção de sementes}

\section{Regressão do modelo linearizado}

A escolha dos valores iniciais para as estimativas dos parâmetros do modelo de regressão não linear foi realizada a partir do ajuste do modelo linearizado de (6.2). O modelo de regressão linear ajustado de (4.8) é

$$
y_{i}=6,19123-0,09516 x_{i}
$$

em que $y_{i}=\ln \left(X_{t+1} / Y_{t}\right)$ é a variável dependente e $x_{i}=-\ln \left(Y_{t}\right)$ a variável independente.

A Figura 7.27 (esquerda) apresenta o gráfico de dispersão das variável independente versus variável dependente com a reta da regressão linear. A análise da normalidade dos resíduos foi verificada através do gráfico de normalidade apresentado na Figura 7.27 (direita). Para verificação da qualidade do ajuste linear foi utilizado o coeficiente de determinação $R^{2}$. Para analisar as estimativas dos parâmetros foi feito o teste $t$-Student de significância dos parâmetros.

Tem-se que $R^{2}=0,0064$, o que indica que a variável $x_{i}$ explica apenas $0,64 \%$ da variabilidade de $y_{i}$. Considerando um nível de significância de $\alpha=0,05$, testa-se $H_{01}: \beta_{0}=0$ versus $H_{11}: \beta_{0} \neq 0$, utilizando a estatística $t$-Student; tem-se $t=10,176$ 

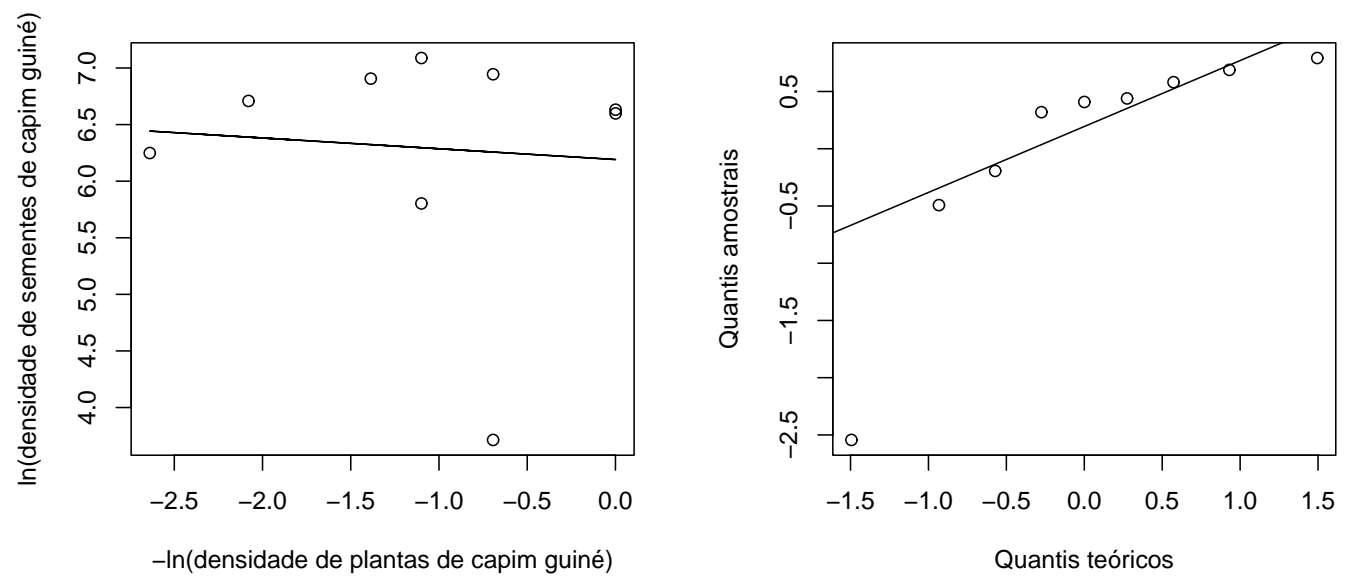

Figura 7.27: Gráficos de dispersão da variável independente versus variável dependente com a reta da regressão linear do modelo (4.8) (esquerda) e de normalidade dos resíduos (direita) para as observações de capim guiné.

e $t_{0}=1.91 .10^{-5}$ e como $t>t_{0}$ rejeita-se a hipótese $H_{0}$, o que indica que o parâmetro é significativo. Analogamente, testa-se $H_{02}: \beta_{1}=0$ versus $H_{12}: \beta_{1} \neq 0$ obtendo-se $t=-0,212$ e $t_{0}=0,838$ e como $t<t_{0}$ não se rejeita a hipótese $H_{0}$ ao nível $\alpha=0,05$ de significância, o que indica que o parâmetro não é significativo.

Apesar da má qualidade do ajuste, as estimativas encontradas para $\beta_{0}$ e $\beta_{1}$ foram utilizadas como valores iniciais para as estimativas dos parâmetros do modelo de regressão não linear.

\section{Regressão do modelo não linear}

A Figura 7.28 (esquerda) apresenta o gráfico de dispersão da variável independente versus variável dependente com a curva da regressão não linear do modelo (6.9) para as observações de capim guiné, confirmando a pressuposição de relação logarítmica entre as variáveis. A Tabela 7.3 apresenta as estimativas clássica e as medidas de precisão para os parâmetros do modelo (6.9).

Tabela 7.3: Resumo dos resultados via abordagem clássica do modelo (6.9) para a população de Panicum maximum (capim guiné).

\begin{tabular}{cccccc}
\hline Parâmetros & Estimativa & Desvio padrão & IC $(95 \%)$ & $t$ & $t_{0}$ \\
\hline $\mathrm{s}$ & 994,6 & 283,6 & {$[323,9 ; 1665,2]$} & 3,5 & $9,9.10^{-3}$ \\
$\mathrm{a}$ & $5,7.10^{-2}$ & $4,5.10^{-2}$ & {$\left[-5,1.10^{-2} ; 1,6.10^{-1}\right]$} & 1,3 & $2,5.10^{-1}$ \\
\hline
\end{tabular}

A homocedasticidade (ou heterocedasticidade) da variância dos resíduos do modelo 
(6.9) foi verificada pela análise do gráfico dos resíduos versus valores ajustados apresentado na Figura 7.28 (direita). A forma da distribuição e a normalidade dos resíduos podem ser analisadas nas Figuras 7.29 através do histograma (esquerda) e do gráfico de normalidade (direita), respectivamente.
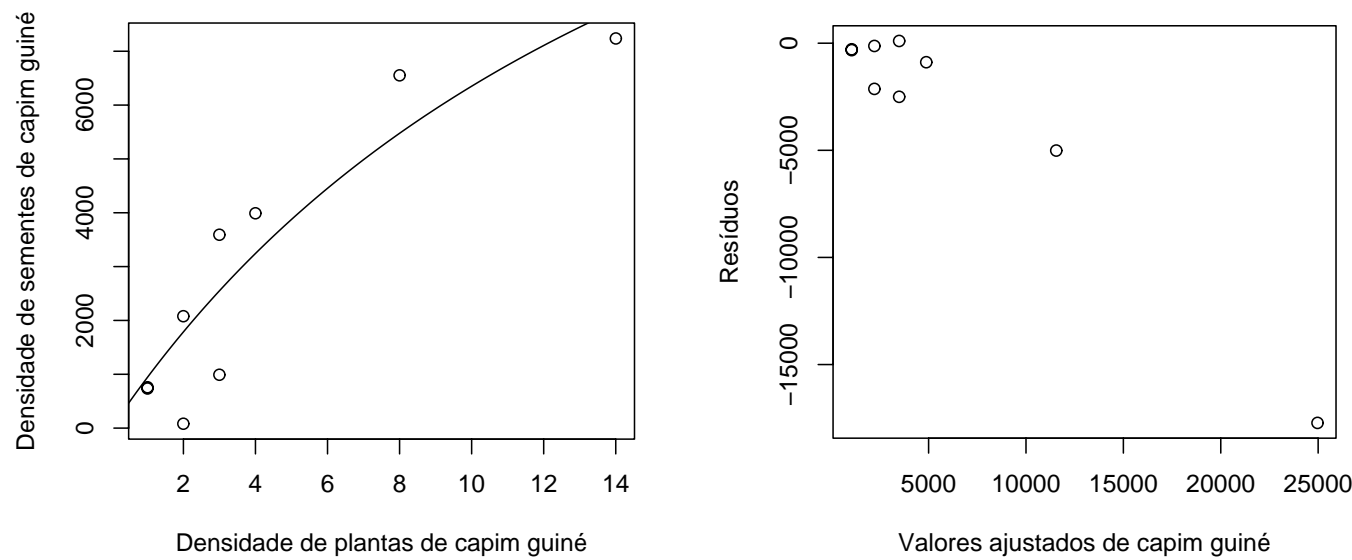

Figura 7.28: Gráficos de dispersão da variável independente versus variável dependente com a curva da regressão não linear do modelo (6.9) (esquerda) e dos resíduos versus valores ajustados (direita) para as observações de capim guiné.
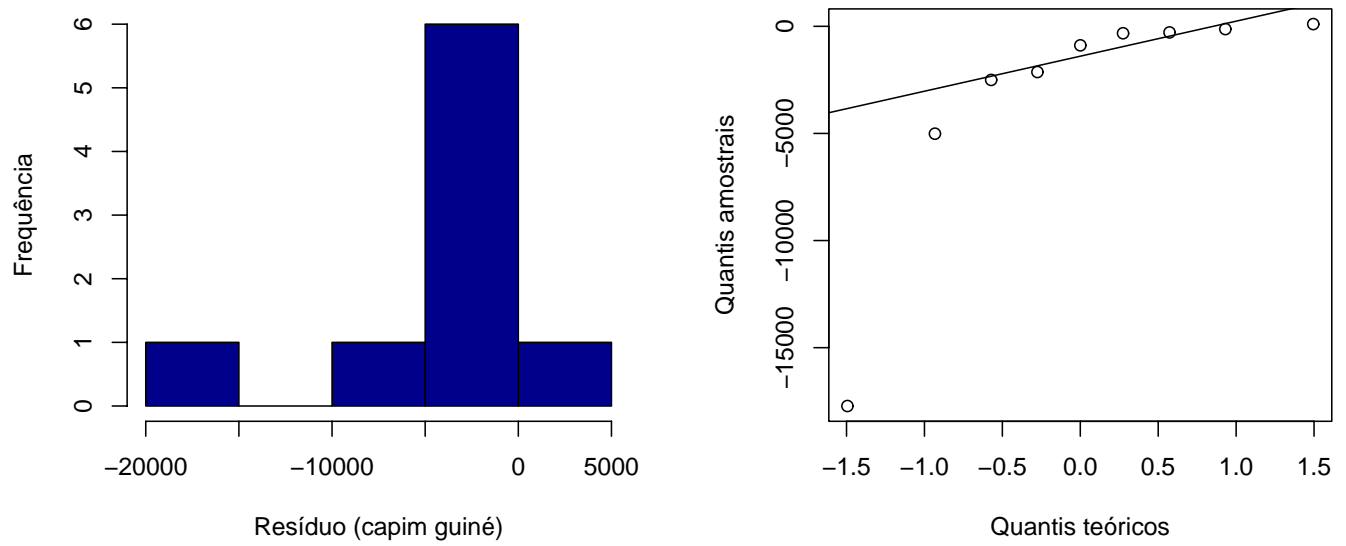

Figura 7.29: Histograma (esquerda) e gráfico de normalidade dos resíduos (direita) para as observações de capim guiné.

O gráfico de dispersão com a curva da regressão não linear apresentado na Figura 7.28 (esquerda), confirma a suposição da relação entre as variáveis ser logarítmica. Provavelmente, isto se deve ao fato de que a população encontrava-se sob alta densidade 
de plantas de capim guiné e, neste caso, os efeitos do aumento do número de sementes por área é não linear.

Nota-se uma ligeira homocedasticidade na variância dos resíduos (Figura 7.28 (direita)) e assimetria a direita na distribuição dos resíduos (Figura 7.29 (esquerda)), no entanto seria necessário um maior número de observações para uma análise gráfica mais criteriosa e eficiente.

\subsubsection{Abordagem bayesiana do modelo de produção de sementes}

Para obtenção da densidade a posteriori dos parâmetros $s, a$ e $\tau$, gerou-se de duas a três cadeias a partir de valores iniciais distintos. Para a primeira cadeia utilizou-se as estimativas de regressão não linear $\hat{s}$ e $\hat{a}$ e para a segunda cadeia as estimativas de regressão linear. Já para a terceira cadeia os valores iniciais foram gerados pelo aplicativo WinBUGS (Spiegelhalter et al., 2006), o qual parte de valores extremos das densidades a priori. Sendo assim, não foi possível gerar amostras a partir da terceira cadeia quando adotou-se prioris não informativas para algum parâmetro, o que se justifica pela pouca precisão da informação a priori adotada para o parâmetro.

A análise dos traços a posteriori dos parâmetros apresentou convergência em alguns casos. Assim, também foi utilizado o teste de Gelman e Rubin (Gelman et al., 2000) como critério de verificação dos algoritmos.

Na Tabela 7.4, apresenta-se o resumo dos resultados bayesianos do modelo (6.9) para a população de capim guiné, adotando-se diferentes densidades a priori para os parâmetros de interesse. Apresenta-se também a análise detalhada com relação a cada priori adotada.

\section{Prioris totalmente informativas Normais para $s$ e $a$ e Gama para $\tau$} $\left(s \sim N(994,6 ; 1), a \sim N\left(5,7.10^{-2} ; 1\right)\right.$ e $\left.\tau \sim G a(1 ; 1)\right)$

Foram realizadas 100000 iterações para gerar as amostras dos parâmetros partindo-se de três cadeias distintas, destas descartou-se as 9999 amostras iniciais com saltos de 15 para diminuir a autocorrelação entre os parâmetros, perfazendo um total de 18000 amostras geradas dos parâmetros $s, a$ e $\tau$ utilizando-se o algoritmo Metropolis-Hastings.

O algoritmo de Metropolis-Hastings se adaptou ao conjunto de dados e às densida- 
Tabela 7.4: Resumo dos resultados via abordagem bayesiana do modelo (6.9) para a população de Panicum maximum (capim guiné).

\begin{tabular}{|c|c|c|c|c|}
\hline \multirow[t]{2}{*}{ Prioris } & & \multicolumn{3}{|c|}{ Parâmetros } \\
\hline & & $s$ & $a$ & $\tau$ (precisão) \\
\hline$s \sim N(994,6 ; 1)$ & Média & 994,6 & $6,2.10^{-2}$ & $1,2.10^{-6}$ \\
\hline$a \sim N\left(5,7.10^{-2} ; 1\right)$ & Mediana & 994,6 & $6,0.10^{-2}$ & $1,1.10^{-6}$ \\
\hline \multirow{2}{*}{$\tau \sim G a(1 ; 1)$} & Desvio padrão & $9,9.10^{-1}$ & $1,8.10^{-2}$ & $5,2.10^{-7}$ \\
\hline & IC $(95 \%)$ & {$[992,6 ; 996,5]$} & {$\left[3,5.10^{-2} ; 1,0.10^{-1}\right]$} & {$\left[3,7.10^{-7} ; 2,4.10^{-6}\right]$} \\
\hline$s \sim N(994,6 ; 1)$ & Média & 994,6 & $6,5.10^{-2}$ & $9,3.10^{-7}$ \\
\hline$a \sim N\left(5,7.10^{-2} ; 1\right)$ & Mediana & 994,6 & $6,1.10^{-2}$ & $8,6.10^{-7}$ \\
\hline \multirow[t]{2}{*}{$\tau \sim G a(0,001 ; 0,001)$} & Desvio padrão & $9,9.10^{-1}$ & $3,6.10^{-2}$ & $4,7.10^{-7}$ \\
\hline & IC $(95 \%)$ & {$[992,6 ; 996,5]$} & {$\left[3,5.10^{-2} ; 1,2.10^{-1}\right]$} & {$\left[2,4.10^{-7} ; 2,1.10^{-6}\right]$} \\
\hline$s \sim N\left(994,6 ; 1.10^{6}\right)$ & Média & 1184 & $-3,1.10^{-1}$ & $8,0.10^{-7}$ \\
\hline$a \sim N\left(5,7.10^{-2} ; 1.10^{6}\right)$ & Mediana & 1089 & $6,6.10^{-2}$ & $7,2.10^{-7}$ \\
\hline \multirow{2}{*}{$\tau \sim G a(0,1 ; 0,1)$} & Desvio padrão & 426,1 & 189,3 & $4,8.10^{-7}$ \\
\hline & IC $(95 \%)$ & {$[618,1 ; 2197]$} & {$\left[-3.10^{-4} ; 9,6.10^{-1}\right]$} & {$\left[6,8.10^{-8} ; 1,9.10^{-6}\right]$} \\
\hline$s \sim N(994,6 ; 1)$ & Média & 994,6 & $6,2.10^{-2}$ & $1,2.10^{-6}$ \\
\hline$a \sim U(0 ; 1)$ & Mediana & 994,6 & $6,0.10^{-2}$ & $1,1.10^{-6}$ \\
\hline \multirow{2}{*}{$\tau \sim G a(1 ; 1)$} & Desvio padrão & $9,9.10^{-1}$ & $2,0.10^{-2}$ & $5,2.10^{-7}$ \\
\hline & IC $(95 \%)$ & {$[992,6 ; 996,5]$} & {$\left[3,5.10^{-2} ; 1,0.10^{-1}\right]$} & {$\left[3,7.10^{-7} ; 2,4.10^{-6}\right]$} \\
\hline$s \sim N(994,6 ; 1)$ & Média & 994,6 & $6,4.10^{-2}$ & $9,1.10^{-7}$ \\
\hline$a \sim U(0 ; 1)$ & Mediana & 994,6 & $6,1.10^{-2}$ & $8,4.10^{-7}$ \\
\hline \multirow{2}{*}{$\tau \sim G a(0,001 ; 0,001)$} & Desvio padrão & 1,0 & $2,8.10^{-2}$ & $4,6.10^{-7}$ \\
\hline & IC $(95 \%)$ & {$[992,6 ; 996,5]$} & {$\left[3,2.10^{-2} ; 1,2.10^{-1}\right]$} & {$\left[2,3.10^{-7} ; 2,0.10^{-6}\right]$} \\
\hline$s \sim N\left(994,6 ; 1.10^{6}\right)$ & Média & 1242 & $1,1.10^{-1}$ & $8,1.10^{-7}$ \\
\hline$a \sim U(0 ; 1)$ & Mediana & 1169 & $9,0.10^{-2}$ & $7,3.10^{-7}$ \\
\hline \multirow[t]{2}{*}{$\tau \sim G a(0,1 ; 0,1)$} & Desvio padrão & 393,3 & $9,6.10^{-2}$ & $4,5.10^{-7}$ \\
\hline & IC $(95 \%)$ & {$[693,5 ; 2231]$} & {$\left[1,5.10^{-2} ; 3,7.10^{-2}\right]$} & {$\left[1,9.10^{-7} ; 1,9.10^{-6}\right]$} \\
\hline
\end{tabular}

des a priori adotadas para os parâmetros. Na Figura 7.30 observou-se poucos pontos discrepantes e uniformidade nos traços a posteriori de $s, a$ e $\tau$ o que indica convergência do algoritmo. O teste gráfico de Gelman e Rubin (Figura 7.31) confirma a convergência do algoritmo de Metropolis-Hastings para os parâmetros. Na Figura 7.32 apresentam-se as densidades a posteriori de $s, a$ e $\tau$.

Prioris totalmente informativas Normais para $s$ e $a$ e não informativa Gama para $\tau$ $\left(s \sim N(994,6 ; 1), a \sim N\left(5,7.10^{-2} ; 1\right)\right.$ e $\left.\tau \sim G a(0,001 ; 0,001)\right)$

Foram realizadas 100000 iterações para gerar as amostras dos parâmetros com duas cadeias, destas 9999 foram descartadas e foi dado um salto de 25 para diminuir a autocorrelação entre os parâmetros, perfazendo um total de 7200 amostras geradas dos parâmetros $s, a$ e $\tau$ utilizando-se o algoritmo Metropolis-Hastings.

O algoritmo de Metropolis-Hastings se adaptou ao conjunto de dados e às densidades a priori adotadas para os parâmetros. Na Figura 7.33 notou-se poucos pontos 

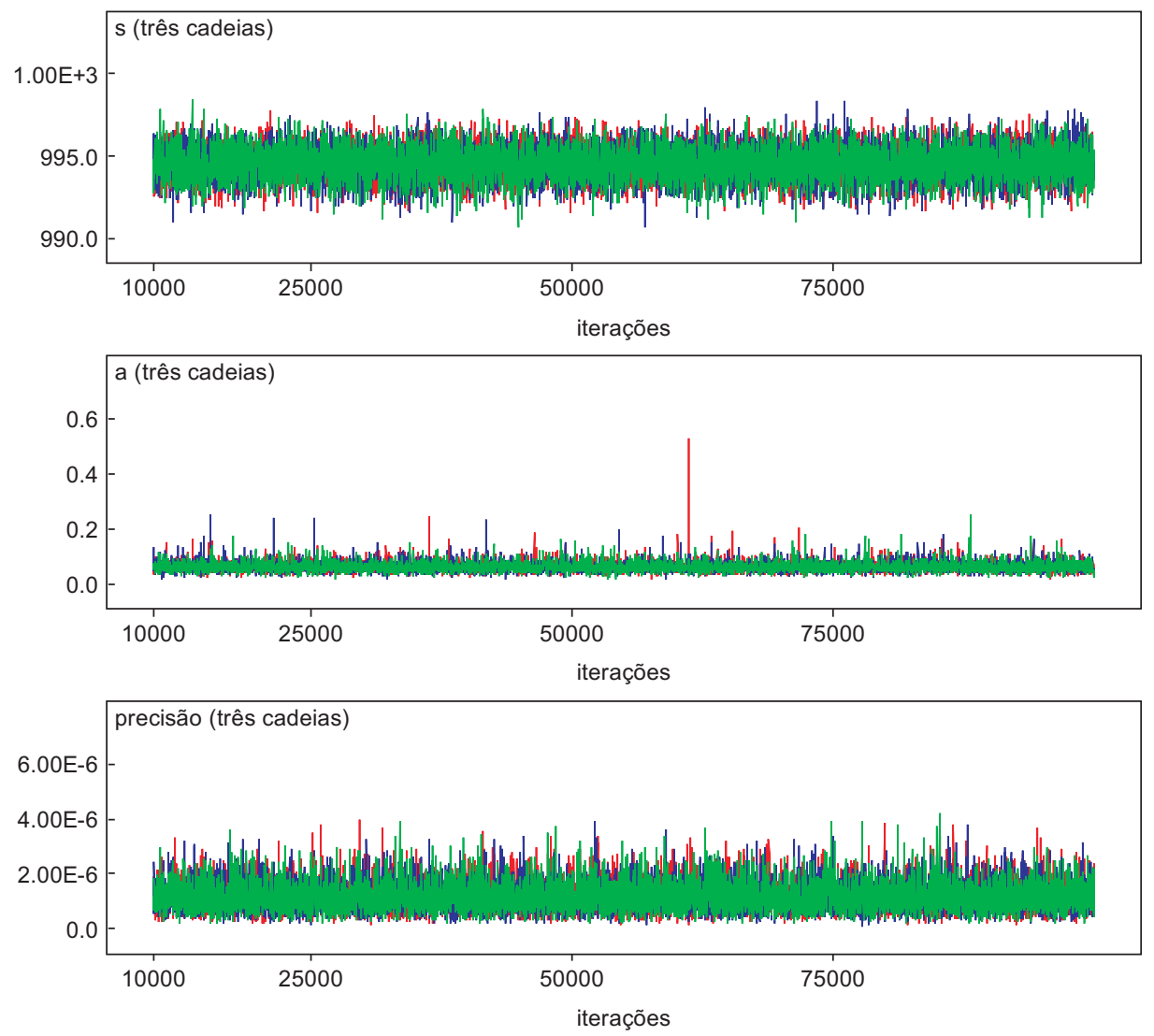

Figura 7.30: Traços a posteriori das três cadeias geradas de $s, a$ e $\tau$ considerando a população de capim guiné e as prioris: $s \sim N(994,6 ; 1), a \sim N\left(5,7.10^{-2} ; 1\right)$ e $\tau \sim G a(1 ; 1)$ Nota-se uniformidade nos traços $a$ posteriori de $s, a$ e $\tau$ o que indica a convergência do algoritmo.
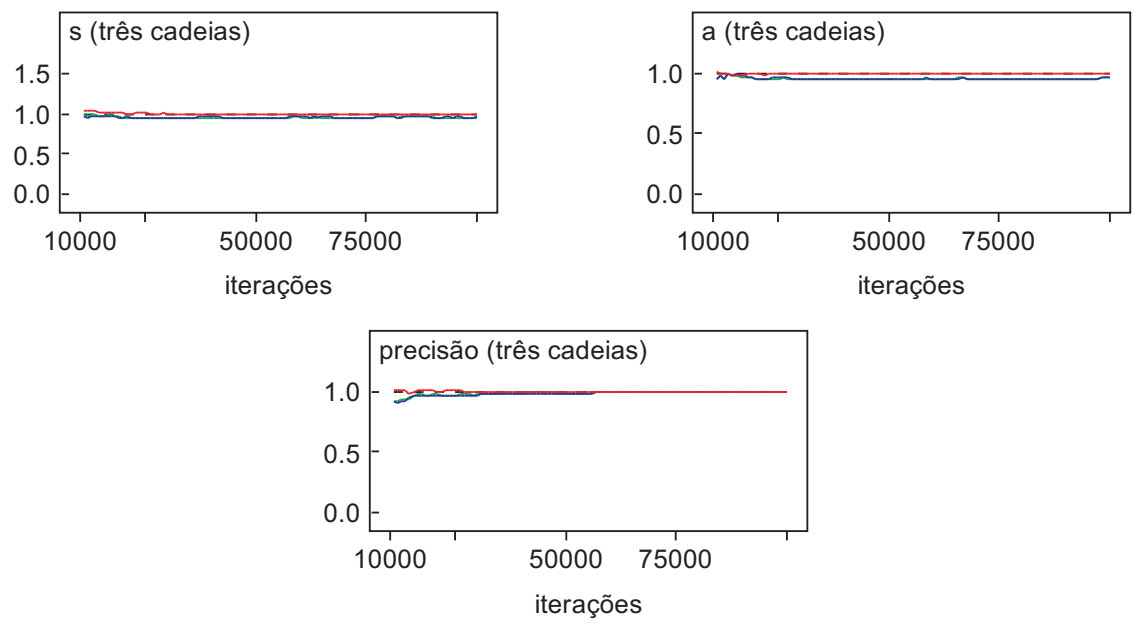

Figura 7.31: Teste gráfico de Gelman e Rubin: verifica-se que houve convergência do algoritmo de Metropolis-Hastings na geração de amostras das três cadeias para os parâmetros $s, a$ e $\tau$ considerando a população de capim guiné e as prioris: $s \sim N(994,6 ; 1), a \sim N\left(5,7.10^{-2} ; 1\right)$ e $\tau \sim G a(1 ; 1)$. 

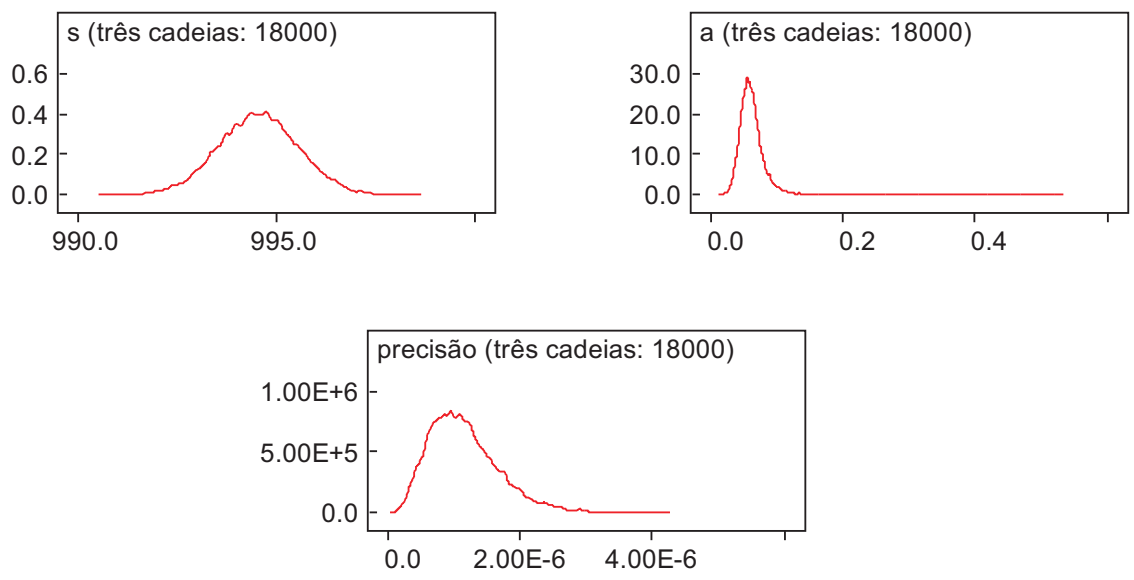

Figura 7.32: Densidades a posteriori de $s, a$ e $\tau$ obtidas a partir das 18000 amostras geradas pelas três cadeias considerando a população de capim guiné e as prioris: $s \sim N(994,6 ; 1), a \sim N\left(5,7.10^{-2} ; 1\right)$ e $\tau \sim G a(1 ; 1)$.

discrepantes e uniformidade nos traços a posteriori de $s, a$ e $\tau$ o que indica convergência do algoritmo. Pelo teste gráfico de Gelman e Rubin (Figura 7.34) confirma-se a convergência do algoritmo de Metropolis-Hastings para os parâmetros $a$ e $\tau$. Para $s$ o fator de Gelman e Rubin $(1,002)$ indica um nível aceitável de convergência do algoritmo. As densidades a posteriori de $s, a$ e $\tau$ são apresentadas na Figura 7.35.

\section{Prioris moderadamente informativas Normais para $s$ e $a$ e Gama para $\tau$} $\left(s \sim N\left(994,6 ; 1.10^{6}\right), a \sim N\left(5,7.10^{-2} ; 1.10^{6}\right)\right.$ e $\left.\tau \sim G a(0,1 ; 0,1)\right)$

Foram realizadas 100000 iterações para gerar as amostras dos parâmetros partindo-se de três cadeias distintas, destas 9999 foram descartadas com saltos de 50 para diminuir a autocorrelação entre os parâmetros, perfazendo um total de 5400 amostras geradas dos parâmetros $s, a$ e $\tau$ utilizando-se o algoritmo Metropolis-Hastings.

O algoritmo de Metropolis-Hastings se adaptou ao conjunto de dados e às densidades a priori adotadas para os parâmetros. Na Figura 7.36 notou-se pontos extremamente discrepantes nos traços a posteriori de $s, a$ e $\tau$. Assim, houve convergência do algoritmo apenas para o parâmetro $\tau$, o que é confirmado na Figura 7.37. Na Figura 7.38 apresentam-se as densidades a posteriori de $s, a$ e $\tau$. 

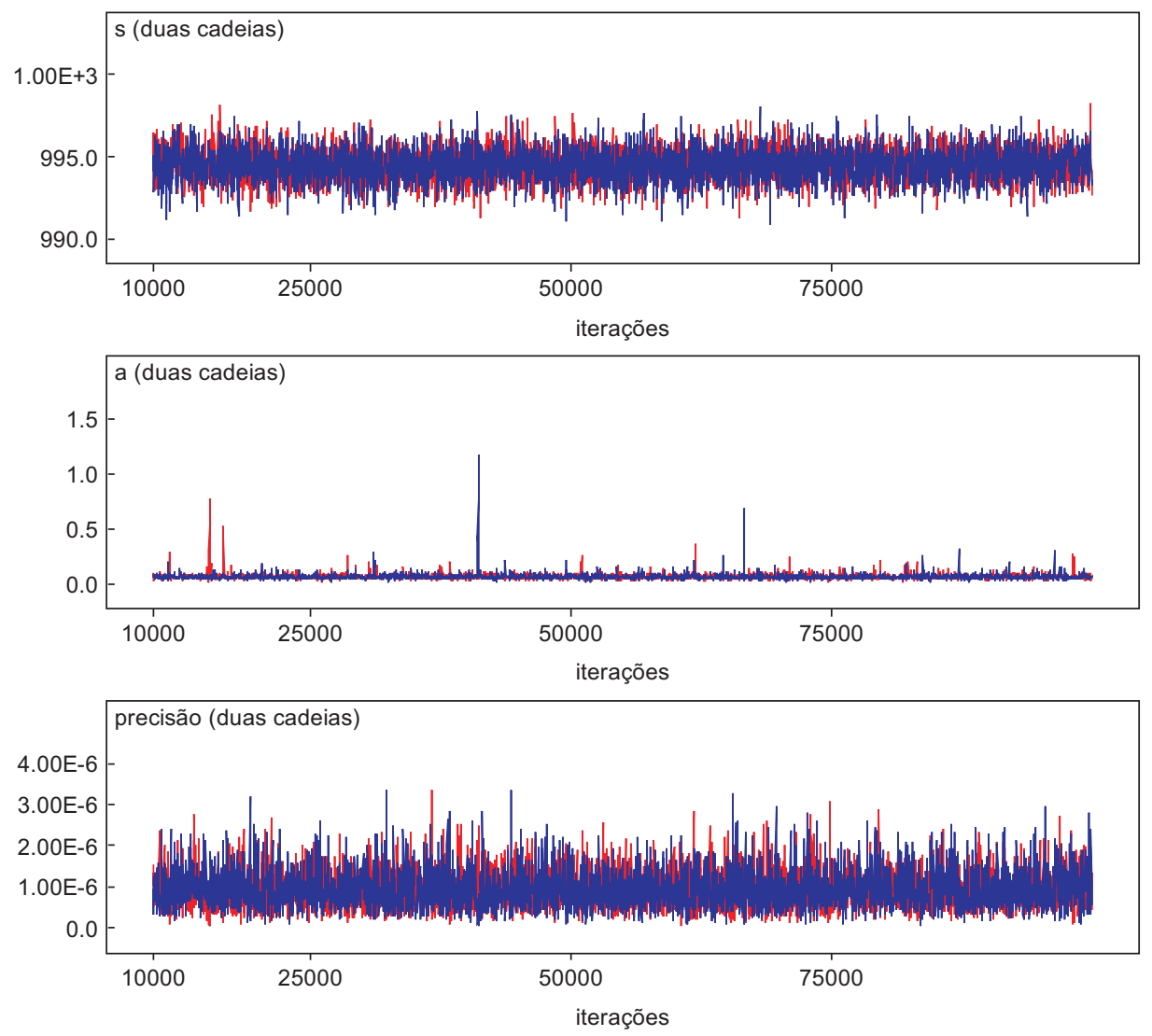

Figura 7.33: Traços a posteriori das duas cadeias geradas de $s, a$ e $\tau$ considerando a população de capim guiné e as prioris: $s \sim N(994,6 ; 1), a \sim N\left(5,7.10^{-2} ; 1\right)$ e $\tau \sim G a(0,001 ; 0,001)$. Nota-se alguns pontos discrepantes, mas uniformidade nos traços a posteriori de $s, a$ e $\tau$.
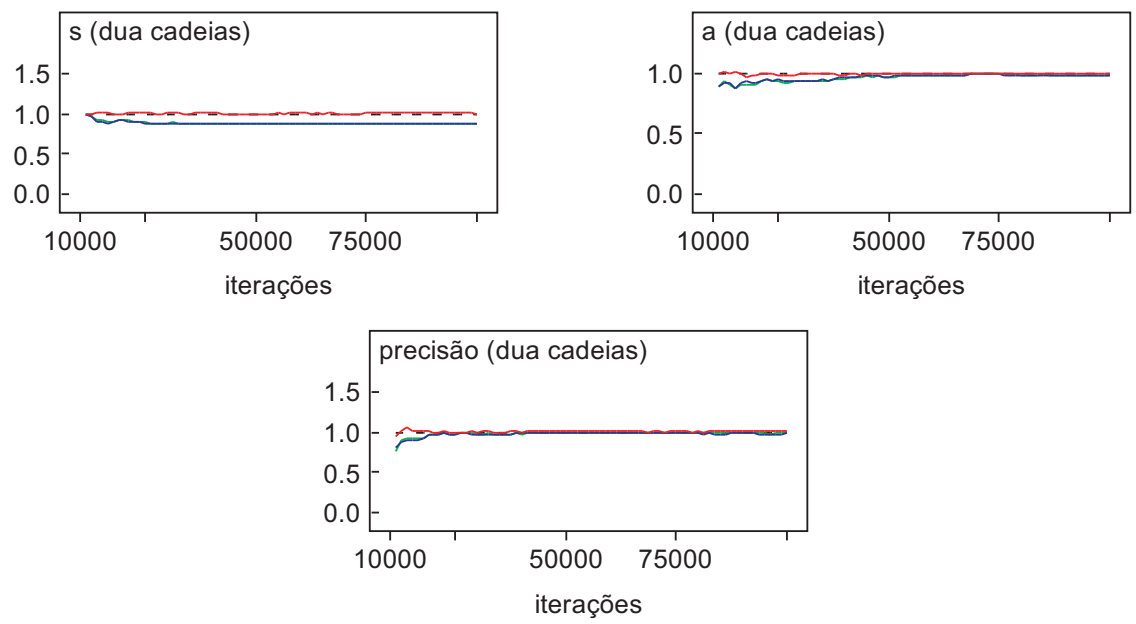

Figura 7.34: Teste gráfico de Gelman e Rubin: verifica-se convergência do algoritmo de Metropolis-Hastings na geração de amostras das duas cadeias para os parâmetros $a$ e $\tau$ considerando a população de capim guiné e as prioris: $s \sim N(994,6 ; 1), a \sim N\left(5,7.10^{-2} ; 1\right)$ e $\tau \sim G a(0,001 ; 0,001)$. 

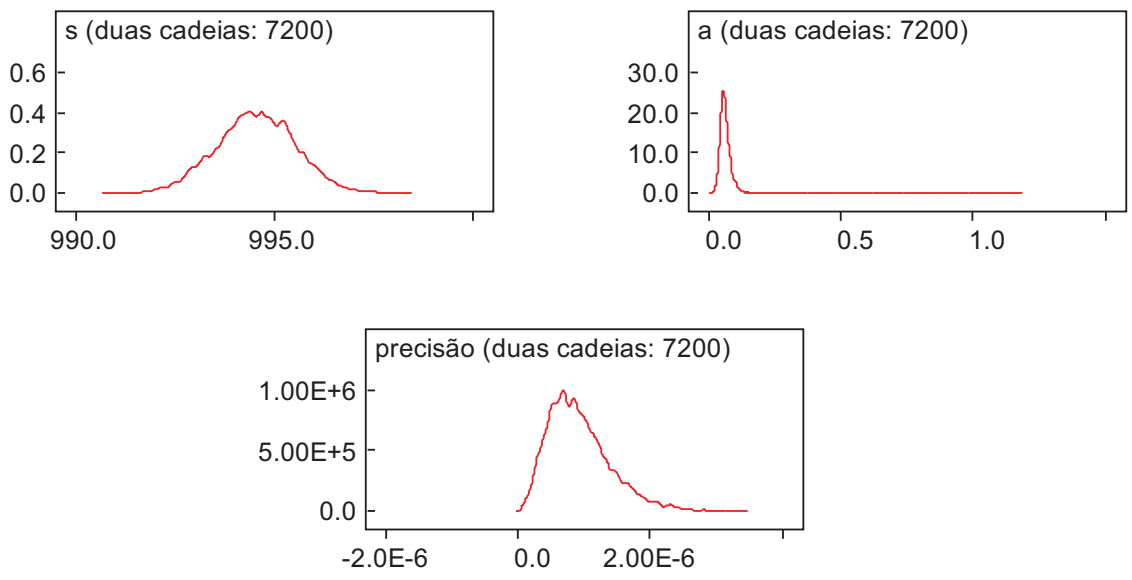

Figura 7.35: Densidades a posteriori de $s, a$ e $\tau$ obtidas a partir das 7200 amostras geradas pelas duas cadeias considerando a população de capim guiné e as prioris: $s \sim N(994,6 ; 1), a \sim N\left(5,7.10^{-2} ; 1\right)$ e $\tau \sim G a(0,001 ; 0,001)$.
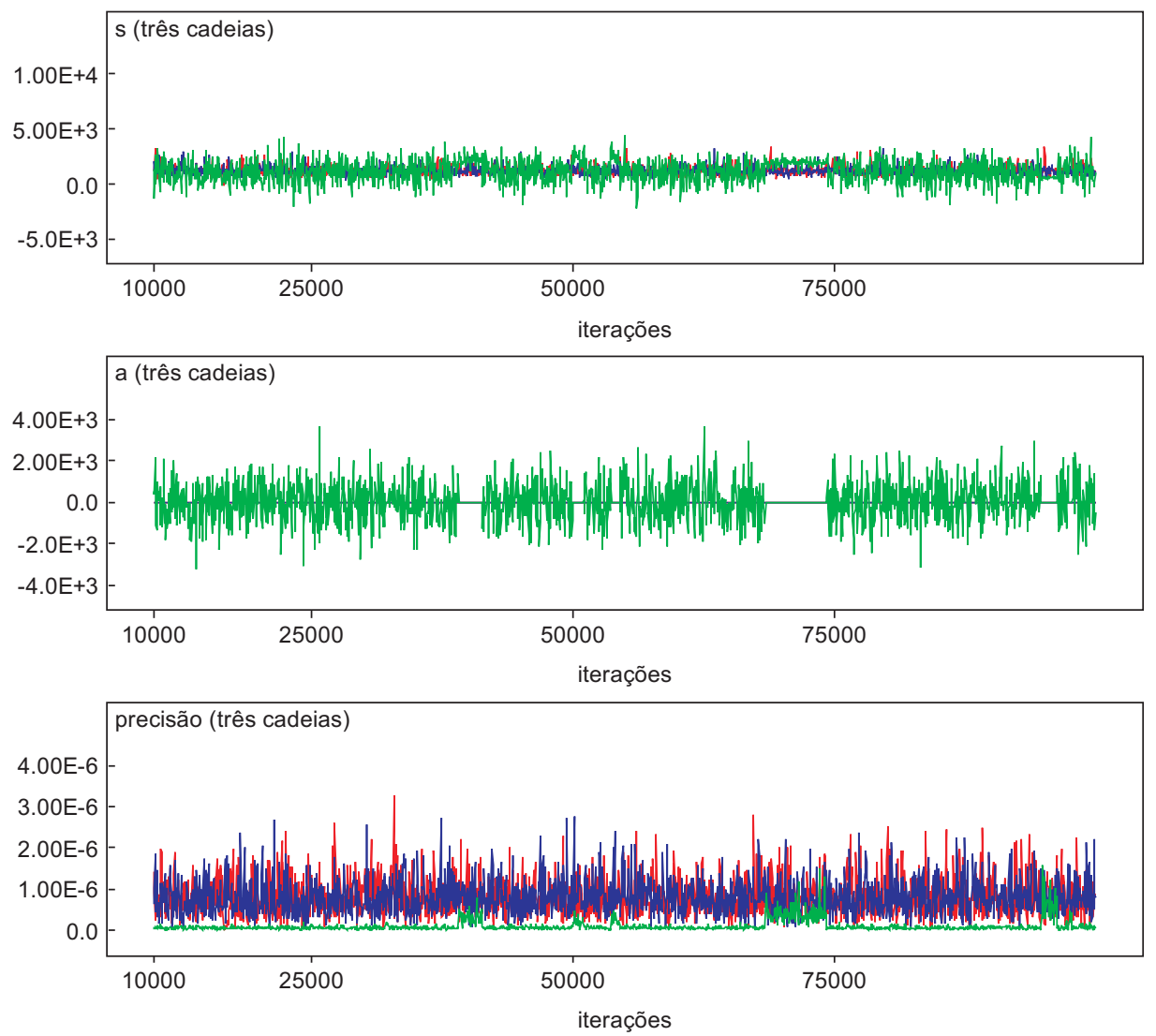

Figura 7.36: Traços a posteriori das três cadeias geradas de $s$, a e $\tau$ considerando a população de capim guiné e as prioris: $s \sim N\left(994,6 ; 1.10^{6}\right), a \sim N\left(5,7.10^{-2} ; 1.10^{6}\right)$ e $\tau \sim G a(0,1 ; 0,1)$. Nota-se pontos extremamente discrepantes nos traços a posteriori de $s, a$ e $\tau$. 

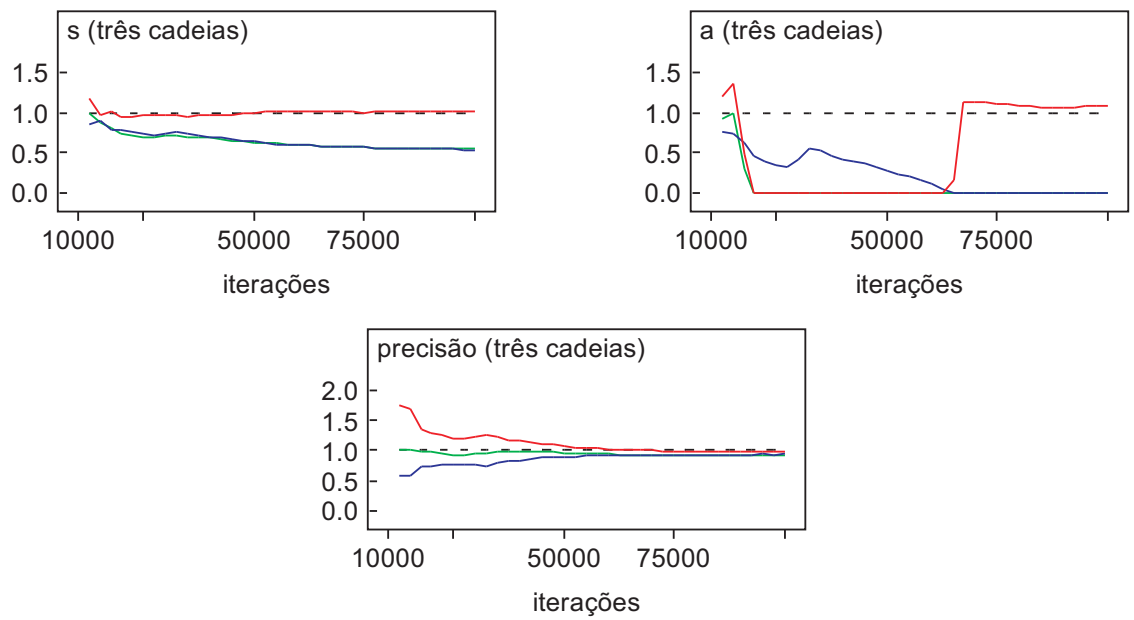

Figura 7.37: Teste gráfico de Gelman e Rubin: verifica-se que apenas houve convergência do algoritmo de Metropolis-Hastings na geração de amostras das três cadeias para os parâmetros $\tau$ considerando a população de capim guiné e as prioris: $s \sim N\left(994,6 ; 1.10^{6}\right), a \sim N\left(5,7.10^{-2} ; 1.10^{6}\right)$ e $\tau \sim G a(0,1 ; 0,1)$.
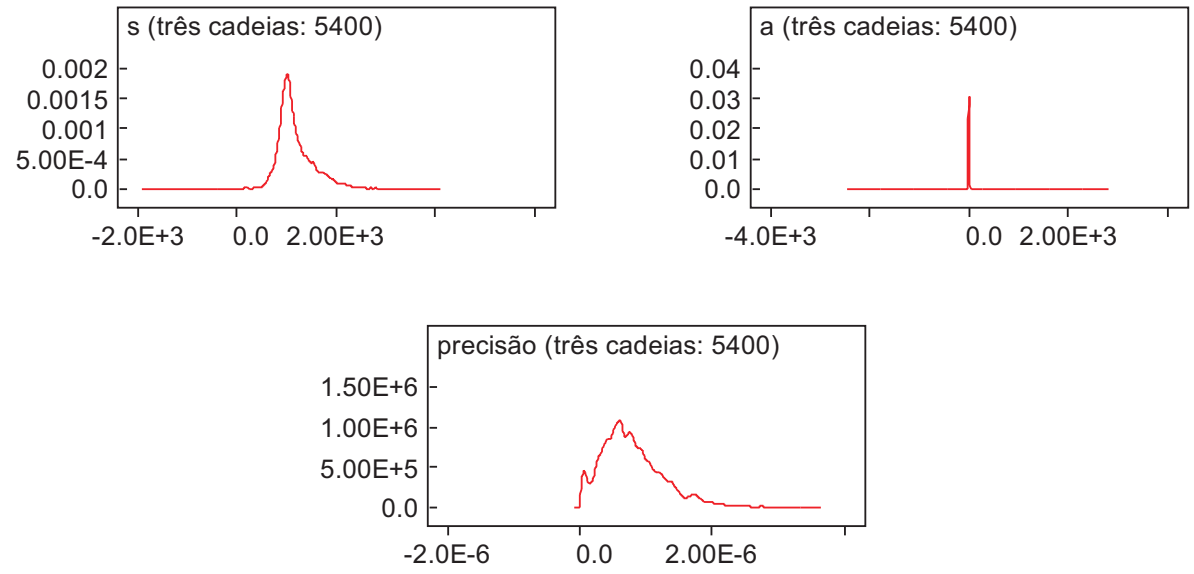

Figura 7.38: Densidades a posteriori de $s$, $a$ e $\tau$ obtidas a partir das 5400 amostras geradas pelas três cadeias considerando a população de capim guiné e as prioris: $s \sim N\left(994,6 ; 1.10^{6}\right), a \sim N\left(5,7.10^{-2} ; 1.10^{6}\right)$ e $\tau \sim G a(0,1 ; 0,1)$. 
Prioris totalmente informativas Normal para $s$ e Gama para $\tau$, e Uniforme para $a$ $(s \sim N(994,6 ; 1), a \sim U(0 ; 1)$ e $\tau \sim G a(1 ; 1))$

Foram realizadas 100000 iterações para gerar as amostras dos parâmetros partindo-se de três cadeias distintas, das quais foram descartadas as 9999 amostras iniciais com saltos de 10 para diminuir a autocorrelação entre os parâmetros, perfazendo um total de 27000 amostras geradas dos parâmetros $s, a$ e $\tau$ utilizando-se o algoritmo "Slice-sampling".

O algoritmo "Slice-sampling" se adaptou ao conjunto de dados e às densidades $a$ priori adotadas para os parâmetros. Na Figura 7.39 verificou-se poucos pontos discrepantes e uniformidade nos traços a posteriori dos parâmetros. A convergência do algoritmo para os parâmetros $s$ e $\tau$ é confirmada na Figura 7.40; já para $a$ o fator de Gelman e Rubin $(0,9991)$ garante um nível aceitável de convergência do algoritmo. Na Figura 7.41 apresentam-se as densidades a posteriori de $s, a$ e $\tau$.
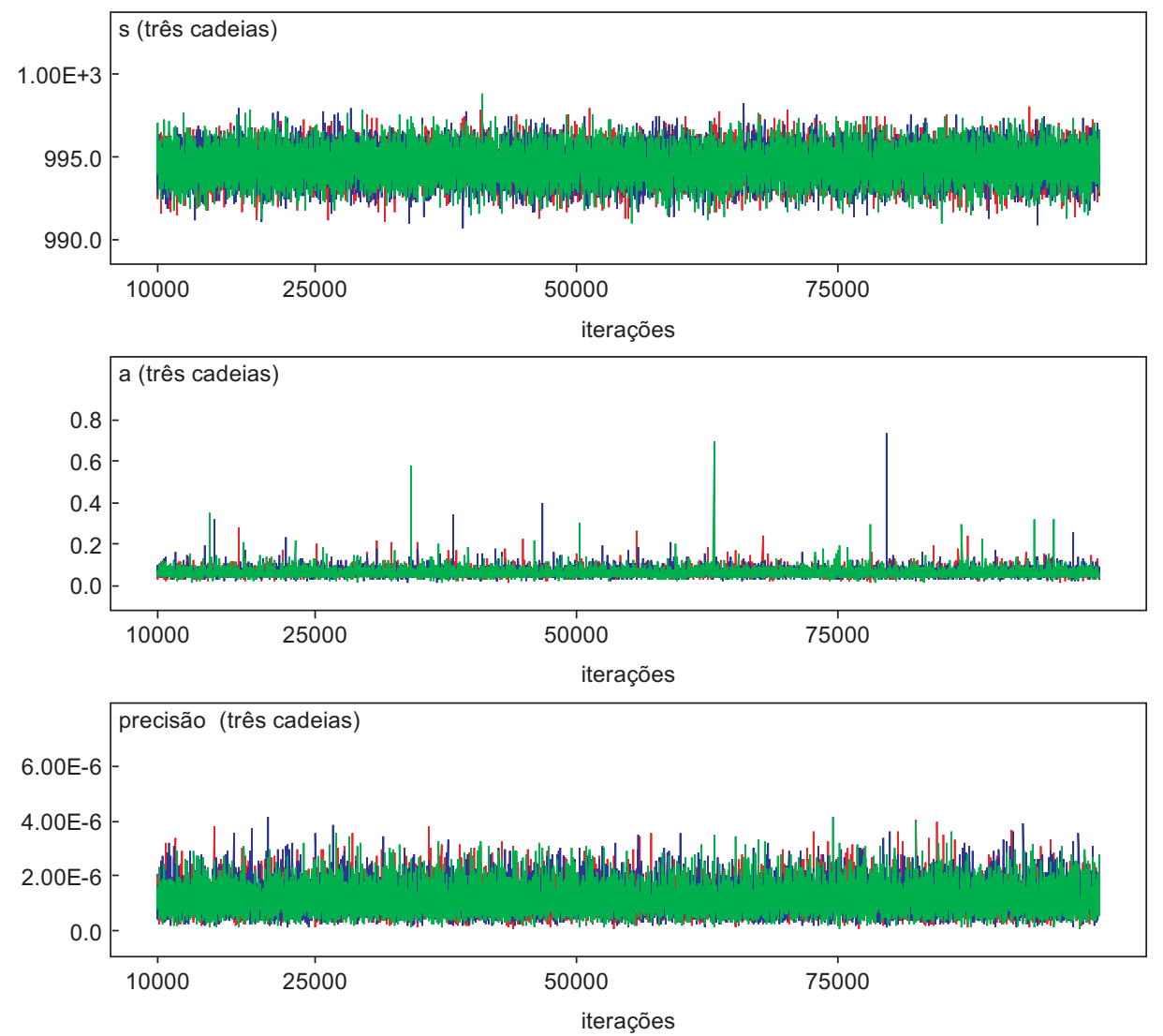

Figura 7.39: Traços a posteriori das três cadeias geradas de $s, a$ e $\tau$ considerando a população de capim guiné e as prioris: $s \sim N(994,6 ; 1), a \sim U(0 ; 1)$ e $\tau \sim G a(1 ; 1)$. Nota-se uniformidade nos traços $a$ posteriori de $s$ e $\tau$, mas alguns pontos discrepantes nos traços de $a$. 

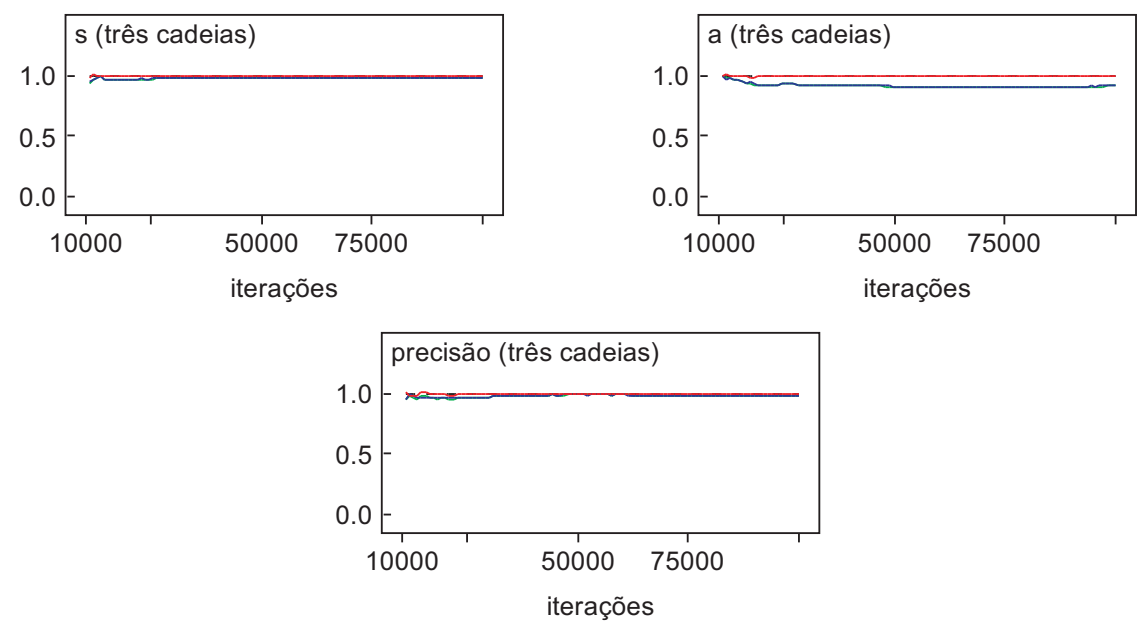

Figura 7.40: Teste gráfico de Gelman e Rubin: verifica-se que houve convergência do algoritmo "Slicesampling" na geração de amostras das três cadeias para o parâmetro $s$ e $\tau$ considerando a população de capim guiné e as prioris: $s \sim N(994,6 ; 1), a \sim U(0 ; 1)$ e $\tau \sim G a(1 ; 1)$.
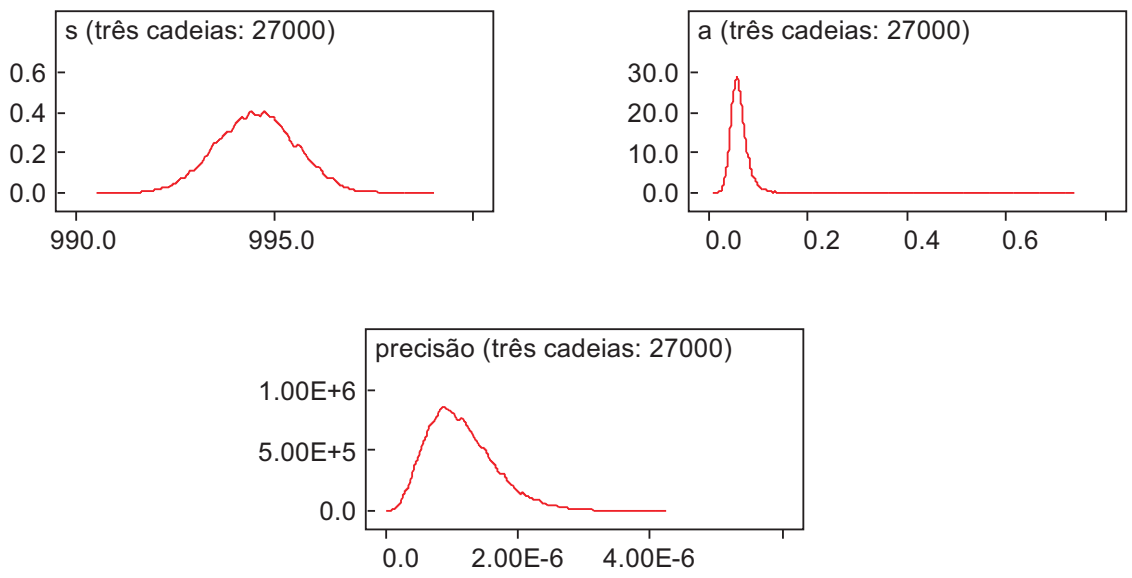

Figura 7.41: Densidades a posteriori de $s, a$ e $\tau$ obtidas a partir das 27000 amostras geradas pelas três cadeias considerando a população de capim guiné e as prioris: $s \sim N(994,6 ; 1), a \sim U(0 ; 1)$ e $\tau \sim G a(1 ; 1)$. 
Prioris totalmente informativa Normal para $s$, não informativa Gama para $\tau$ e Uniforme para $a \quad(s \sim N(994,6 ; 1), a \sim U(0 ; 1)$ e $\tau \sim G a(0,001 ; 0,001))$

Foram realizadas 100000 iterações para gerar as amostras dos parâmetros partindo-se de duas cadeias distintas, das quais foram descartadas as 9999 amostras iniciais com saltos de 10 para diminuir a autocorrelação entre os parâmetros, perfazendo um total de 18000 amostras geradas dos parâmetros $s, a$ e $\tau$ utilizando-se o algoritmo "Slice-sampling".

O algoritmo "Slice-sampling" se adaptou ao conjunto de dados e às densidades $a$ priori adotadas para os parâmetros. Na Figura 7.42 verificou-se uniformidade nos traços a posteriori dos parâmetros $s, a$ e $\tau$, o que indica convergência do algoritmo. Através da Figura 7.43 confirma-se a convergência do algoritmo para $s, a$ e $\tau$. Na Figura 7.44 apresentam-se as densidades a posteriori de $s, a$ e $\tau$.
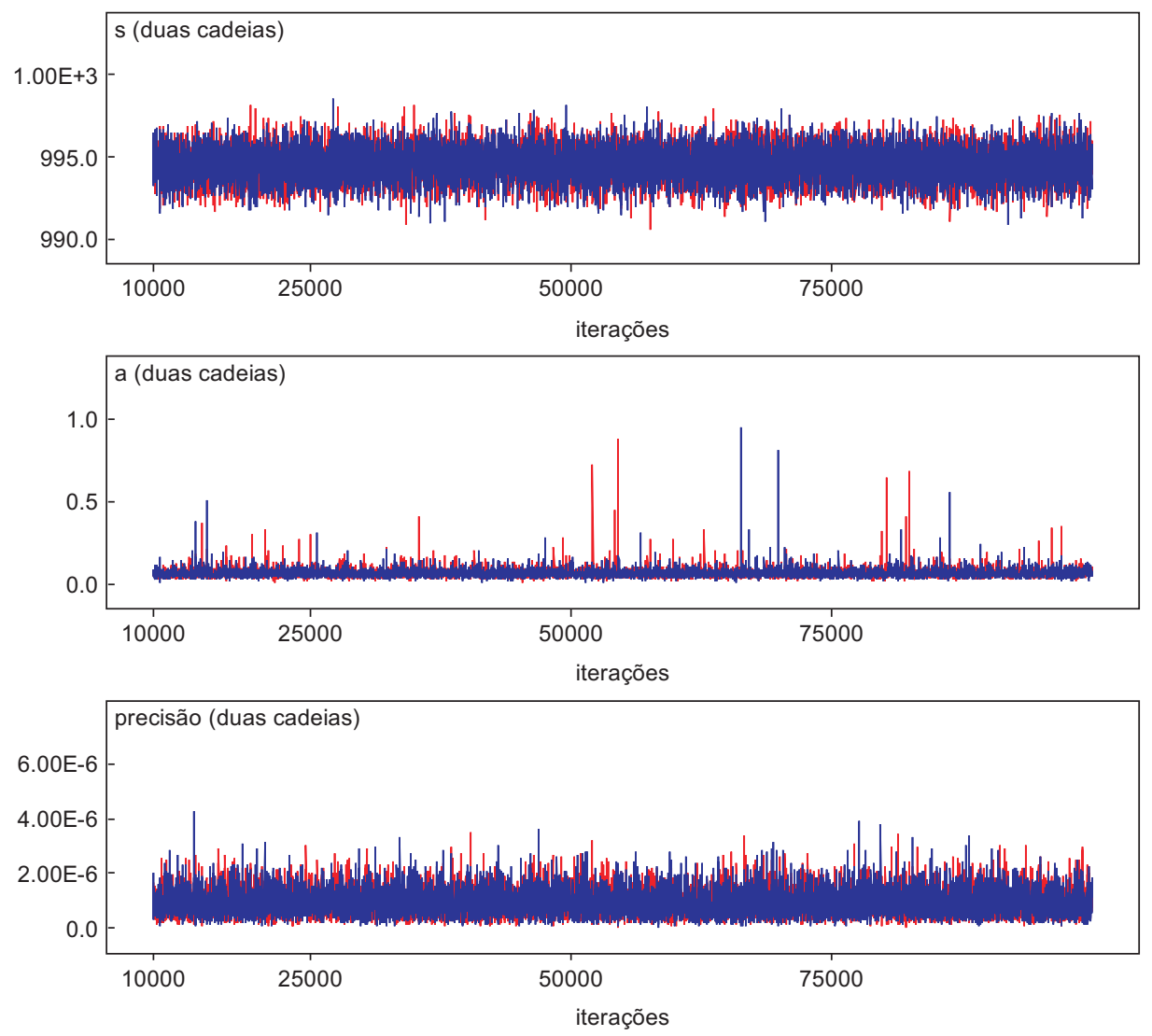

Figura 7.42: Traços a posteriori das duas cadeias geradas de $s$, a e $\tau$ considerando a população de capim guiné e as prioris: $s \sim N(994,6 ; 1), a \sim U(0 ; 1)$ e $\tau \sim G a(0,001 ; 0,001)$. Nota-se poucos pontos discrepantes e uniformidade nos traços a posteriori de $s, a \tau$. 

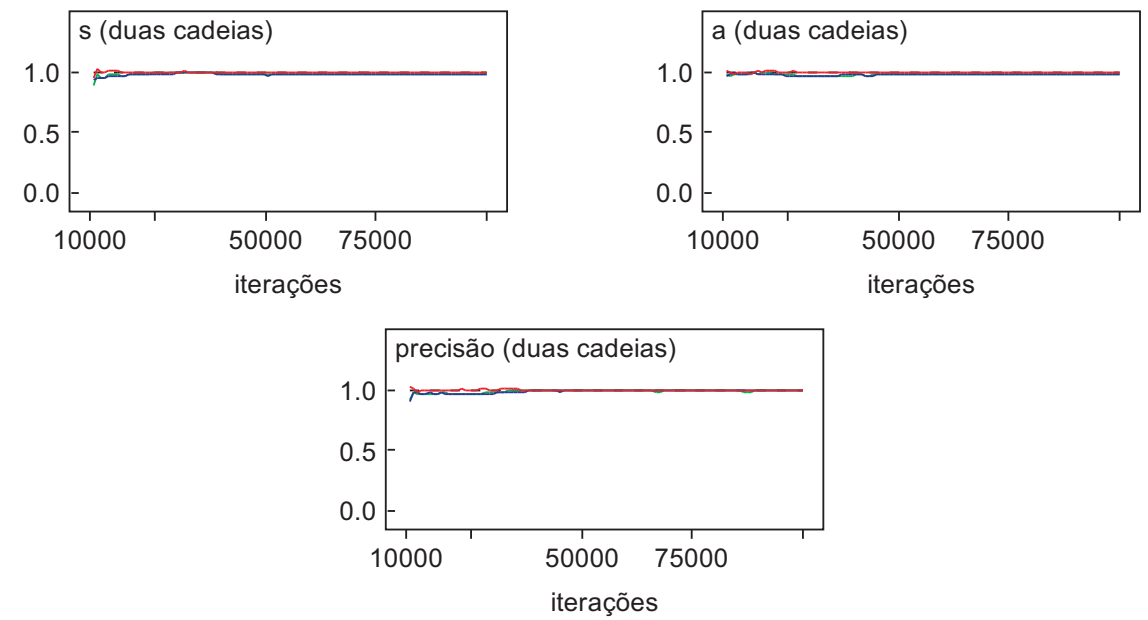

Figura 7.43: Teste gráfico de Gelman e Rubin: verifica-se que houve convergência do algoritmo "Slicesampling" na geração de amostras das duas cadeias para os parâmetros $s, a$ e $\tau$ considerando a população de capim guiné e as prioris: $s \sim N(994,6 ; 1), a \sim U(0 ; 1)$ e $\tau \sim G a(0,001 ; 0,001)$.
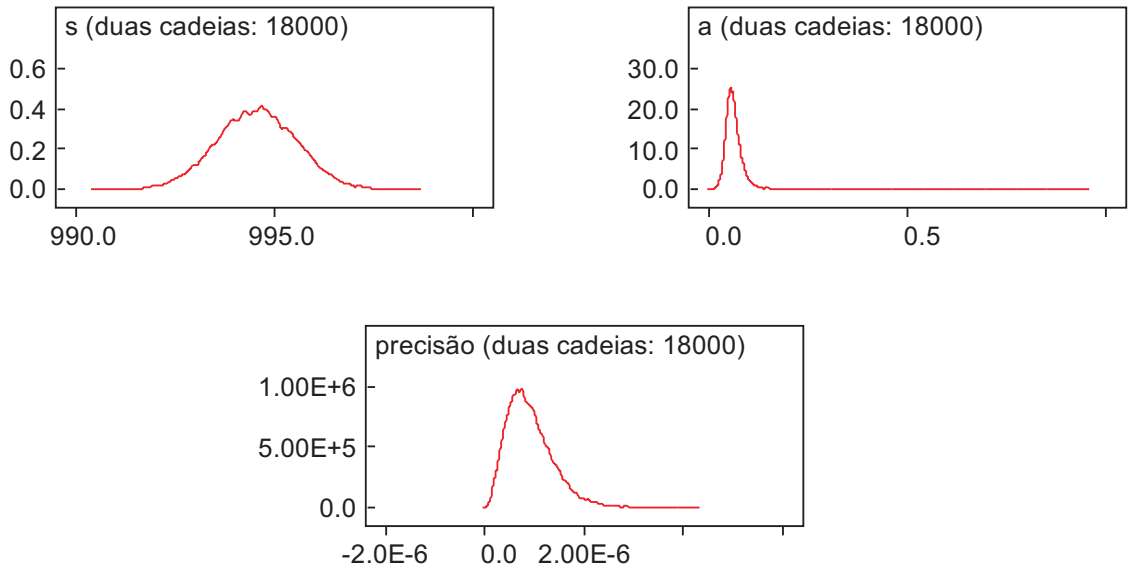

Figura 7.44: Densidades a posteriori de $s, a$ e $\tau$ obtidas a partir das 18000 amostras geradas pelas duas cadeias considerando a população de capim guiné e as prioris: $s \sim N(994,6 ; 1), a \sim U(0 ; 1)$ e $\tau \sim G a(0,001 ; 0,001)$. 
Prioris moderadamente informativas Normal para $s$ e Gama para $\tau$, e Uniforme para $a \quad\left(s \sim N\left(994,6 ; 1.10^{6}\right), a \sim U(0 ; 1)\right.$ e $\left.\tau \sim G a(0,1 ; 0,1)\right)$

Foram realizadas 100000 iterações para gerar as amostras dos parâmetros partindo-se de três cadeias distintas, das quais foram descartadas as 9999 amostras iniciais com saltos de 25 para diminuir a autocorrelação entre os parâmetros, perfazendo um total de 10800 amostras geradas dos parâmetros $s, a$ e $\tau$ utilizando-se o algoritmo "Slice-sampling".

O algoritmo "Slice-sampling" se adaptou ao conjunto de dados e às densidades a priori adotadas para os parâmetros. Na Figura 7.45 verificou-se razoável uniformidade nos traços a posteriori dos parâmetros $s, a$ e $\tau$. A convergência do algoritmo é confirmada na Figura 7.46 para os parâmetros $s, a$ e $\tau$. Na Figura 7.47 apresentam-se as densidades a posteriori de $s, a$ e $\tau$.
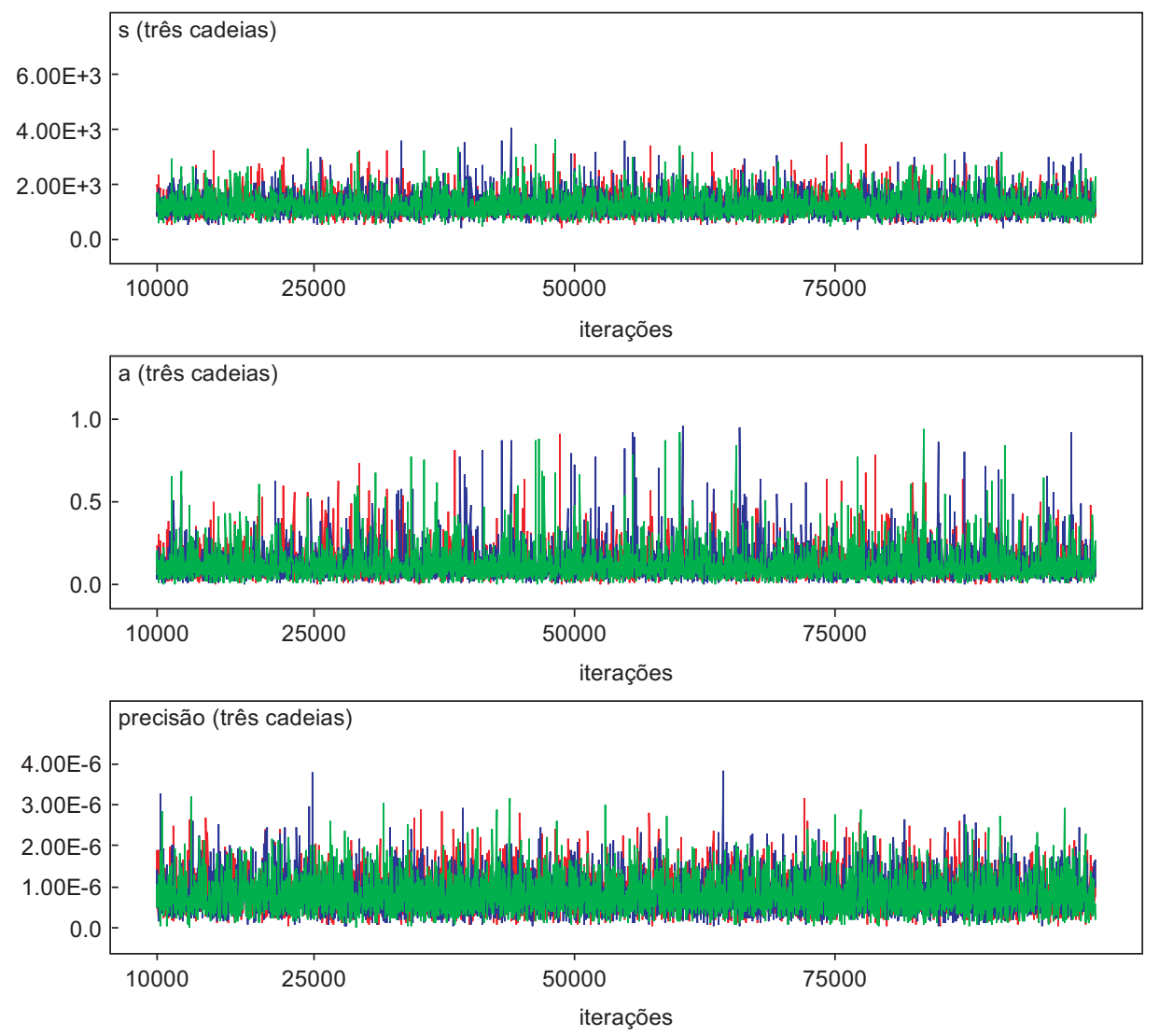

Figura 7.45: Traços a posteriori das três cadeias geradas de $s, a$ e $\tau$ considerando a população de capim guiné e as prioris: $s \sim N\left(994,6 ; 1.10^{6}\right), a \sim U(0 ; 1)$ e $\tau \sim G a(0,1 ; 0,1)$. Nota-se razoável uniformidade nos traços a posteriori de $s, a$ e $\tau$. 

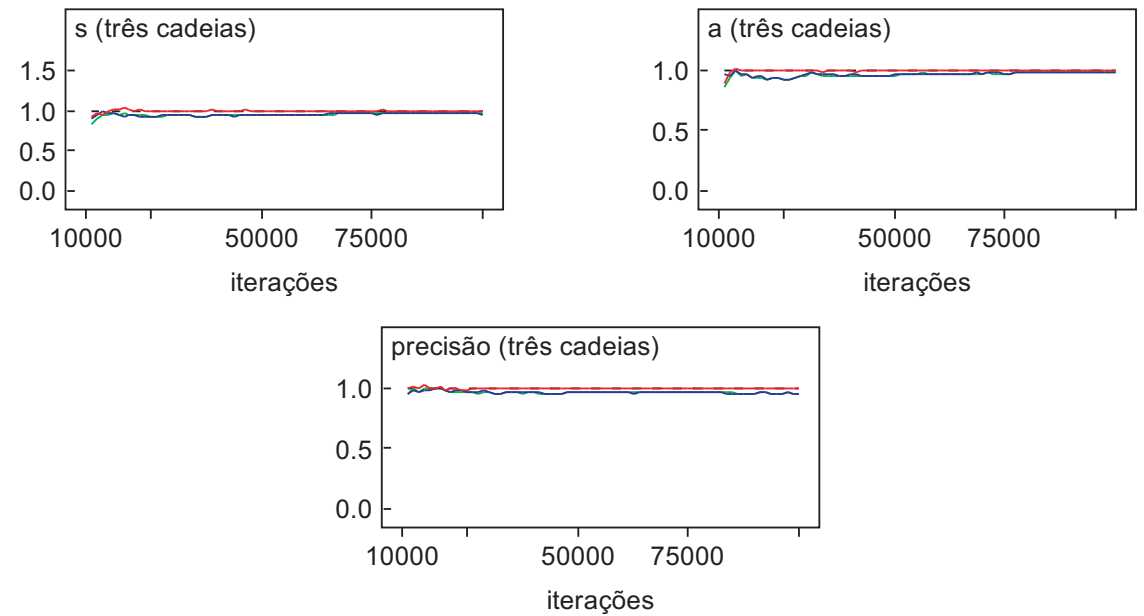

Figura 7.46: Teste gráfico de Gelman e Rubin: verifica-se que houve convergência do algoritmo "Slicesampling" na geração de amostras das três cadeias para os parâmetros $s, a$ e $\tau$ considerando a população de capim guiné e as prioris: $s \sim N\left(994,6 ; 1.10^{6}\right), a \sim U(0 ; 1)$ e $\tau \sim G a(0,1 ; 0,1)$.
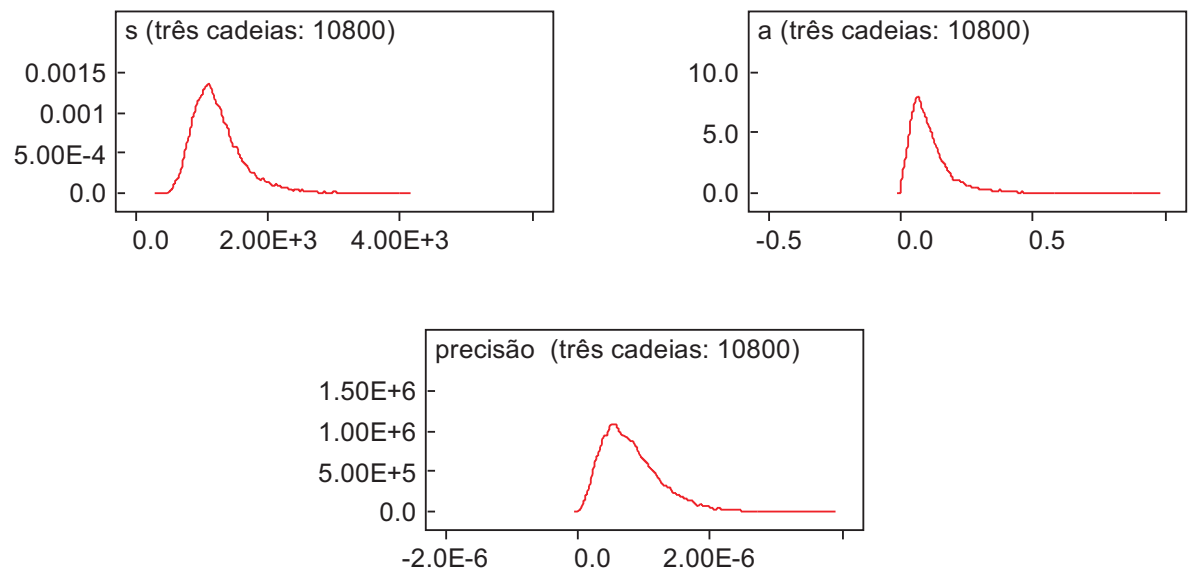

Figura 7.47: Densidades a posteriori de $s$, a e $\tau$ obtidas a partir das 10800 amostras geradas pelas três cadeias considerando a população de capim guiné e as prioris: $s \sim N\left(994,6 ; 1.10^{6}\right), a \sim U(0 ; 1)$ e $\tau \sim G a(0,1 ; 0,1)$. 


\subsection{Euphorbia heterophylla (leiteiro)}

\subsubsection{Diagnósticos envolvendo a variável dependente}

Notou-se acentuada assimetria à esquerda com relação a distribuição da variável densidade de sementes produzidas de leiteiro (Figura 7.48 (esqueda)), o que indica a presença de valores discrepantes na amostra.
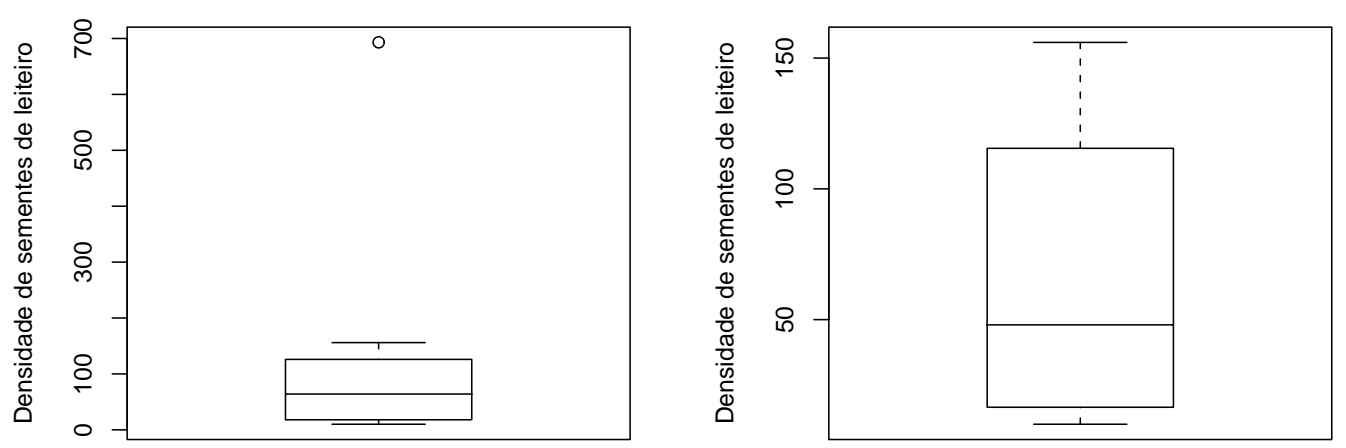

Figura 7.48: Gráfico de caixa: densidade de sementes produzidas de leiteiro com (esquerda) e sem (direita) observações discrepantes.

Com a remoção dos valores atípicos (Figura 7.48 (direita)) esta assimetria foi suavizada permitindo realizar a inferência clássica via regressão não linear.

A Figura 7.49 apresenta o gráfico de dispersão das observações de densidade de plantas daninhas versus densidade de sementes produzidas (esquerda) e histograma (direita) para a população de leiteiro, o qual fornece uma idéia da forma da distribuição da variável densidade de sementes produzidas de leiteiro.

Como observado na Figura 7.48, o histograma de freqüência mostra uma clara assimetria à esquerda na distribuição de $X_{i}$ (Figura 7.49 (direita)). No gráfico de dispersão das variáveis (Figura 7.49 (esquerda)) foi observada, apesar do reduzido número de observações, uma relação que aproxima-se da linear. 

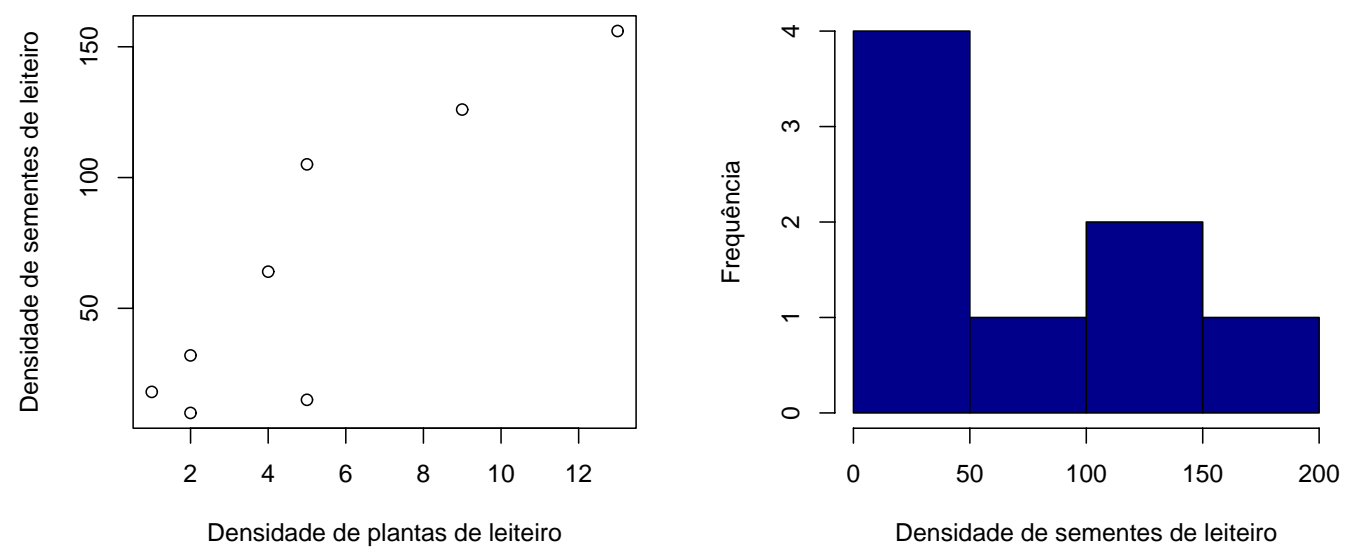

Figura 7.49: Gráfico de dispersão da variável independente versus variável dependente (esquerda) e histograma (direita) para as observações de leiteiro.

\subsubsection{Abordagem clássica do modelo de produção de sementes}

\section{Regressão do modelo linearizado}

A escolha dos valores iniciais para as estimativas dos parâmetros do modelo de regressão não linear foi realizada a partir do ajuste do modelo linearizado de (6.2). O modelo de regressão linear ajustado de (4.8) é

$$
y_{i}=2,47781+0,04746 x_{i}
$$

em que $y_{i}=\ln \left(X_{t+1} / Y_{t}\right)$ é a variável dependente e $x_{i}=-\ln \left(Y_{t}\right)$ a variável independente.

Na Figura 7.50 (esquerda), apresenta-se o gráfico de dispersão da variável independente versus variável dependente com a reta da regressão linear. A análise da normalidade dos resíduos foi verificada através do gráfico de normalidade apresentado na Figura 7.50 (direita). Para verificação da qualidade do ajuste linear foi utilizado o coeficiente de determinação $R^{2}$. Para analisar as estimativas dos parâmetros foi feito o teste $t$-Student de significância dos parâmetros.

Tem-se que $R^{2}=0,003407$, o que indica que a variável independente explica apenas 0,3407\% da variabilidade da variável dependente. Considerando um nível de significância de $\alpha=0,05$, testa-se $H_{01}: \beta_{0}=0$ versus $H_{11}: \beta_{0} \neq 0$, utilizando a estatística 

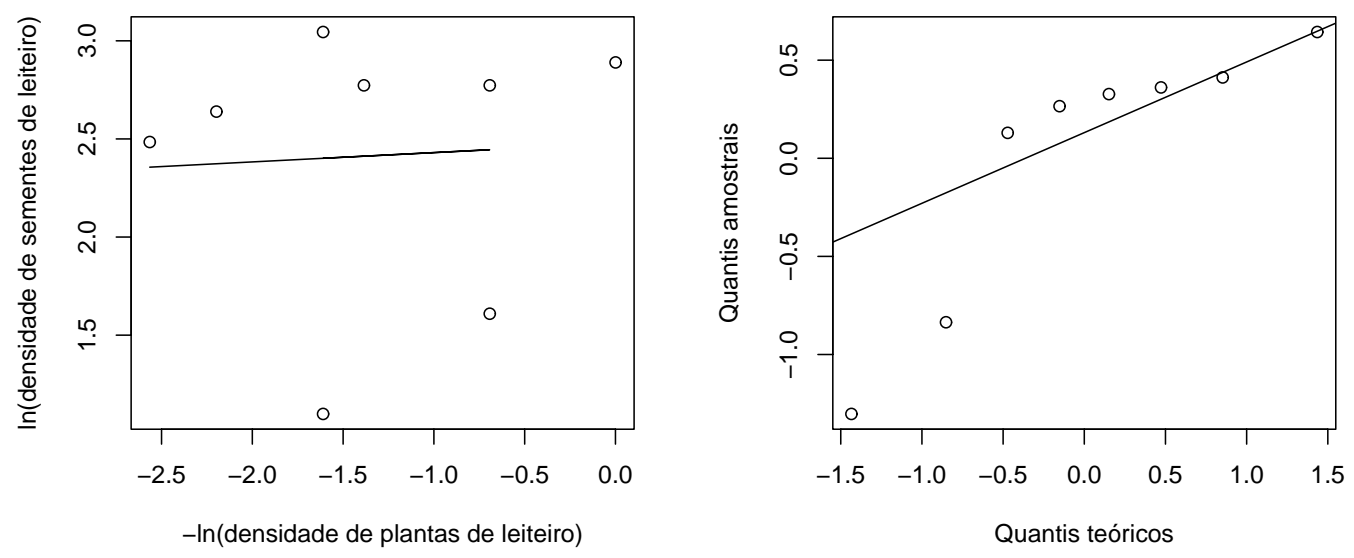

Figura 7.50: Gráficos de dispersão da variável independente versus variável dependente com a reta da regressão linear do modelo (4.8) (esquerda) e de normalidade dos resíduos (direita) para as observações de leiteiro.

$t$-Student; tem-se $t=4,793$ e $t_{0}=0,00302$ e como $t>t_{0}$ rejeita-se a hipótese $H_{0}$, o que indica que o parâmetro é significativo. Analogamente, testa-se $H_{02}: \beta_{1}=0$ versus $H_{12}: \beta_{1} \neq 0$ obtendo-se $t=0,143$ e $t_{0}=0,89080$ e como $t<t_{0}$ não se rejeita a hipótese $H_{0}$ ao nível $\alpha=0,05$ de significância, o que indica que o parâmetro não é significativo.

Apesar da má qualidade do ajuste, as estimativas encontradas para $\beta_{0}$ e $\beta_{1}$ foram utilizadas como valores iniciais para as estimativas dos parâmetros do modelo de regressão não linear, pois de certa maneira trazem alguma informação com respeito aos parâmetros $s$ e $a$.

\section{Regressão do modelo não linear}

A Figura 7.51 (direita) apresenta o gráfico de dispersão da variável independente versus variável dependente com a curva da regressão não linear do modelo (6.9) para as observações de leiteiro, confirmando a pressuposição de relação logarítmica entre as variáveis. A Tabela 7.5 apresenta as estimativas clássica e as medidas de precisão para os parâmetros do modelo (6.9).

Tabela 7.5: Resumo dos resultados via abordagem clássica do modelo (6.9) para a população de Euphorbia heterophylla (leiteiro).

\begin{tabular}{cccccc}
\hline Parâmetros & Estimativa & Desvio padrão & IC $(95 \%)$ & $t$ & $t_{0}$ \\
\hline $\mathrm{s}$ & 13,9 & 5,2 & {$[1,6 ; 26,7]$} & 2,7 & $3,7.10^{-2}$ \\
$\mathrm{a}$ & $9,9.10^{-3}$ & $4,0.10^{-2}$ & {$\left[-8,8.10^{-2} ; 1,1.10^{-1}\right]$} & $2,4.10^{-1}$ & $8,1.10^{-1}$ \\
\hline
\end{tabular}


A homocedasticidade (ou heterocedasticidade) da variância dos resíduos do modelo (6.9) foi verificada pela análise do gráfico dos resíduos versus valores ajustados apresentado na Figura 7.51 (direita). A forma da distribuição e a normalidade dos resíduos podem ser analisadas nas Figuras 7.52 através do histograma (esquerda) e do gráfico de normalidade (direita), respectivamente.
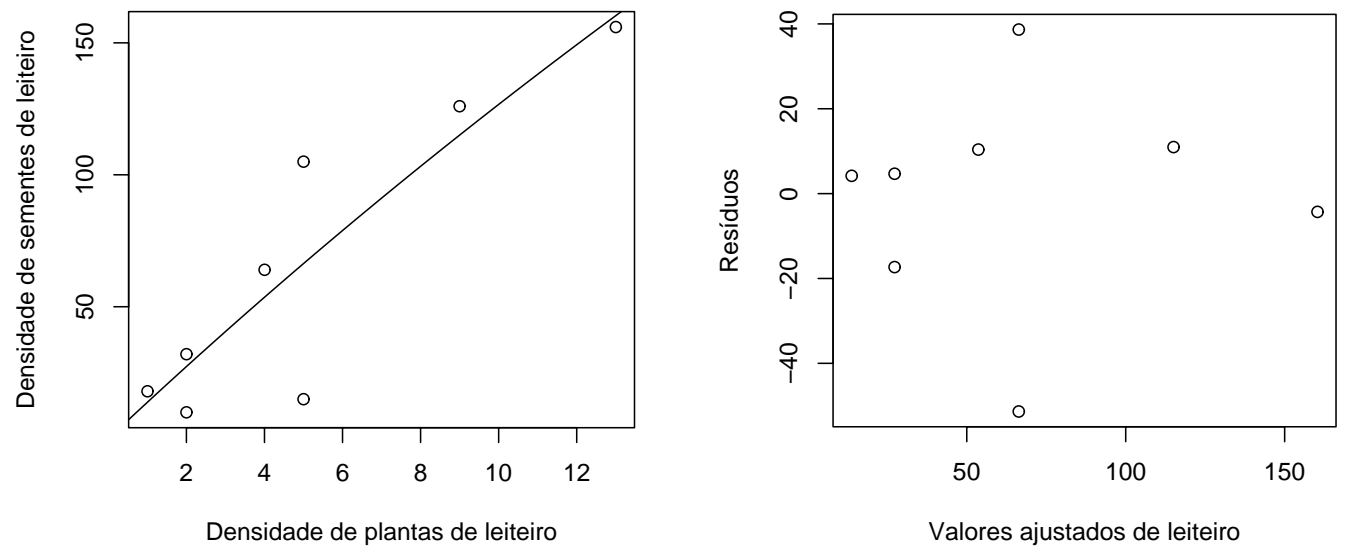

Figura 7.51: Gráficos de dispersão da variável independente versus variável dependente com a curva da regressão não linear do modelo (6.9) (esquerda) e dos resíduos versus valores ajustados (direita) para as observações de leiteiro.
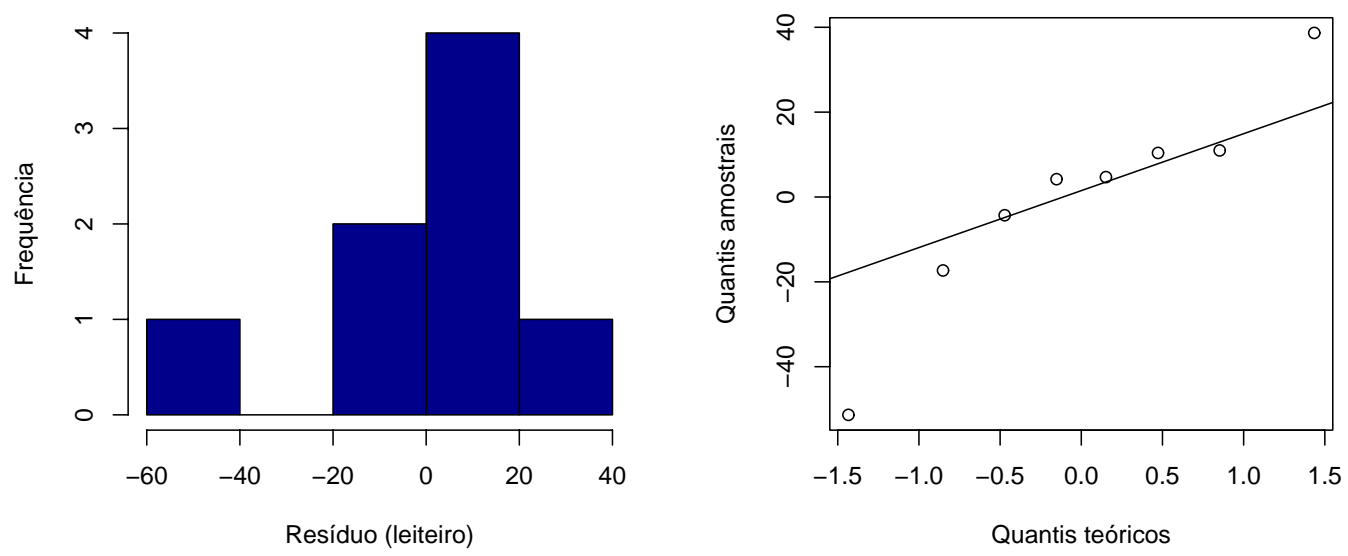

Figura 7.52: Histograma (esquerda) e gráfico de normalidade dos resíduos (direita) para as observações de leiteiro.

O gráfico de dispersão com a curva da regressão não linear apresentado na Figura 7.51 (esquerda), confirma a suposição da relação entre as variáveis ser linear. Provavelmente, isto se deve ao fato de que a população encontrava-se sob baixa densidade de 
plantas de leteiro e os efeitos do aumento do número de sementes por área é aditivo em baixas densidades.

Nota-se uma ligeira heterocedasticidade na variância dos resíduos (Figura 7.51 (direita)) e assimetria a esquerda na distribuição dos resíduos (Figura 7.52 (esquerda)), no entanto seria necessário um maior número de observações para uma análise gráfica mais criteriosa e eficiente.

\subsubsection{Abordagem bayesiana do modelo de produção de sementes}

Para obtenção da densidade a posteriori dos parâmetros $s, a$ e $\tau$, gerou-se de duas a três cadeias a partir de valores iniciais distintos. Para a primeira cadeia utilizou-se as estimativas de regressão não linear $\hat{s}$ e $\hat{a}$ e para a segunda cadeia as estimativas de regressão linear. Já para a terceira cadeia os valores iniciais foram gerados pelo aplicativo WinBUGS (Spiegelhalter et al., 2006), o qual parte de valores extremos das densidades a priori. Sendo assim, não foi possível gerar amostras a partir da terceira cadeia quando adotou-se prioris não informativas para algum parâmetro, o que se justifica pela pouca precisão da informação a priori adotada adotada para o parâmetro.

A análise dos traços a posteriori dos parâmetros apresentou convergência apenas em alguns casos. Assim, também foi utilizado o teste de Gelman e Rubin (Gelman et al., 2000) como critério de verificação dos algoritmos.

Na Tabela 7.6, apresenta-se o resumo dos resultados bayesianos do modelo (6.9) para a população de leiteiro, adotando-se diferentes densidades a priori para os parâmetros de interesse. Apresenta-se também a análise detalhada com relação a cada priori adotada.

\section{Prioris totalmente informativas Normais para $s$ e $a$ e Gama para $\tau$}

$\left(s \sim N(13,9 ; 1), a \sim N\left(9,9.10^{-3} ; 1\right)\right.$ e $\left.\tau \sim G a(1 ; 1)\right)$

Foram realizadas 100000 iterações para gerar as amostras dos parâmetros partindo-se de três cadeias distintas, destas descartou-se as 9999 amostras iniciais com saltos de 40 para diminuir a autocorrelação entre os parâmetros, perfazendo um total de 6750 amostras geradas dos parâmetros $s, a$ e $\tau$ utilizando-se o algoritmo Metropolis-Hastings.

O algoritmo de Metropolis-Hastings se adaptou ao conjunto de dados e às densida- 
Tabela 7.6: Resumo dos resultados via abordagem bayesiana do modelo (6.9) para a população de Euphorbia heterophylla (leiteiro).

\begin{tabular}{|c|c|c|c|c|}
\hline \multirow[t]{2}{*}{ Prioris } & & \multicolumn{3}{|c|}{ Parâmetros } \\
\hline & & $s$ & $a$ & $\tau$ (precisão) \\
\hline$s \sim N(13,9 ; 1)$ & Média & 14 & $1,9.10^{-2}$ & $1,9.10^{-3}$ \\
\hline$a \sim N\left(9,9.10^{-3} ; 1\right)$ & Mediana & 14 & $1,4.10^{-2}$ & $1,7.10^{-3}$ \\
\hline \multirow[t]{2}{*}{$\tau \sim G a(1 ; 1)$} & Desvio padrão & $9,6.10^{-1}$ & $6,4.10^{-2}$ & $9,1.10^{-4}$ \\
\hline & IC $(95 \%)$ & {$[12,1 ; 15,9]$} & {$\left[-9,4.10^{-3} ; 6,2.10^{-2}\right]$} & {$\left[5,2.10^{-4} ; 4,0.10^{-3}\right]$} \\
\hline$s \sim N(13,9 ; 1)$ & Média & 14,0 & $2,4.10^{-2}$ & $1,5.10^{-3}$ \\
\hline$a \sim N\left(9,9.10^{-3} ; 1\right)$ & Mediana & 14,0 & $1,5.10^{-2}$ & $1,3.10^{-3}$ \\
\hline \multirow[t]{2}{*}{$\tau \sim G a(0,001 ; 0,001)$} & Desvio padrão & $9,6.10^{-1}$ & $7,2.10^{-2}$ & $8,0.10^{-4}$ \\
\hline & IC $(95 \%)$ & {$[12,2 ; 15,9]$} & {$\left[-1,1.10^{-2} ; 9,3.10^{-2}\right]$} & {$\left[3,1.10^{-4} ; 3,3.10^{-3}\right]$} \\
\hline$s \sim N\left(13,9 ; 1.10^{6}\right)$ & Média & 35,1 & $-3,7$ & $1,8.10^{-4}$ \\
\hline$a \sim N\left(9,9.10^{-3} ; 1.10^{6}\right)$ & Mediana & 61,2 & 6,6 & $1,5.10^{-4}$ \\
\hline \multirow[t]{2}{*}{$\tau \sim G a(0,1 ; 0,1)$} & Desvio padrão & 1092 & 898,2 & $1,2.10^{-4}$ \\
\hline & IC $(95 \%)$ & {$[-2079 ; 2113]$} & {$[-1872 ; 1838]$} & {$\left[4,3.10^{-5} ; 5,0.10^{-4}\right]$} \\
\hline$s \sim N(13,9 ; 1)$ & Média & 14,2 & $2,1.10^{-2}$ & $1,9.10^{-3}$ \\
\hline$a \sim U(0 ; 1)$ & Mediana & 14,1 & $1,6.10^{-2}$ & $1,8.10^{-3}$ \\
\hline \multirow[t]{2}{*}{$\tau \sim G a(1 ; 1)$} & Desvio padrão & $9,2.10^{-1}$ & $2,5.10^{-2}$ & $9,1.10^{-4}$ \\
\hline & IC $(95 \%)$ & {$[12,4 ; 15,9]$} & {$\left[1,1.10^{-3} ; 6,2.10^{-2}\right]$} & {$\left[5,5.10^{-4} ; 4, .10^{-3}\right]$} \\
\hline$s \sim N(13,9 ; 1)$ & Média & 14,2 & $2,7.10^{-2}$ & $1,4.10^{-3}$ \\
\hline$a \sim U(0 ; 1)$ & Mediana & 14,2 & $1,8.10^{-2}$ & $1,3.10^{-3}$ \\
\hline \multirow[t]{2}{*}{$\tau \sim G a(0,001 ; 0,001)$} & Desvio padrão & $9,3.10^{-1}$ & $4,8.10^{-2}$ & $8,0.10^{-4}$ \\
\hline & IC $(95 \%)$ & {$[12,3 ; 15,9]$} & {$\left[1,1.10^{-3} ; 9,5.10^{-2}\right]$} & {$\left[3,0.10^{-4} ; 3,4.10^{-3}\right]$} \\
\hline$s \sim N\left(13,9 ; 1.10^{6}\right)$ & Média & 37,9 & $2,8.10^{-1}$ & $9,6.10^{-4}$ \\
\hline$a \sim U(0 ; 1)$ & Mediana & 28,9 & $9,4.10^{-1}$ & $7,7.10^{-4}$ \\
\hline \multirow[t]{2}{*}{$\tau \sim G a(0,1 ; 0,1)$} & Desvio padrão & 24,7 & $2,8.10^{-1}$ & $6,7.10^{-4}$ \\
\hline & IC $(95 \%)$ & {$[12,5 ; 99,4]$} & {$\left[5,9.10^{-3} ; 9,4.10^{-1}\right]$} & {$\left[1,7.10^{-4} ; 2,7.10^{-3}\right]$} \\
\hline
\end{tabular}

des a priori adotadas para os parâmetros. Na Figura 7.53, observou-se poucos pontos discrepantes e uniformidade nos traços a posteriori de $s, a$ e $\tau$ o que indica convergência do algoritmo. De fato, através do teste gráfico de Gelman e Rubin (Figura 7.54) confirmou-se a convergência do algoritmo de Metropolis-Hastings na geração de amostras das três cadeias para os parâmetros $s, a$ e $\tau$. Na Figura 7.55 apresentam-se as densidades a posteriori de $s, a$ e $\tau$.

Prioris totalmente informativas Normais para $s$ e $a$ e não informativa Gama para $\tau$ $\left(s \sim N(13,9 ; 1), a \sim N\left(9,9.10^{-3} ; 1\right)\right.$ e $\left.\tau \sim G a(0,001 ; 0,001)\right)$

Foram realizadas 100000 iterações para gerar as amostras dos parâmetros partindo-se de duas cadeias distintas, destas descartou-se as 9999 amostras iniciais com saltos de 40 para diminuir a autocorrelação entre os parâmetros, perfazendo um total de 4500 amostras geradas dos parâmetros $s, a$ e $\tau$ utilizando-se o algoritmo Metropolis-Hastings.

O algoritmo de Metropolis-Hastings se adaptou ao conjunto de dados e às densida- 

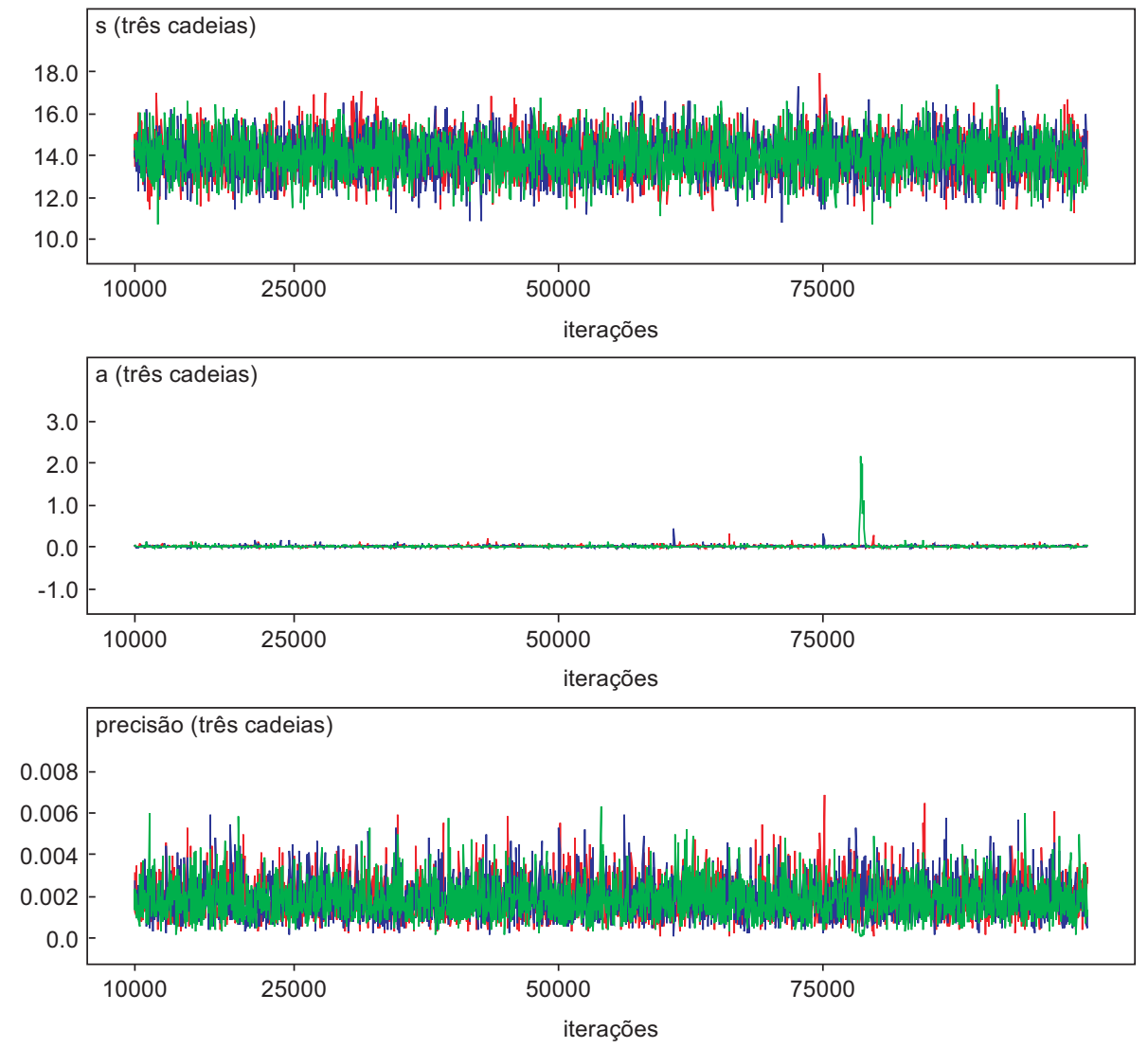

Figura 7.53: Traços a posteriori das três cadeias geradas de $s, a$ e $\tau$ considerando a população de leiteiro e as prioris: $s \sim N(13,9 ; 1), a \sim N\left(9,9.10^{-3} ; 1\right)$ e $\tau \sim G a(1 ; 1)$. Nota-se poucos pontos discrepantes e uniformidade nos traços a posteriori de $s, a$ e $\tau$ o que indica a convergência do algoritmo.
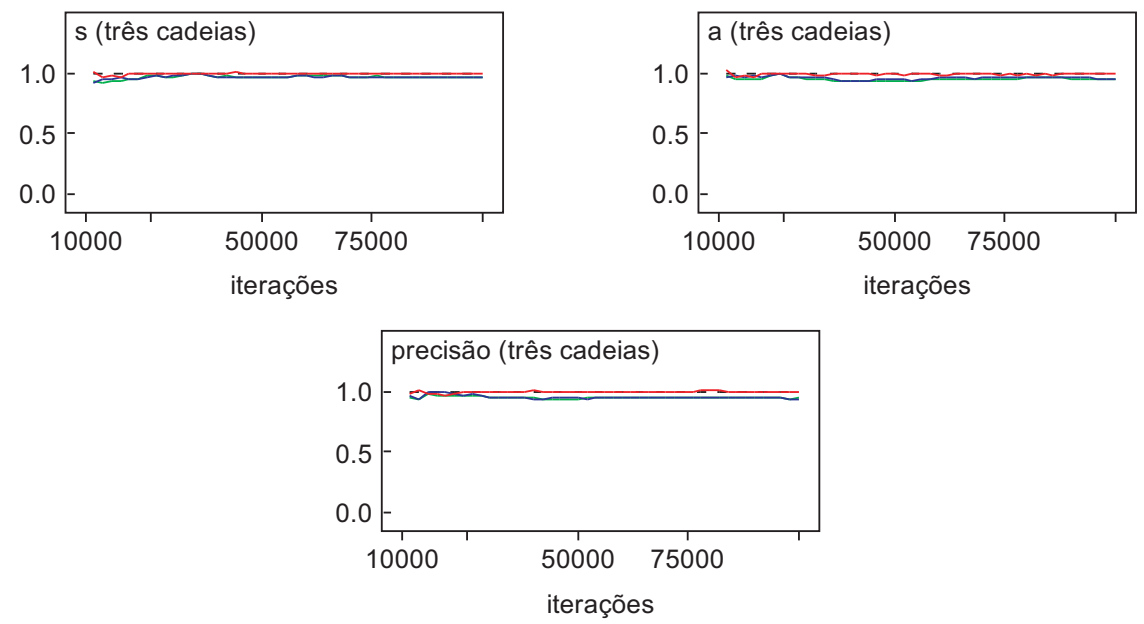

Figura 7.54: Teste gráfico de Gelman e Rubin: verifica-se que houve convergência do algoritmo de Metropolis-Hastings na geração de amostras das três cadeias para os parâmetros $s, a$ e $\tau$ considerando a população de leiteiro e as prioris: $s \sim N(13,9 ; 1), a \sim N\left(9,9.10^{-3} ; 1\right)$ e $\tau \sim G a(1 ; 1)$. 

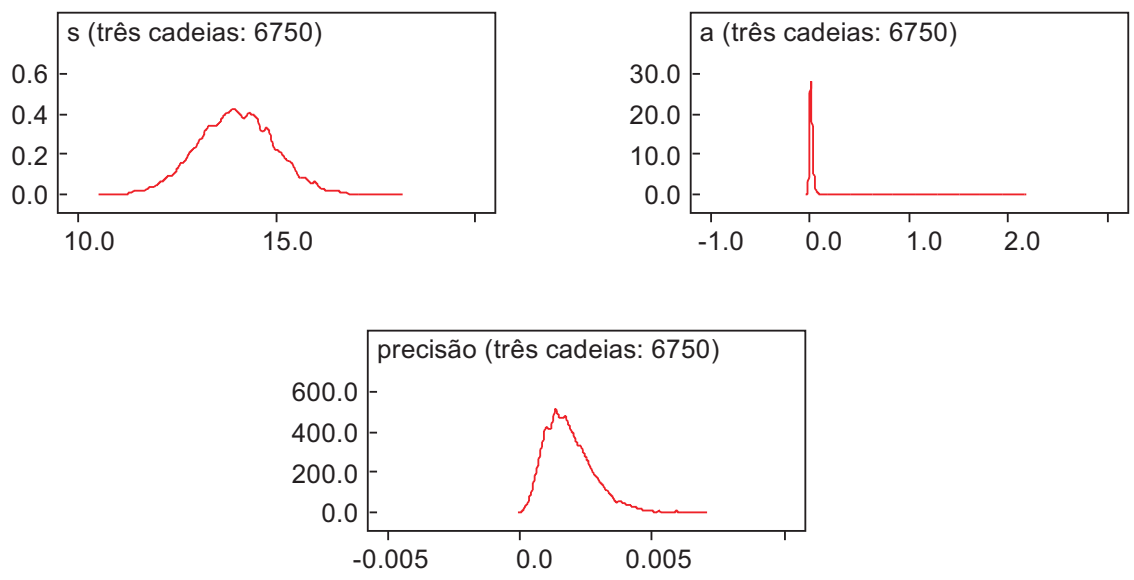

Figura 7.55: Densidades a posteriori de $s, a$ e $\tau$ obtidas a partir das 6750 amostras geradas pelas três cadeias considerando a população de leiteiro e as prioris: $s \sim N(13,9 ; 1), a \sim N\left(9,9.10^{-3} ; 1\right)$ e $\tau \sim G a(1 ; 1)$.

des a priori adotadas para os parâmetros. Na Figura 7.56, observou-se poucos pontos discrepantes e uniformidade nos traços a posteriori de $s, a$ e $\tau$ o que indica convergência do algoritmo. De fato, através do teste gráfico de Gelman e Rubin (Figura 7.57) confirmou-se a convergência do algoritmo de Metropolis-Hastings na geração de amostras das três cadeias para os parâmetros $s, a$ e $\tau$. As densidades a posteriori de $s, a$ e $\tau$ são apresentadas na Figura 7.58.

Prioris moderadamente informativas Normais para $s$ e $a$ e Gama para $\tau$ $\left(s \sim N\left(13,9 ; 1.10^{6}\right), a \sim N\left(9,9.10^{-3} ; 1.10^{6}\right)\right.$ e $\left.\tau \sim G a(0,1 ; 0,1)\right)$

Foram realizadas 100000 iterações para gerar as amostras dos parâmetros partindo-se de três cadeias distintas, das quais foram descartadas as 4999 amostras iniciais com saltos de 15 para diminuir a autocorrelação entre os parâmetros, perfazendo um total de 18999 amostras geradas dos parâmetros $s, a$ e $\tau$ utilizando-se o algoritmo Metropolis-Hastings.

O algoritmo de Metropolis-Hastings se adaptou ao conjunto de dados e às densidades a priori adotadas para os parâmetros. Na Figura 7.59 verificou-se uniformidade nos traços a posteriori dos parâmetros $s$ e $a$ o que indica convergência do algoritmo para estes parâmetros, o que é confirmado na Figura 7.60. Para $\tau$ o fator de Gelman e Rubin $(1,0)$ garante um nível aceitável de convergência do algoritmo. Na Figura 7.61 apresentam-se as densidades a posteriori de $s, a$ e $\tau$.

As análises foram repetidas partindo-se de duas cadeias, descartando-se as 4999 

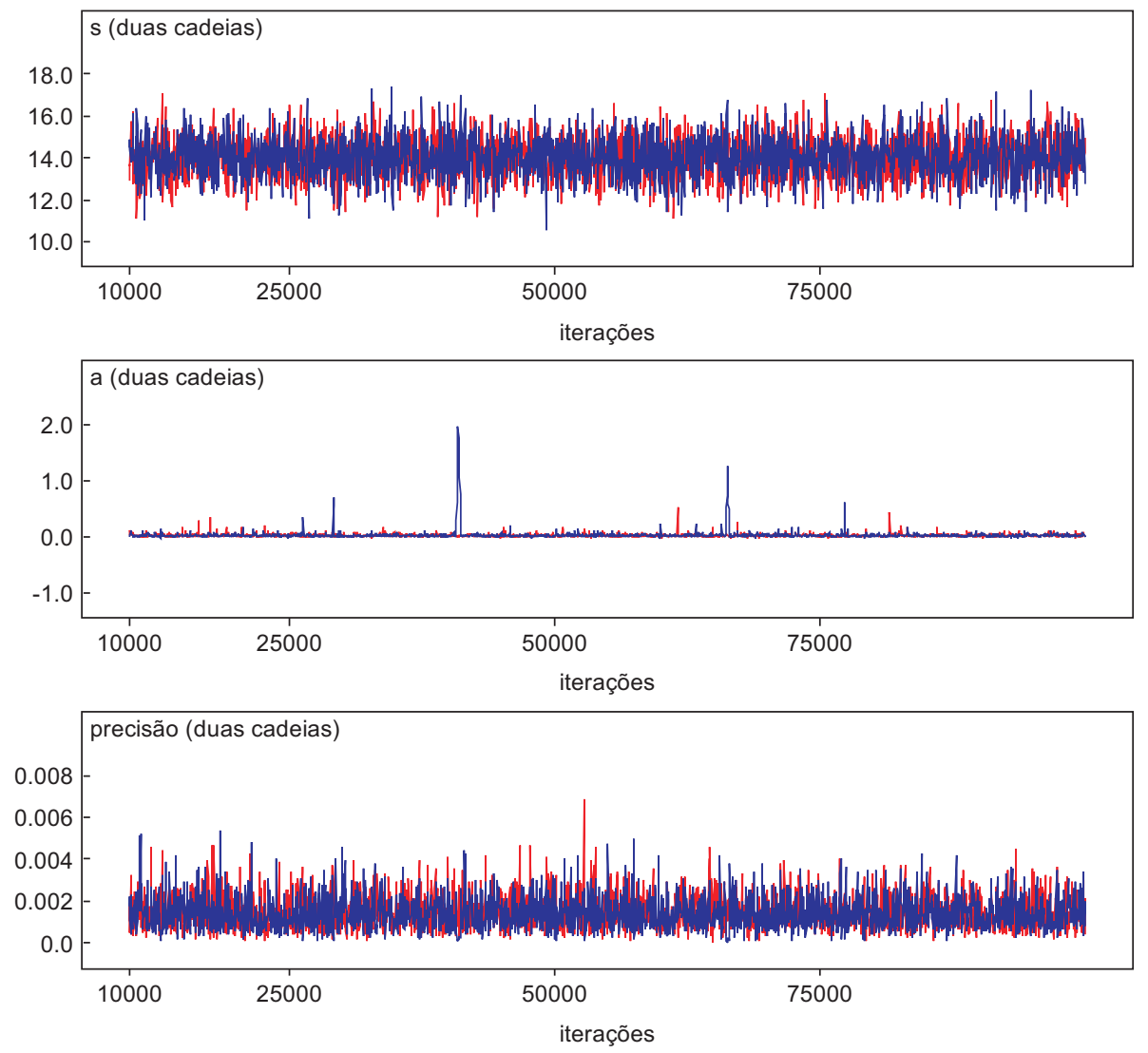

Figura 7.56: Traços a posteriori das duas cadeias geradas de $s, a$ e $\tau$ considerando a população de leiteiro e as prioris: $s \sim N(13,9 ; 1), a \sim N\left(9,9.10^{-3} ; 1\right)$ e $\tau \sim G a(0,001 ; 0,001)$. Nota-se pontos discrepantes mas razoável uniformidade nos traços a posteriori de $s, a$ e $\tau$.
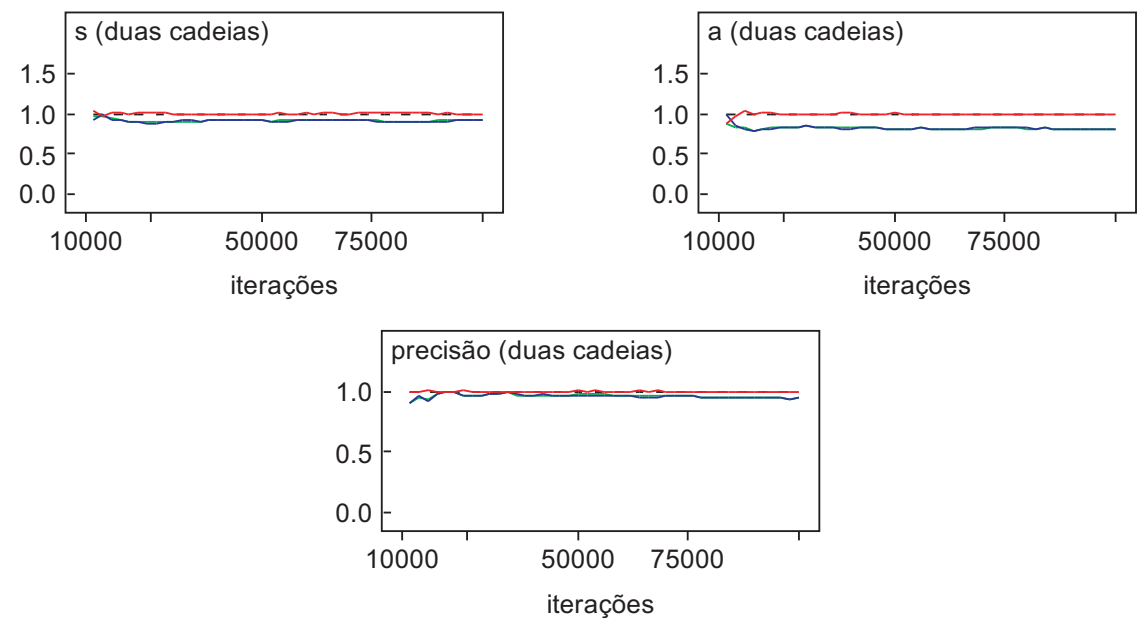

Figura 7.57: Teste gráfico de Gelman e Rubin: verifica-se que houve convergência do algoritmo de Metropolis-Hastings na geração de amostras das duas cadeias para os parâmetros $s$ e $\tau$ considerando a população de leiteiro e as prioris: $s \sim N(13,9 ; 1), a \sim N\left(9,9.10^{-3} ; 1\right)$ e $\tau \sim G a(0,001 ; 0,001)$. 

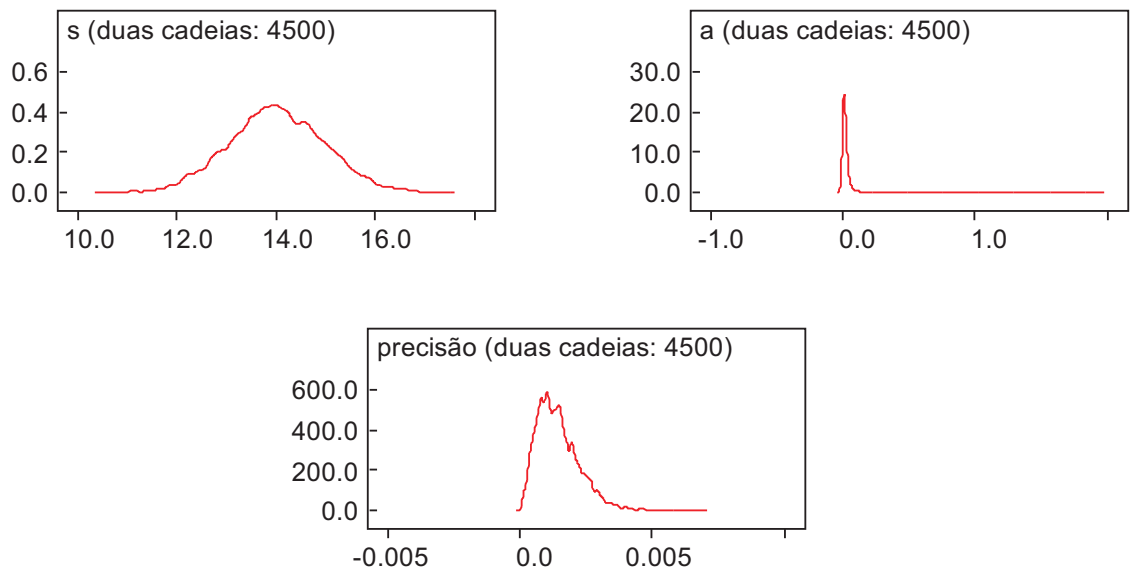

Figura 7.58: Densidades a posteriori de $s, a$ e $\tau$ obtidas a partir das 4500 amostras geradas pelas duas cadeias considerando a população de leiteiro e as prioris: $s \sim N(13,9 ; 1), a \sim N\left(9,9.10^{-3} ; 1\right)$ e $\tau \sim$ $G a(0,001 ; 0,001)$.

amostras iniciais, com saltos de 15 entre as amostras para diminuir a autocorrelação entre os parâmetros, perfazendo um total de 9200 amostras geradas. Nestas condições, obteve-se estatísticas próximas das obtidas quando utiliza-se três cadeias para gerar as amostras, mas não apresentou melhor convergência do algoritmo.

Prioris totalmente informativas Normal para $s$ e Gama para $\tau$, e Uniforme para $a$ $(s \sim N(13,9 ; 1), a \sim U(0 ; 1)$ e $\tau \sim G a(1 ; 1))$

Foram realizadas 100000 iterações para gerar as amostras dos parâmetros partindo-se de três cadeias distintas, das quais foram descartadas as 9999 amostras iniciais com saltos de 10 para diminuir a autocorrelação entre os parâmetros, perfazendo um total de 27000 amostras geradas dos parâmetros $s, a$ e $\tau$ utilizando-se o algoritmo "Slice-sampling".

O algoritmo "Slice-sampling" se adaptou ao conjunto de dados e às densidades $a$ priori adotadas para os parâmetros. Na Figura 7.62 verificou-se uniformidade nos traços a posteriori dos parâmetros $s$ e $\tau$, e alguns pontos discrepantes nos traços de $a$. A convergência do algoritmo para estes parâmetros é confirmada na Figura 7.63. Na Figura 7.64 apresentam-se as densidades a posteriori de $s, a$ e $\tau$. 

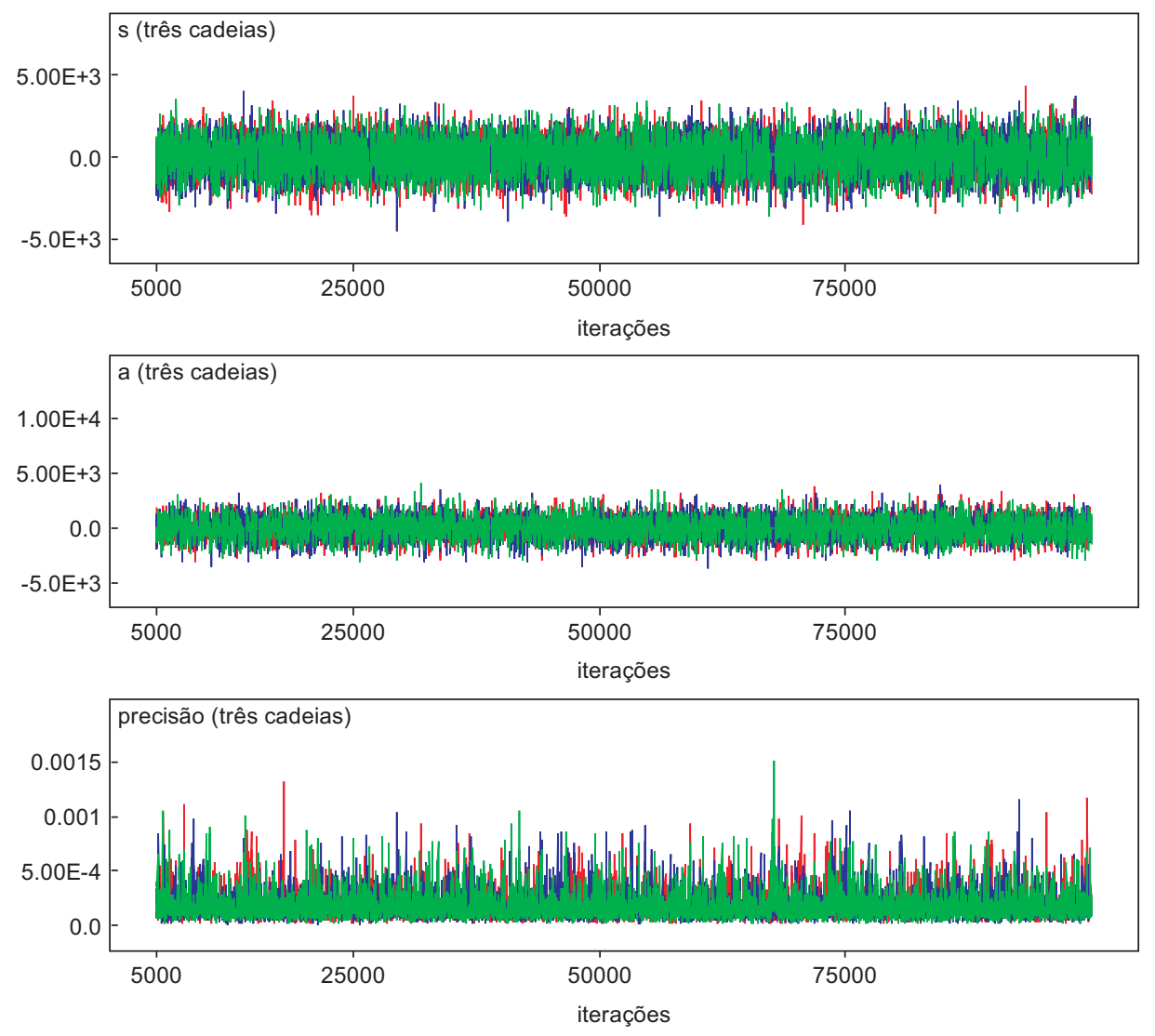

Figura 7.59: Traços a posteriori das três cadeias geradas de $s, a$ e $\tau$ considerando a população de leiteiro e as prioris: $s \sim N\left(13,9 ; 1.10^{6}\right), a \sim N\left(9,9.10^{-3} ; 1.10^{6}\right)$ e $\tau \sim G a(0,1 ; 0,1)$. Nota-se uniformidade nos traços a posteriori de $s$ e $a$, mas alguns pontos discrepantes nos traços de $\tau$.
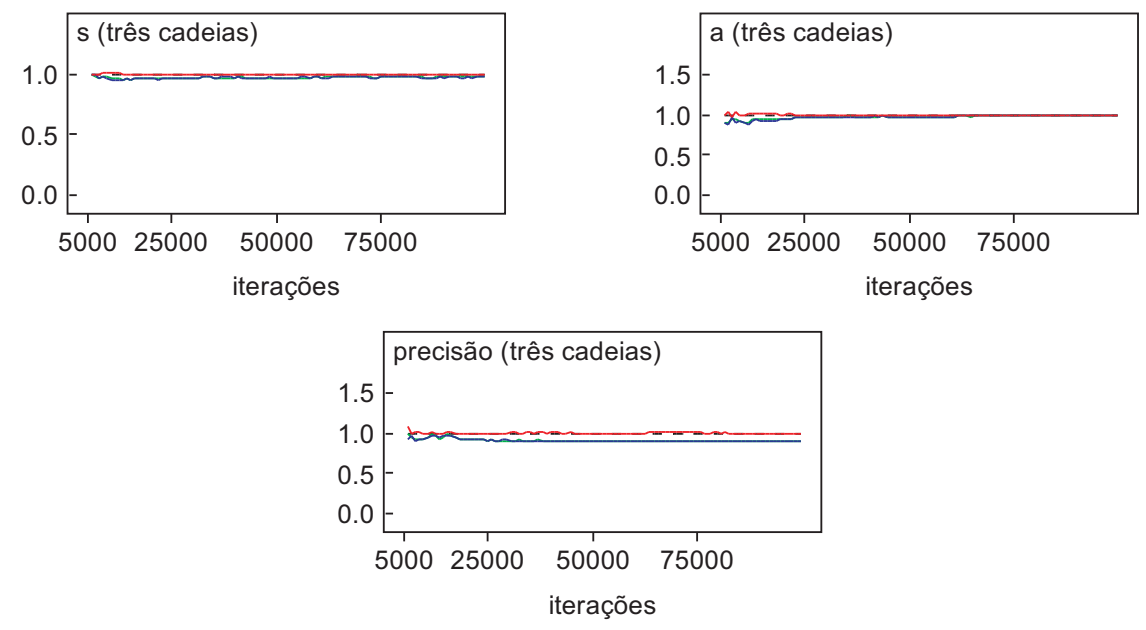

Figura 7.60: Teste gráfico de Gelman e Rubin: verifica-se que houve convergência do algoritmo de Metropolis-Hastings na geração de amostras das três cadeias para os parâmetros $s$ e $a$ considerando a população de leiteiro e as prioris: $s \sim N\left(13,9 ; 1.10^{6}\right), a \sim N\left(9,9.10^{-3} ; 1.10^{6}\right)$ e $\tau \sim G a(0,1 ; 0,1)$. 

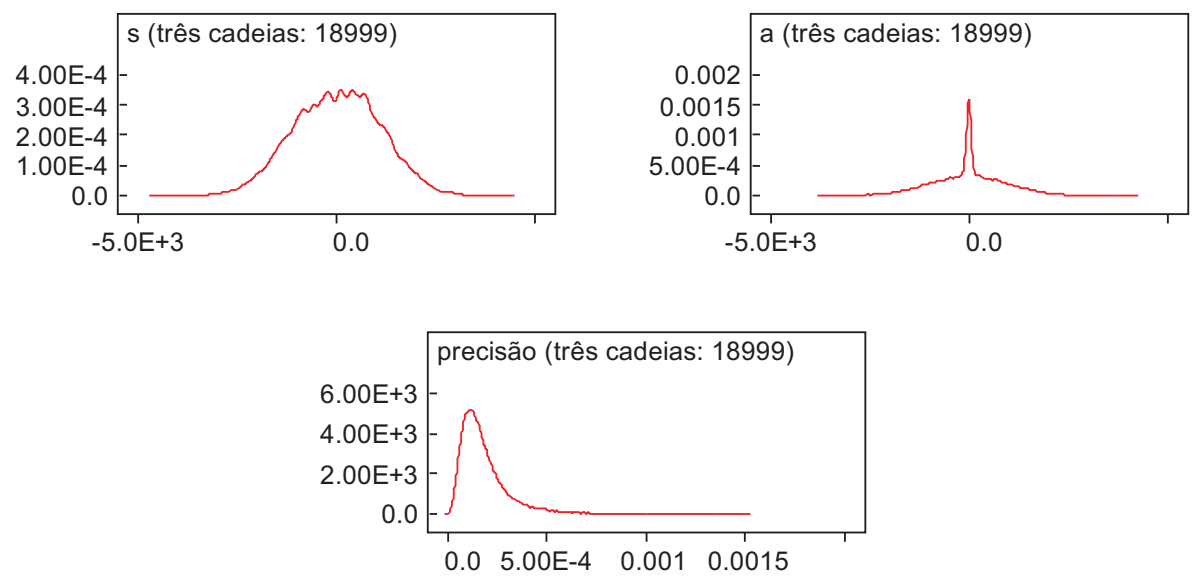

Figura 7.61: Densidades a posteriori de $s, a$ e $\tau$ obtidas a partir das 18999 amostras geradas pelas três cadeias considerando a população de leiteiro e as prioris: $s \sim N\left(13,9 ; 1.10^{6}\right), a \sim N\left(9,9.10^{-3} ; 1.10^{6}\right)$ e $\tau \sim G a(0,1 ; 0,1)$
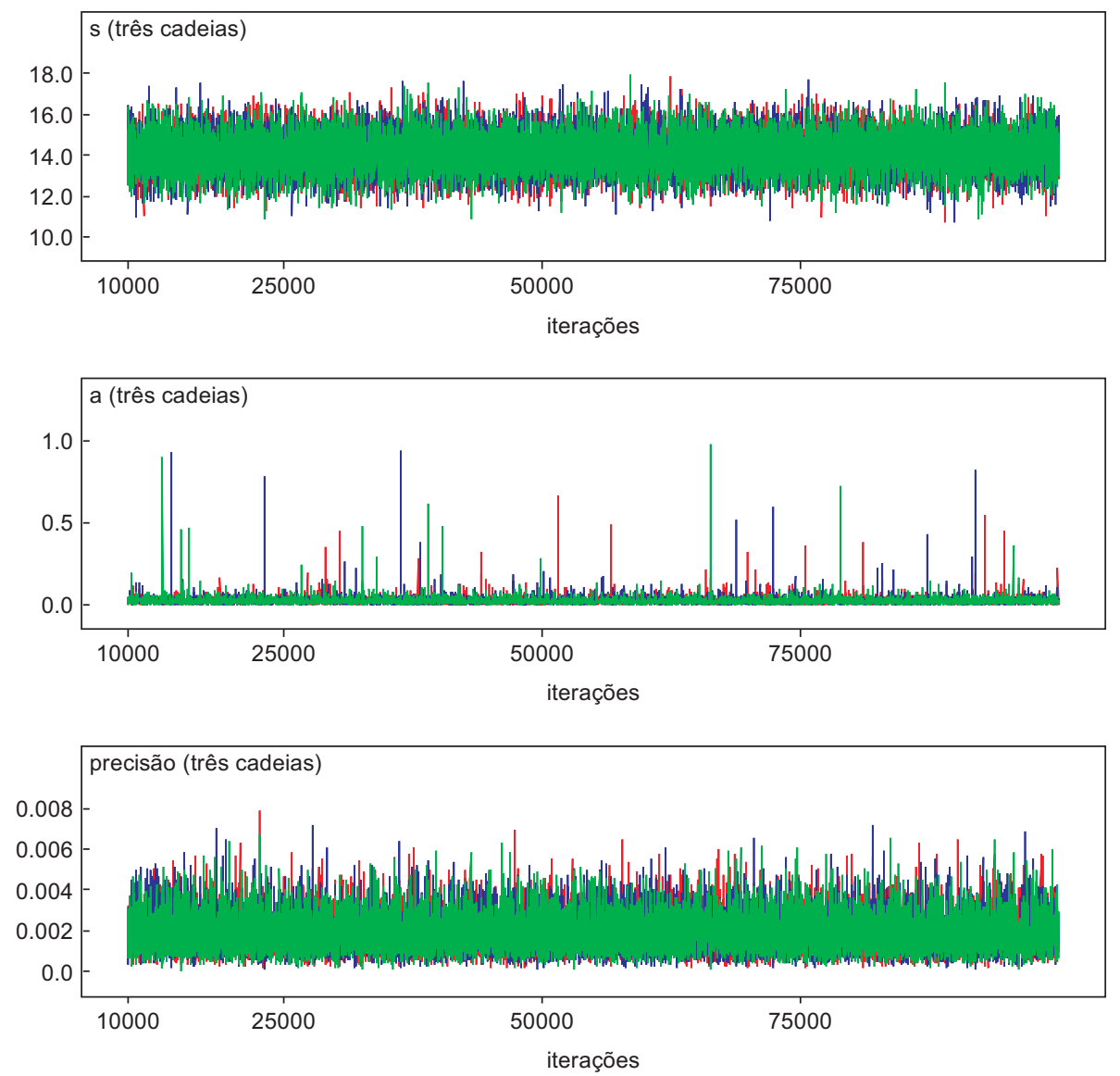

Figura 7.62: Traços a posteriori das três cadeias geradas de $s, a$ e $\tau$ considerando a população de leiteiro e as prioris: $s \sim N(13,9 ; 1), a \sim U(0 ; 1)$ e $\tau \sim G a(1 ; 1)$. Nota-se uniformidade nos traços a posteriori de $s$ e $\tau$, mas alguns pontos discrepantes nos traços de $a$. 

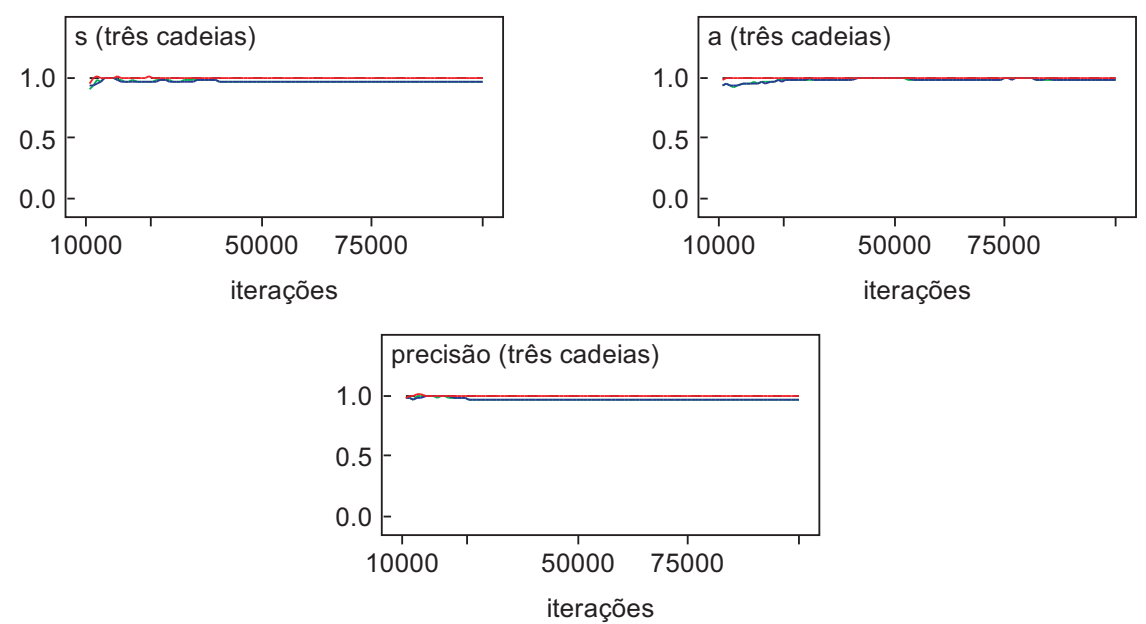

Figura 7.63: Teste gráfico de Gelman e Rubin: verifica-se que houve convergência do algoritmo "Slicesampling" na geração de amostras das três cadeias para os parâmetros $s, a$ e $\tau$ considerando a população de leiteiro e as prioris: $s \sim N(13,9 ; 1), a \sim U(0 ; 1)$ e $\tau \sim G a(1 ; 1)$.
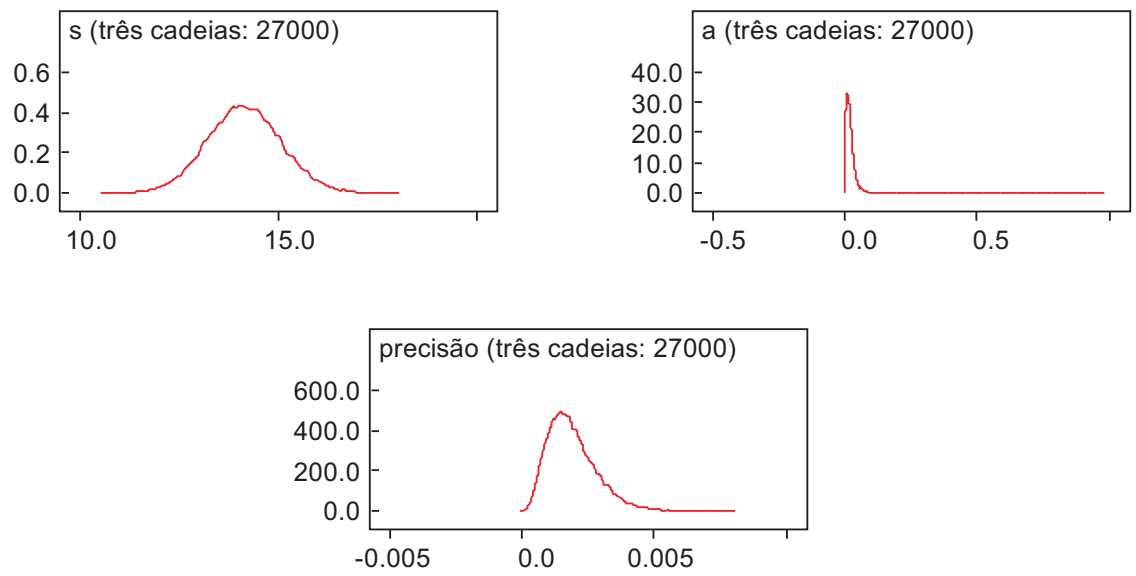

Figura 7.64: Densidades a posteriori de $s, a$ e $\tau$ obtidas a partir das 27000 amostras geradas pelas três cadeias considerando a população de leiteiro e as prioris: $s \sim N(13,9 ; 1), a \sim U(0 ; 1)$ e $\tau \sim G a(1 ; 1)$. 
Prioris totalmente informativa Normal para $s$, não informativa Gama para $\tau$ e Uniforme para $a \quad(s \sim N(13,9 ; 1), a \sim U(0 ; 1)$ e $\tau \sim G a(0,001 ; 0,001))$

Foram realizadas 100000 iterações para gerar as amostras dos parâmetros partindo-se de duas cadeias distintas, das quais foram descartadas as 9999 amostras iniciais com saltos de 10 para diminuir a autocorrelação entre os parâmetros, perfazendo um total de 18000 amostras geradas dos parâmetros $s, a$ e $\tau$ utilizando-se o algoritmo "Slice-sampling".

O algoritmo "Slice-sampling" se adaptou ao conjunto de dados e às densidades $a$ priori adotadas para os parâmetros. Na Figura 7.65 verificou-se uniformidade nos traços a posteriori dos parâmetros $s$ e $a$, e pontos discrepantes nos traços de $\tau$; o que indica convergência do algoritmo, o que é confirmado na Figura 7.66 para $s$. Para $a$ e $\tau$ os fatores de Gelman e Rubin (1,001 e 1,0, respectivamente) garantem um nível aceitável de convergência do algoritmo. Na Figura 7.67 apresentam-se as densidades a posteriori de $s, a$ e $\tau$.
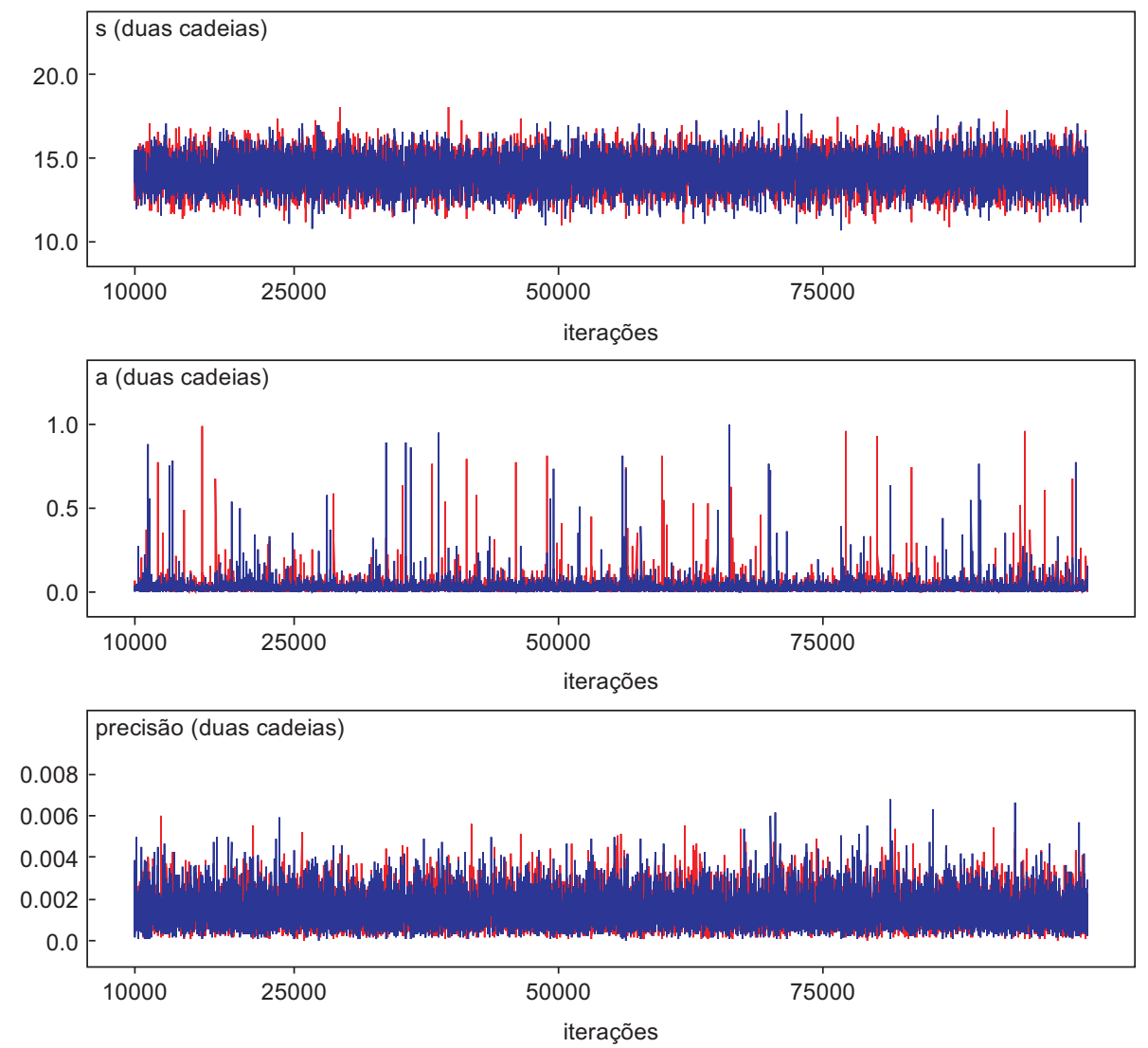

Figura 7.65: Traços a posteriori das duas cadeias geradas de $s, a$ e $\tau$ considerando a população de leiteiro e as prioris: $s \sim N(13,9 ; 1), a \sim U(0 ; 1)$ e $\tau \sim G a(0,001 ; 0,001)$. Nota-se uniformidade nos traços $a$ posteriori de $s$ e $\tau$, mas pontos discrepantes nos traços de $a$. 

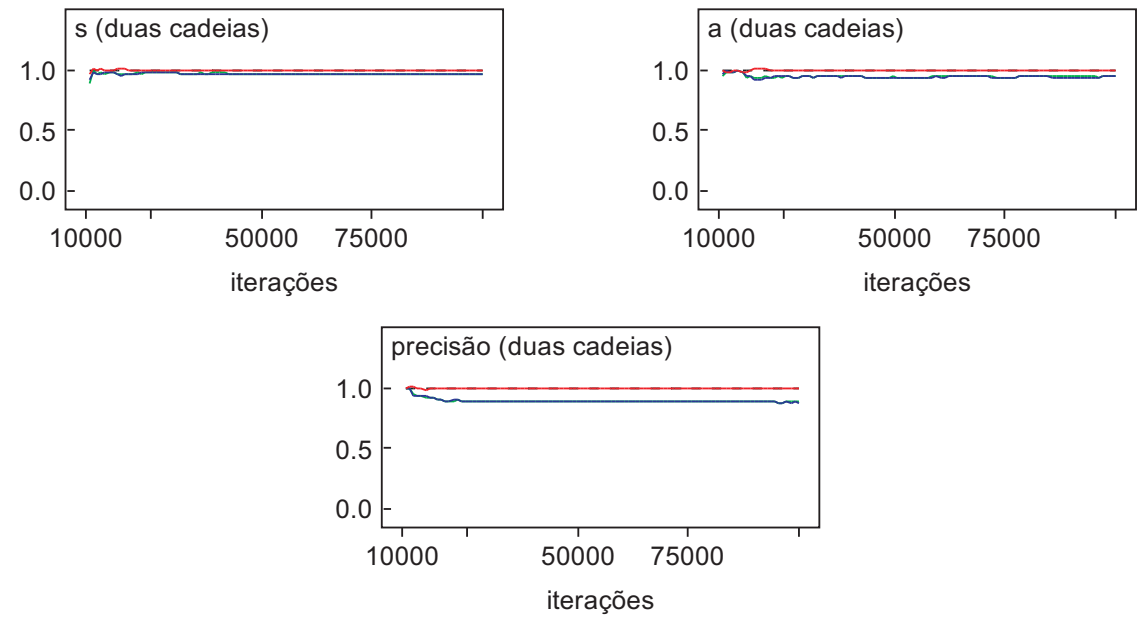

Figura 7.66: Teste gráfico de Gelman e Rubin: verifica-se que houve convergência do algoritmo "Slicesampling" na geração de amostras das duas cadeias para o parâmetro $s$ considerando a população de leiteiro e as prioris: $s \sim N(13,9 ; 1), a \sim U(0 ; 1)$ e $\tau \sim G a(0,001 ; 0,001)$.
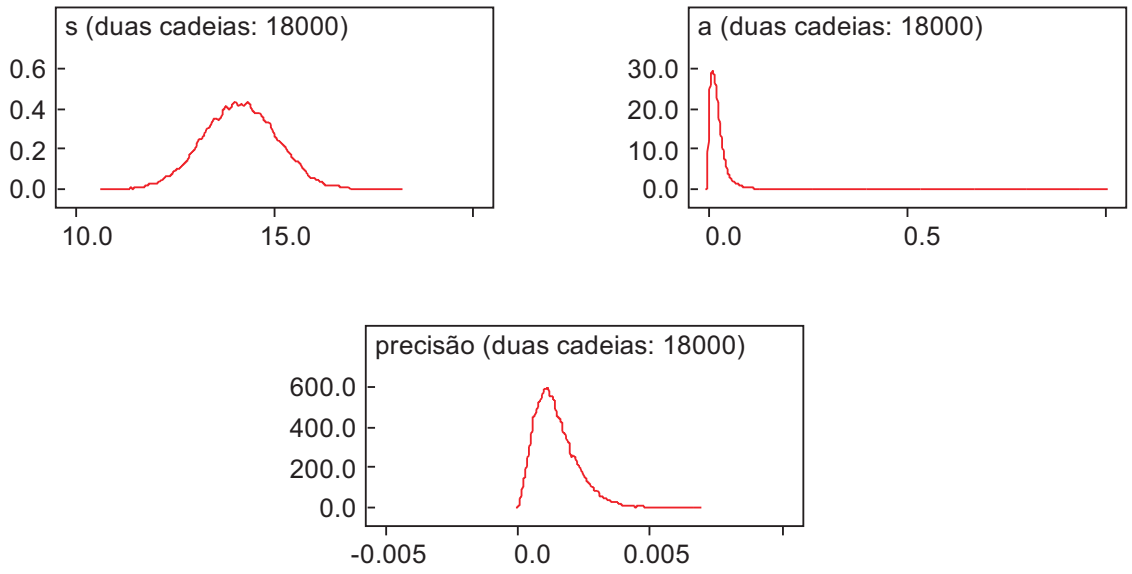

Figura 7.67: Densidades a posteriori de $s$, a e $\tau$ obtidas a partir das 18000 amostras geradas pelas duas cadeias considerando a população de leiteiro e as prioris: $s \sim N(13,9 ; 1), a \sim U(0 ; 1)$ e $\tau \sim$ $G a(0,001 ; 0,001)$. 
Prioris moderadamente informativas Normal para $s$ e Gama para $\tau$, e Uniforme para $a \quad\left(s \sim N\left(13,9 ; 1.10^{6}\right), a \sim U(0 ; 1)\right.$ e $\left.\tau \sim G a(0,1 ; 0,1)\right)$

Foram realizadas 100000 iterações para gerar as amostras dos parâmetros partindo-se de três cadeias distintas, das quais foram descartadas as 10000 amostras iniciais com saltos de 25 para diminuir a autocorrelação entre os parâmetros, perfazendo um total de 10800 amostras geradas dos parâmetros $s, a$ e $\tau$ utilizando-se o algoritmo "Slice-sampling".

O algoritmo "Slice-sampling" se adaptou ao conjunto de dados e às densidades $a$ priori adotadas para os parâmetros. Na Figura 7.68 verificou-se uniformidade nos traços a posteriori dos parâmetros $s$ e $a$, e poucos pontos discrepantes nos traços de $\tau$. A convergência do algoritmo para as três cadeias geradas é confirmada na Figura 7.69 para o parâmetro $s$ e $a$. Para $\tau$ o fator de Gelman e Rubin (1,002) garante um nível aceitável de convergência do algoritmo. Na Figura 7.70 apresentam-se as densidades $a$ posteriori de $s, a$ e $\tau$.
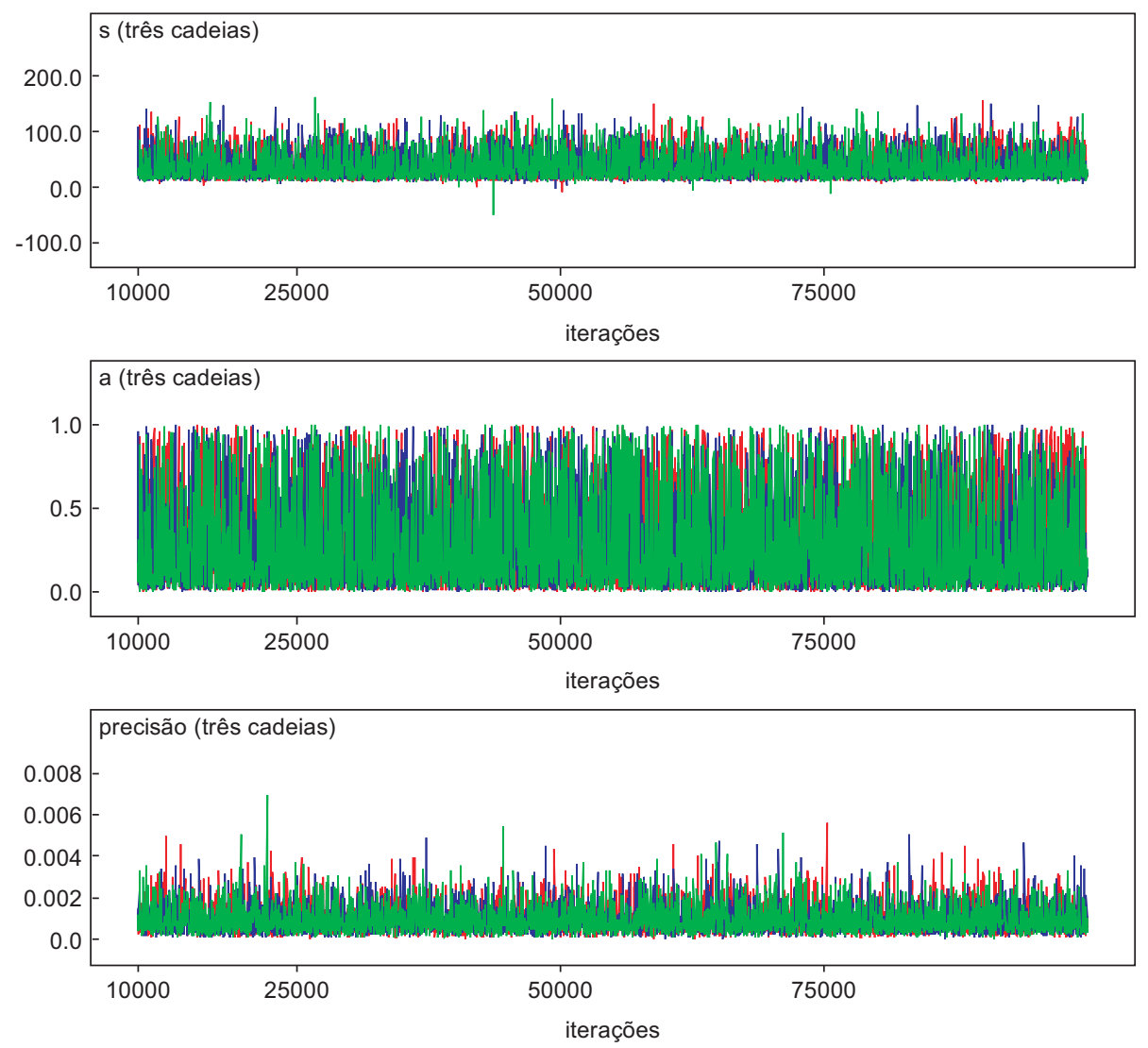

Figura 7.68: Traços a posteriori das três cadeias geradas de $s, a$ e $\tau$ considerando a população de leiteiro e as prioris: $s \sim N\left(13,9 ; 1.10^{6}\right), a \sim U(0 ; 1)$ e $\tau \sim G a(0,1 ; 0,1)$. Nota-se uniformidade nos traços $a$ posteriori de $s$ e $a$, e alguns pontos discrepantes nos traços de $\tau$. 

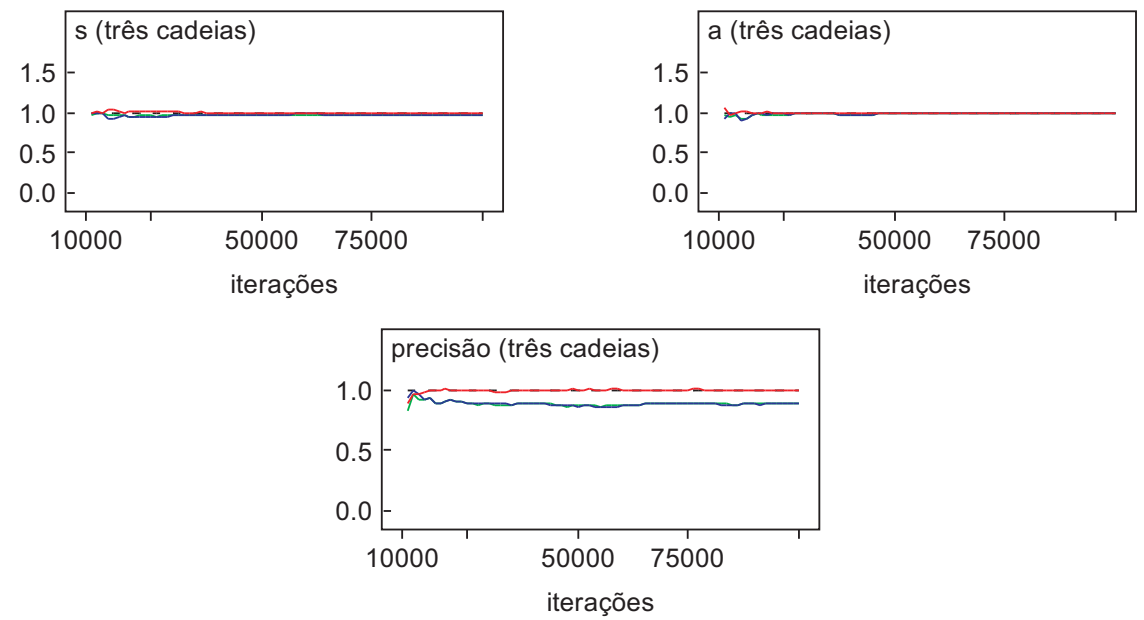

Figura 7.69: Teste gráfico de Gelman e Rubin: verifica-se que houve convergência do algoritmo "Slicesampling" na geração de amostras das três cadeias para os parâmetros $s$ e $a$ considerando a população de leiteiro e as prioris: $s \sim N\left(13,9 ; 1.10^{6}\right), a \sim U(0 ; 1)$ e $\tau \sim G a(0,1 ; 0,1)$.
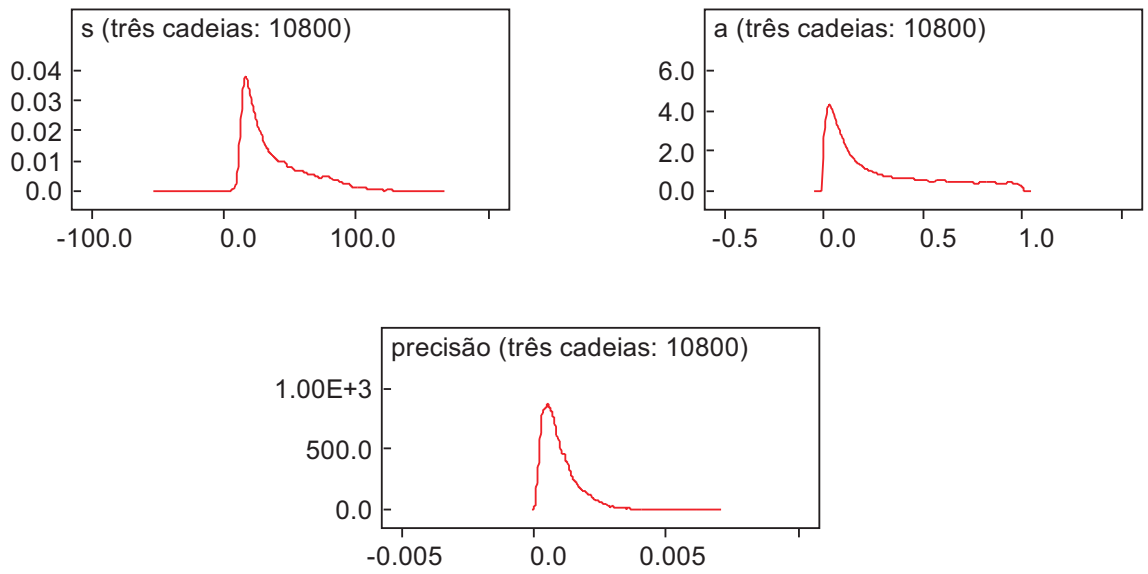

Figura 7.70: Densidades a posteriori de $s$, a e $\tau$ obtidas a partir das 10800 amostras geradas pelas três cadeias considerando a população de leiteiro e as prioris: $s \sim N\left(13,9 ; 1.10^{6}\right), a \sim U(0 ; 1)$ e $\tau \sim$ $G a(0,1 ; 0,1)$. 


\subsection{Simulação da dinâmica de produção de sementes usando inferência bayesiana}

Segundo Aguirre (2000), comparar a simulação do modelo obtido com dados medidos é provavelmente a forma mais usual de se validar um modelo. Nesse caso, deseja-se saber se o modelo reproduz ao longo do tempo os dados observados. Desta forma, a partir das estimativas bayesianas encontradas para os parâmetros do modelo de produção de sementes, é possível simular o comportamento dinâmico das espécies daninhas: Digitaria ciliaris, Panicum maximum e Euphorbia heterophylla. Além disso, é possível simular, antes da aplicação em campo, qual seria o comportamento de determinada população caso alguma prática de controle fosse adotada.

Como em Gonzalez-Andujar (1996), apresenta-se a dinâmica simulada da produção de sementes das espécies daninhas estudadas em duas situações: 1) considerando os fatores extrínsecos constantes, e 2) quando uma prática de controle (rotação, herbicida, etc.) é introduzida ao modelo.

O comportamento dinâmico das espécies daninhas estudadas considerando os fatores extrínsecos constantes foi simulado via o modelo de produção de sementes (3.7) com taxa de crescimento (3.24) e $b=1$, isto é:

$$
X_{t+1}=\frac{\hat{s} g X_{t}}{1+\hat{a} g X_{t}}
$$

em que $X_{0}=1, g=0,1$, e $\hat{s}$ e $\hat{a}$ são as estimativas bayesianas obtidas partindo-se das diferentes informações a priori repetidas abaixo para fácil referência:

1. Prioris totalmente informativas Normais para $s$ e $a$ e Gama para $\tau$, ou seja: $s \sim N(\hat{s} ; 1), a \sim N(\hat{a} ; 1)$ e $\tau \sim G a(1 ; 1) ;$

2. Prioris totalmente informativas Normais para $s$ e $a$ e não informativa Gama para $\tau$, ou seja: $s \sim N(\hat{s} ; 1), a \sim N(\hat{a} ; 1)$ e $\tau \sim G a(0,001 ; 0,001)$

3. Prioris moderadamente informativas Normais para $s$ e $a$ e Gama para $\tau$, ou seja: $s \sim N\left(\hat{s} ; 1.10^{6}\right), a \sim N\left(\hat{a} ; 1.10^{6}\right)$ e $\tau \sim G a(0,1 ; 0,1) ;$

4. Prioris totalmente informativas Normal para $s$ e Gama para $\tau$ e Uniforme para $a$, ou seja: $s \sim N(\hat{s} ; 1), a \sim U(0 ; 1)$ e $\tau \sim G a(1 ; 1)$; 
5. Prioris totalmente informativa Normal para $s$, não informativa Gama para $\tau$ e Uniforme para $a$, ou seja: $s \sim N(\hat{s} ; 1), a \sim U(0 ; 1)$ e $\tau \sim G a(0,001 ; 0,001)$;

6. Prioris moderadamente informativas Normal para $s$ e Gama para $\tau$, e Uniforme para $a$, ou seja: $s \sim N\left(\hat{s} ; 1.10^{6}\right), a \sim U(0 ; 1)$ e $\tau \sim G a(0,1 ; 0,1)$.

Também é possível simular qual seria o comportamento dinâmico de uma população com a introdução de uma medida de controle $h$. Neste caso adota-se o modelo

$$
X_{t+1}=\frac{(1-h) \hat{s} g X_{t}}{1+\hat{a} g X_{t}}
$$

onde $h$ representa a eficácia de alguma prática de controle (rotação, herbicida, etc.) e $X_{0}=1, g=0,1, \hat{s}$ e $\hat{a}$ como já definidos. Para ilustar o comportamento populacional via modelo (7.5), optou-se simular o comportamento dinâmico da espécie Panicum maximum (capim guiné) partindo-se das prioris: $s \sim N(994,6 ; 1), a \sim U(0 ; 1)$ e $\tau \sim$ $G a(1 ; 1)$, em que a produção de sementes chega a 16000 sementes por $m^{2}$ partindo de $g=0,1$ e $X_{0}=1$.

\section{Digitaria ciliaris (capim colchão)}

A dinâmica simulada para a população de capim colchão considerando as estimativas bayesianas partindo-se das prioris 1., 2., 4. e 5 . apresentaram-se muito parecidas devido a proximidade dos valores obtidos na inferência bayesiana. Assim, a Figura 7.71 apresenta a dinâmica simulada da espécie considerando um valor aproximado de $\hat{a}$ para as quatro prioris acima mencionadas, em que a produção de sementes converge para o equilíbrio após $t=4$ com mais de 3000 sementes por $m^{2}$. Nas Figuras 7.72 e 7.73, apresentam-se a dinâmica simulada partindo-se das prioris 3. e 6., em que a produção de sementes converge para o equilíbrio após $t=3$ com 1415 e 1608 sementes por $m^{2}$, respectivamente.

\section{Panicum maximum (capim guiné)}

A dinâmica simulada para a população de capim guiné considerando as estimativas bayesianas partindo-se das prioris 1. e 4., bem com das prioris 2. e 5., apresentaramse muito parecidas devido a proximidade dos valores obtidos na inferência bayesiana. Assim, as Figuras 7.74 e 7.76 apresentam a dinâmica simulada da espécie considerando 
um valor aproximado de $\hat{a}$ para as prioris 1. e 4. e para as prioris 2. e 5., nas quais nota-se convergência para o equílibrio na produção de sementes após $t=3$ com 16026 e 15286 sementes por $m^{2}$, respectivamente. Partindo-se da priori 3., a população de capim guiné converge para uma densidade negativa de sementes, -3762,7 sementes por $m^{2}$, o que é absurdo e indica que a informação a priori não é conveniente. Na Figura 7.77 apresenta-se a dinâmica simulada partindo-se da priori 6., em que há convergência para o equilíbrio após $t=3$ chegando a atingir uma produção de 10896 sementes por $m^{2}$.

\section{Euphorbia heterophylla (leiteiro)}

A dinâmica simulada para a população de leiteiro considerando as estimativas bayesianas partindo-se das prioris 1., 4., 2., 5. e 6. são apresentadas nas Figuras 7.78, 7.79, $7.80,7.81$ e 7.82 , respectivamente. Nota-se sensibilidade a pequenas variações de $\hat{s}$ e $\hat{a}$ e convergência para uma densidade estável entre 130,0988 e 676,0270 sementes por $\mathrm{m}^{2}$. Exceto para a priori 3., há convergência da produção de sementes para uma densidade negativa: -9,2711 sementes por $m^{2}$, o que é absurdo.

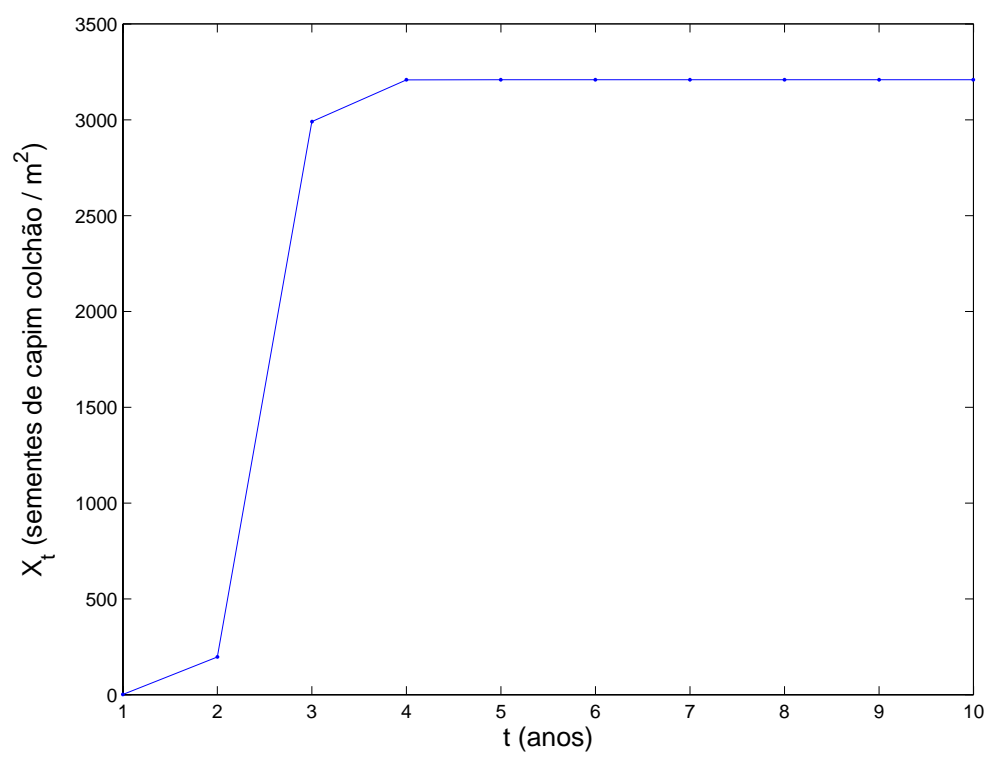

Figura 7.71: Dinâmica simulada do modelo 7.4 para a população de capim colchão. Tem-se $\hat{s}=209,6$; $\hat{a}=0,065 ; X_{0}=1 ; g=0,1$ e densidade limiar de 4000 plântulas $/ m^{2}$ quando a taxa de produtividade de sementes é nula. 


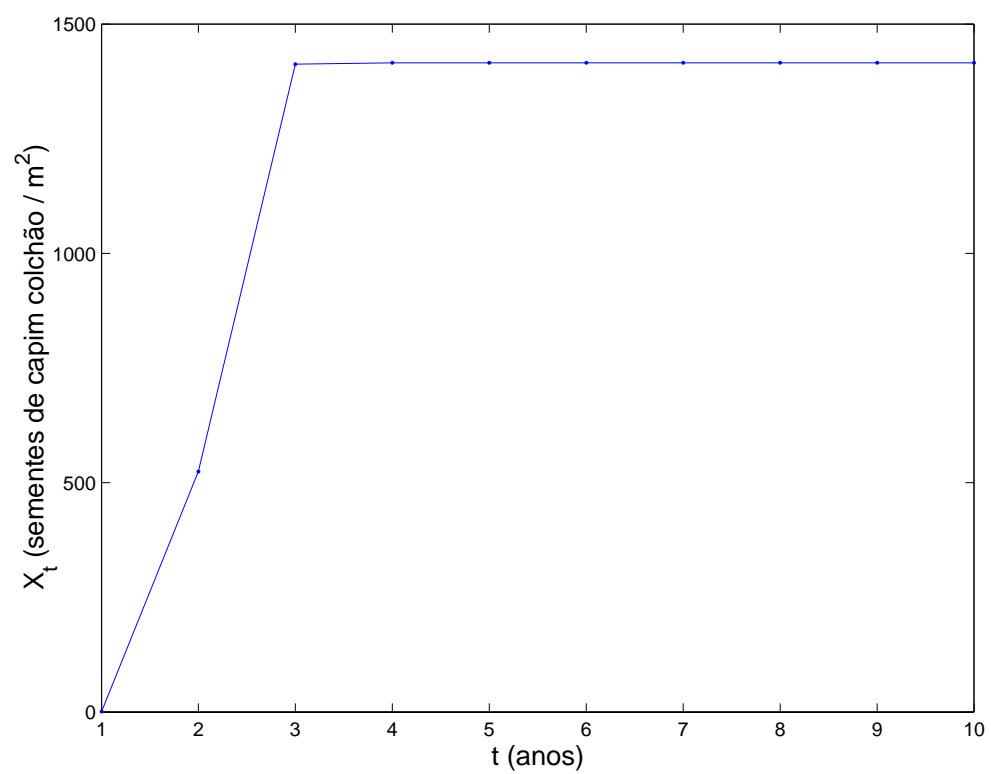

Figura 7.72: Dinâmica simulada do modelo 7.4 para a população de capim colchão. Tem-se $\hat{s}=832,6$; $\hat{a}=0,5875 ; X_{0}=1 ; g=0,1$ e densidade limiar de 4000 plântulas $/ m^{2}$ quando a taxa de produtividade de sementes é nula.

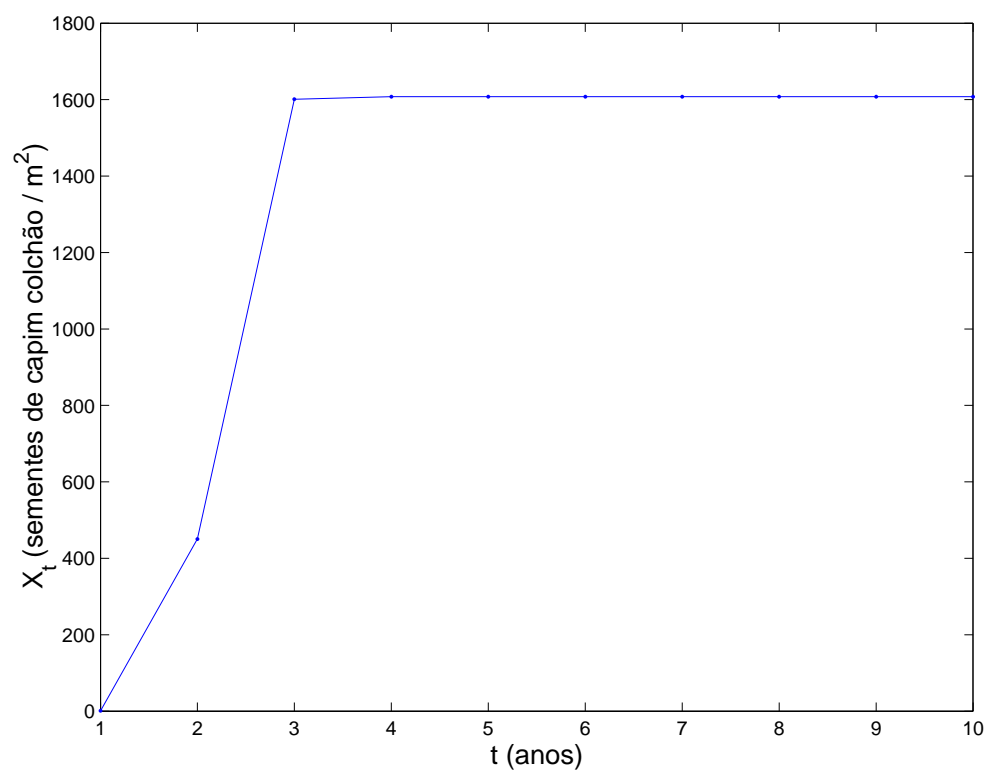

Figura 7.73: Dinâmica simulada do modelo 7.4 para a população de capim colchão. Tem-se $\hat{s}=625,4$; $\hat{a}=0,3884 ; X_{0}=1 ; g=0,1$ e densidade limiar de 4000 plântulas $/ m^{2}$ quando a taxa de produtividade de sementes é nula. 


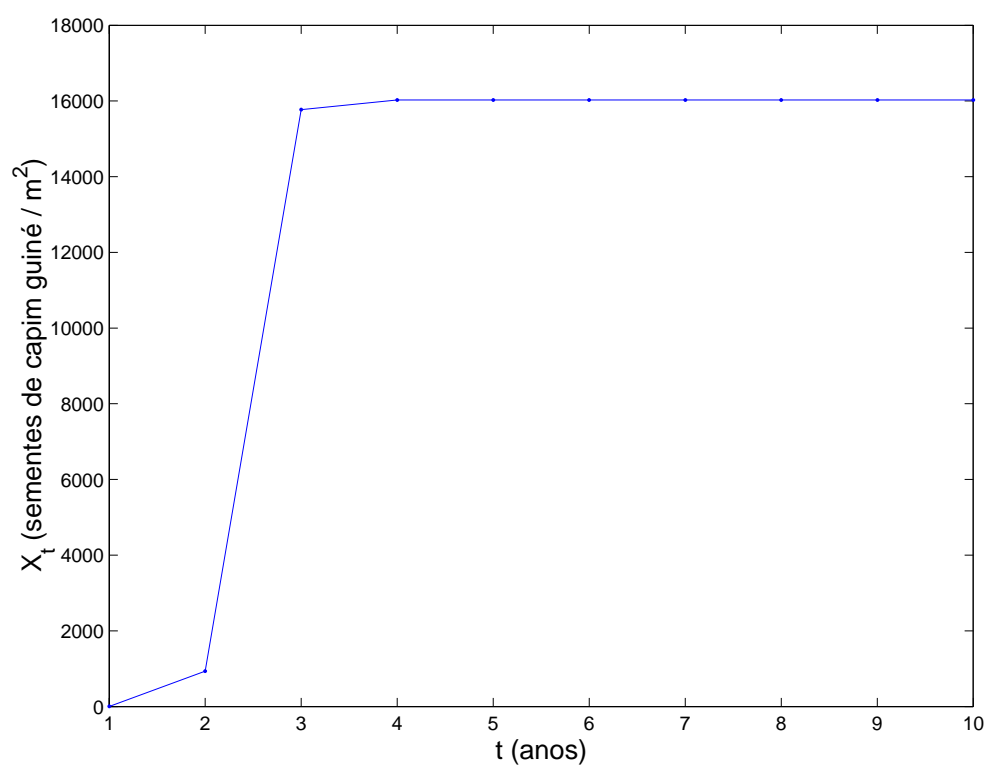

Figura 7.74: Dinâmica simulada do modelo 7.4 para a população de capim guiné. Tem-se $\hat{s}=994,6$; $\hat{a}=0,062 ; X_{0}=1 ; g=0,1$ e densidade limiar de 4000 plântulas $/ m^{2}$ quando a taxa de produtividade de sementes é nula.

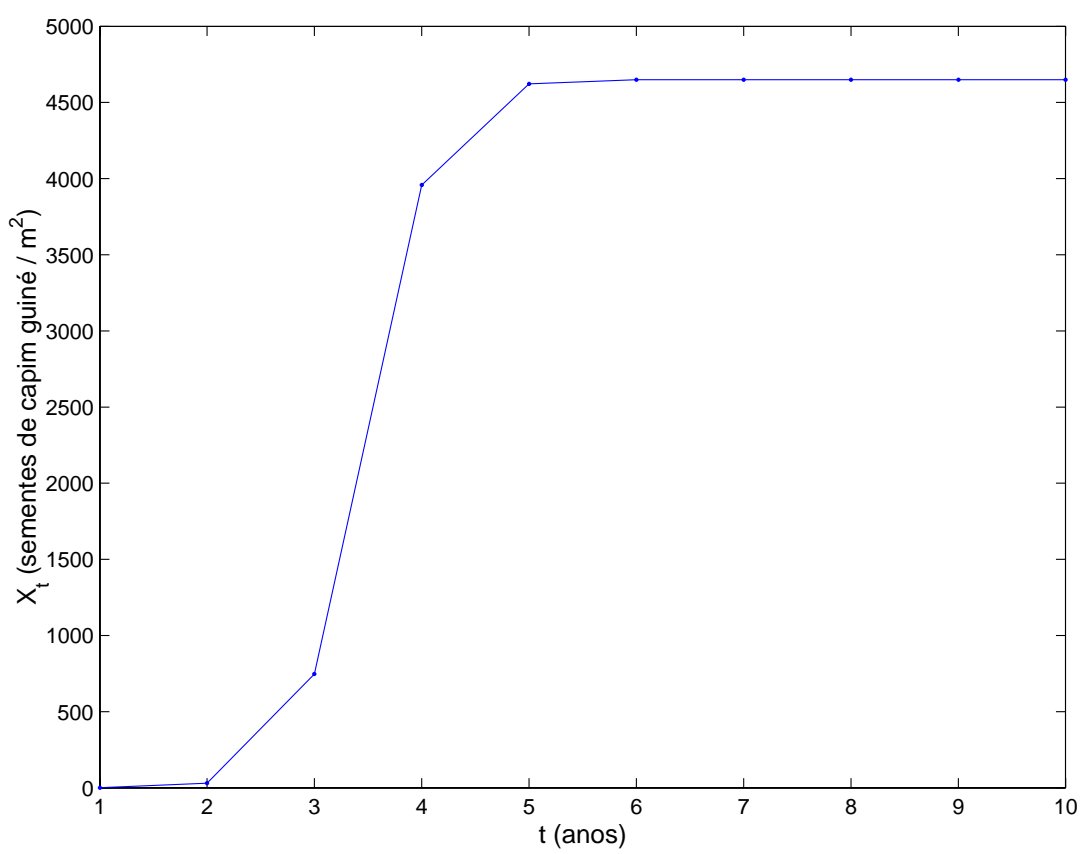

Figura 7.75: Dinâmicas simuladas do modelo 7.5 para a população de capim guiné. Tem-se $\hat{s}=994,6$; $\hat{a}=0,062 ; g=0,1 ; X_{0}=1$; densidade limiar de 4000 plântulas $/ m^{2}$ quando a taxa de produtividade de sementes é nula e $h=0,90$. 


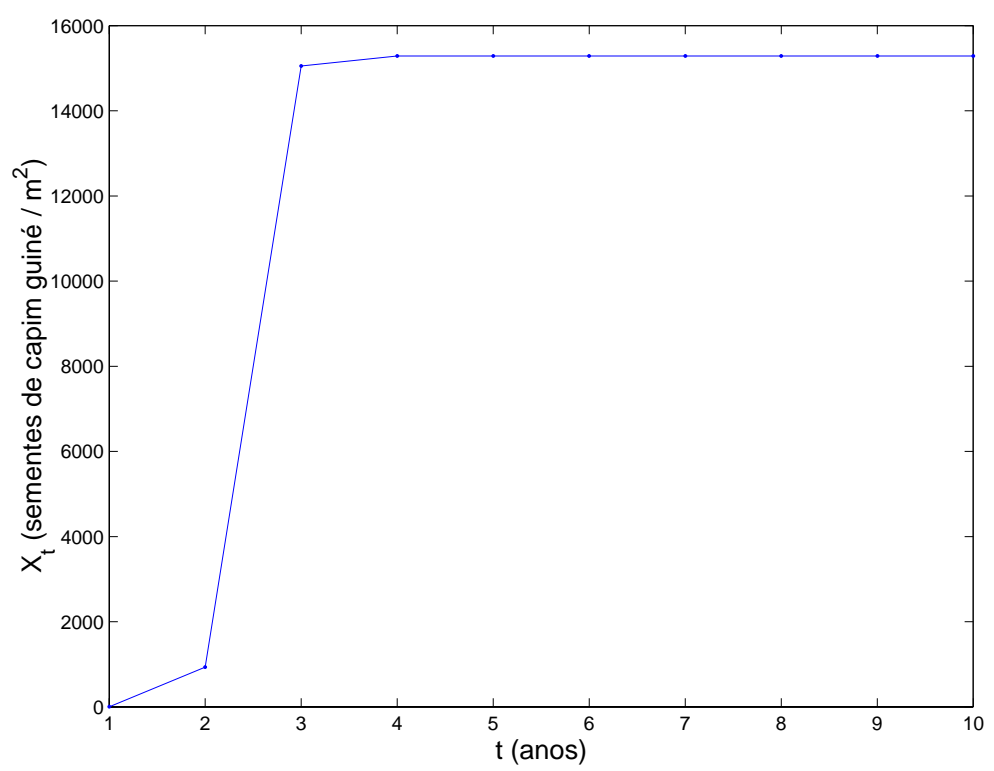

Figura 7.76: Dinâmica simulada do modelo 7.4 para a população de capim guiné. Tem-se $\hat{s}=994,6$; $\hat{a}=0,065 ; X_{0}=1 ; g=0,1$ e densidade limiar de 4000 plântulas $/ m^{2}$ quando a taxa de produtividade de sementes é nula.

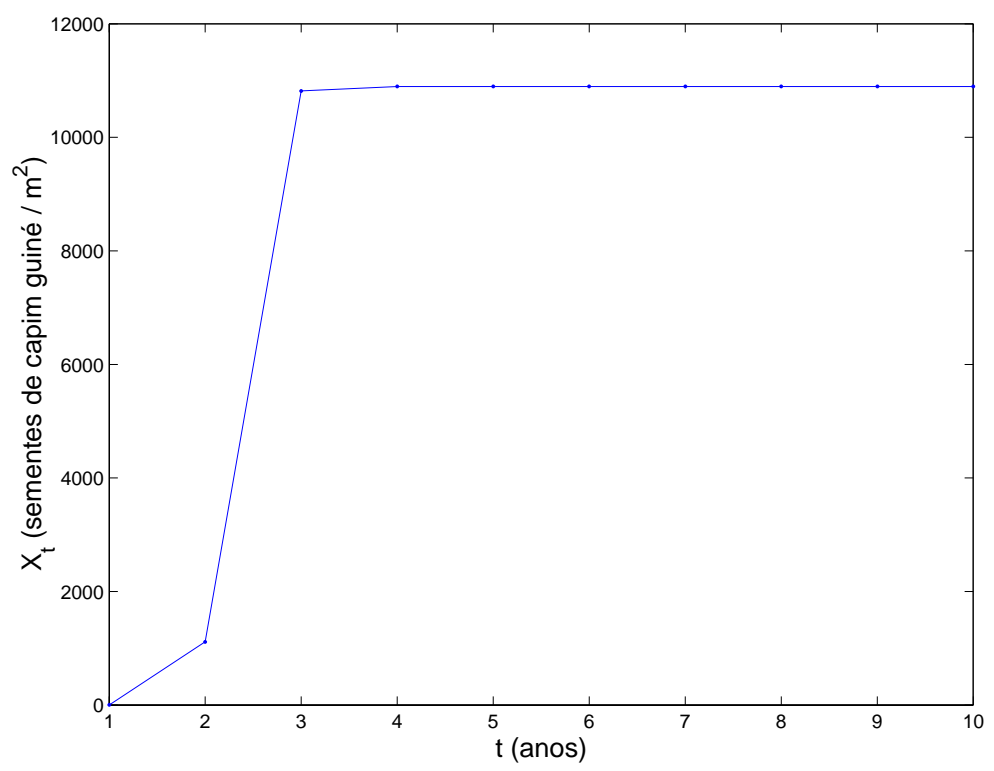

Figura 7.77: Dinâmica simulada do modelo 7.4 para a população de capim guiné. Tem-se $\hat{s}=1242$; $\hat{a}=0,1139 ; X_{0}=1 ; g=0,1$ e densidade limiar de 4000 plântulas $/ m^{2}$ quando a taxa de produtividade de sementes é nula. 


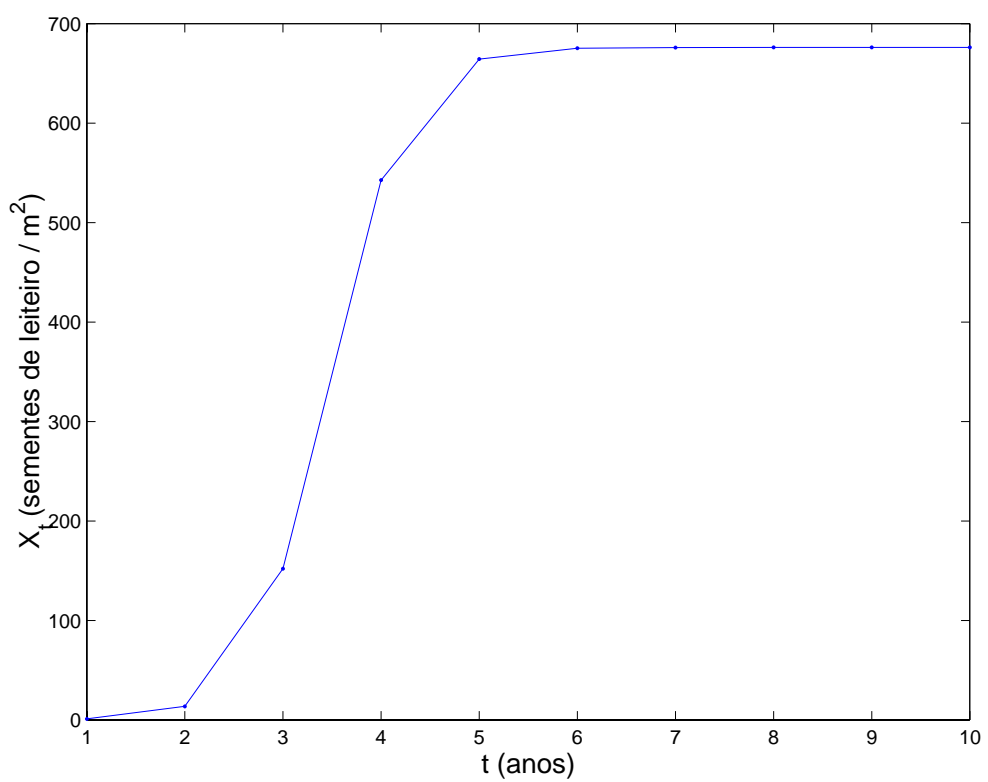

Figura 7.78: Dinâmica simulada do modelo 7.4 para a população de leiteiro. Tem-se $\hat{s}=14 ; \hat{a}=0,01923$; $X_{0}=1 ; g=0,1$ e densidade limiar de 4000 plântulas $/ m^{2}$ quando a taxa de produtividade de sementes é nula.

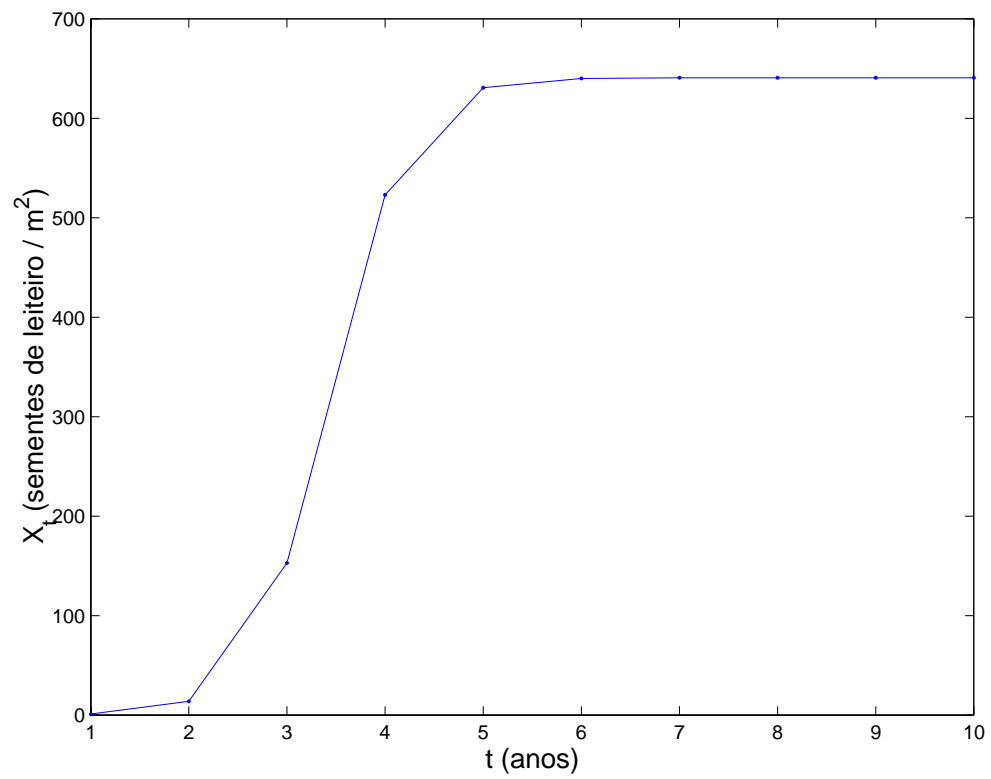

Figura 7.79: Dinâmica simulada do modelo 7.4 para a população de leiteiro. Tem-se $\hat{s}=14,16$; $\hat{a}=$ 0,$02054 ; X_{0}=1 ; g=0,1$ e densidade limiar de 4000 plântulas $/ m^{2}$ quando a taxa de produtividade de sementes é nula. 


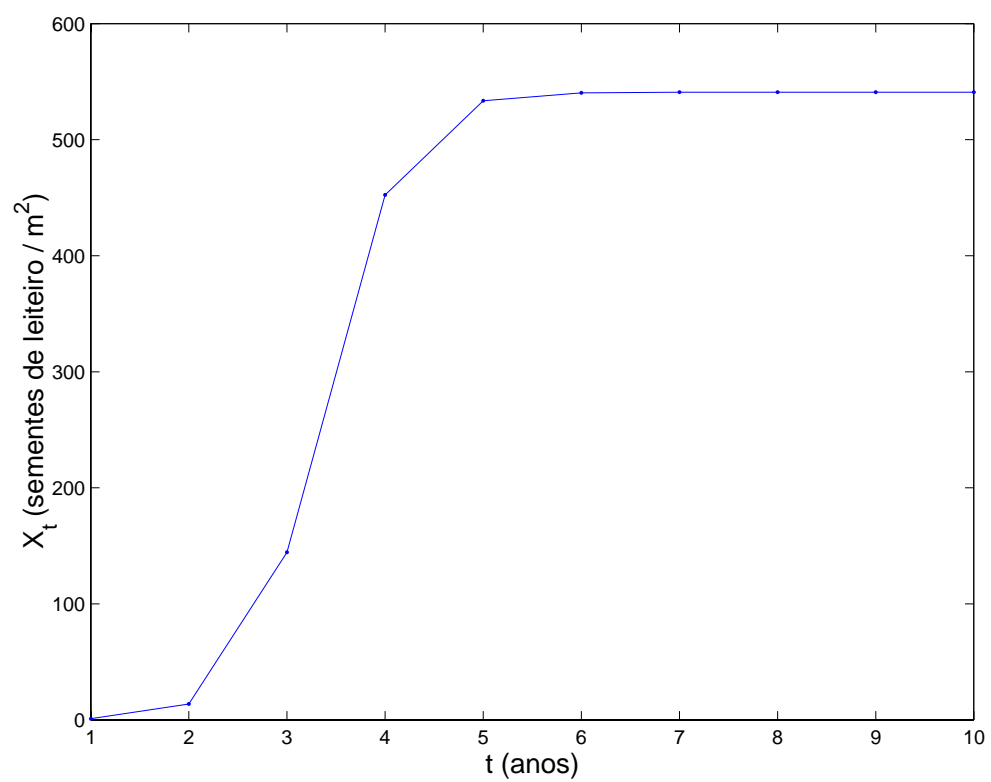

Figura 7.80: Dinâmica simulada do modelo 7.4 para a população de leiteiro. Tem-se $\hat{s}=14,02 ; \hat{a}=$ 0,$02407 ; X_{0}=1 ; g=0,1$ e densidade limiar de 4000 plântulas $/ m^{2}$ quando a taxa de produtividade de sementes é nula.

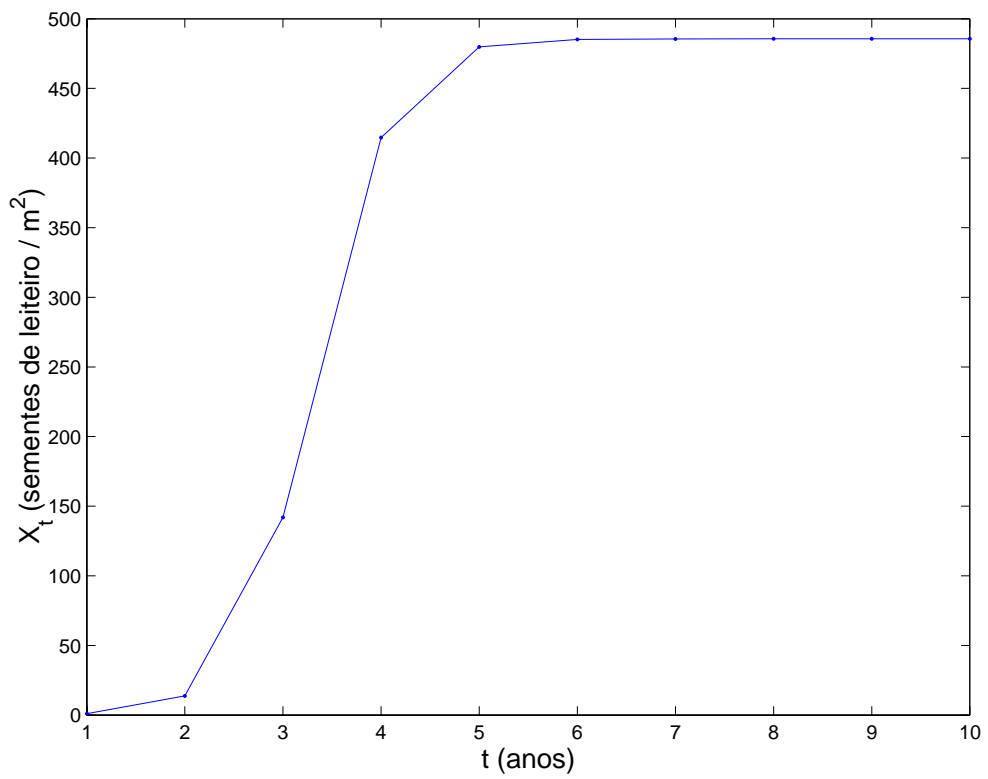

Figura 7.81: Dinâmica simulada do modelo 7.4 para a população de leiteiro. Tem-se $\hat{s}=14,15$; $\hat{a}=$ 0,$02708 ; X_{0}=1 ; g=0,1$ e densidade limiar de 4000 plântulas $/ m^{2}$ quando a taxa de produtividade de sementes é nula. 


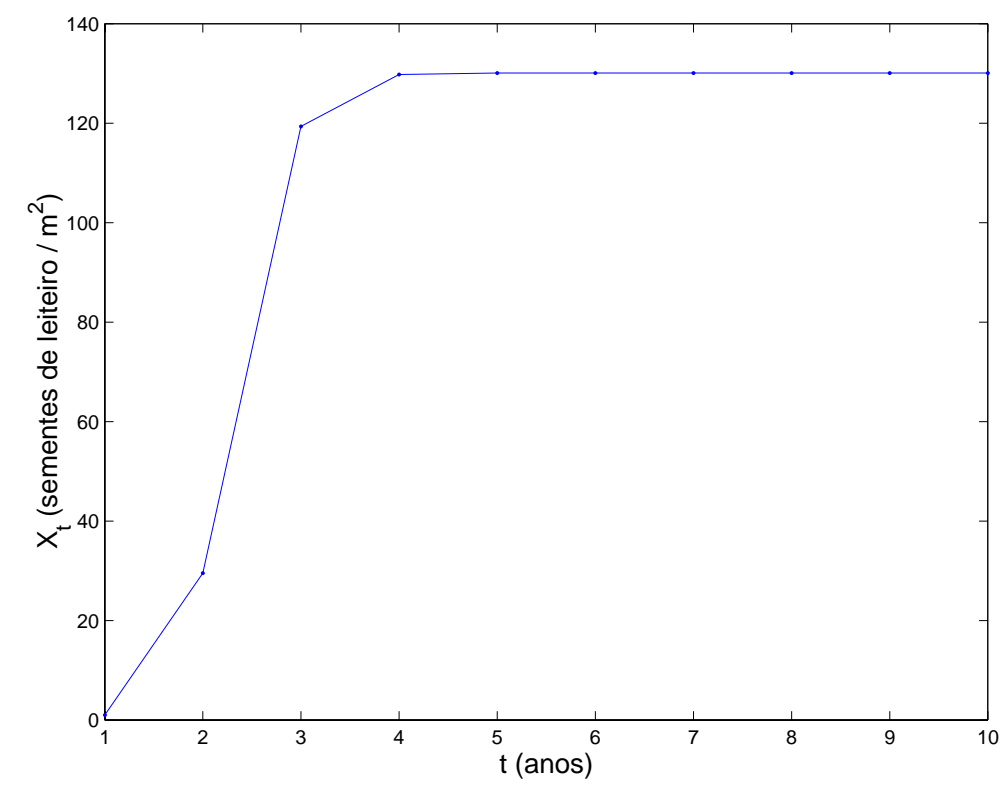

Figura 7.82: Dinâmica simulada do modelo 7.4 para a população de leiteiro. Tem-se $\hat{s}=37,87 ; \hat{a}=0,2834$; $X_{0}=1 ; g=0,1$ e densidade limiar de 4000 plântulas $/ m^{2}$ quando a taxa de produtividade de sementes é nula.

\subsection{Curvas das densidades de gerações sucessivas da pro- dução de sementes}

O comportamento dinâmico simulado para valores de $\hat{a}$ negativo $(\hat{a}<0)$ não faz sentido biológico por não haver produção negativa de sementes. Logo, a partir da análise da dinâmica simulada e do desvio padrão das estimativas bayesianas é possível inferir que a priori Uniforme para o parâmetro $a$ conduz a resultados mais adequados que a priori Normal. Desta forma, as respostas do modelo (6.1) com $b=1$ para as populações de Digitaria ciliaris (capim colchão), Panicum maximum (capim guiné) e Euphorbia heterophylla (leiteiro) partindo-se das prioris 4., 5. e 6. comparadas à curva de regressão não linear da inferência clássica são apresentadas nas Figuras 7.83, 7.84 e 7.85, respectivamente.

Observou-se que quanto maior o grau de informação a priori adotado maior a proximidade entre a curva de regressão não linear e a curva de produção de sementes gerada pela priori. De fato, os resultados da inferência bayesiana foram obtidos a partir de densidades de probabilidade a priori com média na estimativa clássica $\hat{s}$. 


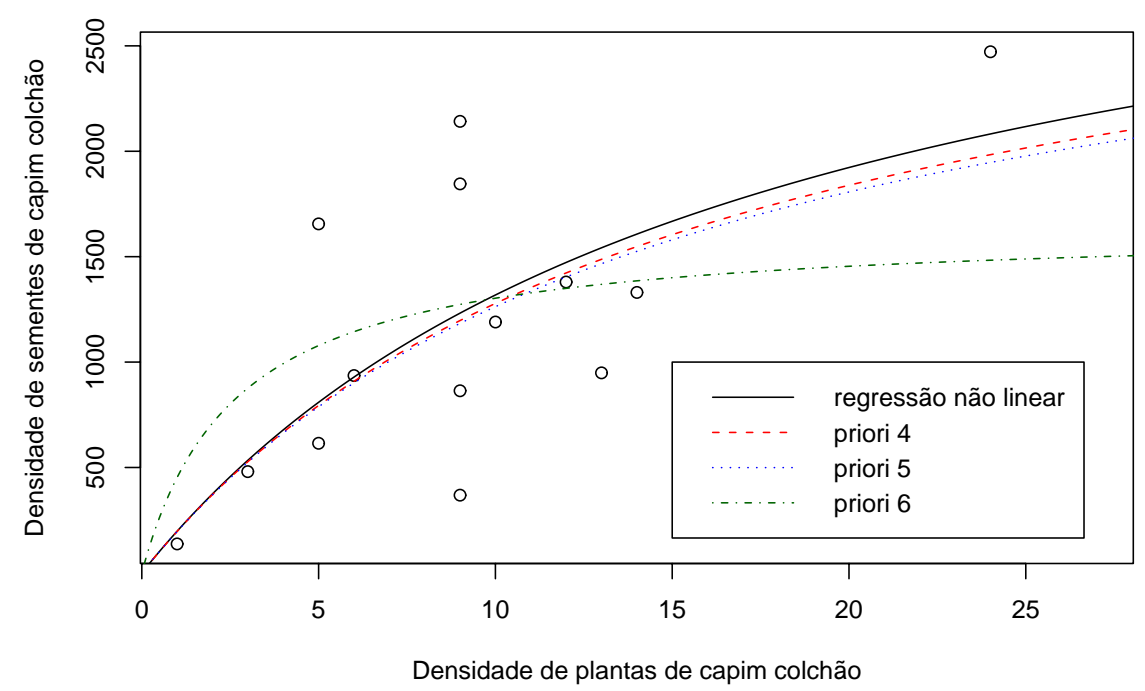

Figura 7.83: Respostas do modelo (6.1) com $b=1$ para as observações de capim colchão partindo-se do ajuste de regressão não linear da abordagem clássica e do ajuste bayesiano via prioris 4., 5. e 6 .

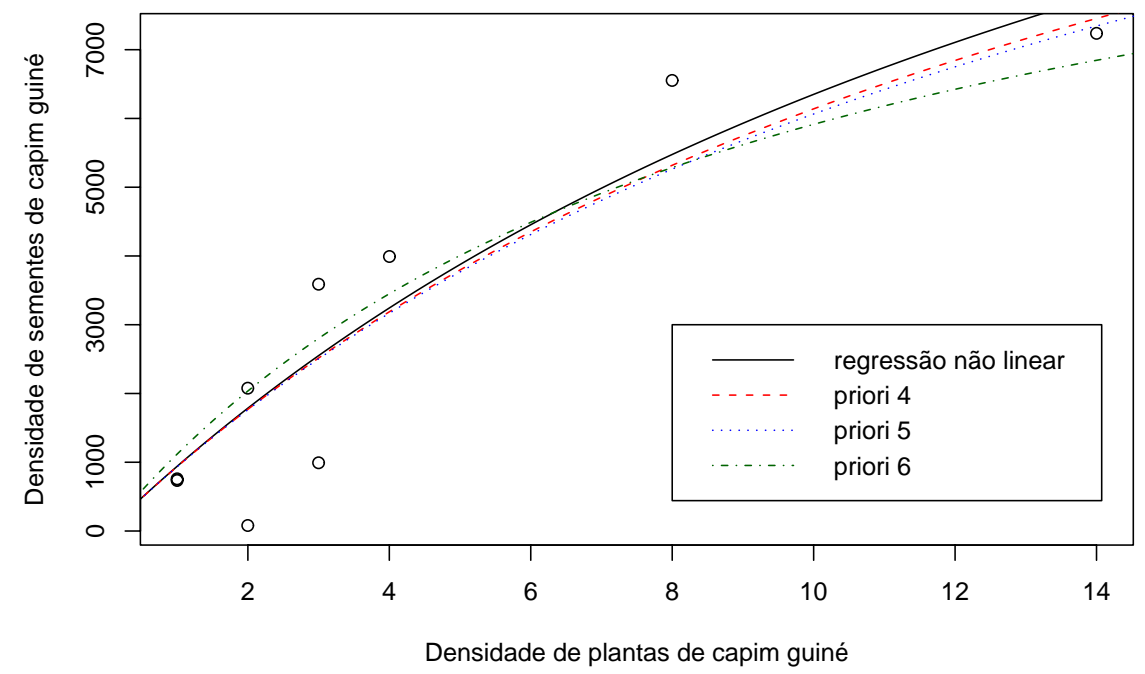

Figura 7.84: Respostas do modelo (6.1) com $b=1$ para as observações de capim guiné partindo-se do ajuste de regressão não linear da abordagem clássica e do ajuste bayesiano via prioris 4., 5. e 6 . 


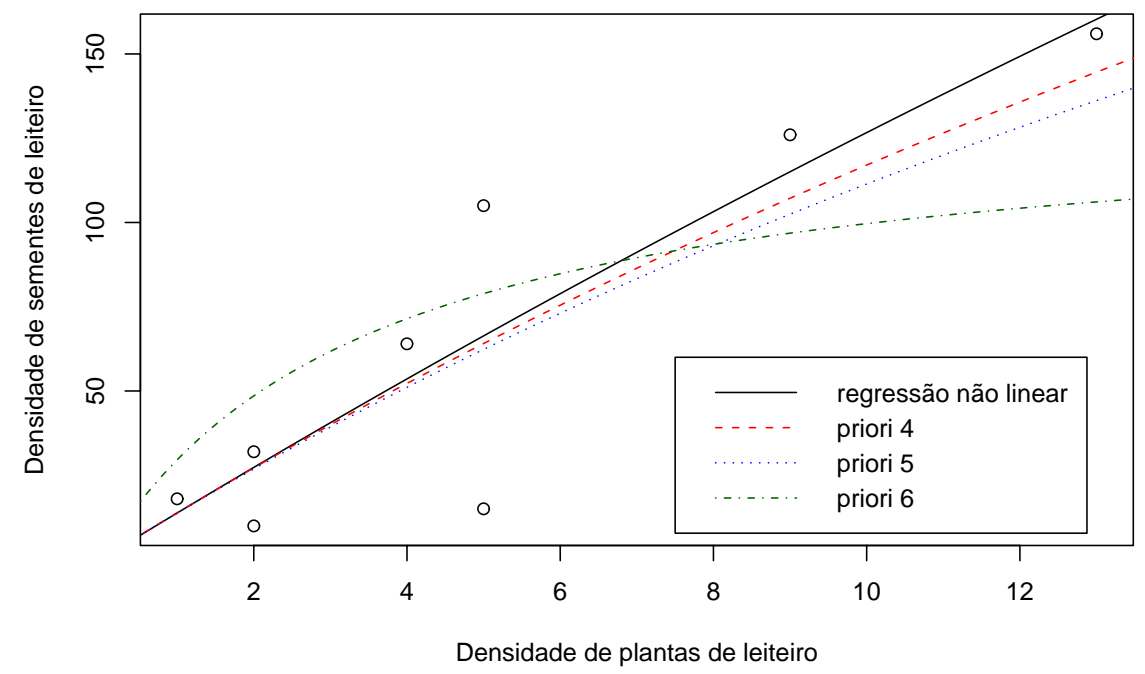

Figura 7.85: Respostas do modelo (6.1) com $b=1$ para as observações de leiteiro partindo-se do ajuste de regressão não linear da abordagem clássica e do ajuste bayesiano via prioris 4., 5. e 6.

\subsection{Discussão}

As variáveis independentes do modelo de produção de sementes de plantas daninhas a serem ajustados são a densidade de plantas daninhas presentes em 38 das 41 parcelas experimentais. Como comentado, há 18 espécies de plantas daninhas encontradas na área experimental. No entanto, foram utilizadas apenas espécies daninhas com tamanho amostral $n \geq 9$; são estas: Digitaria ciliaris (capim colchão), Panicum maximum (capim guiné) e Euphorbia heterophylla (leiteiro), com $n=16, n=10$ e $n=9$, respectivamente.

Devido ao pequeno tamanho amostral, os resultados obtidos na inferência clássica, tanto para a regressão linear de (4.8) como para a regressão não linear de (6.9), não foram satisfatórios. Entretanto, forneceram alguma informação com respeito aos parâmetros do modelo de produção de sementes, o que garantiu a aplicação da metodologia bayesiana. Sendo assim, verificou-se que as estimativas pontuais para os parâmetros de interesse via inferência clássica são mais próximas das estimativas bayesianas quando adotou-se densidades a priori totalmente informativas para $s, a$ e $\tau$.

Os resultados obtidos a partir de prioris totalmente informativas para os parâmetros $s, a$ e $\tau$ são próximos dos encontrados usando prioris não informativa para $\tau$ e totalmente informativa para $s$ e $a$. Entretanto, devido a pouca informação com respeito a $\tau$, 
$\operatorname{Var}(\tau)=1000$, só foi possível gerar duas cadeias quando partiu-se de prioris não informativas, pois para a terceira cadeia os valores iniciais foram gerados pelo aplicativo WinBUGS, o qual parte de valores extremos das densidades a priori. Com relação a estimação por intervalos, notou-se que os intervalos de credibilidade são menores partindo-se de prioris totalmente informativas para $s, a$ e $\tau$.

A vantagem da abordagem bayesiana, com respeito às técnicas de estimação pontual ou por intervalos, é que os intervalos de credibilidade tendem a ser mais estreitos que os de confiança obtidos na inferência clássica; o que pode ser confirmado nas Tabelas 7.1, 7.3 e 7.5 da inferência clássica versus as Tabelas 7.2, 7.4 e 7.6 da inferência bayesiana, para as populações de capim colchão, capim guiné e leiteiro, respectivamente. No entanto, deve-se ressaltar que a principal restrição da estimação pontual é que quando estima-se um parâmetro através de um único valor numérico toda a informação presente nos dados é resumida através deste número. Do ponto de vista bayesiano, toda a informação presente na densidade a posteriori é resumida através deste número. Logo, a densidade a posteriori de um parâmetro contém toda a informação probabilística a respeito deste e um gráfico de sua função de densidade a posteriori é a melhor descrição do processo de inferência.

As Figuras 7.9, 7.12, 7.15, 7.18, 7.21 e 7.24 apresentam as densidades a posteriori obtidas para a população de capim colchão. As Figuras 7.32, 7.35, 7.38, 7.41, 7.44 e 7.47 apresentam as densidades a posteriori obtidas para a população de capim guiné. As Figuras $7.55,7.58,7.61,7.64,7.67$ e 7.70 apresentam as densidades a posteriori obtidas para a população de leiteiro.

Os algoritmos de Metropolis-Hastings e "Slice-sampling" apresentaram nível de convergência aceitável. Apenas quando considerou-se a população de capim guiné e partiuse de prioris moderadamente informativas Normais para $s$ e $a$ e Gama para $\tau$, ou seja: $s \sim N\left(994,6 ; 1.10^{6}\right), a \sim N\left(5,7.10^{-2} ; 1.10^{6}\right)$ e $\tau \sim G a(0,1 ; 0,1)$, o resultado não foi satisfatório. Neste caso, a convergência do algoritmo é alcançada quando são realizadas mais que 100000 iterações. Isto indica que quanto maior a incerteza da informação $a$ priori adotada maior a dificuldade de convergência do algoritmo MCMC. Além disso, a dinâmica simulada para a espécie daninha a partir destas estimativas bayesianas não faz sentido biológico para estas prioris.

Deve-se ressaltar que também é possível simular qual seria o comportamento dinâ- 
mico de uma população com a introdução de uma medida de controle, o que é interesse para possibilitar comparações frente a dinâmica populacional intrínseca simulada e, conseqüentemente, planejar e adequar estratégias de manejo. A simulação para a população de Panicum maximum (capim guiné) considerando os fatores extrínsecos constantes e com a introdução de um parâmetro de controle fica como exemplo. As Figuras 7.74 e 7.75, apresentam a dinâmica da espécie num período de 10 gerações partindo-se de uma única semente com sucesso de germinação e considerando que a produtividade de sementes é nula ao atingir uma população de 4000 plântulas por $m^{2}$. Nota-se que:

1. Considerando os fatores extrínsecos constantes a espécie converge para uma densidade estável com uma produção de aproximadamente 16000 sementes por $\mathrm{m}^{2}$;

2. Com a introdução de um parâmetro de controle o crescimento da população é reduzido:

。 em $t=3$ : tem-se menos de 1000 sementes por $m^{2}$ enquanto sem controle tem-se 16000 sementes nesta etapa;

- em $t=5$ : há convergência para uma densidade estável com 4649,8 sementes por $m^{2}$ enquanto sem controle atinge-se a densidade de equilíbrio com 16021 sementes.

Conclui-se que o comportamento dinâmico simulado para valores de $\hat{a}$ negativo $(\hat{a}<0)$ não faz sentido biológico, assim, a partir da análise da dinâmica simulada e do desvio padrão das estimativas bayesianas é possível inferir que o uso da priori Uniforme para o parâmetro $a$ conduz a resultados mais adequados, e portanto, a densidades a posteriori mais convenientes. Logo, os melhores resultados obtidos para as populações de Digitaria ciliaris (capim colchão), Panicum maximum (capim guiné) e Euphorbia heterophylla (leiteiro) via inferência bayesiana são repetidos na Tabela 7.7 e as respectivas densidades a posteriori foram apresentadas nas Figuras 7.18, 7.41 e 7.64. 
Tabela 7.7: Resumo dos melhores resultados obtidos via abordagem bayesiana para as populações de capim colchão, capim guiné e leiteiro.

\begin{tabular}{llccc}
\hline Prioris & \multicolumn{3}{c}{ Parâmetros } \\
& & $s$ & $a$ & $\tau$ (precisão) \\
\hline capim colchão & & & \\
\hline$s \sim N(209,6 ; 1)$ & Média & 209,6 & $6,5.10^{-2}$ & $4,6.10^{-6}$ \\
$a \sim U(0 ; 1)$ & Mediana & 209,6 & $6,2.10^{-2}$ & $4,40^{-6}$ \\
$\tau \sim G a(1 ; 1)$ & Desvio padrão & 1,0 & $1,8.10^{-2}$ & $1,7.10^{-6}$ \\
& IC $(95 \%)$ & {$[207,6 ; 211,6]$} & {$\left[3,7.10^{-2} ; 1,1.10^{-1}\right]$} & {$\left[2,0.10^{-6} ; 8,4.10^{-6}\right]$} \\
\hline capim guiné & & \multicolumn{3}{c}{} \\
\hline$s \sim N(994,6 ; 1)$ & Média & 994,6 & $6,2.10^{-2}$ & $1,2.10^{-6}$ \\
$a \sim U(0 ; 1)$ & Mediana & 994,6 & $6,0.10^{-2}$ & $1,1.10^{-6}$ \\
$\tau \sim G a(1 ; 1)$ & Desvio padrão & $9,9.10^{-1}$ & $2,0.10^{-2}$ & $5,2.10^{-7}$ \\
& IC (95\%) & {$[992,6 ; 996,5]$} & {$\left[3,5.10^{-2} ; 1,0.10^{-1}\right]$} & {$\left[3,7.10^{-7} ; 2,4.10^{-6}\right]$} \\
\hline Leiteiro & & \multicolumn{3}{c}{} \\
\hline$s \sim N(13,9 ; 1)$ & Média & 14,2 & $2,1.10^{-2}$ & $1,9.10^{-3}$ \\
$a \sim U(0 ; 1)$ & Mediana & 14,1 & $1,6.10^{-2}$ & $1,8.10^{-3}$ \\
$\tau \sim G a(1 ; 1)$ & Desvio padrão & $9,2.10^{-1}$ & $2,5.10^{-2}$ & $9,1.10^{-4}$ \\
& IC $(95 \%)$ & {$[12,4 ; 15,9]$} & {$\left[1,1.10^{-3} ; 6,2.10^{-2}\right]$} & {$\left[5,5.10^{-4} ; 4, .10^{-3}\right]$} \\
\hline
\end{tabular}




\section{Capítulo 8}

\section{Conclusões e proposições para}

\section{futuros trabalhos}

\subsection{Conclusões}

Os modelos dinâmicos do banco de sementes apresentados consideram as características de cada etapa do ciclo de vida de uma planta individual ou espécie. Essas características podem determinar, por exemplo, a habilidade competitiva da espécie em capturar recursos. O nível de mortalidade de plantas daninhas é determinado pelo processo populacional extrínseco e intrínseco, bem como, pela interação de ambos.

O presente trabalho, teve por objetivo apresentar um procedimento para obtenção de informações mais precisas com respeito à produção de sementes de populações de plantas daninhas em agrosistemas. A dinâmica destas populações pode ser descrita pelo modelo (6.1), o qual relaciona as densidades de sementes produzidas e de plantas daninhas em áreas de cultivo. Como ferramenta, utilizou-se a inferência estatística por meio de resultados obtidos na observação de amostras extraídas destas populações a partir de um experimento conduzido em campo. Assim, estudou-se as abordagens de inferência clássica e a bayesiana para obtenção das estimativas dos parâmetros do modelo (6.1), cuja formulação estatística é expressa por (6.9).

Na inferência clássica, a obtenção dos estimadores dos parâmetros do modelo de regressão não linear (6.9) se deu via utilização de métodos numéricos, o que envolveu o uso do aplicativo R. No entanto, na regressão não linear as propriedades que garantem 
eficiência dos estimadores dos parâmetros (não enviesado, normalmente distribuído e de variância mínima) somente são obtidas assintoticamente, ou seja, quando o tamanho da amostra tende ao infinito (Favoretti, 1995; Batista, 2004). Em particular, neste trabalho, tem-se amostras pequenas das populações de interesse, o que justifica a má qualidade do ajuste de (6.9).

Como não foi possível utilizar os resultados assintóticos da teoria clássica, verificouse que o uso de métodos bayesianos é uma alternativa apropriada. A vantagem da inferência bayesiana esta na obtenção de uma estimativa mais robusta, eliminando-se o uso de resultados assintóticos, obtendo-se uma função de densidade contendo toda a informação probabilística a respeito dos parâmetros de interesse, a partir da informação de estudos preliminares a priori das populações de plantas daninhas pertencentes ao ambiente agrícola observado. A procura de uma densidade geradora de amostras dos parâmetros se deu via método de Monte Carlo com cadeias de Markov. Uma cadeia de Markov é um tipo especial de processo estocástico que cuida da caracterização de seqüência de variáveis aleatórias; de especial interesse é a dinâmica e o comportamento limite da seqüência.

Para cada parâmetro gerou-se de duas a três cadeias distintas, as quais foram geradas a partir de valores iniciais distintos. Uma questão importante e de ordem prática é como os valores iniciais influenciam o comportamento da cadeia. A idéia é que conforme o número de iterações aumenta, a cadeia gradualmente esquece os valores iniciais e eventualmente converge para uma distribuição de equilíbrio. Em aplicações práticas é comum que as iterações iniciais sejam descartadas, como se formassem uma amostra de aquecimento.

Assim, após o descarte dos valores iniciais gerados pelas cadeias, verificou-se que houve convergência das amostras a posteriori para uma região em torno de seus possíveis valores verdadeiros, mesmo quando adotou-se uma densidade contendo pouca informação a priori. Além disso, observou-se que quanto menor o grau de informação a priori, maior a amplitude dos intervalos de credibilidade para os parâmetros. Logo, os intervalos de credibilidade mais precisos ocorreram para prioris informativas. Isto implica que quanto maior a precisão a priori, mais fechada será a distribuição a posteriori dos parâmetros. Deve-se ressaltar que a escolha da priori é muito importante no processo de inferência, ou seja, obtém-se resultados bayesianos mais precisos quando 
utiliza-se densidades a priori informativas apropriadas.

Verificou-se que o uso de métodos bayesianos pode ser uma alternativa promissora para analisar modelos não lineares de produção de sementes de plantas daninhas em sistemas agrícolas, podendo contribuir para a adequação de estratégias de manejo através da simulação da sobrevivência e produtividade de espécies daninhas em áreas cultivadas.

\subsection{Proposições para trabalhos futuros}

No sentido de gerar futuras contribuições, seguem algumas propostas para continuação do trabalho:

- Obter a densidade geradora de amostras dos parâmetros do modelo de produção de sementes de plantas daninhas a partir da priori não informativa de Jeffreys, a qual se baseia no uso da medida de informação de Fisher sobre os parâmetros interesse. Este tipo de distribuição pode desempenhar um papel de referência, mesmo que se disponha de uma consistente informação a priori, como forma de:

1. deduzir a informação a posteriori a partir de um conhecimento escasso, ou seja quando apenas a amostra fornece a informação sobre o parâmetro;

2. permitir a comparação com os resultados da inferência clássica que usa apenas a informação amostral; e

3. averiguar a influência nas inferências partindo-se de informações a priori informativas;

- Fazer o estudo da adequabilidade e seleção de modelos. Várias metodologias para abordar esta questão têm sido sugerida na vasta literatura dedicada a esta temática; a abordagem inicial sugere a utilização de fatores de Bayes para a comparação de modelos, mas, alternativamente pode fazer-se o estudo usando distribuições preditivas a posteriori.

- Estudar a viabilidade do uso do banco de sementes em um sistema de plantio direto para analisar a probabilidade de infestação das próximas gerações de plantas, via correlação das sementes presentes no solo no período entre a colheita e o plantio e também com a produção de sementes das Tabelas B.16 e B.17. As sementes deste 
período entre colheita e plantio também podem ser correlacionadas com o banco de sementes e com a produção de sementes antes da próxima colheita;

- Comparar a influência de tratamentos na dinâmica do banco sementes através da correlação do banco de sementes dentro das parcelas (onde não houve tratamento com herbicida) com o banco de sementes fora das parcelas (onde houve tratamento). O conhecimento da extensão do banco e das espécies daninhas que o compõe pode ser utilizado na construção de modelos de estabelecimento populacional no tempo e na definição de programas de manejo adequados;

- Validar o modelo de produção de sementes de plantas daninhas;

- Desenvolver um simulador da dinâmica do banco de sementes de plantas daninhas em culturas agrícolas segundo o grau da infestação, utilizando a modelagem matemática da dinâmica da infestação;

- Estudar um modelo de otimização da aplicação de herbicidas para a otimização de risco de infestação de culturas por plantas daninhas a partir da sua densidade, atributos e incorporação de novas práticas de manejo. 


\section{Bibliografia}

Aguirre, L. A. (2000). Introdução à Identificação de Sistemas: Técnicas Lineares e Não-lineares Aplicadas a Sistemas Reais, Editora UFMG, Belo Horizonte, MG.

Ara, A. B., Musetti, A. V. e Schneiderman, B. (2003). Introdução à Estatística, Editora Edgard Blücher Ltda., São Paulo, SP.

Ayres-Junior, F. (1968). Cálculo Diferencial e Integral, Ao Livro Técnico S. A., Rio de Janeiro, RJ.

Batista, J. L. F. (2004). Análise de Regressão Aplicada, Notas de aula, ESALQ-USP, Piracicaba, SP.

Bazzaz, F. A., Ackerly, D. D., Woodward, F. I. e Rochefort, L. (1992). CO 2 enrichment and dependence of reproduction on density in an annual plant and a simulation of its population dynamics, Journal of Ecology 80(4): 643-651.

Bicudo, C. E. M. (1998). Identificação, monitoramento, avaliação e minimização de impactos negativos, Estratégia Nacional de Diversidade Biológica .

Boldrini, J. L., Costa, S. I. R., Figueiredo, V. L. e Wetzler, H. G. (1986). Álgebra Linear - 3a. edição, Editora HARBRA Ltda., São Paulo, SP.

Buhler, D. D., Hartzler, R. G. e Forcella, F. (1997). Implications of weed seedbank dynamics to weed management, Weed Science 45(3): 329-336.

Canner, S. R., Wiles, L. J. e McMaster, G. S. (2002). Weed reproduction model parameters may be estimated from crop yield loss data, Weed Science 50(6): 763-772.

Carmona, R. (1992). Problemática e manejo de bancos de sementes de invasoras em solos agrícolas, Planta Daninha 10(1/2): 5-16. 
Castrucci, P. e Batista, L. (1980). Controle Linear - Método básico, Edgard Blücher, São Paulo, SP.

Cespedes, J. G. (2003). Eficiência de produção: um enfoque bayesiano, Dissertação de Mestrado em Estatística e Experimentação Agronômica, Escola Superior de Agricultura "Luiz de Queiroz", Universidade de São Paulo, Piracicaba, SP.

Christoffoleti, P. J. e Caetano, R. S. X. (1998). Soil seed banks, Scientia Agricola 55(Número Especial): 74-78.

Coghlan, A. (1995). Hi-tech farming to save the enviroment?, New Scientist 23: 25.

Correia, N. M. e Rezende, P. M. (2002). Manejo Integrado de Plantas Daninhas na Cultura da Soja, Editora UFLA, Lavras, MG.

Cousens, R. (1985a). A simple model relating yield loss to weed density, Annals of Applied Biology 107(2): 239-252.

Cousens, R. (1985b). An empirical model relating crop yield to weed and crop density and a statistical comparison with other models, Journal of Agricultural Sciences 105(3): 513-521.

Cousens, R. (1991). Aspects of the design, analysis and interpretation of competition (interference) experiments, Weed Technology 5(3): 664-673.

Cousens, R., Brain, P., O'Donovan, J. T. e O'Sullivan, P. A. (1987). The use biologically realistic equations to describe the effects of weed density and relative time of emergence on crop yield, Weed Science 35(5): 720-725.

Cousens, R. e Mortimer, M. (1995). Dynamics of Weed Populations, Cambridge University Press, Cambridge, UK.

Cousens, R. e Moss, S. R. (1990). A model of the effects of cultivation on the vertical distribution of weed seeds within the soil, Weed Research 30(1): 61-70.

Cussans, G. W. e Moss, S. R. (1982). Population dynamics of annual grass weeds, Proceedings of the 1982 British Crop Protection Symposium 'Decision Making in the Practice of Crop Protection' pp. 91-98.

Dantas, C. A. B. e Rodrigues, F. W. (1979). Introdução à Estatística, ACESP, São Paulo, SP. 
Diggle, A. J., Neve, P. B. e Smith, F. P. (2003). Herbicides used in combination can reduce the probability of herbicide resistence in finite weed population, Weed Research 43(5): 371-382.

Doyle, C. J. (1997). A review of the use of models of weed control in integrated crop protection, Agriculture, Ecosystems and Environment 64(2): 165-172.

Doyle, C. J., Cousens, R. e Moss, S. R. (1986). A model of the economics of controlling Alopecurus myosuroides huds in winter wheat, Crop Protection 5(2): 143-150.

Edelstein-Keshet, L. (1988). Mathematical Models in Biology, Random House, New York, NY.

Ehlers, R. S. (2004a). Inferência estatística, Notas de aula revisadas em 16/09/2004, Disponível: <http://www.est.ufpr.br/ paulojus/CE227/ce227/>. Acesso em: 29 out 2004 .

Ehlers, R. S. (2004b). Introdução a inferência bayesiana, Notas de aula revisadas em 16/09/2004, <Disponível: http://www.est.ufpr.br/ paulojus/CE227/ce227/>. Acesso em: 29 out 2004.

EMATER (2002). Tecnologia de aplicação de herbicidas, Empresa Paranaense de Assistência Técnica e Extensão Rural, Disponível: $<$ http://www.emater.pr.gov.br/HPPGraos/Paginas/Textecni/Tecaplher.htm>. Acesso em: 04 mai 2004.

Favoretti, A. C. (1995). Modelos não-lineares: um enfoque bayesiano, Dissertação de Mestrado em Ciências de Computação e Matemática Computacional, Instituto de Ciências Matemáticas e de Computação, Universidade de São Paulo, São Carlos, SP.

Fishman, G. S. (1996). Monte Carlo: Concepts, Algorithms, and Applications, SpringerVerlag, New York, NY.

Forcella, F. (1992). Prediction of weed seedling densities from buried seed reserves, Weed Research 32(1): 29-38.

Freckleton, R. P. e Watkinson, A. R. (2002). Are weed population dynamics chaotic?, Journal of Applied Ecology 39(5): 699-707. 
Freitas, R. R. (1990). Dinâmica do banco de sementes em uma comunidade de plantas daninhas com aspectos da germinação e dormência de sementes de capimmarmelada (Brachiaria plantaginea (Link) Hitc.), Dissertação de Mestrado em Ecofisiologia de Plantas Cultivadas, Escola Superior de Agricultura de Lavras, Lavras, MG.

Gelman, G. A. B., Carlin, J. S., Stern, H. S. e Rubin, D. B. (2000). Bayesian Data Analysis, Chapman \& Hall/CRC, Boca Raton, FL.

Gonzalez-Andujar, J. L. (1996). High control measures cannot produce extinction in weed populations, Ecological Modelling 91(1-3): 293-294.

Gonzalez-Andujar, J. L. (1997). A matrix model for the population dynamics and vertical distribution of weed seedbanks, Ecological Modelling 97(1-2): 117-120.

Guimarães, S. C. (2000). Biologia de erva-de-touro (Tridax procumbens L.): desenvolvimento, capacidade reprodutiva e germinação de sementes, Tese de Doutorado em Fitotecnia, Universidade Federal de Lavras, Lavras, MG.

Hassell, M. P. (1975). Density dependence in single-species populations, Journal of Animal Ecology 44(1): 283-295.

Hastings, A., Hom, C., Ellner, S., Turchin, P. e Codfray, H. C. J. (1993). Chaos in ecology: is mother nature a strange attractor?, Annual Review of Ecology and Systematics 24: 1-33.

Isaaks, E. H. e Srivastana, R. M. (1989). An Introduction to Applied Geoestatistics, Oxford University Press, New York, NY.

Judez, L., Miguel, J. M., mas, J. e Bru, R. (2002). Modeling crop regional production using positive mathematical programming, Mathematical and Computer Modelling 35(1-2): 77-86.

Kim, D. S., Brain, P., Marshall, E. J. P. e Caseley, J. C. (2002). Modelling herbicide dose and weed density effects on crop: weed competition, Weed Research 42(1): 1-13.

Krejci, L. C. e Lourenço, P. Y. (1986). Controle de plantas daninhas (importância, métodos e conceituações), INTEC - Informativo Técnico Copener I. 
Kropff, M. J., Weaver, S. E. e Smits, M. A. (1992). Use of ecophysiological models for crop-weed interference: relations amongst weed density, relative time of weed emergence, relative leaf area, and yield loss, Weed Science 40(2): 296-301.

Lacerda, A. L. S. (2003). Fluxos de emergência e banco de sementes de plantas daninhas em sistemas de semeadura direta e convencional e curvas dose-resposta ao Glyphosate, Tese de Doutorado em Fitotecnia, Escola Superior de Agricultura "Luiz de Queiroz", Universidade de São Paulo, Piracicaba, SP.

Lefkovit, L. P. (1965). Study of population growth in organisms grouped by stages, Biometrics 21(1): 1-18.

Leslie, P. H. (1945). On the use of matrices in certain population mathematics, Biometrika 33(3): 183-212.

Lintell-Smith, G., Watkinson, A. R. e Firbank, L. G. (1991). The effects of reduce nitrogen and weed-weed competition on the populations of three common cereal weeds, Proceedings of the Brighton Crop Protection Conference - Weeds - 1991 pp. 135-140.

Lorenzi, H. (2000). Plantas Daninhas do Brasil - 3a. edição, Instituto Plantarum, Nova Odessa, SP.

Lotka, A. J. (1925). Elements of Physical Biology, William and Wilkins, Baltimore, MD.

Manly, B. F. J. (1997). Randomization, Bootstrap and Monte Carlo Methods in Biology, Chapman \& Hall, Londres, UK.

Martins, C. C. e Silva, W. R. (1994). Estudos de banco de sementes do solo, Informativo Abrates 4(1): 49-56.

MathWorks (2006). Home page for the MathWorks web site, Disponível: $<$ http://www.mathworks.com>. Acesso em: 07 abr 2006.

Melo, A. C. O. (1999). Aspectos práticos computacionais dos algoritmos de simulação $M C M C$, Dissertação de Mestrado em Ciências de Computação e Matemática Computacional, Instituto de Ciências Matemáticas e de Computação, Universidade de São Paulo, São Carlos, SP. 
Mena, L. (2000). Processos com parâmetros aleatórios para modelos de séries temporais, Dissertação de Mestrado em Ciências de Computação e Matemática Computacional, Instituto de Ciências Matemáticas e de Computação, Universidade de São Paulo, São Carlos, SP.

Monquero, P. A. (2003). Dinâmica populacional e mecanismos de tolerância de espécies de plantas daninhas ao herbicida glyphosate, Tese de Doutorado em Fitotecnia, Escola Superior de Agricultura "Luiz de Queiroz", Universidade de São Paulo, Piracicaba, $\mathrm{SP}$.

Monteiro, L. H. A. (2002). Sistemas Dinâmicos, Editora Livraria da Física, São Paulo, SP.

Mortimer, A. M. (1987). The population ecology of weeds - implications for integrated weed management, forecasting and conservation, Proceedings of the 1987 British Crop Protection Conference - Weeds pp. 935-944.

Mortimer, A. M., Sutton, J. e Gould, P. (1989). On robust weed populations models, Weed Research 29(4): 229-238.

Neal, R. M. (2003). Slice sampling, The Annals of Statistics 31(3): 705-767.

Nogueira, F. M. A. (2004). Modelagem e simulação - cadeias de markov, Notas de aula revisada no segundo período letivo de 2004, Disponível: $<$ http://www.engprod.ufjf.br/fernando/epd019/cadeiaMarkov.pdf $>$. Acesso em: 29 out 2005.

Norris, R. F. (1992). Case history for weed competition/population ecology: barny ardgrass (Echinochloa crus-galli L.) in sugar-beets (Beta vulgaris), Weed Techno$\log y$ 6(1): 220-227.

Ogata, K. (2003). Engenharia de Controle Moderno, Prentice Hall do Brasil, 4 ed. São Paulo, SP.

Park, S. E., Benjamin, L. R. e Watkinson, A. R. (2003). The theory and application of plant competition models: an agronomic perspective, Annals of Botany 92(6): 741748. 
Paulino, C. D., Turkman, M. A. e Murteira, B. (2003). Estatística Bayesiana, Fundação Calouste Gulbenkiman, Lisboa, POR.

Pielou, E. C. (1977). An Introduction to Mathematical Ecology, Wiley, New York, NY.

Plucknett, D. L. e Winkelmann, D. L. (1995). Technology for sustainable agriculture, Scientific American pp. 182-186.

Rizzardi, M. A., Fleck, N. G., Mundstock, C. M. e Bianchi, M. A. (2003a). Perdas de rendimento de grãos de soja causadas por interferência de picão-preto e guanxuma, Ciência Rural 33(4): 621-627.

Rizzardi, M. A., Fleck, N. G., Riboldi, J. e Agostinetto, D. (2003b). Ajuste de modelo para quantificar o efeito de plantas daninhas e época de semeadura no rendimento de soja, Pesquisa Agropecuária Brasileira 38(1): 35-43.

Sakai, K. (2001). Nonlinear Dynamics and Chaos in Agricultural Systems, Elsevier, Amsterdan, HO.

Selman, M. (1970). The populations dymanics of Avena fatua (wild oats) in continuous spring barley; desirable frequency of spraying with tri-allate, Proceedings of the 10th British Weed Control Conference pp. 1176-1188.

Spiegelhalter, D., Thomas, A., Best, N. e Lunn, D. (2006). Winbugs home page, Disponível: <http://www.mrc-bsu.cam.ac.uk/bugs/winbugs/contents.html >. Acesso em: 07 abr 2006.

Stoller, E. W., Harrison, S. K., Wax, L. M., Regnier, E. E. e Nafziger, E. D. (1987). Weed interference in soybeans (Glycine max), Reviews of Weed Science 3: 155-181.

Swinton, S. M. e King, R. P. (1994). A bioeconomic model for weed management in corn and soybean, Agricultural systems 44(3): 313-335.

Usher, M. B. (1973). Biological Management and Conservation, Chapman \& Hall, Londres, UK.

Venables, W. N. e Smith, D. M. (2005). An introduction to R, Disponível: $<$ http://www.r-project.org >. Acesso em: 07 abr 2006. 
Vismara, L. S., Adati, C. R., Oliveira, V. A. e Cruvinel, P. E. (2004). Modelos não lineares da dinâmica de comunidades de plantas daninhas e de perda de rendimento associada, Anais do III Congresso Temático de Dinâmica e Controle da SBMAC, 31-03 de julho, Ilha Solteira, SP pp. 1566-1571.

Vismara, L. S., Oliveira, V. A. e Karam, D. (2005). Revisão de modelos matemáticos da dinâmica do banco de sementes de plantas daninhas em agroecossistemas, Anais do IV Congresso Temático de Dinâmica, Controle e Aplicações, 6-10 de junho, Bauru, SP pp. 380-389.

Voll, E., Brighenti, A. M., Gazziero, D. L. P. e Adegas, F. S. (2004). Dinâmica da população de Cardiospermum halicacabum e competição com a cultura da soja, Pesquisa Agropecuária Brasileira 39(1): 27-33.

Voll, E., Gazziero, D. L. P. e Karam, D. (1996). Dinâmica de populações de Brachiaria plantaginea (link) hitch. sob manejos de solo e de herbicidas. 2. emergência, Pesquisa Agropecuária Brasileira 31(1): 27-35.

Voll, E., Karam, D. e Gazziero, D. L. P. (1997a). Dinâmica de populações de capimcolchão (Digitara horizontalis willd.) sob manejos de solo e de herbicidas, Pesquisa Agropecuária Brasileira 32(4): 373-378.

Voll, E., Karam, D. e Gazziero, D. L. P. (1997b). Dinâmica de populações de trapoeraba (Commelina benghalensis 1.) sob manejos de solo e de herbicidas, Pesquisa Agropecuária Brasileira 32(6): 571-578.

Wilson, R. G. e Phipps, P. A. (1985). A long term experiment on tillage, rotation and herbicide use for control of A. fatua in cereals, Proceedings of the 1985 British Crop Protection Conference - Weeds pp. 693-700.

Wu, J. J. (2001). Optimal weed control under static and dynamic decision rules, Agricultural Economics 25(1): 119-130. 


\section{Apêndice $A$}

\section{Alguns conceitos de probabilidade e estatística}

Apresentam-se a seguir, algumas definições segundo Dantas e Rodrigues (1979), relevantes para entendimento do Capítulo 4, e as distribuições Normal e Gama de acordo com Ehlers (2004a).

\section{A.1 Definições e conceitos de probabilidade e estatística}

A Estatística é uma ciência baseada na Teoria das Probabilidades, cujo principal objetivo é auxiliar a tirar conclusões ou a tomar decisões, em situações de incerteza, a partir de informações incompletas. Em resumo, as etapas principais da análise de um problema, através de técnicas estatísticas são

1. Definição clara e precisa do problema e da população envolvida;

2. Determinação do tipo de informação (e quantidade) que deve ser coletada;

3. Coleta da informação utilizando as técnicas de amostragem;

4. Análise estatística dos dados;

5. Conclusões e recomendações. 
Neste contexto, a palavra variável ${ }^{1}$ designa toda característica (numérica ou nominal) associada aos elementos de uma população.

Definição A.1 (variável aleatória) Variável aleatória é toda função, a valores reais, definida no espaço amostral associado a um experimento aleatório.

Definição A.2 (probabilidade condicional) Sejam A e B dois eventos de um mesmo espaço amostral tal que $P(B) \neq 0$. Nestas condições, a probabilidade condicional de $A$, dado que ocorreu B, é definida pela relação

$$
P(A \mid B)=\frac{P(A \cap B)}{P(B)}
$$

Definição A.3 (distribuição de probabilidade) A cada um dos valores de uma variável aleatória discreta pode-se associar a probabilidade que este valor ocorra. Essa associação recebe o nome de distribuição de probabilidade da variável aleatória.

Indicando as probabilidades de ocorrência de cada um dos valores de uma variável aleatória $X$ por $P\left(x_{i}\right)=P\left(X=x_{i}\right)$, devem ser satisfeitas as seguintes condições

1. $P\left(x_{i}\right) \geq 0$, para todo $i$;

2. $\sum_{i} P\left(x_{i}\right)=1$.

Definição A.4 (distribuição conjunta) A distribuição conjunta de duas variáveis aleatórias $(X, Y)$ é uma tabela que associa a cada par de valores $(x, y)$ das variáveis, a probabilidade de $P[x=x, y=y]$.

Definição A.5 (distribuições marginais) Quando as distribuições de cada uma das variáveis são obtidas a partir da distribuição conjunta, estas se denominam distribuições marginais.

Definição A.6 (independência de variáveis aleatórias) Duas variáveis aleatórias $X$ e $Y$, dizem-se independentes se para todo par de valores $x$ e y tem-se

$$
P[X=x, Y=y]=p[X=x], P[Y=y]
$$

\footnotetext{
${ }^{1}$ Uma variável é discreta quando o conjunto de seus valores é finito ou pelo menos enumerável e é contínua quando o conjunto de seus valores for um subconjunto não enumerável.
} 
Segue-se da definição que para variáveis aleatórias independentes, as distribuições marginais determinam a distribuição conjunta.

Definição A.7 (densidade de probabilidade) A probabilidade da variável aleatória contínua $X$ assumir valores num subintervalo $(c, d)$ é igual a área sob a curva delimitada por paralelas ao eixo das ordenadas pelos pontos $c$ e $d$. Uma curva com estas propriedades é denominada densidade de probabilidade da variável aleatória.

Definição A.8 (função de distribuição) A função que cada número real $x$ associa a probabilidade da variável aleatória $X$ assumir um valor menor ou igual a $x$ é denominada função de distribuição de $X$.

Se $F$ denota uma função de distribuição de $X$, tem-se

$$
F(x)=P[X<x]
$$

Se $f(x)$ é a densidade de probabilidade de $X$ então o valor da função de distribuição no ponto $x$ é igual a área sob a densidade à esquerda de $x$. A função de densidade de probabilidade satisfaz as seguintes propriedades

1. $f(x) \geq 0 ; \forall x \in \mathcal{R}$;

2. $P(a \leq x \leq b)=\int_{a}^{b} f(x) d x$;

3. $\int_{-\infty}^{\infty} f(x) d x=1$.

Definição A.9 (esperança matemática) A esperança matemática de uma variável aleatória $X, E(X)$, é o número que se obtém multiplicando-se cada valor da variável pela sua correspondente probabilidade.

Definição A.10 (vício ou viés de um estimador) Seja uma amostra aleatória $X_{i}$, $i=1, \cdots, n$, tomada de uma distribuição parametrizada por $\theta$. O erro quadrático médio de um estimador $\hat{\theta}$ de $\theta$ é definido como

$$
\operatorname{EQM}(\theta)=\operatorname{Var}(\hat{\theta})+[E(\hat{\theta})-\theta]^{2}
$$

onde o termo $E(\hat{\theta})-\theta$ é chamado vício ou viés do estimador. 
A interpretação clássica desta Definição é que, após observar todas as possíveis amostras de tamanho $n$ desta distribuição a média de valores calculados de $\hat{\theta}$ será $\theta$, isto é $E(\hat{\theta})=\theta$. Se $E(\hat{\theta}) \neq \theta$ então o estimador é dito ser viesado ou viciado (Ehlers, 2004a).

\section{A.2 Distribuições Normal e Gama}

\section{A.2.1 Distribuição Normal}

$X$ tem distribuição Normal com parâmetros $\mu$ e $\sigma^{2}$, denotando-se $X \sim N\left(\mu, \sigma^{2}\right)$, se sua função de densidade é dada por:

$$
p\left(x \mid \mu, \sigma^{2}\right)=\left(2 \pi \sigma^{2}\right)^{-1 / 2} \exp \left[-(x-\mu)^{2} / 2 \sigma^{2}\right], \quad-\infty<x<\infty,
$$

para $-\infty<\mu<\infty$ e $\sigma^{2}>0$. Quando $\mu=0$ e $\sigma^{2}=1$ a distribuição é chamada normal padrão. A distribuição log-normal é definida como a distribuição de $e^{X}$.

No caso vetorial, $X=\left(X_{1}, \cdots, X_{p}\right)$ tem distribuição normal multivariada com vetor de médias $\mu$ e matriz de variância-covariância $\Sigma$, denotando-se $X \sim N(\mu, \Sigma)$ se sua função de densidade é:

$$
p(x \mid \mu, \Sigma)=(2 \pi)^{-p / 2}|\Sigma|^{-1 / 2} \exp \left[-(x-\mu)^{\prime} \Sigma^{-1}(x-\mu) / 2\right]
$$

para $\mu \in \Re^{p}$ e $\Sigma$ positiva-definida (Ehlers, 2004a).

\section{A.2.2 Distribuição Gama}

$X$ tem distribuição Gama com parâmetros $\alpha$ e $\beta$, denotando-se $X \sim G a(\alpha, \beta)$, se sua função de densidade é dada por:

$$
p(x \mid \alpha, \beta)=\frac{\beta^{\alpha}}{\Gamma(\alpha)} x^{\alpha-1} e^{-\beta x}, x>0,
$$

para $\alpha, \beta>0$ (Ehlers, 2004a).

$$
E(X)=\alpha / \beta \text { e } V(X)=\alpha / \beta^{2} .
$$


Casos particulares da distribuição Gama são a distribuição de Erlang, $G a(\alpha, 1)$, a distribuição exponencial, $G a(1, \beta)$, e a distribuição qui-quadrado com $\nu$ graus de liberdade, $G a(\nu / 2,1 / 2)$. 


\section{Apêndice B}

\section{Tabelas das observações realizadas em campo}

Neste Apêndice, estão dispostas todas as tabelas de dados coletados em campo, na área experimental da EMBRAPA Milho e Sorgo situada no município de Sete Lagoas, MG. A localização das 41 parcelas experimentais distribuídas pelo campo foram georeferenciadas e as latitudes e longitudes são apresentadas na Tabela B.1. As Tabelas B.2-B.10 exibem o número de cada espécie de plantas daninhas encontradas em cada quadro de $0,25 \mathrm{~m}^{2}$ colocado dentro das parcelas. Nas Tabelas B.11-B.14 encontram-se o número de espécies daninhas por metro quadrado em cada parcela somando as espécies encontradas nos quadros em cada parcela. Estas espécies de plantas daninhas foram classificadas em espécies de "folha larga" e de "folha estreita"; a Tabela B.15 apresenta a densidade de plantas daninhas por metro quadrado segundo esta classificação. As Tabelas B.16 e B.17 exibem as densidades de sementes das espécies de plantas encontradas em cada parcela e a Tabela B.18 a densidade de sementes total de cada parcela. Estes dados foram coletados em campo sob observação de um especialista e representam a ocupação das plantas emergentes, cujas sementes germinaram. 
Tabela B.1: Localização das 41 parcelas experimentais obtida por uso do GPS.

\begin{tabular}{ccc}
\hline Parcela & Medição-1 & Medição-2 \\
\hline Parcela & Latitude & Longitude \\
\hline 1 & 7847799,150527330 & 586113,183360760 \\
\hline 2 & 7847699,507785420 & 586102,576266328 \\
\hline 3 & 7847603,578693840 & 586079,937293408 \\
\hline 4 & 7847482,296959680 & 586116,142588431 \\
\hline 5 & 7847569,800179510 & 586164,722345541 \\
\hline 6 & 7847664,369617390 & 586193,469462528 \\
\hline 7 & 7847763,926956360 & 586199,481159328 \\
\hline 8 & 7847861,868771190 & 586217,761244919 \\
\hline 9 & 7847915,455012520 & 586307,567213339 \\
\hline 10 & 7847827,864351200 & 586306,260200605 \\
\hline 11 & 7847729,871446530 & 586288,984638006 \\
\hline 12 & 7847629,514008580 & 586285,905269271 \\
\hline 13 & 7847535,441921870 & 586252,984363802 \\
\hline 14 & 7847447,907384560 & 586205,262212223 \\
\hline 15 & 7847362,027529300 & 586154,325912283 \\
\hline 16 & 7847314,824556160 & 586264,092403908 \\
\hline 17 & 7847405,767333180 & 586305,593598989 \\
\hline 18 & 7847496,496173760 & 586347,987195187 \\
\hline 19 & 7847594,136311340 & 586379,346729417 \\
\hline 20 & 7847690,670699420 & 586385,187343689 \\
\hline 21 & 7847789,391521810 & 586397,666600316 \\
\hline 22 & 7847888,893831950 & 586411,204152397 \\
\hline 23 & 7847856,185804420 & 586506,164299675 \\
\hline 24 & 7847758,342737180 & 586489,551649208 \\
\hline 25 & 7847659,404892700 & 586480,838280201 \\
\hline 26 & 7847559,887688720 & 586474,020191494 \\
\hline 27 & 7847466,156139020 & 586439,268677153 \\
\hline 28 & 7847375,789716790 & 586398,297727061 \\
\hline 29 & 7847284,956884380 & 586356,797614576 \\
\hline 30 & 7847252,029211630 & 586449,352225306 \\
\hline 31 & 7847342,351492240 & 586490,664494191 \\
\hline 32 & 7847432,450361440 & 586532,731257396 \\
\hline 33 & 7847526,027757400 & 586566,888490205 \\
\hline 34 & 7847625,269161990 & 586577,850413405 \\
\hline 35 & 7847724,816411810 & 586583,047039596 \\
\hline 36 & 7847823,112854450 & 586600,296722088 \\
\hline 38 & 7847690,517466590 & 586679,640844428 \\
\hline 40 & 7847499,910805100 & 586676,177704551 \\
\hline & 7847398,758615010 & 586626,814183498 \\
\hline 3847314,545019120 & 586588,354804653 \\
\hline & & \\
\hline 31
\end{tabular}


Tabela B.2: Densidade de plantas por espécie em cada quadro.

\begin{tabular}{|c|c|c|c|}
\hline Parcela & Quadro & Densidade de plantas & Espécie \\
\hline 1 & $\mathrm{~A}$ & 1 & braquiária \\
\hline 1 & $\mathrm{~A}$ & 10 & capim colchão \\
\hline 1 & $\mathrm{~A}$ & 2 & capim marmelada \\
\hline 1 & $\mathrm{~A}$ & 4 & timbête \\
\hline 1 & $\mathrm{~A}$ & 2 & erva-de-touro \\
\hline 1 & $\mathrm{~A}$ & 2 & mentrasto \\
\hline 1 & $\bar{B}$ & 8 & timbête \\
\hline 1 & $\bar{B}$ & 6 & mentrasto \\
\hline 1 & $\mathrm{~B}$ & 2 & erva de santa luzia \\
\hline 1 & $\mathrm{C}$ & 3 & timbête \\
\hline 1 & $\mathrm{C}$ & 3 & capim marmelada \\
\hline 1 & $\mathrm{C}$ & 5 & capim colchão \\
\hline 1 & $\mathrm{C}$ & 1 & sorgo selvagem \\
\hline 1 & $\overline{\mathrm{D}}$ & 6 & braquiária \\
\hline 1 & $\mathrm{D}$ & 2 & capim marmelada \\
\hline 2 & $\mathrm{~A}$ & 10 & capim colchão \\
\hline 2 & $\overline{\mathrm{A}}$ & 5 & capim marmelada \\
\hline 2 & $\mathrm{~A}$ & 1 & capim guiné \\
\hline 2 & $\bar{B}$ & 14 & capim colchão \\
\hline 2 & $\mathrm{~B}$ & 2 & trapoeraba \\
\hline 2 & $\overline{\mathrm{B}}$ & 2 & caruru \\
\hline 2 & $\mathrm{C}$ & 6 & capim colchão \\
\hline 2 & $\mathrm{C}$ & 2 & capim marmelada \\
\hline 2 & $\mathrm{D}$ & 7 & capim colchão \\
\hline 2 & $\mathrm{D}$ & 3 & capim marmelada \\
\hline 2 & $\mathrm{D}$ & 2 & capim guiné \\
\hline 2 & $\overline{\mathrm{D}}$ & 6 & caruru \\
\hline 3 & $\mathrm{~A}$ & 1 & caruru \\
\hline 3 & $\mathrm{~A}$ & 2 & timbête \\
\hline 3 & $\mathrm{~A}$ & 6 & sorgo selvagem \\
\hline 3 & $\mathrm{~A}$ & 2 & capim colchão \\
\hline 3 & $\bar{A}$ & 2 & braquiária \\
\hline 3 & $\bar{B}$ & 3 & caruru \\
\hline 3 & $\mathrm{~B}$ & 2 & sorgo selvagem \\
\hline 3 & $\mathrm{~B}$ & 2 & braquiária \\
\hline 3 & $\mathrm{C}$ & 8 & picão preto \\
\hline 3 & $\mathrm{C}$ & 3 & sorgo selvagem \\
\hline 3 & $\mathrm{C}$ & 3 & braquiária \\
\hline 3 & $\mathrm{D}$ & 2 & caruru \\
\hline 3 & $\mathrm{D}$ & 2 & braquiária \\
\hline 3 & $\mathrm{D}$ & 3 & capim marmelada \\
\hline 3 & $\bar{D}$ & 1 & timbête \\
\hline 3 & $\mathrm{D}$ & 4 & sorgo selvagem \\
\hline 4 & $\mathrm{~A}$ & 10 & trapoeraba \\
\hline 4 & $\mathrm{~B}$ & 12 & trapoeraba \\
\hline 4 & $\mathrm{~B}$ & 5 & caruru \\
\hline 4 & $\mathrm{C}$ & 8 & trapoeraba \\
\hline 4 & $\mathrm{C}$ & 4 & capim marmelada \\
\hline 4 & $\mathrm{D}$ & 4 & trapoeraba \\
\hline 4 & $\mathrm{D}$ & 6 & capim marmelada \\
\hline
\end{tabular}


Tabela B.3: Densidade de plantas por espécie em cada quadro (continuação).

\begin{tabular}{|c|c|c|c|}
\hline Parcela & Quadro & Densidade de plantas & Espécie \\
\hline 5 & $\mathrm{~A}$ & 5 & capim marmelada \\
\hline 5 & $\mathrm{~A}$ & 4 & trapoeraba \\
\hline 5 & $\mathrm{~B}$ & 5 & capim marmelada \\
\hline 5 & $\mathrm{~B}$ & 2 & trapoeraba \\
\hline 5 & $\mathrm{C}$ & 8 & trapoeraba \\
\hline 5 & $\bar{D}$ & 5 & capim marmelada \\
\hline 5 & $\mathrm{D}$ & 8 & trapoeraba \\
\hline 6 & $\mathrm{~A}$ & 2 & sorgo selvagem \\
\hline 6 & $\mathrm{~A}$ & 4 & capim marmelada \\
\hline 6 & $\mathrm{~A}$ & 1 & trapoeraba \\
\hline 6 & $\overline{\mathrm{A}}$ & 2 & capim colchão \\
\hline 6 & $\mathrm{~B}$ & 2 & trpoeraba \\
\hline 6 & $\mathrm{C}$ & 5 & capim marmelada \\
\hline 6 & $\mathrm{C}$ & 3 & capim colchão \\
\hline 6 & $\mathrm{C}$ & 2 & sorgo selvagem \\
\hline 6 & $\mathrm{D}$ & 5 & capim marmelada \\
\hline 6 & $\mathrm{D}$ & 3 & trapoeraba \\
\hline 7 & $\mathrm{~A}$ & 8 & capim marmelada \\
\hline 7 & $\mathrm{~B}$ & 8 & capim colchão \\
\hline 7 & $\mathrm{~B}$ & 3 & capim marmelada \\
\hline 7 & $\bar{B}$ & 2 & sorgo selvagem \\
\hline 7 & $\mathrm{C}$ & 5 & capim marmelada \\
\hline 7 & $\mathrm{C}$ & 4 & capim colchão \\
\hline 7 & $\mathrm{C}$ & 4 & erva de santa luzia \\
\hline 7 & $\mathrm{C}$ & 2 & mentrasto \\
\hline 7 & $\mathrm{D}$ & 4 & capim colchão \\
\hline 7 & $\mathrm{D}$ & 3 & capim marmelada \\
\hline 8 & $\mathrm{~A}$ & 6 & braquiária \\
\hline 8 & $\mathrm{~A}$ & 3 & capim colchão \\
\hline 8 & $\mathrm{~A}$ & 15 & mentrasto \\
\hline 8 & $\mathrm{~B}$ & 3 & capim colchão \\
\hline 8 & $\mathrm{~B}$ & 16 & mentrasto \\
\hline 8 & $\mathrm{~B}$ & 3 & capim colchão \\
\hline 8 & $\mathrm{~B}$ & 16 & mentrasto \\
\hline 8 & $\mathrm{C}$ & 4 & capim colchão \\
\hline 8 & $\mathrm{C}$ & 2 & braquiária \\
\hline 8 & $\mathrm{C}$ & 38 & mentrasto \\
\hline 8 & $\mathrm{D}$ & 18 & mentrasto \\
\hline 8 & $\bar{D}$ & 6 & erva quente \\
\hline 8 & $\mathrm{D}$ & 5 & capim colchão \\
\hline 8 & $\mathrm{D}$ & 1 & leiteiro \\
\hline 9 & A & 23 & picão preto \\
\hline 9 & $\mathrm{~A}$ & 4 & capim colchão \\
\hline 9 & $\overline{\mathrm{A}}$ & 1 & capim guiné \\
\hline 9 & $\mathrm{~A}$ & 8 & mentrasto \\
\hline 9 & $\mathrm{~B}$ & 14 & picão preto \\
\hline 9 & $\mathrm{~B}$ & 3 & timbête \\
\hline 9 & $\bar{B}$ & 5 & mentrasto \\
\hline 9 & $\mathrm{C}$ & 10 & picão preto \\
\hline 9 & $\mathrm{C}$ & 3 & braquiária \\
\hline 9 & $\mathrm{C}$ & 1 & trapoeraba \\
\hline 9 & $\mathrm{C}$ & 5 & mentrasto \\
\hline 9 & $\mathrm{D}$ & 8 & picão preto \\
\hline 9 & $\mathrm{D}$ & 3 & capim marmelada \\
\hline
\end{tabular}


Tabela B.4: Densidade de plantas por espécie em cada quadro (continuação).

\begin{tabular}{|c|c|c|c|}
\hline Parcela & Quadro & Densidade de plantas & Espécie \\
\hline 9 & $\mathrm{D}$ & 10 & mentrasto \\
\hline 10 & $\overline{\mathrm{A}}$ & 10 & mentrasto \\
\hline 10 & $\mathrm{~A}$ & 3 & capim colchão \\
\hline 10 & $\bar{B}$ & 5 & capim colchão \\
\hline 10 & $\overline{\mathrm{B}}$ & 7 & caruru \\
\hline 10 & $\bar{B}$ & 3 & trapoeraba \\
\hline 10 & $\bar{B}$ & 2 & mentrasto \\
\hline 10 & $\mathrm{C}$ & 10 & mentrasto \\
\hline 10 & $\mathrm{D}$ & 22 & mentrasto \\
\hline 10 & $\mathrm{D}$ & 4 & capim colchão \\
\hline 11 & $\overline{\mathrm{A}}$ & 4 & capim colchão \\
\hline 11 & $\mathrm{~A}$ & 2 & capim marmelada \\
\hline 11 & $\overline{\mathrm{A}}$ & 2 & mentrasto \\
\hline 11 & $\overline{\mathrm{A}}$ & 3 & trapoeraba \\
\hline 11 & $\mathrm{~B}$ & 5 & capim colchão \\
\hline 11 & $\mathrm{~B}$ & 4 & capim marmelada \\
\hline 11 & $\mathrm{C}$ & 3 & capim marmelada \\
\hline 11 & $\mathrm{C}$ & 2 & capim guiné \\
\hline 11 & $\mathrm{D}$ & 3 & capim marmelada \\
\hline 11 & $\overline{\mathrm{D}}$ & 3 & capim colchão \\
\hline 12 & $\bar{A}$ & 8 & trapoeraba \\
\hline 12 & $\bar{B}$ & 6 & trapoeraba \\
\hline 12 & $\bar{B}$ & 1 & capim marmelada \\
\hline 12 & $\mathrm{C}$ & 6 & trapoeraba \\
\hline 12 & $\overline{\mathrm{D}}$ & 5 & trapoeraba \\
\hline 12 & $\mathrm{D}$ & 1 & capim marmelada \\
\hline 13 & $\mathrm{~A}$ & 6 & capim marmelada \\
\hline 13 & $\mathrm{~B}$ & 4 & capim marmelada \\
\hline 13 & $\mathrm{C}$ & 5 & capim marmelada \\
\hline 13 & $\mathrm{C}$ & 2 & sorgo selvagem \\
\hline 13 & $\mathrm{C}$ & 5 & capim marmelada \\
\hline 13 & $\mathrm{C}$ & 2 & sorgo selvagem \\
\hline 13 & $\mathrm{D}$ & 8 & capim marmelada \\
\hline 13 & $\mathrm{D}$ & 1 & mentrasto \\
\hline 14 & $\mathrm{~A}$ & 4 & trapoeraba \\
\hline 14 & $\overline{\mathrm{A}}$ & 6 & capim marmelada \\
\hline 14 & $\mathrm{~A}$ & 5 & capim colchão \\
\hline 14 & $\mathrm{~B}$ & 8 & capim colchão \\
\hline 14 & $\bar{B}$ & 6 & trapoeraba \\
\hline 14 & $\mathrm{C}$ & 6 & capim colchão \\
\hline 14 & $\mathrm{C}$ & 3 & trapoeraba \\
\hline 14 & $\mathrm{D}$ & 4 & trapoeraba \\
\hline 14 & $\mathrm{D}$ & 1 & capim marmelada \\
\hline 14 & $\mathrm{D}$ & 8 & capim colchão \\
\hline 15 & $\overline{\mathrm{A}}$ & 6 & capim colchão \\
\hline 15 & $\mathrm{~A}$ & 5 & leiteiro \\
\hline 15 & $\mathrm{~A}$ & 1 & poaia \\
\hline 15 & $\bar{B}$ & 8 & capim colchão \\
\hline 15 & $\mathrm{~B}$ & 1 & capim marmelada \\
\hline 15 & $\bar{B}$ & 1 & leiteiro \\
\hline 15 & $\mathrm{C}$ & 4 & capim colchão \\
\hline 15 & $\mathrm{C}$ & 2 & leiteiro \\
\hline 15 & $\mathrm{C}$ & 1 & capim marmelada \\
\hline 15 & $\mathrm{D}$ & 8 & capim colchão \\
\hline
\end{tabular}


Tabela B.5: Densidade de plantas por espécie em cada quadro (continuação).

\begin{tabular}{|c|c|c|c|}
\hline Parcela & Quadro & Densidade de plantas & Espécie \\
\hline 15 & $\mathrm{D}$ & 1 & leiteiro \\
\hline 15 & $\mathrm{D}$ & 1 & capim marmelada \\
\hline 15 & $\mathrm{D}$ & 5 & timbête \\
\hline 15 & $\mathrm{D}$ & 4 & mentrasto \\
\hline 16 & $\mathrm{~A}$ & 4 & capim colchão \\
\hline 16 & $\overline{\mathrm{A}}$ & 2 & capim marmelada \\
\hline 16 & $\bar{A}$ & 1 & trapoeraba \\
\hline 16 & $\mathrm{~B}$ & 4 & capim colchão \\
\hline 16 & $\mathrm{~B}$ & 1 & capim marmelada \\
\hline 16 & $\mathrm{~B}$ & 1 & botão de ouro \\
\hline 16 & $\mathrm{~B}$ & 1 & leiteiro \\
\hline 16 & $\mathrm{~B}$ & 1 & pé de galinha \\
\hline 16 & $\mathrm{C}$ & 4 & capim colchão \\
\hline 16 & $\mathrm{C}$ & 1 & botão de ouro \\
\hline 16 & $\mathrm{D}$ & 4 & capim colchão \\
\hline 16 & $\mathrm{D}$ & 3 & leiteiro \\
\hline 16 & $\mathrm{D}$ & 2 & pé de galinha \\
\hline 17 & $\mathrm{~A}$ & 6 & trapoeraba \\
\hline 17 & $\mathrm{~A}$ & 6 & botão de ouro \\
\hline 17 & $\mathrm{~A}$ & 2 & caruru \\
\hline 17 & $\mathrm{~B}$ & 5 & trapoeraba \\
\hline 17 & $\mathrm{C}$ & 6 & trapoeraba \\
\hline 17 & $\mathrm{D}$ & 4 & trapoeraba \\
\hline 18 & $\mathrm{~A}$ & 3 & capim colchão \\
\hline 18 & $\mathrm{~A}$ & 1 & pé de galinha \\
\hline 18 & $\mathrm{~B}$ & 4 & capim colchão \\
\hline 18 & $\bar{B}$ & 3 & capim mamelada \\
\hline 18 & $\mathrm{~B}$ & 1 & leiteiro \\
\hline 18 & $\mathrm{~B}$ & 1 & caruru \\
\hline 18 & $\mathrm{~B}$ & 1 & trapoeraba \\
\hline 18 & $\mathrm{C}$ & 3 & capim colchão \\
\hline 18 & $\mathrm{C}$ & 4 & leiteiro \\
\hline 18 & $\mathrm{C}$ & 3 & caruru \\
\hline 18 & $\mathrm{D}$ & 3 & capim colchão \\
\hline 18 & $\mathrm{D}$ & 2 & capim marmelada \\
\hline 18 & $\mathrm{D}$ & 1 & trapoeraba \\
\hline 19 & $\mathrm{~A}$ & 2 & capim marmelada \\
\hline 19 & $\mathrm{~A}$ & 1 & capim colchão \\
\hline 19 & $\overline{\mathrm{A}}$ & 1 & capim guiné \\
\hline 19 & $\mathrm{~B}$ & 2 & capim marmelada \\
\hline 19 & $\mathrm{~B}$ & 2 & capim colchão \\
\hline 19 & $\mathrm{~B}$ & 5 & mentrasto \\
\hline 19 & $\mathrm{C}$ & 1 & capim marmelada \\
\hline 19 & $\mathrm{C}$ & 2 & leiteiro \\
\hline 19 & $\mathrm{C}$ & 3 & mentrasto \\
\hline 19 & $\mathrm{D}$ & 3 & capim marmelada \\
\hline 19 & $\mathrm{D}$ & 3 & leiteiro \\
\hline 19 & $\overline{\mathrm{D}}$ & 1 & trapoeraba \\
\hline 20 & $\mathrm{~A}$ & 4 & capim colchão \\
\hline 20 & $\mathrm{~B}$ & 2 & capim colchão \\
\hline 20 & $\mathrm{~B}$ & 8 & mentrasto \\
\hline 20 & $\mathrm{C}$ & 1 & capim marmelada \\
\hline 20 & $\mathrm{C}$ & 3 & capim colchão \\
\hline 20 & $\mathrm{C}$ & 10 & mentrasto \\
\hline
\end{tabular}


Tabela B.6: Densidade de plantas por espécie em cada quadro (continuação).

\begin{tabular}{|c|c|c|c|}
\hline Parcela & Quadro & Densidade de plantas & Espécie \\
\hline 20 & $\mathrm{C}$ & 1 & leiteiro \\
\hline 20 & $\mathrm{D}$ & 5 & capim colchão \\
\hline 20 & $\mathrm{D}$ & 3 & capim marmelada \\
\hline 20 & $\mathrm{D}$ & 1 & leiteiro \\
\hline 20 & $\mathrm{D}$ & 3 & mentrasto \\
\hline 21 & $\mathrm{~A}$ & 3 & leiteiro \\
\hline 21 & $\mathrm{~A}$ & 1 & capim colchão \\
\hline 21 & $\mathrm{~A}$ & 3 & mentrasto \\
\hline 21 & $\bar{B}$ & 3 & leiteiro \\
\hline 21 & $\mathrm{~B}$ & 8 & mentrasto \\
\hline 21 & $\mathrm{~B}$ & 2 & capim colchão \\
\hline 21 & $\mathrm{~B}$ & 2 & timbête \\
\hline 21 & $\mathrm{C}$ & 4 & capim colchão \\
\hline 21 & $\mathrm{C}$ & 5 & mentrasto \\
\hline 21 & $\mathrm{C}$ & 3 & leiteiro \\
\hline 21 & $\mathrm{D}$ & 4 & leiteiro \\
\hline 21 & $\mathrm{D}$ & 2 & capim colchão \\
\hline 22 & $\bar{A}$ & 3 & capim marmelada \\
\hline 22 & $\bar{B}$ & 6 & capim marmelada \\
\hline 22 & $\mathrm{C}$ & 8 & capim marmelada \\
\hline 22 & $\mathrm{D}$ & 6 & capim marmelada \\
\hline 22 & $\mathrm{D}$ & 2 & poaia \\
\hline 22 & $\mathrm{D}$ & 1 & capim colchão \\
\hline 23 & $\mathrm{~A}$ & 4 & capim colchão \\
\hline 23 & $\mathrm{~B}$ & 6 & capim colchão \\
\hline 23 & $\mathrm{C}$ & 5 & capim guiné \\
\hline 23 & $\mathrm{C}$ & 2 & capim colchão \\
\hline 23 & $\overline{\mathrm{D}}$ & 6 & capim guiné \\
\hline 23 & $\mathrm{D}$ & 4 & capim colchão \\
\hline 24 & $\mathrm{~A}$ & 3 & capim colchão \\
\hline 24 & $\mathrm{~A}$ & 1 & capim guiné \\
\hline 24 & $\mathrm{~A}$ & 1 & capim marmelada \\
\hline 24 & $\mathrm{~B}$ & 3 & capim marmelada \\
\hline 24 & $\mathrm{C}$ & 4 & capim marmelada \\
\hline 24 & $\bar{D}$ & 2 & capim guiné \\
\hline 24 & $\mathrm{D}$ & 1 & capim marmelada \\
\hline 25 & $\mathrm{~A}$ & 8 & capim colchão \\
\hline 25 & $\mathrm{~A}$ & 2 & trapoeraba \\
\hline 25 & $\mathrm{~B}$ & 6 & capim colchão \\
\hline 25 & $\mathrm{~B}$ & 4 & trapoeraba \\
\hline 25 & $\mathrm{C}$ & 1 & trapoeraba \\
\hline 25 & $\mathrm{C}$ & 2 & picão \\
\hline 25 & $\mathrm{C}$ & 5 & capim colchão \\
\hline 25 & $\mathrm{C}$ & 1 & capim marmelada \\
\hline 25 & $\mathrm{D}$ & 1 & trapoeraba \\
\hline 25 & $\bar{D}$ & 5 & capim colchão \\
\hline 26 & $\overline{\mathrm{A}}$ & 5 & capim colchão \\
\hline 26 & $\mathrm{~A}$ & 3 & capim marmelada \\
\hline 26 & $\mathrm{~B}$ & 3 & capim marmelada \\
\hline 26 & $\mathrm{~B}$ & 4 & capim colchão \\
\hline 26 & $\mathrm{C}$ & 5 & capim colchão \\
\hline 26 & $\mathrm{C}$ & 3 & capim marmelada \\
\hline 26 & $\mathrm{D}$ & 2 & picão preto \\
\hline
\end{tabular}


Tabela B.7: Densidade de plantas por espécie em cada quadro (continuação).

\begin{tabular}{|c|c|c|c|}
\hline Parcela & Quadro & Densidade de plantas & Espécie \\
\hline 27 & $\mathrm{~A}$ & 4 & capim colchão \\
\hline 27 & $\mathrm{~A}$ & 3 & capim marmelada \\
\hline 27 & $\mathrm{~A}$ & 1 & capim marmelada \\
\hline 27 & $\bar{B}$ & 3 & capim marmelada \\
\hline 27 & $\bar{B}$ & 2 & capim guiné \\
\hline 27 & $\mathrm{C}$ & 1 & capim marmelada \\
\hline 27 & $\mathrm{C}$ & 1 & capim guiné \\
\hline 27 & $\overline{\mathrm{D}}$ & 2 & capim marmelada \\
\hline 27 & $\mathrm{D}$ & 1 & capim guiné \\
\hline 27 & $\bar{D}$ & 1 & capim colchão \\
\hline 28 & $\mathrm{~A}$ & 2 & capim colchão \\
\hline 28 & $\mathrm{~A}$ & 1 & capim marmelada \\
\hline 28 & $\bar{A}$ & 1 & capim colchão \\
\hline 28 & $\mathrm{~B}$ & 2 & capim marmelada \\
\hline 28 & $\bar{B}$ & 1 & capim guiné \\
\hline 28 & $\mathrm{~B}$ & 1 & leiteiro \\
\hline 28 & $\bar{B}$ & 1 & capim colchão \\
\hline 28 & $\mathrm{C}$ & 1 & capim marmelada \\
\hline 28 & $\mathrm{C}$ & 1 & capim colchão \\
\hline 28 & $\mathrm{D}$ & 1 & capim colchão \\
\hline 28 & $\mathrm{D}$ & 4 & timbête \\
\hline 29 & $\overline{\mathrm{A}}$ & 6 & capim colchão \\
\hline 29 & $\bar{A}$ & 1 & picão preto \\
\hline 29 & $\mathrm{~A}$ & 4 & mentrasto \\
\hline 29 & $\mathrm{~B}$ & 1 & capim marmelada \\
\hline 29 & $\mathrm{~B}$ & 2 & capim colchão \\
\hline 29 & $\bar{B}$ & 3 & mentrasto \\
\hline 29 & $\mathrm{C}$ & 3 & capim colchão \\
\hline 29 & $\mathrm{C}$ & 1 & picão preto \\
\hline 29 & $\mathrm{C}$ & 3 & mentrasto \\
\hline 29 & $\mathrm{D}$ & 2 & picão preto \\
\hline 29 & $\mathrm{D}$ & 2 & capim colchão \\
\hline 29 & $\bar{D}$ & 1 & capim marmelada \\
\hline 30 & $\mathrm{~A}$ & 6 & mentrasto \\
\hline 30 & $\mathrm{~B}$ & 9 & mentrasto \\
\hline 30 & $\mathrm{C}$ & 8 & mentrasto \\
\hline 30 & $\mathrm{D}$ & 18 & mentrasto \\
\hline 30 & $\bar{D}$ & 1 & picão preto \\
\hline 31 & $\mathrm{~A}$ & 10 & capim guiné \\
\hline 31 & $\mathrm{~B}$ & 6 & capim guiné \\
\hline 31 & $\mathrm{~B}$ & 23 & tiririca \\
\hline 31 & $\mathrm{C}$ & 3 & capim guiné \\
\hline 31 & $\mathrm{C}$ & 25 & tiririca \\
\hline 31 & $\mathrm{D}$ & 4 & capim guiné \\
\hline 31 & $\mathrm{D}$ & 8 & tiririca \\
\hline
\end{tabular}


Tabela B.8: Densidade de plantas por espécie em cada quadro (continuação).

\begin{tabular}{|c|c|c|c|}
\hline Parcela & Quadro & Densidade de plantas & Espécie \\
\hline 32 & $\mathrm{~A}$ & 1 & trapoeraba \\
\hline 32 & $\mathrm{~A}$ & 1 & capim guiné \\
\hline 32 & $\mathrm{~B}$ & 3 & capim guiné \\
\hline 32 & $\mathrm{C}$ & 1 & trapoeraba \\
\hline 32 & $\mathrm{C}$ & 3 & capim guiné \\
\hline 32 & $\mathrm{C}$ & 4 & mentrasto \\
\hline 32 & $\mathrm{D}$ & 1 & capim guiné \\
\hline 32 & $\bar{D}$ & 2 & erva de santa luzia \\
\hline 32 & $\mathrm{D}$ & 3 & mentrasto \\
\hline 33 & $\mathrm{~A}$ & 2 & marmelada \\
\hline 33 & $\mathrm{~A}$ & 5 & mentrasto \\
\hline 33 & $\mathrm{~A}$ & 12 & sorgo selvagem \\
\hline 33 & $\mathrm{~A}$ & 1 & leiteiro \\
\hline 33 & $\mathrm{~B}$ & 2 & capim marmelada \\
\hline 33 & $\mathrm{~B}$ & 1 & leiteiro \\
\hline 33 & $\mathrm{~B}$ & 33 & capim colchão \\
\hline 33 & $\mathrm{C}$ & 5 & mentrasto \\
\hline 33 & $\mathrm{C}$ & 2 & capim guiné \\
\hline 33 & $\mathrm{D}$ & 1 & leiteiro \\
\hline 33 & $\mathrm{D}$ & 4 & capim guiné \\
\hline 34 & $\mathrm{~A}$ & 6 & mentrasto \\
\hline 34 & $\bar{A}$ & 3 & capim colchão \\
\hline 34 & $\mathrm{~A}$ & 2 & capim guiné \\
\hline 34 & $\mathrm{~A}$ & 1 & capim marmelada \\
\hline 34 & $\mathrm{~B}$ & 5 & mentrasto \\
\hline 34 & $\mathrm{~B}$ & 1 & capim guiné \\
\hline 34 & $\mathrm{C}$ & 3 & capim guiné \\
\hline 34 & $\mathrm{C}$ & 4 & mentrasto \\
\hline 34 & $\mathrm{D}$ & 8 & capim guiné \\
\hline 34 & $\mathrm{D}$ & 7 & mentrasto \\
\hline 34 & $\mathrm{D}$ & 2 & capim colchão \\
\hline 35 & $\mathrm{~A}$ & 6 & mentrasto \\
\hline 35 & $\mathrm{~A}$ & 1 & capim guiné \\
\hline 35 & $\mathrm{~B}$ & 6 & mentrasto \\
\hline 35 & $\mathrm{C}$ & 4 & mentrasto \\
\hline 35 & $\mathrm{C}$ & 1 & capim guiné \\
\hline 35 & $\mathrm{D}$ & 3 & picão preto \\
\hline 35 & $\mathrm{D}$ & 5 & mentrasto \\
\hline 36 & $\bar{A}$ & 2 & capim colchão \\
\hline 36 & $\overline{\mathrm{A}}$ & 3 & capim colchão \\
\hline 36 & $\mathrm{~B}$ & 1 & capim colchão \\
\hline 36 & $\mathrm{~B}$ & 1 & leiteiro \\
\hline 36 & $\bar{B}$ & 1 & capim marmelada \\
\hline 36 & $\mathrm{~B}$ & 1 & capim guiné \\
\hline 36 & $\mathrm{C}$ & 2 & capim guiné \\
\hline 36 & $\mathrm{C}$ & 1 & capim marmelada \\
\hline 36 & $\mathrm{C}$ & 3 & capim marmelada \\
\hline 36 & $\mathrm{C}$ & 8 & mentrasto \\
\hline 36 & $\mathrm{D}$ & 4 & capim colchão \\
\hline 36 & $\mathrm{D}$ & 1 & leiteiro \\
\hline 36 & $\mathrm{D}$ & 6 & mentrasto \\
\hline
\end{tabular}


Tabela B.9: Densidade de plantas por espécie em cada quadro (continuação).

\begin{tabular}{|c|c|c|c|}
\hline Parcela & Quadro & Densidade de plantas & Espécie \\
\hline 37 & $\mathrm{~A}$ & 1 & capim marmelada \\
\hline 37 & $\mathrm{~A}$ & 2 & mentrasto \\
\hline 37 & $\overline{\mathrm{B}}$ & 1 & picão preto \\
\hline 37 & $\mathrm{~B}$ & 1 & trapoeraba \\
\hline 37 & $\mathrm{~B}$ & 2 & capim colchão \\
\hline 37 & $\mathrm{~B}$ & 5 & mentrasto \\
\hline 37 & $\mathrm{C}$ & 3 & mentrasto \\
\hline 37 & $\mathrm{C}$ & 1 & capim colchão \\
\hline 37 & $\mathrm{C}$ & 1 & picão preto \\
\hline 37 & $\overline{\mathrm{D}}$ & 1 & picão preto \\
\hline 37 & $\mathrm{D}$ & 1 & capim marmelada \\
\hline 38 & $\overline{\mathrm{A}}$ & 3 & capim marmelada \\
\hline 38 & $\mathrm{~A}$ & 1 & trapoeraba \\
\hline 38 & $\bar{A}$ & 2 & leiteiro \\
\hline 38 & $\mathrm{~A}$ & 2 & mentrasto \\
\hline 38 & $\bar{B}$ & 2 & trapoeraba \\
\hline 38 & $\bar{B}$ & 3 & capim colchão \\
\hline 38 & $\bar{B}$ & 3 & mentrasto \\
\hline 38 & $\bar{B}$ & 1 & leiteiro \\
\hline 38 & $\mathrm{C}$ & 3 & capim colchão \\
\hline 38 & $\mathrm{C}$ & 3 & mentrasto \\
\hline 38 & $\mathrm{C}$ & 1 & capim marmelada \\
\hline 38 & $\mathrm{C}$ & 1 & leiteiro \\
\hline 38 & $\mathrm{D}$ & 5 & mentrasto \\
\hline 38 & $\mathrm{D}$ & 3 & capim colchão \\
\hline 38 & $\overline{\mathrm{D}}$ & 1 & cururu \\
\hline 38 & $\overline{\mathrm{D}}$ & 1 & trapoeraba \\
\hline 39 & $\overline{\mathrm{A}}$ & 4 & mentrasto \\
\hline 39 & $\mathrm{~A}$ & 2 & capim marmelada \\
\hline 39 & $\mathrm{~A}$ & 1 & capim colchão \\
\hline 39 & $\bar{B}$ & 5 & mentrasto \\
\hline 39 & $\bar{B}$ & 1 & trapoeraba \\
\hline 39 & $\mathrm{C}$ & 2 & trapoeraba \\
\hline 39 & $\mathrm{C}$ & 5 & mentrasto \\
\hline 39 & $\mathrm{C}$ & 1 & capim colchão \\
\hline 39 & $\overline{\mathrm{D}}$ & 5 & mentrasto \\
\hline 39 & $\bar{D}$ & 2 & capim colchão \\
\hline 40 & $\mathrm{~A}$ & 4 & capim colchão \\
\hline 40 & $\overline{\mathrm{A}}$ & 2 & capim marmelada \\
\hline 40 & $\bar{A}$ & 1 & trapoeraba \\
\hline 40 & $\bar{B}$ & 3 & capim colchão \\
\hline 40 & $\bar{B}$ & 2 & trapoeraba \\
\hline 40 & $\mathrm{C}$ & 3 & trapoeraba \\
\hline 40 & $\mathrm{C}$ & 2 & capim colchão \\
\hline 40 & $\overline{\mathrm{D}}$ & 3 & trapoeraba \\
\hline 40 & $\mathrm{D}$ & 2 & capim guiné \\
\hline
\end{tabular}


Tabela B.10: Densidade de plantas por espécie em cada quadro (continuação).

\begin{tabular}{cccc}
\hline Parcela & Quadro & Densidade de plantas & Espécie \\
\hline 41 & $\mathrm{~A}$ & 5 & trapoeraba \\
\hline 41 & $\mathrm{~A}$ & 3 & capim colchão \\
\hline 41 & $\mathrm{~A}$ & 4 & mentrasto \\
\hline 41 & $\mathrm{~A}$ & 1 & leiteiro \\
\hline 41 & $\mathrm{~B}$ & 3 & capim colchão \\
\hline 41 & $\mathrm{~B}$ & 3 & trapoeraba \\
\hline 41 & $\mathrm{~B}$ & 4 & mentrasto \\
\hline 41 & $\mathrm{C}$ & 3 & capim colchão \\
\hline 41 & $\mathrm{C}$ & 5 & trapoeraba \\
\hline 41 & $\mathrm{C}$ & 1 & mentrasto \\
\hline 41 & $\mathrm{D}$ & 3 & trapoeraba \\
\hline 41 & $\mathrm{D}$ & 2 & mentrasto \\
\hline
\end{tabular}


Tabela B.11: Densidade de plantas daninhas por $m^{2}$ por espécies em cada parcela.

\begin{tabular}{|c|c|c|}
\hline Parcela & Densidade & Espécie \\
\hline 1 & 7 & braquiária \\
\hline 1 & 15 & capim colchão \\
\hline 1 & 7 & capim marmelada \\
\hline 1 & 15 & timbête \\
\hline 1 & 2 & erva-de-touro \\
\hline 1 & 8 & mentrasto \\
\hline 1 & 2 & erva de santa luzia \\
\hline 1 & 1 & sorgo selvagem \\
\hline 2 & 37 & capim colchão \\
\hline 2 & 10 & capim marmelada \\
\hline 2 & 3 & capim guiné \\
\hline 2 & 2 & trapoeraba \\
\hline 2 & 8 & caruru \\
\hline 3 & 6 & caruru \\
\hline 3 & 3 & timbête \\
\hline 3 & 15 & sorgo selvagem \\
\hline 3 & 2 & capim colchão \\
\hline 3 & 9 & braquiária \\
\hline 3 & 8 & picão preto \\
\hline 3 & 3 & capim marmelada \\
\hline 4 & 34 & trapoeraba \\
\hline 4 & 5 & caruru \\
\hline 4 & 10 & capim marmelada \\
\hline 5 & 15 & capim marmelada \\
\hline 5 & 22 & trapoeraba \\
\hline 6 & 4 & sorgo selvagem \\
\hline 6 & 18 & capim marmelada \\
\hline 6 & 6 & trapoeraba \\
\hline 6 & 7 & capim colchão \\
\hline 7 & 19 & capim marmelada \\
\hline 7 & 16 & capimcolchão \\
\hline 7 & 2 & sorgo selvagem \\
\hline 7 & 4 & erva de santa luzia \\
\hline 7 & 2 & mentrasto \\
\hline 8 & 8 & braquiária \\
\hline 8 & 15 & capim colchão \\
\hline 8 & 49 & mentrasto \\
\hline 8 & 6 & erva quente \\
\hline 8 & 1 & leiteiro \\
\hline 9 & 55 & picão preto \\
\hline 9 & 4 & capim colchão \\
\hline 9 & 1 & capim guiné \\
\hline 9 & 11 & timbête \\
\hline 9 & 20 & mentrasto \\
\hline 9 & 1 & trapoeraba \\
\hline 9 & 3 & capim marmelada \\
\hline 9 & 3 & braquiária \\
\hline 10 & 44 & mentrasto \\
\hline 10 & 12 & capim colchão \\
\hline 10 & 7 & caruru \\
\hline 10 & 3 & trapoeraba \\
\hline
\end{tabular}


Tabela B.12: Densidade de plantas daninhas por $m^{2}$ por espécies em cada parcela (continuação).

\begin{tabular}{|c|c|c|}
\hline Parcela & Densidade & Espécie \\
\hline 11 & 10 & capim colchão \\
\hline 11 & 12 & capim marmelada \\
\hline 11 & 2 & mentrasto \\
\hline 11 & 3 & trapoeraba \\
\hline 11 & 2 & capim guiné \\
\hline 12 & 24 & trapoeraba \\
\hline 12 & 2 & capim marmelada \\
\hline 13 & 23 & capim marmelada \\
\hline 13 & 2 & sorgo selvagem \\
\hline 13 & 1 & mentrasto \\
\hline 14 & 17 & trapoeraba \\
\hline 14 & 7 & capim marmelada \\
\hline 14 & 27 & capim colchão \\
\hline 15 & 26 & capim colchão \\
\hline 15 & 9 & leiteiro \\
\hline 15 & 1 & poaia \\
\hline 15 & 3 & capim marmelada \\
\hline 15 & 5 & timbête \\
\hline 15 & 4 & mentrasto \\
\hline 16 & 16 & capim colchão \\
\hline 16 & 3 & capim marmelada \\
\hline 16 & 1 & trapoeraba \\
\hline 16 & 2 & botão de ouro \\
\hline 16 & 4 & leiteiro \\
\hline 16 & 2 & pé de galinha \\
\hline 17 & 21 & trapoeraba \\
\hline 17 & 6 & botão de ouro \\
\hline 17 & 2 & caruru \\
\hline 18 & 13 & capim colchão \\
\hline 18 & 1 & pé de galinha \\
\hline 18 & 5 & capim marmelada \\
\hline 18 & 5 & leiteiro \\
\hline 18 & 4 & caruru \\
\hline 18 & 2 & trapoeraba \\
\hline 19 & 8 & capim marmelada \\
\hline 19 & 3 & capim colchão \\
\hline 19 & 1 & capim guiné \\
\hline 19 & 8 & mentrasto \\
\hline 19 & 5 & leiteiro \\
\hline 19 & 1 & trapoeraba \\
\hline 20 & 14 & capim colchão \\
\hline 20 & 21 & mentrasto \\
\hline 20 & 4 & capim marmelada \\
\hline 20 & 2 & leiteiro \\
\hline 21 & 13 & leiteiro \\
\hline 21 & 9 & capim colchão \\
\hline 21 & 22 & mentrasto \\
\hline 21 & 2 & timbête \\
\hline 22 & 23 & capim marmelada \\
\hline 22 & 2 & poaia \\
\hline 22 & 1 & capim colchão \\
\hline 23 & 16 & capim colchão \\
\hline 23 & 11 & capim guiné \\
\hline
\end{tabular}


Tabela B.13: Densidade de plantas daninhas por $m^{2}$ por espécies em cada parcela (continuação).

\begin{tabular}{|c|c|c|}
\hline Parcela & Densidade & Espécie \\
\hline 24 & 3 & capim colchão \\
\hline 24 & 3 & capim guiné \\
\hline 24 & 9 & capim marmelada \\
\hline 25 & 24 & capim colchão \\
\hline 25 & 8 & trapoeraba \\
\hline 25 & 2 & picão preto \\
\hline 25 & 1 & capim marmelada \\
\hline 26 & 14 & capim colchão \\
\hline 26 & 9 & capim marmelada \\
\hline 26 & 2 & picão preto \\
\hline 27 & 5 & capim colchão \\
\hline 27 & 10 & capim marmelada \\
\hline 27 & 4 & capim guiné \\
\hline 28 & 6 & capim colchão \\
\hline 28 & 4 & capim marmelada \\
\hline 28 & 1 & capim guiné \\
\hline 28 & 1 & leiteiro \\
\hline 28 & 4 & timbête \\
\hline 29 & 13 & capim colchão \\
\hline 29 & 4 & picão preto \\
\hline 29 & 10 & mentrasto \\
\hline 29 & 2 & capim marmelada \\
\hline 30 & 41 & mentrasto \\
\hline 30 & 1 & picão preto \\
\hline 31 & 23 & capim guiné \\
\hline 31 & 56 & tiririca \\
\hline 32 & 8 & capim guiné \\
\hline 32 & 2 & trapoeraba \\
\hline 32 & 7 & mentrasto \\
\hline 32 & 2 & erva de santa luzia \\
\hline 33 & 4 & capim marmelada \\
\hline 33 & 10 & mentrasto \\
\hline 33 & 12 & sorgo selvagem \\
\hline 33 & 3 & leiteiro \\
\hline 33 & 3 & capim colchão \\
\hline 33 & 6 & capim guiné \\
\hline 34 & 22 & mentrasto \\
\hline 34 & 5 & capim colchão \\
\hline 34 & 14 & capim guiné \\
\hline 34 & 1 & capim marmelada \\
\hline 35 & 21 & mentrasto \\
\hline 35 & 2 & capim guiné \\
\hline 35 & 3 & picão preto \\
\hline 36 & 10 & capim colchão \\
\hline 36 & 2 & leiteiro \\
\hline 36 & 5 & capim marmelada \\
\hline 36 & 3 & capim guiné \\
\hline 36 & 14 & mentrasto \\
\hline 37 & 2 & capim marmelada \\
\hline 37 & 10 & mentrasto \\
\hline 37 & 3 & picão preto \\
\hline 37 & 1 & trapoeraba \\
\hline 37 & 3 & capim colchão \\
\hline
\end{tabular}


Tabela B.14: Densidade de plantas daninhas por $m^{2}$ por espécies em cada parcela (continuação).

\begin{tabular}{ccc}
\hline Parcela & Densidade & Espécie \\
\hline 38 & 4 & capim marmelada \\
\hline 38 & 4 & trapoeraba \\
\hline 38 & 4 & leiteiro \\
\hline 38 & 13 & mentrasto \\
\hline 38 & 9 & capim colchão \\
\hline 38 & 1 & caruru \\
\hline 39 & 19 & mentrasto \\
\hline 39 & 2 & capim marmelada \\
\hline 39 & 4 & capim colchão \\
\hline 39 & 3 & trapoeraba \\
\hline 40 & 9 & capim colchão \\
\hline 40 & 2 & capim marmelada \\
\hline 40 & 9 & trapoeraba \\
\hline 40 & 2 & capim guiné \\
\hline 41 & 16 & trapoeraba \\
\hline 41 & 9 & capim colchão \\
\hline 41 & 11 & mentrasto \\
\hline 41 & 1 & leiteiro \\
\hline
\end{tabular}


Tabela B.15: Densidade de plantas daninhas por $m^{2}$ em cada parcela segundo a classificação "folha larga" e "folha estreita".

\begin{tabular}{|c|c|c|c|}
\hline Parcela & Folha estreita & Folha larga & Total \\
\hline 1 & 45 & 12 & 57 \\
\hline 2 & 50 & 10 & 60 \\
\hline 3 & 32 & 14 & 46 \\
\hline 4 & 10 & 39 & 49 \\
\hline 5 & 15 & 22 & 37 \\
\hline 6 & 29 & 6 & 35 \\
\hline 7 & 37 & 6 & 43 \\
\hline 8 & 24 & 55 & 79 \\
\hline 9 & 22 & 76 & 98 \\
\hline 10 & 12 & 54 & 66 \\
\hline 11 & 24 & 5 & 29 \\
\hline 12 & 2 & 24 & 26 \\
\hline 13 & 25 & 1 & 26 \\
\hline 14 & 34 & 17 & 51 \\
\hline 15 & 43 & 5 & 48 \\
\hline 16 & 25 & 3 & 28 \\
\hline 17 & 0 & 29 & 29 \\
\hline 18 & 53 & 6 & 30 \\
\hline 19 & 17 & 9 & 26 \\
\hline 20 & 20 & 21 & 41 \\
\hline 21 & 24 & 22 & 46 \\
\hline 22 & 24 & 2 & 26 \\
\hline 23 & 27 & 0 & 27 \\
\hline 24 & 15 & 0 & 15 \\
\hline 25 & 25 & 10 & 35 \\
\hline 26 & 23 & 2 & 25 \\
\hline 27 & 19 & 0 & 19 \\
\hline 28 & 16 & 0 & 16 \\
\hline 29 & 14 & 15 & 29 \\
\hline 30 & 0 & 45 & 42 \\
\hline 31 & 79 & 0 & 79 \\
\hline 32 & 8 & 11 & 19 \\
\hline 33 & 28 & 10 & 38 \\
\hline 34 & 20 & 22 & 42 \\
\hline 35 & 2 & 24 & 26 \\
\hline 36 & 20 & 14 & 34 \\
\hline 37 & 5 & 14 & 19 \\
\hline 38 & 17 & 18 & 35 \\
\hline 39 & 6 & 22 & 28 \\
\hline 40 & 13 & 9 & 22 \\
\hline 41 & 10 & 27 & 37 \\
\hline
\end{tabular}


Tabela B.16: Sementes produzidas por uma planta de cada espécie daninha por parcela. Espécie 1: trapoeraba, 2: mentrasto, 3: capim colchão, 4: braquiária, 5: capim marmelada, 6: leiteiro, 7: picão preto, 8: sorgo selvagem, 9: caruru branco, 10: capim guiné, 11: erva de santa luzia, 12: pé de galinha, 13: timbête.

\begin{tabular}{|c|c|c|c|c|c|c|c|c|c|c|c|c|c|}
\hline Parcela & 1 & 2 & 3 & 4 & 5 & 6 & 7 & 8 & 9 & 10 & 11 & 12 & 13 \\
\hline 1 & & & & & 215 & & & 352 & 89 & & 198 & & 15 \\
\hline 2 & & & 146 & 379 & & & & & 188 & 1197 & & & \\
\hline 3 & & & & & & & & & 3 & & & & \\
\hline 4 & & & & 103 & 44 & & & & & & & & \\
\hline 5 & & & & & 115 & 68 & & & & & & & \\
\hline 6 & & & & & 66 & & & 43 & & & & & 9 \\
\hline 7 & & & & & 76 & & & & & & 237 & & \\
\hline 8 & & & & & & & & & & & & & \\
\hline 9 & & & & & 134 & 61 & 405 & & 38 & 735 & & 93 & \\
\hline 10 & & & 115 & & & & 23 & 209 & 452 & 41 & & & \\
\hline 11 & & & 119 & & 400 & 12 & & & & 1269 & & & \\
\hline 12 & & & & & 138 & 64 & & & 496 & & & & \\
\hline 13 & & & & & & & 232 & 469 & & & & & 33 \\
\hline 14 & & & & & & 14 & & 298 & & & & & \\
\hline 15 & & & & & & & & & & & & & \\
\hline 16 & & & & & & 16 & & & 227 & & & & \\
\hline 17 & & & 135 & & & 28 & & & 14 & & & & \\
\hline 18 & & & & & & 3 & & & 106 & & & & \\
\hline 19 & & & & & & 21 & & & & & & & \\
\hline 20 & & & & & 37 & 5 & & & & & & & \\
\hline 21 & & & 41 & & & 12 & 21 & & & & & & \\
\hline 22 & & & 138 & & 328 & & & & & & & & 17 \\
\hline 23 & & & 269 & & & & & & & & & & \\
\hline 24 & & & 160 & & 46 & & & & & & & & \\
\hline 25 & & & 103 & & & & 85 & & & 41 & & & 7 \\
\hline 26 & & & 95 & & 23 & & & 46 & & & & & \\
\hline 27 & & & 123 & & 46 & 18 & & 27 & & 998 & & & \\
\hline 28 & & & 156 & & 17 & & & & & 759 & & & 5 \\
\hline 29 & & & 73 & & 41 & 21 & & & & & & & 21 \\
\hline 30 & & & & & & & & & & & & & 10 \\
\hline 31 & & & & & & 19 & & & & 897 & & & \\
\hline 32 & & & 228 & & & 103 & & & & 819 & 153 & & \\
\hline 33 & & & & 79 & & 231 & & 189 & & & & & \\
\hline 34 & & & & & & & & & & 517 & & & \\
\hline 35 & & 369 & & & & 12 & & & & & & & \\
\hline 36 & & & & & & 16 & & & & 331 & 169 & 101 & \\
\hline 37 & & & & & 23 & 12 & 295 & & & & & & 125 \\
\hline 38 & & 994 & 205 & & 43 & & & & & & & & \\
\hline 39 & & & & & & 39 & 239 & 53 & 54 & 1039 & & & \\
\hline 40 & & & 96 & & & 52 & & & 715 & & & 116 & \\
\hline 41 & 13 & & 238 & & & & 25 & & & & & & 7 \\
\hline
\end{tabular}


Tabela B.17: Sementes produzidas por uma planta de cada espécie daninha por parcela. Espécie 14: serralha, 15: cordão-de-frade.

\begin{tabular}{|c|c|c|}
\hline Parcela & 14 & 15 \\
\hline 1 & & \\
\hline 2 & & \\
\hline 3 & & \\
\hline 4 & & \\
\hline 5 & & \\
\hline 6 & & \\
\hline 7 & & \\
\hline 8 & & \\
\hline 9 & & \\
\hline 10 & & \\
\hline 11 & & \\
\hline 12 & & \\
\hline 13 & & \\
\hline 14 & & \\
\hline 15 & & \\
\hline 16 & & \\
\hline 17 & & \\
\hline 18 & & \\
\hline 19 & & \\
\hline 20 & & \\
\hline 21 & & 132 \\
\hline 22 & & \\
\hline 23 & & \\
\hline 24 & & \\
\hline 25 & & \\
\hline 26 & & \\
\hline 27 & & \\
\hline 28 & & \\
\hline 29 & & \\
\hline 30 & & \\
\hline 31 & & \\
\hline 32 & & \\
\hline 33 & & \\
\hline 34 & & \\
\hline 35 & & \\
\hline 36 & & \\
\hline 37 & 198 & \\
\hline 38 & & \\
\hline 39 & & \\
\hline 40 & & \\
\hline 41 & & \\
\hline
\end{tabular}


Tabela B.18: Total de sementes produzidas em cada parcela.

\begin{tabular}{|c|c|}
\hline Parcela & Total de sementes produzidas por parcela \\
\hline 1 & 869 \\
\hline 2 & 1910 \\
\hline 3 & 3 \\
\hline 4 & 147 \\
\hline 5 & 183 \\
\hline 6 & 118 \\
\hline 7 & 313 \\
\hline 8 & 0 \\
\hline 9 & 1466 \\
\hline 10 & 840 \\
\hline 11 & 1800 \\
\hline 12 & 698 \\
\hline 13 & 734 \\
\hline 14 & 312 \\
\hline 15 & 0 \\
\hline 16 & 243 \\
\hline 17 & 177 \\
\hline 18 & 109 \\
\hline 19 & 21 \\
\hline 20 & 42 \\
\hline 21 & 206 \\
\hline 22 & 483 \\
\hline 23 & 269 \\
\hline 24 & 206 \\
\hline 25 & 236 \\
\hline 26 & 164 \\
\hline 27 & 1212 \\
\hline 28 & 937 \\
\hline 29 & 156 \\
\hline 30 & 10 \\
\hline 31 & 916 \\
\hline 32 & 1303 \\
\hline 33 & 499 \\
\hline 34 & 517 \\
\hline 35 & 381 \\
\hline 36 & 617 \\
\hline 37 & 653 \\
\hline 38 & 1242 \\
\hline 39 & 1424 \\
\hline 40 & 979 \\
\hline 41 & 283 \\
\hline
\end{tabular}

